\title{
2010 Massachusetts Recreational Boater Survey
}

Final Report Submitted to the Massachusetts Ocean Partnership

\author{
Prepared by
}

Dan Hellin, Jack Wiggin, and Kristin Uiterwyk

Urban Harbors Institute, University of Massachusetts Boston

Kim Starbuck and Nicholas Napoli

Massachusetts Ocean Partnership

David Terkla and Chris Watson

Department of Environmental, Earth and Ocean Sciences, University of Massachusetts Boston

\author{
Anthony Roman \\ Center for Survey Research, University of Massachusetts Boston \\ Leona Roach \\ Marine Consulting Services \\ Tim Welch \\ Ecotrust
}

June 2011

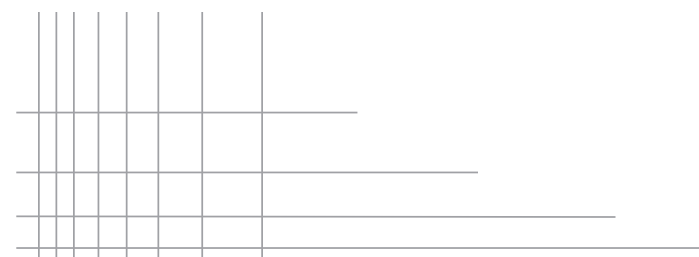




\section{ABSTRACT}

The Massachusetts Ocean Management Plan (Plan) completed in 2009 recognized recreational boating as an activity with "significant actual and prospective conflicts among multiple waterway uses in Massachusetts" and included the economic value of recreational boating as a key socio-economic indicator that will be used to inform coastal management. At the time of Plan completion, statistically robust recreational boating data were identified as an important need for comprehensive ocean planning.

To fill this data gap, the 2010 Massachusetts Recreational Boater Survey gathered information on boating activity in Massachusetts' coastal and ocean waters directly from recreational boaters. Researchers sent 10,000 surveys to owners of Massachusetts registered and documented vessels in the spring of 2010 asking for participation in the six month study. Over $22 \%$ responded and provided detailed information through monthly surveys between May and October about their boating trips including expenditures, recreational activities, and routes. Boaters plotted their spatial data (routes and activity areas) using an innovative online open source mapping tool. Using statistical methods and economic models, the demographic and economic information from the sample of boaters was generalized to the population of Massachusetts boaters.

Results revealed the economic contribution of this activity to the Massachusetts economy - an estimated $\$ 806$ million in 2010. Information gathered through the survey was also compiled into comprehensive maps depicting recreational boating patterns and density, and was used to better understand details of the recreational boating community, such as the most common boat size, the typical age of Bay State boaters, etc.

The research findings will be incorporated into the Massachusetts Ocean Management Plan and can be used by resource managers, the boating industry and others in many ways, such as ensuring boating routes and destinations receive appropriate attention in ocean planning efforts.

\section{ACKNOWLEDGEMENTS}

The following people provided invaluable insight, knowledge, expertise and support during the design, development and implementation of the 2010 Massachusetts Recreational Boater Survey:

\section{Advisory Group:}

Nathalie Grady (Massachusetts Marine Trades Association); Peter Caten (Massachusetts Boating and Yacht Clubs Association); David Fronzuto (Massachusetts Harbormasters Association); Dan Pingaro (Sailors for the Sea); Rob Johnston (George Perkins Marsh Institute, Clark University); and Bob Leeworthy (Office of National Marine Sanctuaries, National Oceanic and Atmospheric Administration).

\section{Those who donated prizes for survey participant recruitment:}

The Massachusetts Ocean Partnership; the Massachusetts Marine Trades Association; Sea Tow South Shore; Newburyport Marinas; and Kingman Yacht Center.

\section{Others:}

Brian Clarridge, Swaati Eklund and John Rogers, The Center for Survey Research John Weber, Prassede Vella and Dan Sampson, MA Office of Coastal Zone Management

\section{Charles Steinback, Ecotrust}

The Donahue Institute (University of Massachusetts); Newburyport Marina; Cape Ann Marina: Boston Harbor Shipyard \& Marina; Onset Bay Marina; Hyannis Marina; the Harbormaster of Tisbury; the Harbormasters of Nantucket; and Molly Kile.

\section{Primary Authors:}

Dan Hellin, Urban Harbors Institute, University of Massachusetts Boston

Kim Starbuck, Massachusetts

Ocean Partnership

David Terkla and Chris Watson, Department of Environmental, Earth and Ocean Sciences, University of Massachusetts Boston

Anthony Roman, Center for Survey Research, University of Massachusetts, Boston

\section{Contributors:}

Jack Wiggin and Kristin Uiterwyk, Urban Harbors Institute, University of Massachusetts Boston

Nicholas Napoli, Massachusetts Ocean Partnership

Leona Roach, Marine Consulting Services

Tim Welch, Ecotrust

\section{Editors:}

\section{Kim Starbuck}

Leona Roach

Kristin Uiterwyk

Prassede Vella, MA Office of Coastal Zone Management

June 2011

This research is funded by the Gordon and Betty Moore Foundation.

\section{Recommended Citation:}

Hellin, D., Starbuck, K., Terkla, D., Roman, A., and Watson, C. (2011, June) 2010 Massachusetts Recreational Boater Survey (03.uhi.11). Boston: Massachusetts Ocean Partnership

This report may be downloaded at http://massoceanpartnership.org/wp-content/ uploads/2011/06/2010_massachusetts_ recreational-tr-uhi-11.pdf

The Massachusetts Ocean Partnership initiated and Participated IN THIS STUDY AS PART OF A CONTINUING EFFORT TO ADVANCE THE SCIENTIFIC BASIS OF COASTAL AND MARINE SPATIAL PLANNING.

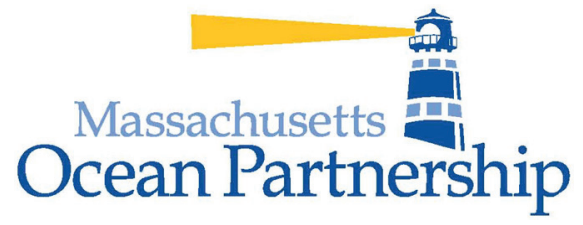

Massachusetts Ocean Partnership

The Nonprofit Center

89 South Street

Boston MA 02111

www.massoceanpartnership.org 


\section{CONTENTS}

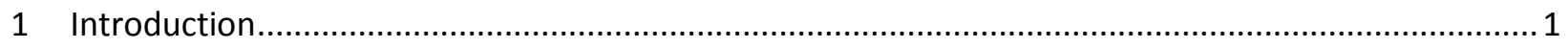

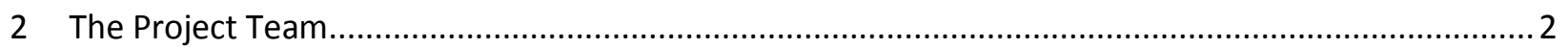

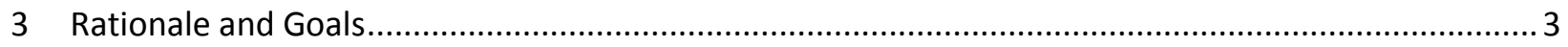

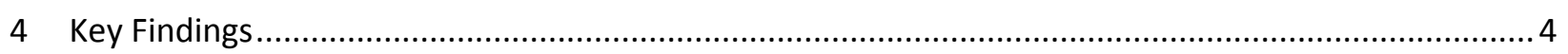

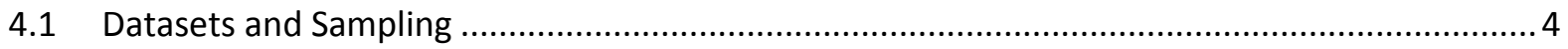

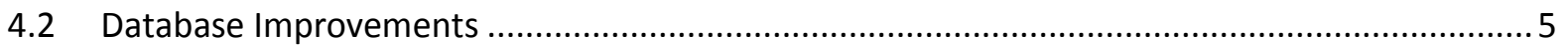

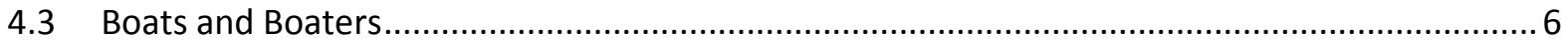

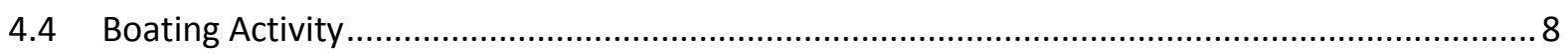

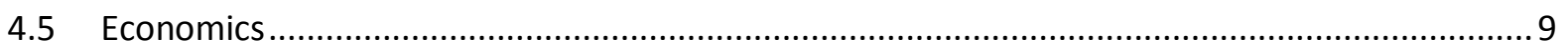

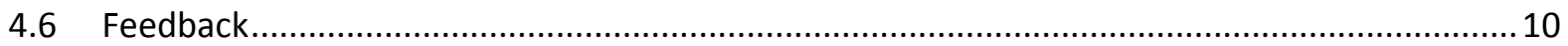

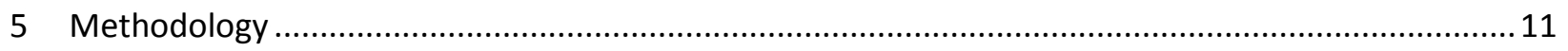

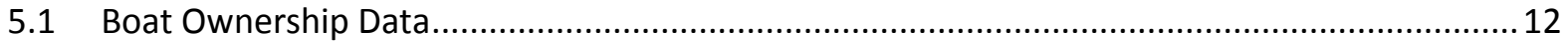

5.1.1 Massachusetts Registered Boats .................................................................... 13

5.1.2 US Coast Guard (USCG) Documented Vessels ..................................................... 13

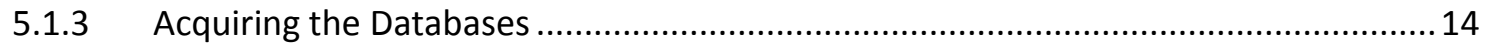

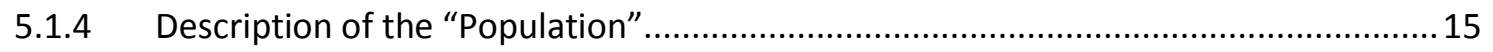

5.1.5 Strengths and Weaknesses of the Datasets........................................................... 19

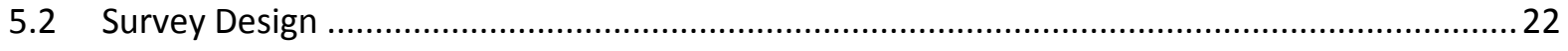

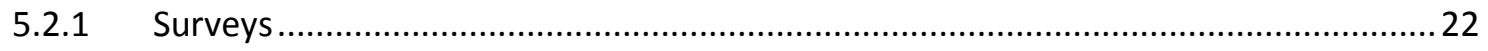

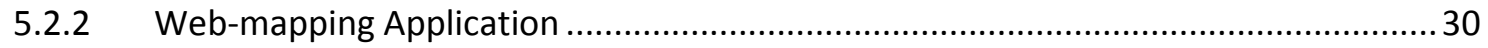

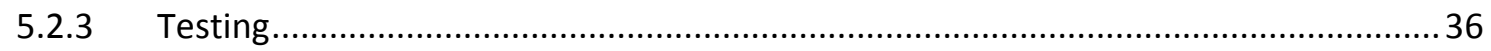

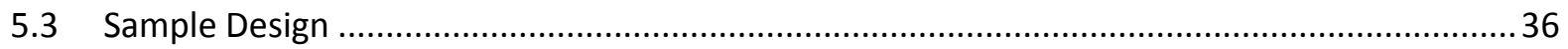

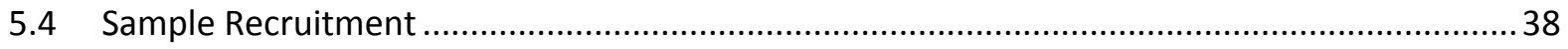

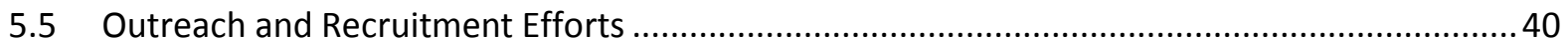

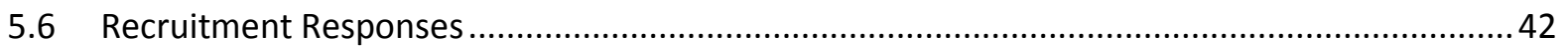

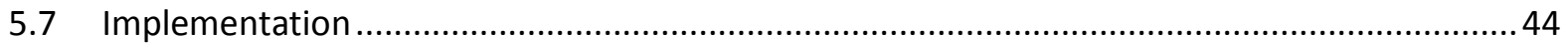

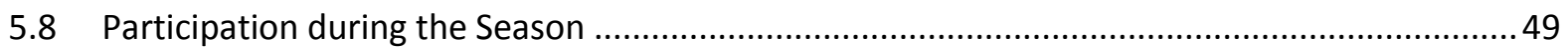




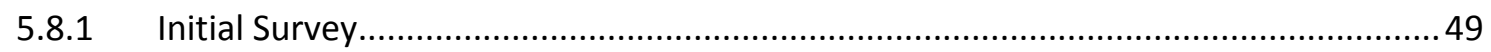

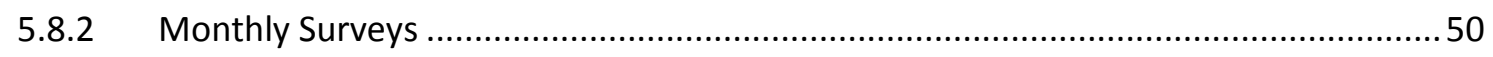

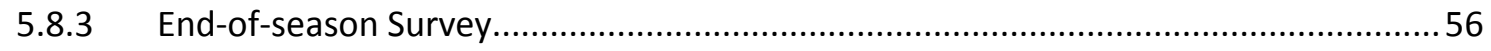

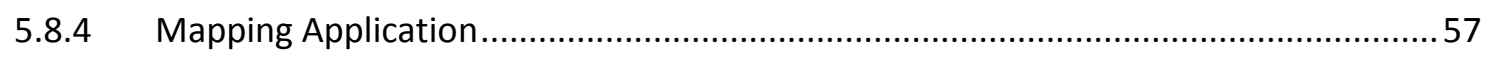

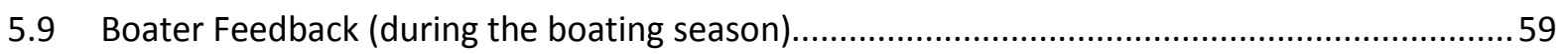

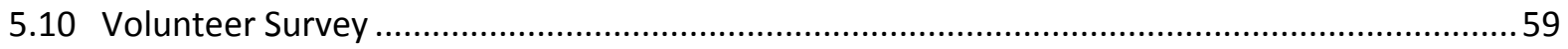

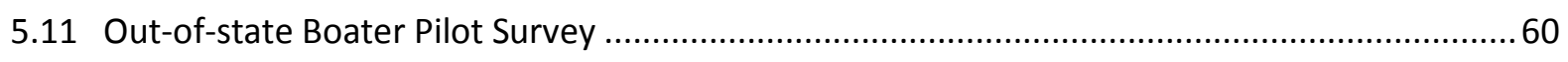

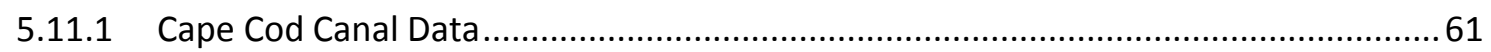

5.11.2 US Coast Guard Notice of Arrival/Departure Data ..................................................62

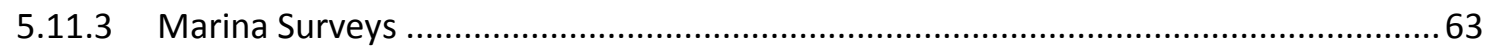

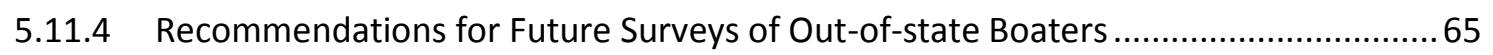

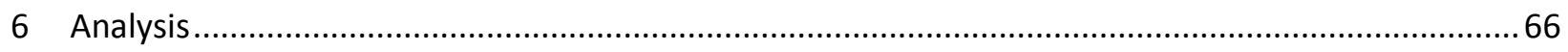

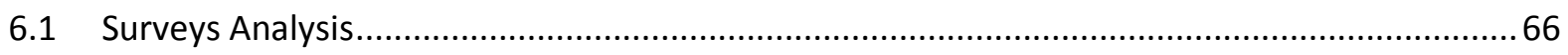

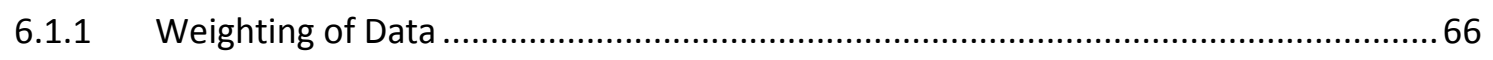

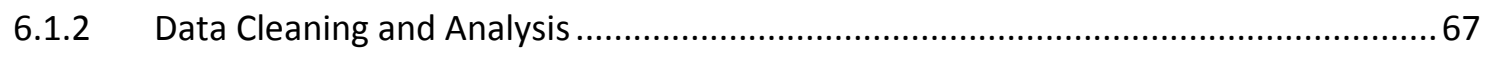

6.2 Economic Contribution Analysis and the IMPLAN Model ...................................................69

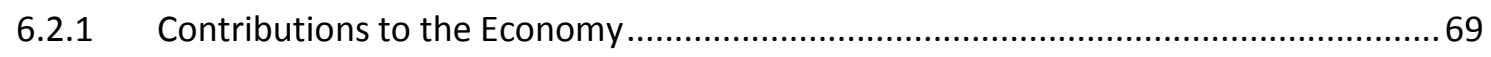

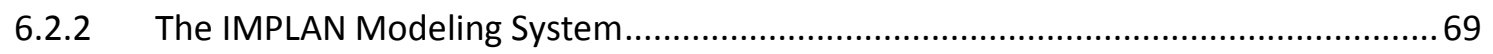

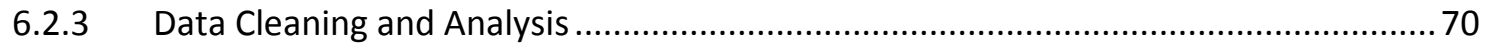

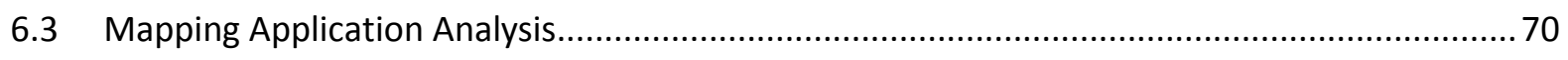

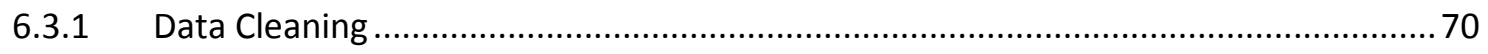

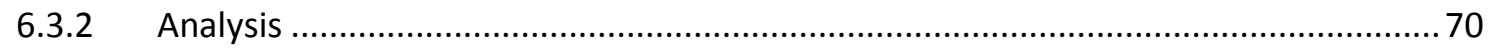

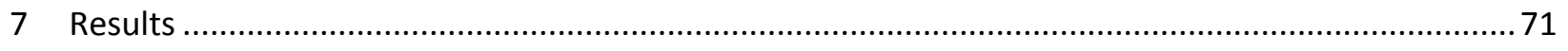

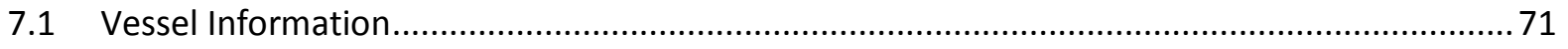

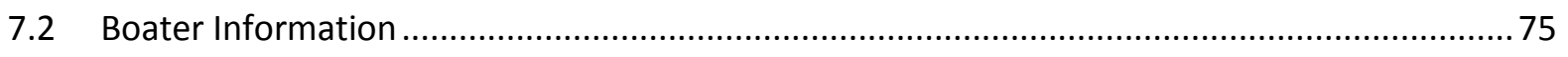

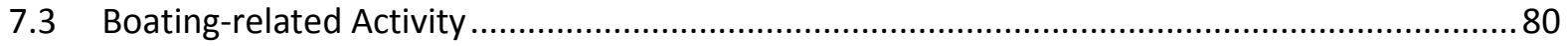

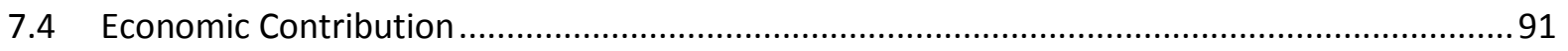

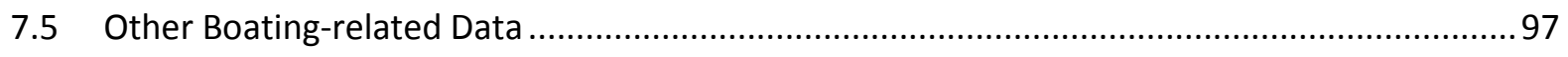

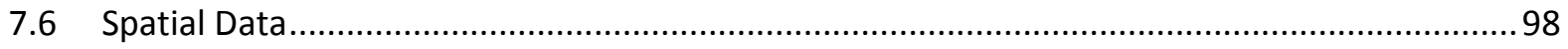




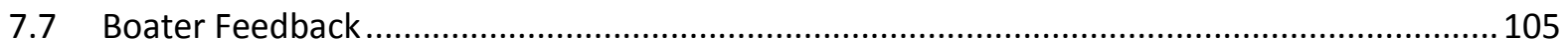

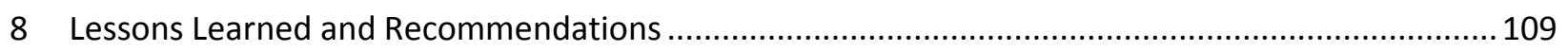

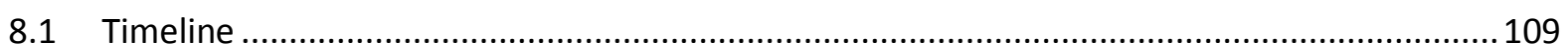

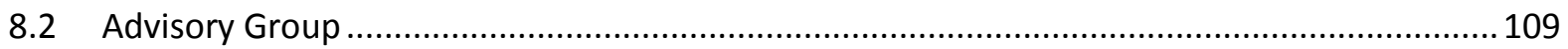

8.3 Determining the Population of Boats Using the Waters of Massachusetts ............................ 110

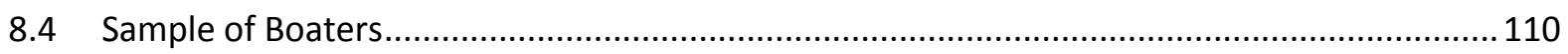

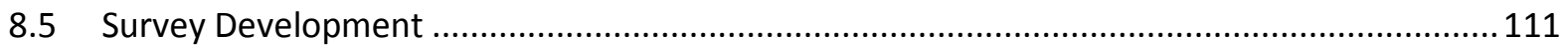

8.6 Implementation of the Surveys and Mapping Application.................................................. 112

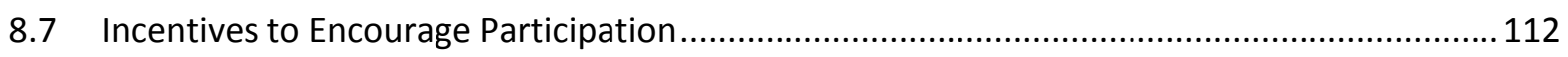

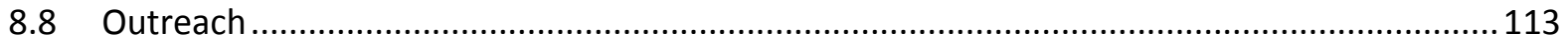

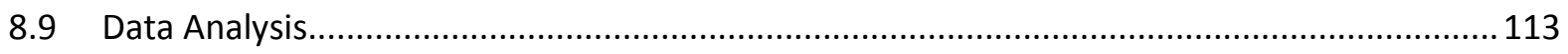

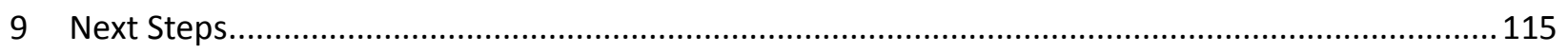

Appendix A: Map of Recreational Boating Activity from the Massachusetts Ocean Management Plan. 116

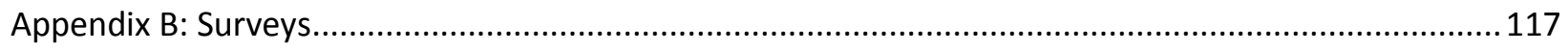

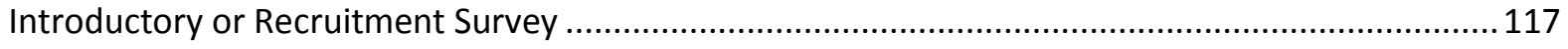

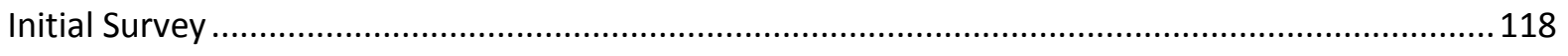

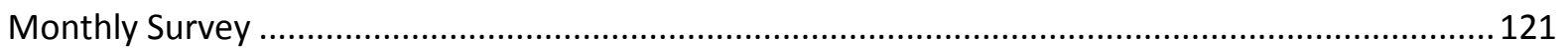

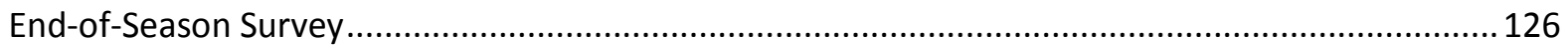

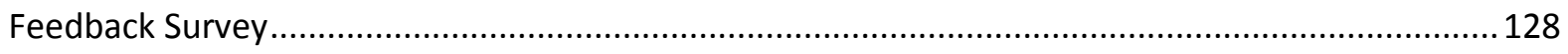

Appendix C: Project Sheet included in the Recruitment Package and Used to Publicize the Survey.......129

Appendix D: Generic Press Release Text ................................................................................. 130

Appendix E: Generalized Text Used for the Monthly E-mails ......................................................... 131

Appendix F: Generalized Text Used for the Second Reminder E-mails .............................................. 132

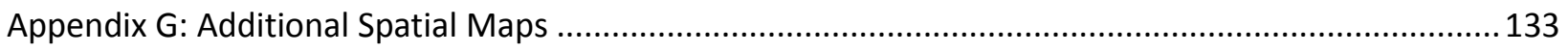




\section{LIST OF TABLES}

Table 1: $\quad$ Breakdown of all boats in the database of registered boats by primary use type.

Table 2: $\quad$ Breakdown of pleasure and commercial fishing boats in the database of registered boats by size

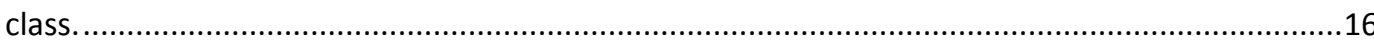

Table 3: $\quad$ Breakdown of documented boats by size class.

Table 4: Breakdown of pleasure and commercial fishing boats in the database of registered boats by size class and vessel type.

Table 5: Breakdown of pleasure and commercial fishing boats in the database of registered boats by propulsion type.

Table 6: Breakdown of pleasure and commercial fishing boats in the database of registered boats by fuel type.

Table 7: $\quad$ Breakdown of pleasure and commercial fishing boats in the database of registered boats by hull material. .....

Table 8:

Description of the surveys that were sent to boat owners.

Table 9:

The population of recreational boats in Massachusetts and the sample drawn. 38

Table 10:

The relationship between the unique identifiers and the sampling strata. .40

Table 11:

Results of the recruitment survey.

Table 12:

Timeline of mailings and other communications with boaters during the 2010 boating season...47

Table 13: Results of the initial survey. .50

Table 14:

Overall results of the monthly surveys. . .51

Table 15:

Monthly survey results by region. .53

Table 16:

Monthly survey results by boat size. .54

Table 17: Breakdown of how many boaters completed multiple surveys throughout the boating season...55

Table 18: Results of the end-of-season survey. .57

Table 19:

Summary of spatial data provided by participating boaters. . .58

Table 20: Boat type by region based on responses to the initial survey. .71

Table 21: Boat size class by region based on responses to the initial survey. .72

Table 22: Boat hull material by region based on responses to the initial survey. .72

Table 23: Boat propulsion type by region based on responses to the initial survey. .73

Table 24: Boat fuel type by region based on responses to the initial survey. . .73

Table 25: Boat in-season storage type by region based on responses to the initial survey. .74 
Table 26: $\quad$ Boat in-season storage facility type by region based on responses to the initial survey.

Table 27: $\quad$ Boat out-of-season storage type by region based on responses to the initial survey....................75

Table 28: $\quad$ Boat out-of-season storage facility type by region based on responses to the initial survey. .......75

Table 29: $\quad$ Boater's sex by region based on responses to the initial survey. NA means "no answer" ............76

Table 30: $\quad$ Mean age of boaters by region based on responses to the initial survey. ....................................76

Table 31: Mean number of years respondents had been regular boat operators based on responses to

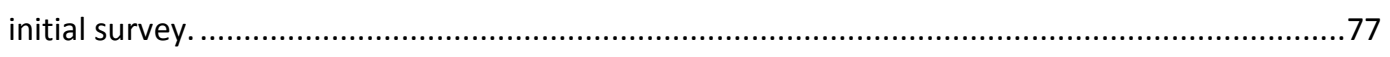

Table 32: $\quad$ Mean number of years respondents had owned a boat based on responses to the initial survey.

Table 33: $\quad$ Percent of boaters who had taken a boating safety course based on responses to the initial survey. 78

Table 34: $\quad$ Percent of boaters who had taken a navigation course based on responses to the initial survey. 78

Table 35: $\quad$ Percent of boaters with different employment statuses based on responses to the initial survey.

Table 36: $\quad$ Percent of boaters with annual household incomes based on responses to the initial survey......80

Table 37: $\quad$ Percentage of boaters who did or did not visit their boat based on responses to the monthly surveys.

Table 38: $\quad$ Percentage of boaters who did or did not take a trip out on the water based on responses to the monthly surveys. . .82

Table 39: $\quad$ Mean number of days that boaters took their vessel out on the water based on responses to the monthly surveys.

Table 40: $\quad$ Mean and maximum number of people on board during the reported trip based on responses to the monthly surveys.

Table 41: $\quad$ Percentage of boaters who trailered their boat to a launch location during the reported trip based on responses to the monthly surveys

Table 42: $\quad$ Percentage of boaters who trailered their boats from different location types during the reported trip based on responses to the monthly surveys.

Table 43: $\quad$ Percentage of boaters who paid a launch fee or a parking fee at a launch site during the reported trip based on responses to the monthly surveys. .......................................................................8

Table 44: $\quad$ Mean amount that boats paid as a launch fee or a parking fee at a launch site during the reported trip based on responses to the monthly surveys.

Table 45: $\quad$ Mean number of miles traveled to reach the site where boaters launched or boarded their vessel during the reported trip based on responses to the monthly surveys. .86 
Table 47: $\quad$ Percentage of boaters who engaged in specific activities during the monthly reported trip. The percentages are conditionally-shaded to highlight seasonal variations within each activity type

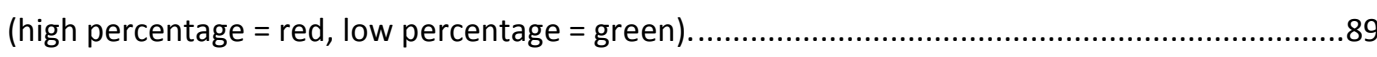

Table 48: $\quad$ Spending by coastal and ocean recreational boaters in Massachusetts, 2010..........................92

Table 49: $\quad$ Summary of indirect and induced effects (by category) of coastal and ocean recreational boating spending in Massachusetts, 2010.

Table 50: $\quad$ Total jobs supported by coastal and ocean recreational boating spending in Massachusetts, 2010.

Table 51: $\quad$ Spending by coastal and ocean recreational boaters in the Southeast Region, 2010.................95

Table 52: $\quad$ Spending by coastal and ocean recreational boaters in the East Central region, 2010.................96

Table 53: $\quad$ The average number of hours under power or sail by size class within a region, and by region. ..97

Table 54: $\quad$ How boaters rated their 2010 boating activity compared to other years. . .98

Table 55: $\quad$ Reasons why boaters did not use the online mapping application by percentage of respondents.

Table 56: $\quad$ How easy boaters found the online mapping application as a percentage of respondents.........106

Table 57: $\quad$ Boaters' willingness to participate in future similar boating surveys as a percentage of .106

Table 58: $\quad$ Summary of thoughts and comments made about the online mapping application. 107

Table 59: $\quad$ Summary of thoughts and comments made about the boater survey in general. .108 


\section{LIST OF FIGURES}

Figure 1: $\quad$ Breakdown of the population of documented and registered vessels by size class.

Figure 2: $\quad$ Number of pleasure and commercial fishing boats in the database of registered boats by type and size class.

Figure 3: $\quad$ The percent of types of vessel information deemed correct by vessel owners. ..........................20

Figure 4: $\quad$ The flow diagram captures the logic required to provide the mapping tools to the user. 32

Figure 5: $\quad$ Snapshots of the final recreational boater survey web-mapping application user interface: initial instruction screen; route questions; and activity area mapping.

Figure 6: $\quad$ Illustration of the technology stack for the boater survey mapping tool. ..................................35

Figure 7: $\quad$ The sample regions were based on county boundaries. Counties are labeled in the figure.........39

Figure 8: $\quad$ The number of completed recruitment surveys and undeliverable recruitment packages received during the four months following the May 6 mailing. .....................................................43

Figure 9: $\quad$ Percent of returns that were found to be eligible by region. ................................................46

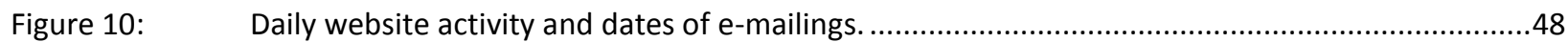

Figure 11: Daily hits on the "thank you" webpage to which boaters were directed automatically when they completed a monthly survey and dates of e-mailings. ............................................................49

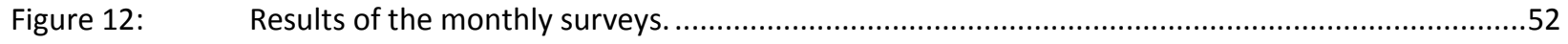

Figure 13: $\quad$ Breakdown of how boaters completed multiple monthly surveys. .........................................56

Figure 14: $\quad$ Summary of spatial data provided by participating boaters..................................................59

Figure 15: $\quad$ Percent of boaters with specified annual household incomes. ................................................80

Figure 16: $\quad$ The percentage of visit-related or trip-related spending that occurred "near to" the launch or boarding location based on responses to the monthly surveys. ..............................................90

Figure 17: $\quad$ Route data as provided by participants in the boater survey. The lines represent the "last trip of the month" routes plotted by recreational boaters between May and October 2010.

Figure 18: $\quad$ Route data as provided by participants in the boater survey aggregated into $1 \mathrm{~km} \times 1 \mathrm{~km}$ cells.. 100

Figure 19: $\quad$ Route data for each month of the boater survey as provided by participants...........................101

Figure 20: $\quad$ Route data for each month of the boater survey as provided by participants.........................102

Figure 21: $\quad$ Route data as provided by participants in the boater survey, broken down by boats of 10 feet or more in length but less than 40 feet (left) and boats greater than 40 feet in length (right).......103

Figure 22: $\quad$ Activity area data as provided by participants in the boater survey. .104

Figure 23: $\quad$ Stellwagen Bank National Marine Sanctuary and the route data gathered during the boater survey. 


\section{LIST OF ACRONYMS}

COTP United States Coast Guard Captain of the Port

CSR Center for Survey Research, University of Massachusetts Boston

CZM Massachusetts Office of Coastal Zone Management

EEA Massachusetts Executive Office of Energy and Environmental Affairs

EEOS Department of Environmental, Earth and Ocean Sciences, University of Massachusetts Boston

EEZ Exclusive Economic Zone

GIS Geographic Information System

IMPLAN IMpact analysis for PLANning - software

MassGIS Massachusetts Office of Geographic Information

MEP Massachusetts Environmental Police

MMTA Massachusetts Marine Trades Association

MOP Massachusetts Ocean Partnership

MORIS Massachusetts Ocean Resources Information System

NOA/D United States Coast Guard Notice of Arrival/Departure

PWC Personal watercraft / jetski

UHI Urban Harbors Institute, University of Massachusetts Boston

USACE United States Army Corps of Engineers

USCG United States Coast Guard 


\section{INTRODUCTION}

With over 155,000 recreational boats in Massachusetts, recreational boating is an important use of the state's coastal and ocean waters that must be considered in Massachusetts ocean planning efforts. To appropriately consider recreational boating activity when planning, it is critical to understand where boaters go, what they do while boating (i.e. fishing, sightseeing, etc.), and how much they spend on boating. During the development of the Massachusetts Ocean Management Plan, it became clear that more information of this type was needed to develop a comprehensive ocean management plan.

The plan, which was developed by Massachusetts Executive Office of Energy and Environmental Affairs (EEA) in response to the 2008 Oceans Act, is a comprehensive ocean management plan for Massachusetts' waters. Using the best available science and stakeholder engagement, the plan was finalized in December 2009 and is intended to protect critical marine resources and foster sustainable uses in state waters. The plan also provides a framework for managing, reviewing and permitting proposed uses of state waters.

As the plan was being developed, the limited amount of information on recreational boating in Massachusetts represented an impediment to developing a comprehensive statewide coastal and ocean management plan. To help fill in these data gaps, organizations such as the Massachusetts Marine Trades Association (MMTA) provided invaluable expert opinion on recreational boating activity, which was incorporated into the plan (see Appendix A). Although this expert opinion provided great insight into recreational boating use in state waters, expert opinion alone is not scientifically quantifiable. In light of this, the plan concluded:

All of these data point to the importance of recreational boating as an existing use across all sectors of the planning area. Recognizing that the resolution of actual and prospective conflicts among multiple waterway uses is a topic of growing management concern in Massachusetts and around the country, the Commonwealth's Work Group on Ocean Recreational and Cultural Services identified recreational boating as a topic of key importance. Both the Work Group on Ocean Recreational and Cultural Services and the Work Group on Transportation, Navigation, and Infrastructure recommended that a comprehensive spatial map of recreational vessel traffic patterns and concentrations be developed for the planning area. Massachusetts Ocean Management Plan, 2009.

Considering the importance of recreational boating to Massachusetts, the plan also identified the economic value of recreational boating as one of the five critical socio-economic indicators needed "to assess the ocean management plan and to identify general trends in the ocean planning area" (Massachusetts Ocean Management Plan, 2009).

This study is responding to the need identified in the plan to gather additional spatial and economic recreational boating data using statistically robust sampling methods. Results from this study will supplement existing information gathered through expert opinion, and will be incorporated in plan updates and likely inform plan revisions. Recreational boating data are essential for effective ocean planning efforts as it informs economic valuations and cumulative human-use impact analyses, as well as provides a better understanding of the tradeoffs in decision-making. 


\section{The Project Team}

To continue its work in supporting the Massachusetts Ocean Management Plan, the Massachusetts Ocean Partnership (MOP) contracted with a team led by the Urban Harbors Institute (UHI) of the University of Massachusetts Boston to design, develop and implement the 2010 Massachusetts Recreational Boater Survey. The team consisted of:

- The Urban Harbors Institute (University of Massachusetts Boston);

- The Massachusetts Ocean Partnership;

- The Massachusetts Office of Coastal Zone Management;

- The Department of Environmental, Earth and Ocean Sciences (University of Massachusetts Boston);

- The Center for Survey Research (University of Massachusetts Boston);

- Marine Consulting Services; and

- Ecotrust.

In addition to the core team organizations, an advisory group was formed to help guide the study:

- Nathalie Grady (Massachusetts Marine Trades Association);

- Peter Caten (Massachusetts Boating and Yacht Clubs Association);

- David Fronzuto (Massachusetts Harbormasters Association);

- Dan Pingaro (Sailors for the Sea);

- Rob Johnston (George Perkins Marsh Institute, Clark University); and

- Bob Leeworthy (Office of National Marine Sanctuaries, National Oceanic and Atmospheric Administration). 


\section{Rationale AND GoALS}

The overall aim of the 2010 Massachusetts Recreational Boater Survey was to assess the characteristics of recreational boating in coastal and ocean waters of Massachusetts. This survey had two main goals:

1. To gather temporal, spatial and economic data to supplement existing information on recreational boating.

The aim was to verify and to expand upon existing temporal and spatial data on recreational boating in Massachusetts using a scientific methodology. Much of the existing information that was used in the Massachusetts Ocean Management Plan was based on expert opinion (provided by a group of knowledgeable boaters) and was therefore largely subjective or anecdotal. The methodology used in this study was based on accepted survey designs and sampling techniques that would produce statistically robust data and could be repeated.

This survey also collected data on recreational boating trip-related spending, which were used to estimate the contribution of coastal and ocean recreational boating activity to a regional and/or state economy. It is important to note that this survey did not aim to quantify the overall economic impact of recreational boating. It focused on the spending associated with boating trips on the water, visits to the boat while docked, and some annual expenses such as maintenance/storage. Additionally, this survey did not capture spending by out-of-state boaters, which may be considerable and may support more fulltime-equivalent jobs than were estimated through this analysis. The economic analyses and results should only be assessed in conjunction with other economic studies.

The information gathered through this survey could be used be used by resource managers, the boating industry and others to:

- Ensure that boaters' favorite routes and destinations receive appropriate attention when management decisions are made about Massachusetts' coastal and ocean waters;

- Help reduce resource use conflicts;

- Improve business planning; and

- Assist in the decision-making process associated with coastal and ocean management in the Commonwealth of Massachusetts.

2. To develop a methodology that could be easily repeated in Massachusetts; adapted for use in other research efforts; and readily customized to be used elsewhere.

The survey design and the open-source online mapping tool could be used in future recreational boating studies in Massachusetts or other locations, and/or could be adapted for use in other research efforts (e.g. studies involving the collection of human use data). 


\section{KEY FINDINGS}

This section summarizes the key findings from the study. More information on these findings can be found throughout the report.

\subsection{Datasets and Sampling}

- Two dataset (one containing details of the boats registered in Massachusetts and the other containing details of US Coast Guard documented vessels believed to be from Massachusetts) were combined to produce a list of 155,331 recreational boats in Massachusetts. This defined the "population" or universe of all boats under consideration for the study.

- A sample of 10,000 boats was selected for inclusion in this study. This represented approximately $6.4 \%$ of all recreational boats in Massachusetts.

- The selection of these boats favored larger boats and boats that were stored nearer to coastal waters. This was due to the specific goal of the study to investigate recreational boater use of coastal and ocean waters. The sampling fractions varied from a low of about $3 \%$ of boats from Western Massachusetts, which is far from any coastal waters, to a high of about $38.1 \%$ for large US Coast Guard documented boats, which were considered highly likely to be used exclusively in coastal and ocean waters. The sample was designed to attempt to target the boats most likely to be of interest to the goals of the study. However, all recreational boats in Massachusetts had a chance of selection into the study. This design was considered both inclusive and efficient.

- Of the 10,000 recruitment surveys that were sent out, 533 were returned with undeliverable addresses.

- Of the remaining 9,467 recruitment surveys that were assumed to be delivered to boat owners, 2,131 were completed and returned either through the mail or via the web. This meant an effective return rate of $22.5 \%$ for the surveys.

- The overall eligibility rate for the returned surveys was $57.9 \%$. In order to remain eligible for the study, boat owners who completed the recruitment survey also had to meet the following criteria:

- They still owned the specific boat;

- They used the boat on salt or brackish water;

- The boat was used for recreational purposes (even if this was not its exclusive use); and

- $\quad$ They provided a valid e-mail address.

- Less than $6 \%$ of eligible returns had to be rejected as they stated that they did not have e-mail or they did not provide an e-mail address. 
- The eligibility rates ranged from a low of $8.9 \%$ for boat owners in Western Massachusetts to a high of about $84 \%$ for documented boats.

- A total of 6,880 e-mails were sent over the six months of monthly surveys, with 550 of these being bounced back. This led to 2,989 completed surveys for an estimated response rate of $47.2 \%$.

- It is only possible to suggest an approximate response rate, as there is no true way to determine exactly how many e-mails arrived in a way that a boat owner saw it and had the opportunity to respond. If the e-mail did not bounce back, then it was assumed that it did get through any firewalls, spam filters, etc. and did get to the desired boat owner.

- As expected, the response rate by month declined over time from a high of $69 \%$ in the May survey to a low of $33.4 \%$ in the October survey. This is not unusual as keeping people interested and engaged over six months of surveys is a difficult task.

- Boaters who had taken an on-water trip were given the opportunity to plot that trip using the online mapping tool. They also had the option to skip the mapping section. Initially, over $70 \%$ of those who did not choose to skip the mapping application went on to plot a route. However, this percentage dropped throughout the study until only $50 \%$ mapped a route in October.

- The mapping of activity areas, and alternate areas, was generally not well undertaken by participants: between $28 \%$ and $15 \%$ of boaters mapped activity areas and only $18 \%$ to $7 \%$ mapped alternate areas.

- A total of 1,094 routes were mapped along with 339 activity areas and 210 alternate activity areas.

\subsection{Database Improvements}

- Implementing minor changes to the information required to register a boat in Massachusetts could dramatically increase the value of the resulting database for research purposes. Making these types of changes may be possible for a couple of reasons:

1. The Massachusetts Environmental Police (MEP) is part of the Executive Office of Energy and Environmental Affairs (EEA), which was one of the driving forces behind the implementation of this study. As the state's boat registration falls under the jurisdiction of MEP, intra-agency coordination may facilitate making changes to the registration process.

2. The MEP has recently started to offer online boat registration and renewal, which would facilitate electronic information gathering. 
- If a few additional pieces of information were gathered during the boat registration process, the resulting database could be greatly enhanced as a tool to survey recreational boaters in the future and more accurately target this and other research. Additional valuable information might include:

- A current, valid e-mail address.

- Whether the boat is used exclusively on freshwater versus saltwater.

- Whether the boat is used exclusively for commercial purposes.

- Whether the boat is used exclusively as a tender.

- Greater details about where the boat is kept.

- If the boat is ever used for recreational fishing.

- There are two categories of vessels that may be missing from, or under-represented in the database of boats registered in Massachusetts:

1. Non-motorized vessels that are not required to be registered in Massachusetts. These would include canoes and kayaks and some (most likely smaller) sailboats. For this study, this was not a significant issue as canoes and kayaks were not the primary focus of the research and small sailboats are most commonly used in nearshore waters.

2. The second category is of greater significance. The waters of Massachusetts are extremely popular with out-of-state boaters. Some are day-trippers who simply pass through the waters of the state, while others are larger vessels that might spend several days or weeks in Massachusetts and may have a significant impact on the local economy in terms of both spending and the jobs supported by the spending activity. At present, the number of out-of-state boaters using the state's waters and their economic impact remains almost entirely unknown.

\subsection{Boats and Boaters}

- Over $89 \%$ of the state-registered vessels were less than 26 feet in length with $57 \%$ of them being between 16 and 26 feet. Only $0.2 \%$ of registered boats were 40 feet or over.

- Less than $3 \%$ of USCG documented vessels were less than 26 feet in length. Over $80 \%$ were between 26 and 40 feet and over $17 \%$ were 40 or more feet in length.

- Over $70 \%$ of registered vessels were open boats. Sailboats and cabin cruisers each accounted for just over $12 \%$ of registered boats.

- Over $35 \%$ of documented vessels were cabin cruisers. No documented vessels were open boats.

- Over $75 \%$ of registered vessels were powered by outboard engines. Sterndrives powered almost $13 \%$ of registered boats and a little over $9 \%$ were powered by inboard engines. 
- Only $2 \%$ of documented vessels were powered by outboard engines. Almost $95 \%$ were powered by inboard engines. None reported having a sterndrive engine.

- Over $92 \%$ of registered boats were gas powered compared to less than $21 \%$ of documented boats. Almost $77 \%$ of documented vessels were diesel powered.

- Both berths and moorings appeared to be common in-season storage types for all boats with the exception of Western Massachusetts. Boaters in this region generally stored their boats on trailers or otherwise on land e.g. up on blocks). This type of storage was also common in Central Massachusetts.

- By far the most common out-of-season storage type for boats was on a trailer or otherwise stored on land. Very few boaters reported that they stored their vessel at berths or on moorings out of season.

- The boat owners who participated in this study were predominantly male.

- The mean age of boaters was 58 years old across the whole of Massachusetts.

- Boaters reported that, on average, they had operated boats for just over 30 years. Owners of documented boats had operated boats for longer than registered boat owners ( 36 years for documented boat owners compared to between 26 and 31 years for others).

- On average, boaters owned their boats for just over 24 years. Again, documented boaters appeared to have owned boats for slightly longer registered boat owners ( 28 years compared to between 22 and 25 years).

- Across the state, approximately $53 \%$ of boaters reported that they had taken a boating safety course (e.g. Boat-Ed through the Massachusetts Environmental Police). Owners of documented boats were most likely to have taken such courses (over 63\%). Between $33 \%$ and $40 \%$ in the Western and Central regions of Massachusetts had taken such a course.

- Across the state, almost $54 \%$ of boaters reported having taken a navigation course such as those offered by the US Coast Guard Auxiliary, US Power Squadrons or American Sailing Association. Almost $81 \%$ of owners of documented boats had taken a navigation course. In Western and Central regions, only a third of registered boat owners reported that they had taken a navigation course. Elsewhere in Massachusetts, $50 \%$ to $56 \%$ of registered boat owners reported having taken such courses.

- Almost $59 \%$ of respondents were employed full-time. Relatively few respondents reported being in part-time employment or being unemployed ( $6 \%$ and $4.4 \%$ respectively across the whole state). Just over $30 \%$ of boaters were retired. 


\subsection{Boating Activity}

- During the peak of the boating season (July and August) between $93 \%$ and $95 \%$ of visits to a boat included taking it out on the water. In May, this figure was under $74 \%$ and was down to $62 \%$ in October. Overall, almost $16 \%$ of vessel visits did not involve an on-water trip.

- On average, boaters went out on the water on their boat on 7.5 and 7.8 days respectively in July and August. As expected, this number was lowest at the beginning and end of the season. If they visited their boat at all in a month, the average number of days per month that boaters went out on the water was six. Documented boat owners appeared to go out on the water more often than other boaters ( 7.6 days per month).

- Almost $72 \%$ of trips by Western Massachusetts boaters and $60 \%$ of trips by Central Massachusetts boaters involved trailering their boat. This compares with between $28 \%$ and $32 \%$ of boaters from the three coastal regions. No owners of documented boats reported trailering them.

- The vast majority of trailered trips (80\%) originated at the boater's permanent home with just under $11 \%$ starting at a second home.

- Overall, less than $36 \%$ of boaters who trailered their boat reported that they had paid a launch fee or a parking fee associated with launching it from a ramp. This number rose to almost $47 \%$ of boaters from Western Massachusetts and $65 \%$ of boaters from Central Massachusetts who trailered their boats.

- The average reported launch fee or parking fee associated with launching a boat from a ramp was $\$ 13.94$ per trip and ranged from an average of $\$ 8.55$ to $\$ 17.27$ depending on the region.

- Boaters were asked to report which activities they engaged in on a specific trip each month. The most popular activities were cruising (over 67\%), entertaining friends and family (almost $48 \%$ ) and fishing (just over 38\%).

- The majority of activities were more popular during the months of July and August (i.e. cruising, entertaining, whale watching, scuba diving/snorkeling, general sightseeing, swimming and waterskiing).

- The average number of hours that a boat was under power or sail during the 2010 boating season was 72.1 hours based on information from 413 boaters. Documented boaters averaged 178 hours under power or sail. The Northeast and East Central regions were the next highest, with averages of 64.7 and 62.7 hours respectively. The Southeast had an average of 50.9 hours. Central and Western Massachusetts were the lowest two regions. 
- The end-of-season survey asked boaters to report how they rated their boating activity during the 2010 season as compared to other years. Over 53\% of the 455 boaters who responded said that it had been "somewhat less" to "much less" active than other years. Just over $17 \%$ said that their season had been "slightly more" to "much more" active compared than normal.

\subsection{Economics}

- It is important to note that by several measures the Massachusetts economy was just starting to recover from the severe 2008-2009 recession at the time of our survey and thus the estimates of recreational spending are likely to be below what they would normally be for a more robust period. Recreational spending is highly discretionary and likely to be one of the first areas to feel recessionary pressures and one of the last areas to recover.

- Based on the data gathered during this study, coastal and ocean recreational boaters in Massachusetts spent, on average, $\$ 529$ million on products and/or services of Massachusetts businesses.

- In-state spending by these boat owners took place in a variety of sectors. The highest triprelated levels of spending were on boat fuel and transient/guest dockage. The highest levels of non-trip-related spending were on seasonal dockage, mooring and storage; and routine maintenance.

- Another important contribution related to the spending of recreational boaters is the employment supported by that spending within the state. The $\$ 529$ million of spending by coastal and ocean recreational boaters supported over 4,730 fulltime-equivalent jobs within the state. As this study did not capture spending by out-of-state boaters, this is likely to be an underestimation.

- The total economic contribution of coastal and ocean recreational boating expenditures to Massachusetts in 2010 was at least almost $\$ 806$ million.

- This is a conservative estimate because it does not include any expenditure by out-ofstate boaters since it was not feasible to survey these visitors.

- It also only reflects monthly coastal and ocean boating activity from May through October in addition to yearly capital and maintenance expenditures.

- In addition, as noted earlier, this survey was conducted just as Massachusetts was coming out of a severe recession and thus overall expenditures are likely to be considerably lower than during a more prosperous economic period.

- As part of the end-of-season survey, over $79 \%$ of boaters reported that almost all their nontrip-related spending (e.g. maintenance, storage, parts and equipment) had occurred in Massachusetts. 
- Almost $50 \%$ of those who took an on-water trip, or simply visited their boat reported that almost all of their trip-related spending occurred near where the boat was launched or boarded. This is important economically as it could represent a significant boost to the local economy if boaters are travelling to an area to launch or board their vessel and most of their expenditure occurs near to that location.

- As previously noted, the majority of boaters reported that their 2010 boating season had been "somewhat less" to "much less" active than other years. Just over $17 \%$ said that their season had been "slightly more" to "much more" active than normal.

\subsection{Feedback}

- Those participants who had used the online mapping application were asked how easy they felt the mapping application had been to use. Of the 258 boaters who responded, $73 \%$ felt that the mapping application had been "somewhat easy" to "very easy" to use. Only $4.5 \%$ felt that the application had been "very difficult" to use.

- The boaters were also asked if they would be willing to participate in a similar boating survey in the future. Of the 458 boaters who responded, over $88 \%$ reported that they would be "somewhat willing" or "very willing" to participate. 


\section{Methodology}

The survey design was based partially on research conducted on behalf of the Florida Fish and Wildlife Conservation Commission as part of Florida Boating Access Facilities Inventory and Economic Study (myfwc.com/media/1162720/About_Econ_BAFI_Full_09.pdf or www.uhi.umb.edu/publications.htm). This study was led by the Urban Harbors Institute and the economic impact assessment was developed by Dr. Edward Mahoney of the Recreational Marine Research Center at Michigan State University. The study conducted in Florida focused on the economic impact of trip-related spending in the state and used an online mapping application to estimate actual, on-water boating activity. However, the application was developed to gather purely economic information rather than spatial data.

In order to gather spatial data for this study, the team contracted with Ecotrust to develop a more advanced online mapping application to capture information on the boaters' routes and areas where boaters engaged in specific activities (e.g. fishing, whale watching, etc.). The Ecotrust application was based on previous work that they had done when developing their Open OceanMap spatial data collection tool.

This study surveyed owners of recreational boats in Massachusetts, with a particular focus on the frequency of trips taken in coastal waters, the routes taken, the purpose of the trip and the money spent on the trip. Trips throughout the entire boating season (May through October) were of interest. In addition, some details of the particular boat owned and some additional information on expenses of owning a boat (such as repair costs, marina costs, off-season storage costs, etc.) were also of interest.

Due to the diverse and extensive amount of information required, the data could not be gathered through a single survey, but rather a series of surveys was needed. Once boaters had agreed to participate, a short initial survey was e-mailed to obtain current information about the boat owned and demographic information on the boat owner. Then, throughout the boating season, monthly surveys were e-mailed asking the participating boaters to describe their boating activity in the previous month and, more specifically the last boating trip that they had undertaken during that month. If boaters had been asked to report on any trip they had taken in a given month, they would probably have reported on the longest, most fun or most memorable trip. This would have biased the responses. In order to account for this, boaters were asked to report specifically on the last trip that they had taken in each month. This is a common practice in survey design.

Reporting months were originally considered the five months of May through September. Later, a sixth month (October) was added. Finally, an end-of-season survey was designed to gather information on general expenses relating to owning the boat. An additional feedback survey was included with the end-of-season survey to gather views, comments and criticism of the overall survey process. Therefore, the overall study consisted of a series of nine separate surveys - an initial survey, six monthly surveys, an end-of-season survey, and the feedback survey. 
To thank boaters for their time and encourage participation throughout the six-month period, each month a random prize drawing was conducted so that one boater who filled out the survey that month would be awarded $\$ 100$ and another would receive a free night's berthing at a marina or a free annual Sea Tow membership. Monthly prizes were kindly donated by the Massachusetts Marine Trades Association, Newburyport Marinas, Kingman Yacht Center and Sea Tow South Shore. In addition, at the end of the study, one person would be randomly chosen to receive the grand prize of $\$ 1,000$ (donated by the Massachusetts Ocean Partnership). Each completed survey represented another entry into the grand prize drawing, so the more surveys a boater completed, the greater the odds of them winning the grand prize. It was hoped this would keep boaters interested and participating throughout the boating season.

One of the most important pieces of information desired was to map the route taken by each boater during the monthly trip they reported. A novel approach was considered in which boaters could actually draw their trips using a web-based mapping application. This, of course, meant that the surveys and maps had to be completed online. Therefore, a survey design was constructed in which the surveys would be available on the web using a web-based survey application (Snap Survey Software). The survey would then pass the respondent to the mapping application while also passing on needed information from the survey. This was termed a "handoff." Therefore, the monthly surveys began with an electronic Snap survey, which asked questions about boat-related activity during the previous month, as well as details of the boater's last on-water trip during that month. Then after answering these questions, the respondent would be passed directly to the mapping application to plot the actual route taken and areas where they had engaged in boating-related activities. In the end, the route and activity area data could be matched with the information from the Snap survey about the trip. An entire web-based survey design was therefore imperative for conducting all surveys. It took a great deal of development effort to have the entire process run smoothly for respondents and to get all information required to be passed from the survey to the mapping software. In the end, a virtual seamless handoff was achieved.

\subsection{Boat Ownership Data}

This study was based on being able to survey a representative sample of Massachusetts boaters and then being able to scale up the information provided so that statewide estimates could be calculated. In order to be able to implement such a methodology, it was critical that there was information available on what the boating population was and how to contact them. It was also important to have additional details that allowed for this population to be stratified (i.e. broken down into sub-categories) for analysis.

There was no existing source of information on who engaged in recreational boating in Massachusetts but there was available information on who owned a boat. It was therefore possible to design a sampling strategy based on the boats in the state, rather than on those who participate in recreational boating. 
There were two primary sources of information on boat ownership in Massachusetts - the state's boat registration database managed by the Massachusetts Environmental Police (MEP) and the United States Coast Guard's (USCG) database of federally documented vessels. It is important to note that in Massachusetts, a vessel documented with the USCG is exempt from state registration so should not have appeared in both databases.

\subsubsection{Massachusetts Registered Boats}

In Massachusetts, "any vessel... propelled or designed to be propelled by machinery, whether or not such machinery is permanently or temporarily affixed or is the principal source of propulsion" (MGL Chapter 90B, Section 36A) must be registered with the MEP. This had previously applied only to vessels of fourteen feet or greater but this was amended to include any vessel that could be mechanically propelled. This regulation states that the only exemptions to this are " $a$ vessel which has a valid marine document issued by the Bureau of Customs of the United States government or any federal agency successor thereto" (e.g. a USCG documented vessel) or a vessel that is registered in another state that is being used in Massachusetts for less than 60 consecutive days.

Massachusetts boat registration requires information such as:

- Name and address;

- Length of vessel;

- Mooring or storage location;

- Primary use (pleasure, commercial fishing, government, livery or enforcement);

- Type (open boat, cabin cruiser, personal water craft, sailboat or other);

- Hull material (aluminum, fiberglass, inflatable, plastic, steel or wood);

- Engine type (inboard, outboard, inboard/outboard [or sterndrive], electric, jetdrive or other); and

- Fuel type (gas or diesel).

This information allowed for any sample to be stratified (e.g. by size) and meant that letters asking boaters to participate could be addressed directly to the owner. As regular registration renewal is required by law every two years, it was likely that contact information would be reasonably up-to-date.

\subsubsection{US Coast Guard (USCG) Documented Vessels}

The USCG's database of documented vessels is maintained by the National Vessel Documentation Center. The center's website states that documentation "provides conclusive evidence of nationality for international purposes, provides for unhindered commerce between the states, and admits vessels to certain restricted trades, such as coastwise trade and the fisheries" (www.uscg.mil/hq/cg5/nvdc/nvdcfaq.asp\#01).

In general, for a vessel to be documented it must measure at least five net tons and be wholly owned by a citizen of the US. Documentation is required for such vessels that are "used in fishing activities on 
navigable waters of the US or in the Exclusive Economic Zone (EEZ), or used in coastwise trade...." (www.uscg.mil/hq/cg5/nvdc/nvdcfaq.asp\#01).

USCG documentation is not required for purely recreational vessels. However, a vessel that is documented rather than state-registered is often viewed by mortgage lenders as a more secure form of collateral insofar as it allows a first preferred ship's mortgage to be recorded which is widely recognized. A certificate of documentation can often facilitate the customs process in foreign ports as it clearly identifies the nationality of the vessel. In Massachusetts a documented vessel does not need to be state-registered so a boater need only pay one fee ( $\$ 100$ every two years to state-register a vessel of 40 feet or greater in Massachusetts, compared to an initial fee of $\$ 133$ to document the vessel with the USCG with no fees associated with annual renewal). Documented vessels are not exempt from Massachusetts sales tax so this is not a factor when a Massachusetts boater is deciding between registering their boat and getting it documented.

The documented vessel database contains information such as the:

- Name and address of the "managing owner";

- Length of vessel;

- Hailing port - it is important to note that the choice of hailing port is not restricted to where the owner lives or where the vessel is kept;

- Primary service (i.e. use) which includes "recreational"; and

- Hull type (wood, steel, fibrous reinforced plastic, aluminum, concrete or other).

Due to the limited information contained in the documented vessel database compared to the state data, these types of vessels are less easy to stratify and were kept as a separate "class" in this study.

\subsubsection{Acquiring the Databases}

Both the Massachusetts database of registered boats and the database of USCG documented vessels are public record. In fact, it is possible to search for details of documented vessels using a number of online search tools. However, these generally only allow you to search by owner or vessel name. It is also possible to request specific information by contacting the MEP or the USCG's National Vessel Documentation Center. Obviously private information such as social security numbers would be removed from any data that were provided.

It is important to note that the availability of boat registration data varies from state to state and what may be available today may be restricted tomorrow. It is also important to note that obtaining such data may take several months.

For this study, initial efforts to acquire the necessary vessel and owner information were made at both a state and federal level. However, it became clear that the request of the USCG's data would likely take several months to process and that there was no clear system in place at a state level for this data to be distributed. Due to the limited time available in which to initiate this study in time to capture boating 
activity during the state's 2010 boating season, other avenues were explored. Based on the knowledge and connections of those involved in the study, it was possible to obtain a Microsoft Access database containing the state boat registration as of October 2009 and a Microsoft Excel spreadsheet containing the results of a search of the documented vessel database. The documented vessel database search results contained information on all documented vessels with an owner address or hailing port in Massachusetts that had "recreational" listed as its primary service (i.e. primary use).

\subsubsection{Description of the "Population"}

The database of Massachusetts registered boats as of October 2009 contained records on 145,105 vessels (Table 1). As this study was focused on recreational use, it was envisaged that only registered boats with a "pleasure" primary use type would be included in the population of registered boats. However, discussions with the advisory group and others suggested that many of those vessels classified as "commercial fishing" might also be used for recreational purposes. It was therefore decided to exclude only those boats listed as "commercial passenger," "livery" or "other" from the population of registered boats. This left 143,507 registered "pleasure" or "commercial fishing" boats (i.e. $98.9 \%$ of all vessels in the original database).

Table 1: $\quad$ Breakdown of all boats in the database of registered boats by primary use type.

\begin{tabular}{lrr}
\hline Vessel Type & Number & $\%$ \\
\hline Pleasure & 141,461 & $97.5 \%$ \\
\hline Commercial Fishing & 2,046 & $1.4 \%$ \\
\hline Commercial Passenger & 144 & $0.1 \%$ \\
\hline Livery & 378 & $0.3 \%$ \\
\hline Other & 1,076 & $0.7 \%$ \\
\hline TOTAL & 145,105 & \\
\hline
\end{tabular}

The majority of the registered vessels were between 16 and 26 feet in length (53.6\%) with $40.2 \%$ of registered boats being less than 16 feet. Only $0.2 \%$ of registered boats were 40 feet or over (Table 2). This differed significantly from the size breakdown of the documented boats (Figure 1).

A total of 11,824 vessels were taken from the US Coast Guard database of documented vessels. These consisted of all vessels with an owner address or hailing port in Massachusetts that had "recreational" listed as its primary service (i.e. primary use). Almost $19 \%$ of documented vessels were 40 feet or over in length and $78.5 \%$ were between 26 and 40 feet. Only $2.7 \%$ of documented vessels were listed as being less than 26 feet in length (Table 3). 
Table 2: Breakdown of pleasure and commercial fishing boats in the database of registered boats by size class.

\begin{tabular}{lrr}
\hline Boat Length (ft) & Number & $\%$ \\
\hline Less than 16 & 57,624 & $40.2 \%$ \\
\hline 16 to $<26$ & 76,881 & $53.6 \%$ \\
\hline 26 to $<40$ & 8,700 & $6.1 \%$ \\
\hline $40+$ & 302 & $0.2 \%$ \\
\hline TOTAL & 143,507 & \\
\hline
\end{tabular}
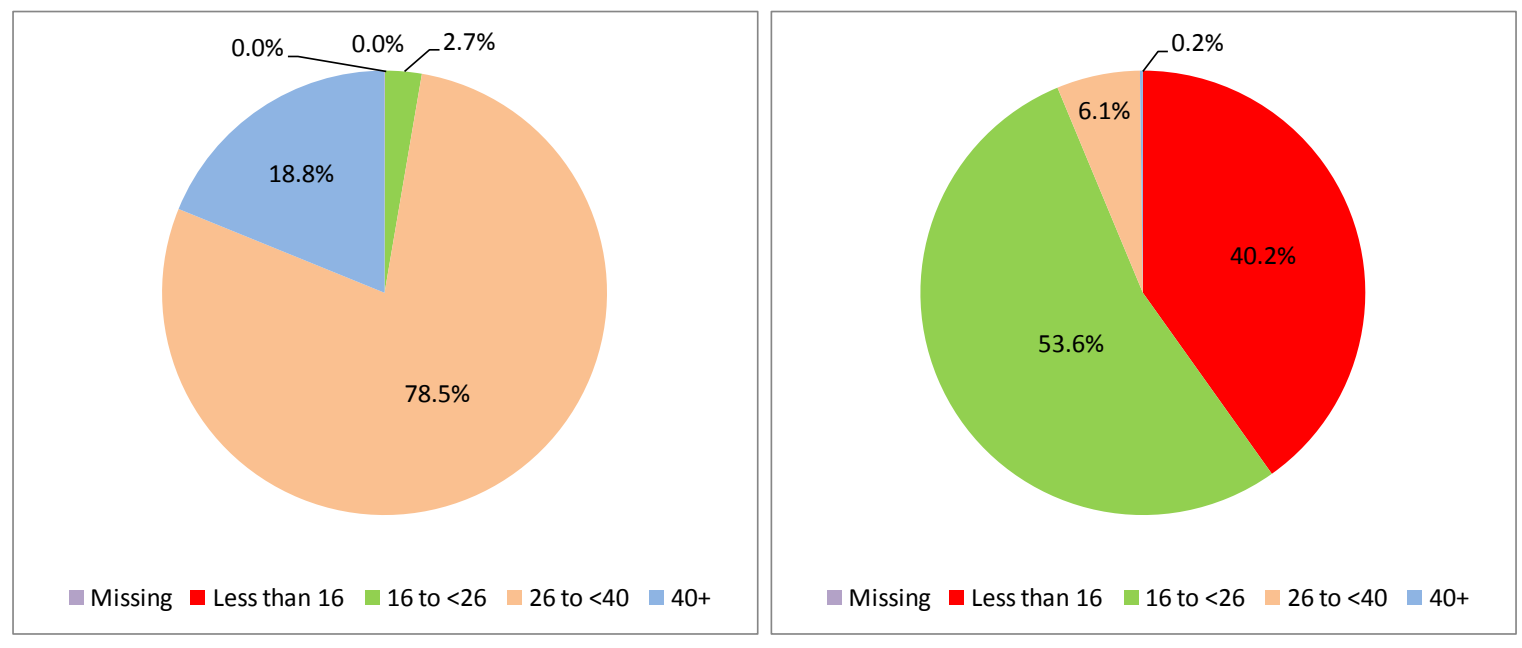

Figure 1: $\quad$ Breakdown of the population of documented (left) and registered vessels by size class.

Table 3: $\quad$ Breakdown of documented boats by size class.

\begin{tabular}{lrr}
\hline Boat Length $(\mathbf{f t})$ & Number & $\%$ \\
\hline Missing & 3 & $0.0 \%$ \\
\hline Less than 16 & 1 & $0.0 \%$ \\
\hline 16 to $<26$ & 314 & $2.7 \%$ \\
\hline 26 to $<40$ & 9,278 & $78.5 \%$ \\
\hline $40+$ & 2,228 & $18.8 \%$ \\
\hline TOTAL & $\mathbf{1 1 , 8 2 4}$ & \\
\hline
\end{tabular}

Limited information was available about the types of documented vessels but the registered boat database did contain such information. As Table 4 shows, 112,436 (78.3\%) of the 143,507 registered boats were open boats and most of these were less than 26 feet in length (Figure 2). Cabin cruisers made up $9.4 \%$ of registered boats and were more commonly found in the larger size classes (26+ feet). Sailboats made up a small percent of boats under 26 feet. However, small boats that are not designed 
to be fitted with an engine do not have to be registered so small sailboats may have been under represented in the registered boat database. Almost all personal watercraft (PWC) were less than 16 feet in length. While five PWC were classed as being over 26 feet in length, it is thought that these were most likely due to boater reporting or data entry errors.

Table 4: $\quad$ Breakdown of pleasure and commercial fishing boats in the database of registered boats by size class and vessel type.

\begin{tabular}{lrrrrr}
\hline \multirow{2}{*}{ Type } & \multicolumn{2}{c}{ Boat Length $\mathbf{f t}$ ) } & & TOTAL \\
& Less than $\mathbf{1 6}$ & $\mathbf{1 6}$ to $<\mathbf{2 6}$ & $\mathbf{2 6}$ to $<\mathbf{4 0}$ & $\mathbf{4 0 +}$ & \\
\hline Cabin Cruiser & 13 & 8,738 & 4,534 & 168 & 13,453 \\
\hline Open Boat & 47,586 & 62,590 & 2,207 & 53 & 112,436 \\
\hline PWC & 8,425 & 45 & 4 & 1 & 8,475 \\
\hline Sailboat & 598 & 3,555 & 1,658 & 42 & 5,853 \\
\hline Other & 1,002 & 1,953 & 297 & 38 & 3,290 \\
\hline TOTAL & $\mathbf{5 7 , 6 2 4}$ & $\mathbf{7 6 , 8 8 1}$ & $\mathbf{8 , 7 0 0}$ & $\mathbf{3 0 2}$ & $\mathbf{1 4 3 , 5 0 7}$ \\
\hline
\end{tabular}

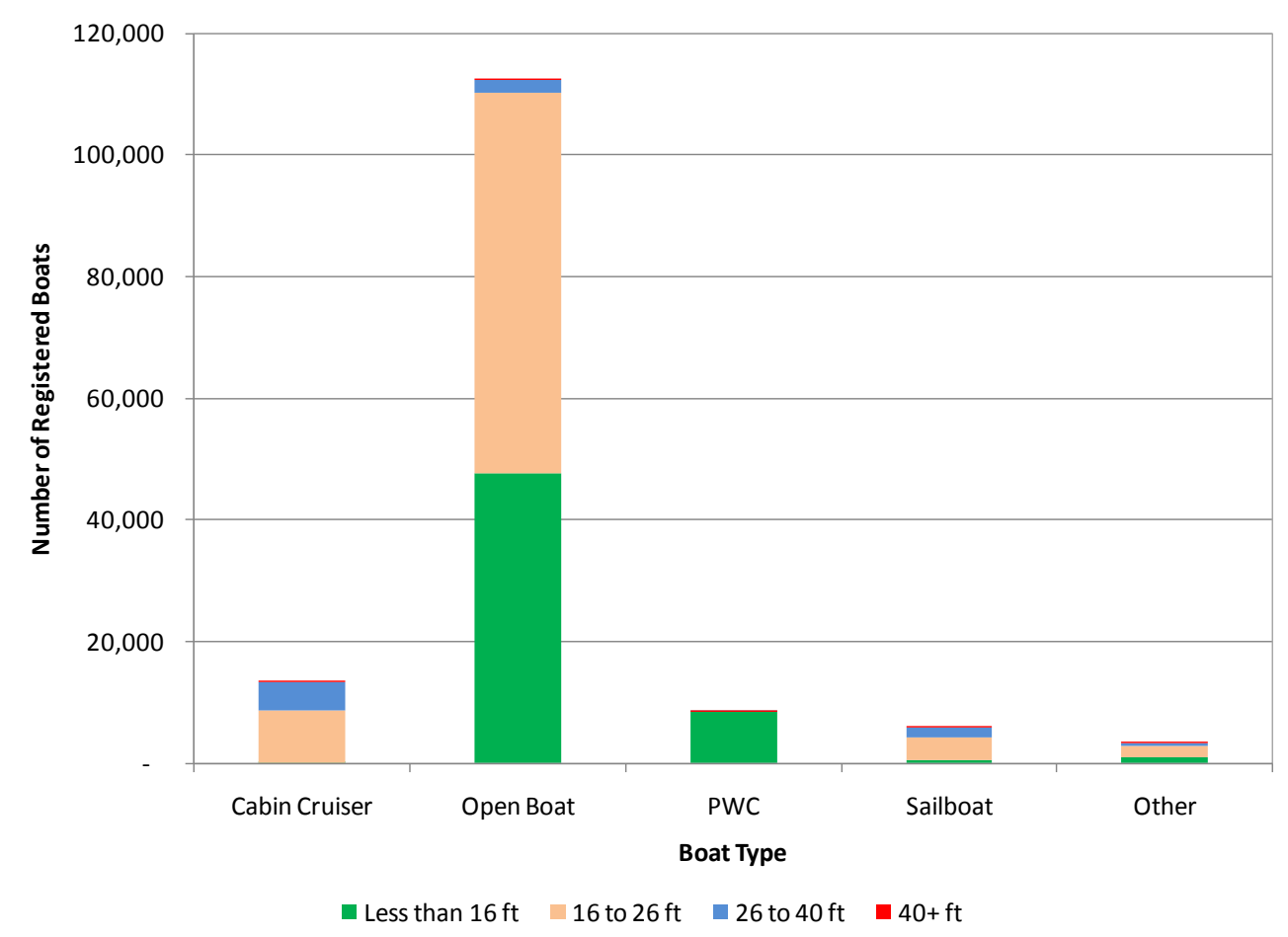

Figure 2: $\quad$ Number of pleasure and commercial fishing boats in the database of registered boats by type and size class. 
The majority (64.2\%) of registered boats were powered by outboard engines with a further $12.2 \%$ being propelled by inboard/outboard drives (sterndrives). Vessels with jetdrives accounted for $5.5 \%$ of the pleasure and commercial fishing boats in the registered boat database and $87.9 \%$ of these vessels were PWCs. Boats powered by inboard engines only accounted for $5.3 \%$ of the vessels in the database (Table 5).

Table 5: $\quad$ Breakdown of pleasure and commercial fishing boats in the database of registered boats by propulsion type.

\begin{tabular}{lrr}
\hline Propulsion Type & Number & $\%$ \\
\hline Outboard & 92,085 & $64.2 \%$ \\
\hline Inboard/Outboard (Sterndrive) & 17,442 & $12.2 \%$ \\
\hline Jetdrive & 7,945 & $5.5 \%$ \\
\hline Inboard & 7,543 & $5.3 \%$ \\
\hline Electric & 4,096 & $2.9 \%$ \\
\hline Airboat & 24 & $0.0 \%$ \\
\hline Other & 927 & $0.6 \%$ \\
\hline No data & 13,445 & $9.4 \%$ \\
\hline TOTAL & $\mathbf{1 4 3 , 5 0 7}$ & \\
\hline
\end{tabular}

The vast majority of boats ( $82.8 \%)$ in the registered boat database used gas-powered motors. Only $1.5 \%$ of the vessels were diesel powered (Table 6).

Table 6: Breakdown of pleasure and commercial fishing boats in the database of registered boats by fuel type.

\begin{tabular}{lrr}
\hline Fuel Type & Number & $\%$ \\
\hline Gas & 118,890 & $82.8 \%$ \\
\hline Diesel & 2,221 & $1.5 \%$ \\
\hline Other & 8,951 & $6.2 \%$ \\
\hline No data & 13,445 & $9.4 \%$ \\
\hline TOTAL & $\mathbf{1 4 3 , 5 0 7}$ & \\
\hline
\end{tabular}

The most common hull materials for registered boats were fiberglass (65.7\%) and aluminum (22\%). A further $6.2 \%$ were inflatables (Table 7). It is likely that many of these 8,962 inflatables were used as tenders to access larger boats, as $98.7 \%$ of them were less than 16 feet in length. In fact, $49 \%$ of them were less than 10 feet in length. 
Table 7: Breakdown of pleasure and commercial fishing boats in the database of registered boats by hull material.

\begin{tabular}{lrr}
\hline Hull Material & Number & $\%$ \\
\hline Fiberglass & 94,350 & $65.7 \%$ \\
\hline Aluminum & 31,574 & $22.0 \%$ \\
\hline Inflatable & 8,962 & $6.2 \%$ \\
\hline Plastic & 3,875 & $2.7 \%$ \\
\hline Wood & 2,557 & $1.8 \%$ \\
\hline Steel & 119 & $0.1 \%$ \\
\hline Other & 2,070 & $1.4 \%$ \\
\hline TOTAL & $\mathbf{1 4 3 , 5 0 7}$ & \\
\hline
\end{tabular}

\subsubsection{Strengths and Weaknesses of the Datasets}

It is important to remember that this study used both the database of registered boaters and the documented vessel database for purposes for which they were not designed. However, these datasets were invaluable for estimating the population of boats in Massachusetts and providing sufficient information (particularly for the registered boats) to allow for a stratified sampling to be undertaken. Probably the greatest strength of these datasets was the apparent accuracy of the contact information for the vessel owners as less than $5.4 \%$ of the initial letters mailed to the sample of boat owners were returned as undeliverable. This may be explained by the fact that the information relating to documented vessels must be verified annually and boat registration in Massachusetts must be renewed every two years.

Both databases contain information on the size of vessels and hull material and the database of registered boats contains additional vessel information (as discussed previously). As part of the study, the participants were provided with the initial survey, which was pre-populated with information about their vessel using the two databases. They were asked to correct any incorrect information. Figure 3 clearly shows that the majority of the information contained in the databases was verified by the boat owners themselves as being correct. A small number of corrections that were made appeared to be inconsistent with other information that existed about the vessel. These were flagged as possible correction errors although they were retained for this initial analysis.

As vessel documentation is a national form of registration dating back to the $11^{\text {th }}$ Act of the First Congress, suggesting changes to the process is beyond the scope of this study. However, implementing minor changes to the Massachusetts boat registration process could dramatically increase the value of the resulting database for research purposes, and may be possible for a couple of reasons: 
1. The Massachusetts Environmental Police (MEP) is part of the Executive Office of Energy and Environmental Affairs (EEA), which was one of the driving forces behind the implementation of this study. As the state's boat registration falls under the jurisdiction of the MEP, intra-agency coordination may facilitate making changes to the registration process.

2. The MEP has recently started to offer online boat registration and renewal, which would facilitate electronic information gathering.

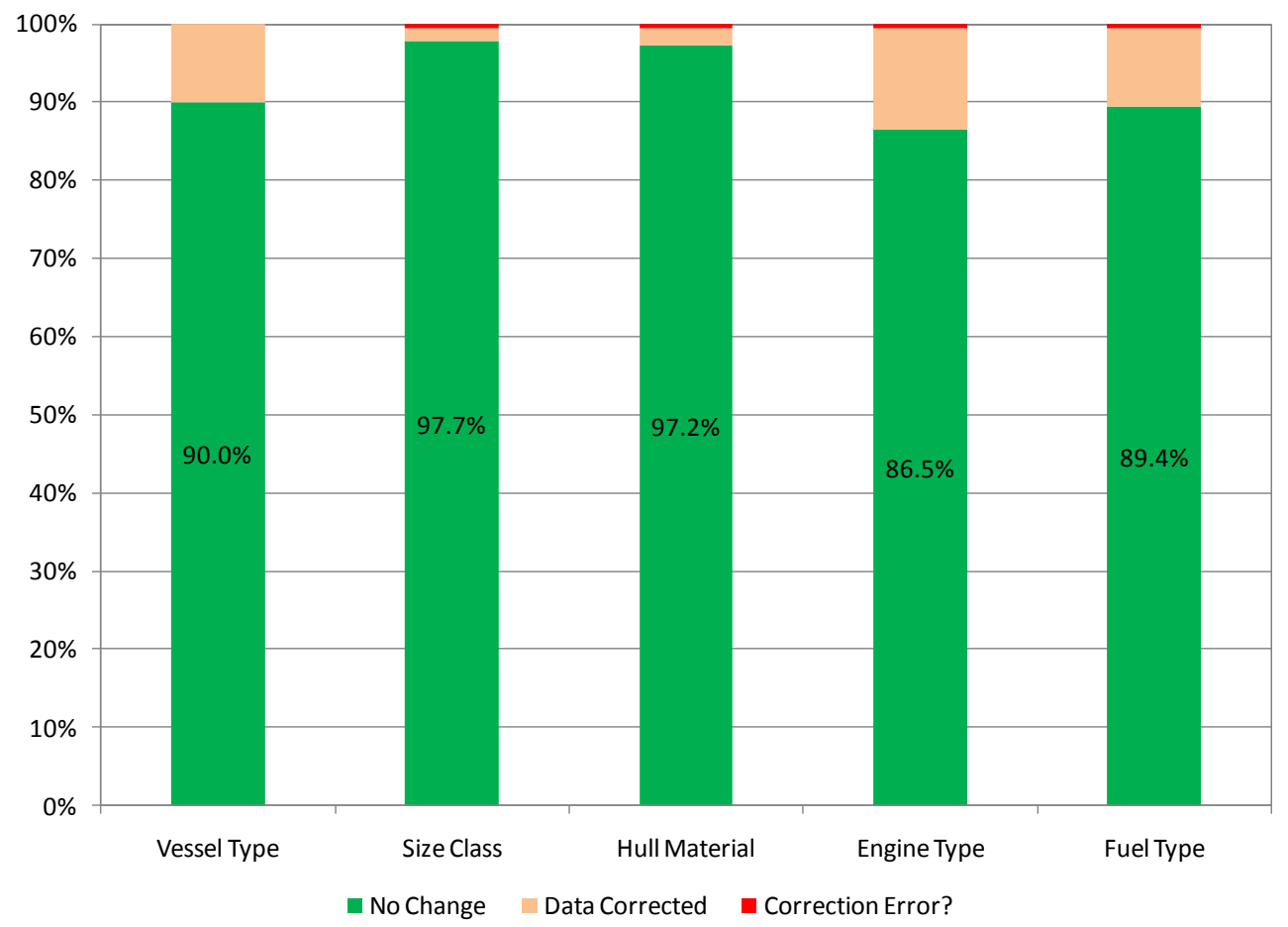

Figure 3: $\quad$ The percent of types of vessel information deemed correct by vessel owners.

If a few additional pieces of information were gathered during the boat registration process, the resulting database could be greatly enhanced as a tool to target more accurately this type of study and other research. Additional valuable information might include:

- A current, valid e-mail address.

A valid e-mail address greatly enhances the ability to conduct surveys and greatly reduces the costs of doing so. Online registration could require a valid e-mail address and printed forms could ask for this information. While not all boaters have e-mail addresses or even use computers, less than $6 \%$ of otherwise-eligible boaters had to be rejected from this study because they did not provide a valid e-mail address

- Whether the boat is used exclusively on freshwater versus saltwater use.

Since this study was focused on coastal and ocean recreational boat use, identifying those boats that are used only on freshwater would allow for more targeted sampling for future studies. 
- Whether the boat is used exclusively for commercial purposes.

While the boat registration form asks the boater to check a box to indicate what the boat is used for, this use type cannot be assumed to be exclusive. For example, commercial fishing boats can be used for recreational purposes and recreational boats can be used for charter fishing, as long as they comply with US Coast Guard safety regulations and are operated by suitably licensed captains. Identifying those boats that are used only for non-recreational uses would again allow for more targeted sampling for future studies.

- Whether the boat is used exclusively as a tender.

Massachusetts law requires that all vessels that are propelled by, or designed to be propelled by, machinery be registered with the MEP. One result of this is that over $40 \%$ of the 143,507 pleasure and commercial fishing boats in the database as of October 2009 were less than 16 feet in length (see Table 2 ) and almost $11 \%$ were 10 feet or less in length. While this study was interested in all boating activity, the focus was on coastal and ocean boating. Therefore, being able to identify those small boats that were only ever used as tenders (e.g. to get to and from a larger boat kept on a mooring) would allow this type of boat to either be excluded from the sample or to be under sampled. More resources could then be focused on the vessel types of greater interest.

- Greater details about where the boat is kept.

The boat registration form currently asks for the mooring/storage location. While this is important information, it would be of greater value if details of the town, type of storage (e.g. mooring, berth, trailer) and type of facility (e.g. marina, residence) at which the boat is generally kept both in and out of season were gathered. This information would allow for sampling strategies to be stratified more accurately based on geographic location.

- If the boat is ever used for recreational fishing. While this study aimed to fill in data gaps associated with recreational boating, there is general agreement that similar gaps exist with regards to recreational fishing. Massachusetts is currently implementing a federally-mandated saltwater fishing license, which will help fill in some of these gaps. However, if a study similar to this one were to be designed to look at boatrelated recreational fishing, having this piece of information would allow for a much more focused sampling effort.

There are two categories of vessels that may be missing from, or under-represented in these databases:

1. Non-motorized vessels that are not required to be registered in Massachusetts. These would include canoes and kayaks and some (most likely smaller) sailboats. For this study, this was not a significant issue as canoes and kayaks were not the primary focus of the research and small sailboats are generally used in nearshore waters. 
2. The second category is of greater significance. The waters of Massachusetts are extremely popular with out-of-state boaters. Some boaters are day-trippers who simply pass through the waters of the state, while others are larger vessels that might spend several weeks in Massachusetts and may have a significant impact on the local economy. At present, the number of out-of-state boaters using the state's waters and their economic impact remains almost entirely unknown. While this type of boating activity was not the focus of this study, some initial datasets were investigated and one possible methodology was piloted on a very small scale.

\subsection{Survey Design}

As the sampling strategy was based on the boats in the two databases, it was important that boaters were reminded to report activity and spending associated with the specific, randomly selected vessel and not with any other boats they might own. To that end, each survey stressed that the respondent should answer based on a specific vessel, and was customized to include the type and size of the particular vessel of interest.

\subsubsection{Surveys}

The overall study consisted of a recruitment survey followed by a series of nine separate surveys - an initial survey, six monthly surveys, an end-of-season survey, and the feedback survey (Table 8 ).

The surveys can be found in Appendix B. Please note that all but the recruitment survey were only available as online Snap surveys - the paper versions in the appendix were created solely for this report. Due to time and budget constraints, a complete survey design protocol was not possible for this study. Such a design would have required a number of focus groups of boat owners, some cognitive interviews (conducted with boat owners using early drafts of the surveys to see how they interpret the questions) and finally a small pilot survey. None of these were possible due to a lack of time for survey preparation and a lack of resources to pay for these efforts. However, the expertise of the advisory group and their contacts in the boating community helped to somewhat overcome the time and budgetary constraints.

In light of this, the survey design effort involved the following steps:

1. Draft questions were proposed by the Urban Harbors Institute (UHI) and the Massachusetts Ocean Partnership (MOP). Many of these were adapted from those used during the 2009 Florida Boating Access Facilities Inventory and Economic Study (as developed by Dr. Edward Mahoney Recreational of the Marine Research Center at Michigan State University) with additional input from the advisory group.

2. The Center for Survey Research (CSR) made comments on these questions and offered suggestions and alternatives.

3. A number of team meetings were held so that issues could be resolved and wording finalized.

4. CSR then formatted the questions as they should appear in a survey and on the web. 
5. The questions were then used with volunteer boat owners and with other stakeholders to get additional input.

6. CSR, UHI and MOP then met to go over the issues raised by the test volunteers and to resolve as many as possible.

7. CSR created a final survey version.

8. UHI and MOP then signed-off on the final version to be used.

Table 8: $\quad$ Description of the surveys that were sent to boat owners.

\begin{tabular}{|c|c|c|c|c|c|c|}
\hline & \multirow{2}{*}{$\begin{array}{l}\text { 1. Recruitment } \\
\text { Survey }\end{array}$} & \multirow{2}{*}{ 2. Initial Survey } & \multicolumn{2}{|c|}{$\begin{array}{l}\text { MONTHLY SURVEYS } \\
\text { (May through October) }\end{array}$} & \multirow{2}{*}{$\begin{array}{l}\text { 4. End-of-season } \\
\text { Survey }\end{array}$} & \multirow{2}{*}{$\begin{array}{l}\text { 5. Feedback } \\
\text { Survey }\end{array}$} \\
\hline & & & \begin{tabular}{|l|} 
3a. Monthly \\
Survey
\end{tabular} & \begin{tabular}{|l|} 
3b. Mapping \\
Component
\end{tabular} & & \\
\hline $\begin{array}{l}\text { Delivery } \\
\text { Method }\end{array}$ & Mail & E-mail & E-mail & $\begin{array}{l}\text { Redirected } \\
\text { from survey }\end{array}$ & E-mail & E-mail \\
\hline Recipients & \begin{tabular}{|l} 
Sample of \\
owners of \\
recreational \\
boats in MA.
\end{tabular} & $\begin{array}{l}\text { All eligible boat } \\
\text { owners }\end{array}$ & $\begin{array}{l}\text { All eligible boat } \\
\text { owners }\end{array}$ & \begin{tabular}{|l|} 
All eligible boat \\
owners who \\
took their boat \\
out on the water
\end{tabular} & $\begin{array}{l}\text { All eligible boat } \\
\text { owners }\end{array}$ & $\begin{array}{l}\text { All eligible boat } \\
\text { owners }\end{array}$ \\
\hline Aim & $\begin{array}{l}\text { To encourage } \\
\text { boaters to } \\
\text { become } \\
\text { potential } \\
\text { participants in } \\
\text { the MA } \\
\text { Recreational } \\
\text { Boater Survey } \\
2010 \text { and allow } \\
\text { for ineligble } \\
\text { participates to } \\
\text { be identified }\end{array}$ & $\begin{array}{l}\text { To gather basic } \\
\text { demographic } \\
\text { information on } \\
\text { the boaters } \\
\text { and details } \\
\text { about the } \\
\text { specific boat of } \\
\text { interest }\end{array}$ & $\begin{array}{l}\text { To gather data } \\
\text { about the } \\
\text { boaters activity } \\
\text { and spending } \\
\text { associated } \\
\text { with use of the } \\
\text { specific boats } \\
\text { of interest } \\
\text { during each } \\
\text { month with } \\
\text { more detailed } \\
\text { information } \\
\text { about the last } \\
\text { time that they } \\
\text { visited or used } \\
\text { the boats }\end{array}$ & \begin{tabular}{|l|} 
To gather \\
spatial data \\
about the \\
boaters activity \\
during the last \\
on-water trip \\
that they took \\
on their boats
\end{tabular} & \begin{tabular}{|l|} 
To gather data \\
about the \\
boaters annual \\
activity and \\
capital \\
expenditure \\
relating to the \\
specific boats
\end{tabular} & \begin{tabular}{|l} 
To gather \\
feedback from \\
boaters to be \\
used to \\
improve future \\
studies
\end{tabular} \\
\hline $\begin{array}{l}\text { Ineligible } \\
\text { Participants }\end{array}$ & & $\begin{array}{l}\text { Those who: } \\
\text { no longer } \\
\text { owned the } \\
\text { boat of } \\
\text { interest; } \\
\text { used it } \\
\text { exclusivley on } \\
\text { freshwater; } \\
\text { used it } \\
\text { exclusively for } \\
\text { commercial } \\
\text { purposes; or } \\
\text { who did not } \\
\text { have a valid e- } \\
\text { mail address }\end{array}$ & $\begin{array}{l}\text { Those who no } \\
\text { longer owned } \\
\text { the boat of } \\
\text { interest }\end{array}$ & \begin{tabular}{|l} 
Those who did \\
not take their \\
boat out on the \\
water during \\
the month
\end{tabular} & & \\
\hline
\end{tabular}


This process led to useful exchanges and input from a wide variety of interested and knowledgeable people. Although not a formal systematic approach for question development, it did serve as a good proxy considering time and resources. The surveys were much improved as a result.

\section{Recruitment Survey}

A recruitment package was mailed out to a sample of 10,000 boaters from the combined registered and documented boaters on May 6, 2010. The package contained information about the study and a recruitment survey to be filled out by boaters who were interested in participating. This was the only survey that was sent in the mail; all the subsequent ones were distributed via e-mail linking the participant to the current, online survey.

As the sampling was based on the vessel rather than the boater, it was important to ensure that the boater was answering questions about the selected vessel and not another that they might own. To this end, the recruitment surveys were customized using a mail merge to include the type, size and registration/documentation number of the specific vessel of interest. So rather than a question asking:

Does your boat have a name?

It asked (for example):

Does your 22-foot Boston Whaler \#MS1234AB have a name?

The main aim of the recruitment survey was to encourage boaters to agree to participate and to ensure that they provided e-mail addresses for future communication. The survey also contained a number of questions that could be used to determine if a boater was eligible to participate:

- Do you currently own a [boat size, make and number]?

As the sampling was based on vessel rather than boater, clearly nobody could remain eligible if they no longer owned the specific boat. Additionally, some respondents entered comments such as "Haven't used it in years and am trying to sell it." These too were deemed ineligible. In a couple of instances, a boater had sold the selected vessel and replaced it with another one of similar size and type. While it may have been possible to include them, it was felt that it would be impractical based on the compressed timeline.

- Do you use your [boat size, make and number] exclusively on freshwater (rivers or lakes)? While freshwater boating is of great importance in Massachusetts, it had been decided that such activity was beyond the scope of this study. Therefore, boaters who used their vessels exclusively in freshwater were deemed ineligible.

- Do you use your [boat size, make and number] exclusively for non-recreational purposes (e.g. as a charter fishing or commercial fishing vessel)?

The focus of this study was on recreational boating in Massachusetts. However, even if a vessel was classed as "commercial fishing" in the state's boat registration database, it could also be 
used for recreational excursions. Therefore, this question allowed for those vessels that were never used for recreational purposes to be deemed ineligible.

The survey also included some questions about what other vessels the boater might own. These were included in an effort to gather some information on boaters who own multiple vessels and in particular, private ownership of watercraft such as canoes and kayaks that do not have to be registered in Massachusetts.

\section{$\underline{\text { Initial Survey }}$}

Once boaters had agreed to participate and were deemed eligible (i.e. still owned the boat of interest, used it on coastal or ocean waters and used it for recreational purposes), they were asked to complete an initial survey verifying the details of their vessel and to provide some basic demographic and personal information.

This survey provided an opportunity for registered boat owners to verify or correct the information extracted from the state's database of registered boats and for owners of documented vessels to provide information not contained in the US Coast Guard's database.

The survey also asked for details on the type of facility at which the vessel was stored (e.g. commercial marina, private club, municipal facility, private residence) and how it was stored (e.g. at a berth, on a mooring, in a dry stack/rack, on a trailer) both during and out of season.

In addition, the boaters were asked some basic demographic information: sex, age, employment status and household income. They were also asked how long they had been a boater, how long they had owned a boat and whether they had taken any boating safety or navigation courses.

It was useful to have boaters complete this survey prior to completing the monthly boating activity surveys because it allowed:

- For the testing of the system that notified participants that a survey was available and linked them their customized survey;

- The team to identify "bad" e-mail addresses and attempt to correct them; and

- The participants to experience filling in a relatively simple online Snap survey before being asked to attempt the longer, more in-depth monthly surveys.

\section{Monthly Boating Activity}

During the 2010 boating season, participating boaters were sent an e-mail at the beginning of the month that contained a link to take them to their customized online monthly survey. This prompted them to report on any activity that they had engaged in the previous month associated with the selected boat. Boaters were reminded to only report on the selected vessel and the survey was customized with the boat type and length (e.g. 22-foot Boston Whaler).

In each month, the first question determined if participants still owned the vessel. If so, they were then asked to report the number of days during the previous month they had visited the boat and the 
number of nights they had stayed on board. They were also asked how many times they had actually taken their boat out on the water and how many nights they had been away from their normal berthing or mooring location.

This study differentiated between a "visit" where a boater was at or on their boat but did not go out on the water, and a "trip" where the boater went out on the water in their vessel. The reason this was important was that the advisory group and others associated with recreational boating had suggested that there is a significant amount of boat-related activity and spending that is not associated with actual on-water trips.

Boaters who did not take on-water trips but who had visited their boat during the previous month were then asked to provide some information about the last time in that month that they had visited their boat. They were asked to provide information about whether it was a day or overnight visit and, if it were the latter, how many nights they had spent visiting their vessel. They were then asked to report their estimated expenditure associated with this visit in the following categories:

- Boat fuel and oil;

- Transient/guest dockage (marina fee);

- Launch fees;

- Pumpout fees;

- Restaurant meals \& drinks (including take-out food \& drinks);

- Groceries;

- Auto gas and oil;

- Shopping and souvenirs;

- Recreation and entertainment;

- Lodging (hotel / motel);

- Lodging (camping / B\&B);

- Fishing gear, bait, ice, etc.; and

- Other

Finally, they were asked to estimate what percentage of this expenditure had occurred "near to" where their boat was berthed or moored. The team acknowledges that the term "near to" was somewhat vague but, after considerable discussion, it was decided that using pre-defined geographic boundaries (such as counties or municipalities) or a specific distance (e.g. within 20 miles) could be problematic as:

- Massachusetts residents do not generally think in terms of counties;

- Municipal boundaries are not always clear, and boaters may not be sure in which municipality they spent money;

- Residents frequently use unofficial names for municipalities. For example, Dorchester and Roxbury are not municipalities but rather are neighborhoods within the City of Boston. People 
also may report that they live in East, West or North Falmouth, or even Falmouth Heights or Woods Hole but these are all part of the Town of Falmouth. The use of dropdown menus in the survey was considered but with 351 municipalities in Massachusetts this would have been impractical; and

- Using a pre-defined distance would frequently cross municipal (or county) boundaries and it would be difficult to determine if the boater was reporting "within 20 miles" by road or "as the crow flies."

Boaters who reported that they had engaged in an on-water trip were asked similar spending questions regarding their last on-water trip of the month. In addition to the spending questions, boaters were asked to report:

- The number of people who accompanied them on the trip;

- Whether or not they trailered their boat; and if so where from what type of location (e.g. residence, marina or dry stack facility, commercial storage facility) and what fees were associated with trailering;

- What activities they engaged in during their on-water trip. These included:

- Cruising

- Entertaining family / friends

- Fishing or shellfishing

- Hunting

- Whale watching

- Bird watching

- Racing

- Sailing

- Scuba diving / snorkeling

- Sightseeing

- Swimming

- Waterskiing / wakeboarding

- Whether the trip occurred on a public holiday (Memorial Day, $4^{\text {th }}$ of July or Labor Day); and

- Whether the trip was taken for something other than purely recreational purposes.

\section{Mapping Component}

Boaters who had undertaken an on-water trip were then automatically linked to the online mapping application. This application allowed them to plot the approximate route of the trip that they had just reported on and the reason that they had chosen the route. They were then asked to identify areas 
where they had engaged in specific activities and to provide information as to what they might have done if they had not been able to engage in that activity at that specific location. The routes were captured as lines (polylines) and activity area information was captured as polygons. These, and the attributes associated with them, could be directly imported into a geographic information system (GIS) to create aggregate maps.

The online mapping application started by providing some instructional material (with the ability to open instructions at any time). An online tutorial video was also created to provide additional guidance. The boaters were asked to plot the routes they had taken during their reported on-water trips. Once they were satisfied with the routes, they were saved and the boaters were asked which factors were important when they selected these routes. Options included:

- Quickest route to my destination;

- I am very familiar with this route;

- Safest route to my destination;

- Challenging navigation;

- Calm waters;

- Scenic beauty;

- Tranquility;

- Absence of other boaters;

- Presence of other boaters;

- Avoid speed zones;

- Access to shoreside facilities/entertainment;

- Access to fuel, marina, mooring, etc.;

- None of the above. I was just cruising; and

- Other.

The boaters were then given the option to map areas where they engaged in specific activities. They were directed to draw a series of areas (polygons) on the map and for each they could identify the activity that they engaged in. The options were the same as those offered for the on-water trip activities but also included "land-based activities" and "other."

For each activity area, they were asked to report how long they engaged in the activity at that location and how they ranked the activity compared to other areas in Massachusetts where they had also engaged in this activity. For each activity, they were asked why they chose the specific location. Reasons included: 
- Area reached quickly and/or easily;

- I am very familiar with the area;

- Calm waters;

- Protected waters;

- Clean and/or clear waters;

- Wildlife viewing opportunities;

- Scenic beauty;

- Tranquility;

- Absence of other boaters;

- Presence of other boaters;

- Fishing opportunities;

- Swimming opportunities;

- Natural or undeveloped shoreline;

- Access to shoreside facilities/entertainment;

- Access fuel, marina, mooring, etc.;

- No specific reason; and

- Other.

After defining an activity area, the boaters were asked what they might have done if they had not been able to engage in their activity at their selected location. Options included:

- Engaged in another activity at the same location. They were then asked to select from the same list of activities offered when they first defined their activity areas.

- Engaged in another boating activity at another location. They were then asked to select from the same list of activities offered when they first defined their activity areas and then to draw the "alternate" activity area.

- Engaged in an activity not associated with recreational boating.

- Stayed at home.

- Other.

This completed the monthly boating activity information gathering.

\section{End-of-season Survey}

At the end of the season, the participating boaters were asked to report on additional, non-trip-related expenditures. This final survey also asked them to estimate their level of boating activity in relation to other years. 
The end-of-season survey was developed largely to capture other expenditure associated with boat ownership but not specifically related to boating visits or trips that boaters had incurred in the last 12 months. Such expenditures might include:

- General maintenance;

- Repairs (including parts and labor);

- Purchase and installation of new products;

- Purchase of boating equipment;

- Loan payments;

- Taxes;

- Insurance;

- Registration fees;

- Mooring, berthing or marina fees; or

- Winter storage costs.

Boaters were also asked to estimate what percentage of their overall, non-trip-related expenditure had occurred within Massachusetts.

Finally the boaters were asked to estimate the amount of time they spent under power or under sail during the 2010 boating season and to rate their level of boating activity compared to other years (much less active than other years; slightly less active; similar to other years etc.).

\section{Feedback Survey}

Once boaters had completed the end-of-season survey, they were presented a feedback survey. This provided an opportunity to comment on the overall survey process and in particular, on their experience with the mapping application. Boaters were asked to provide thoughts and comments and were asked if, in theory, they would be willing to participate in similar type surveys in the future.

\subsubsection{Web-mapping Application}

The web-mapping application was designed to provide the user with the ability to report the trip route and trip-specific activities during the monthly study period (as defined by the survey component described above). These spatial data were then indexed to allow cross-referencing to the Snap part of the survey. For each trip, the boater was asked to map their entire trip by drawing a sequence of points (polylines). Next, the boater was asked to demarcate areas of activity (e.g. fishing, swimming, waterskiing) along the route by drawing one or more polygons (closed sequence of lines) bordering the area of activity. Finally, the boater was asked several questions specific to the route and associated activity areas.

Other design criteria for the web-mapping application were secure, confidential user access; and the ability to capture and merge user identification information from the separate Snap survey component. 


\section{Development \& Design of the Web-mapping Tool}

The web-mapping tool was based on Open OceanMap, open-source software developed by Ecotrust for the collection of marine spatial planning data on the US West Coast. Open OceanMap was originally built as a desktop application, and recently evolved into a web-based GIS application. Initial discussions with Ecotrust confirmed that the web-based Open OceanMap framework could be adapted to meet the needs of the recreational boater survey, and Ecotrust was invited to be a part of the collaborative development team.

Development of the boater survey application included the web-based graphical user interface client, a spatial database, and the underlying physical infrastructure required to host these components and provide web access to the user.

The user interface was designed to provide the user with a mapping tool and associated instructions that would allow the user to draw routes and activity areas, and answer questions related to these features. To meet these requirements, the flow diagram (Figure 4) provided below was created to capture the logic required to provide the following mapping tools to the user:

- Welcome and introduction;

- Explanation of the mapping components including base layers, navigation and drawing tools;

- Route drawing tools, including the ability to continue an unfinished route, edit the route, or discard the route and redraw a new route;

- Answer questions related to the route drawn (not shown below);

- Activity area drawing tools, including the ability to continue an unfinished area, edit the area, discard the area and redraw a new area, draw an alternate activity area, and to draw multiple areas if desired; and

- Answer questions related to the areas drawn.

During development of this flow diagram, wire-frame mockups of the user interface were also developed to demonstrate visual layouts of the graphical user interface that would match the logic in the flow diagram, and provide a functional and aesthetically pleasing interface for the user. After these paper-based products were completed, application development began and evolved based on feedback from both the technical team as well as the advisory group. Snapshots are provided below showing samples of the final user interface (Figure 5).

An additional component of the user interface was the reference mapping required for the user to have a familiar spatial context when plotting their route and activity areas. Primary reference maps included NOAA charts, and two standard layers provided by Google: satellite imagery and terrain. Point locations of boat ramps and marinas were also provided as relevant points of reference. 


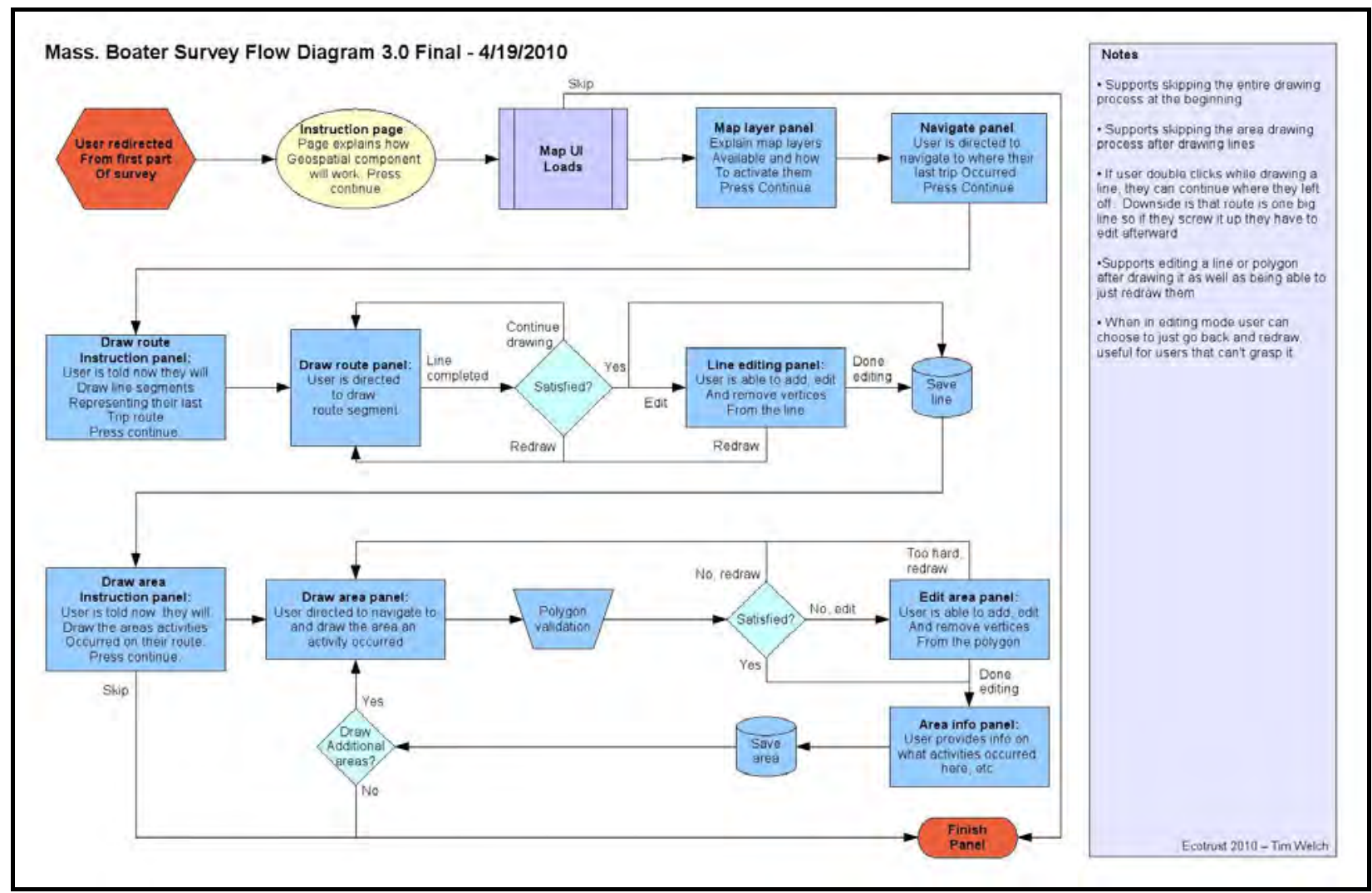

Figure 4: $\quad$ The flow diagram captures the logic required to provide the mapping tools to the user.

One significant advantage to selecting Open OceanMap as the starting point for the boater survey webbased application was the existing successful development and implementation by Ecotrust of the webbased Open OceanMap technology stack. As the Open OceanMap stack could be adapted to meet the needs of the Massachusetts survey, it was possible to focus more intently on the development of the graphic user interface. One of the many components that was not re-engineered for the boater survey application was the spatial database: PostGreSQL/PostGIS. The selection of this database also allowed for the web-based recreational boater survey application to be developed as an open-source tool as requested by the Massachusetts Ocean Partnership.

Primary design considerations for the physical infrastructure to support the boater survey web-mapping application included reliability and scalability. To meet these needs, cloud-based servers were specified and Rackspace (www.rackspacecloud.com) was selected as the vendor. Details related to the technology stack implemented for the boater application are discussed below. 

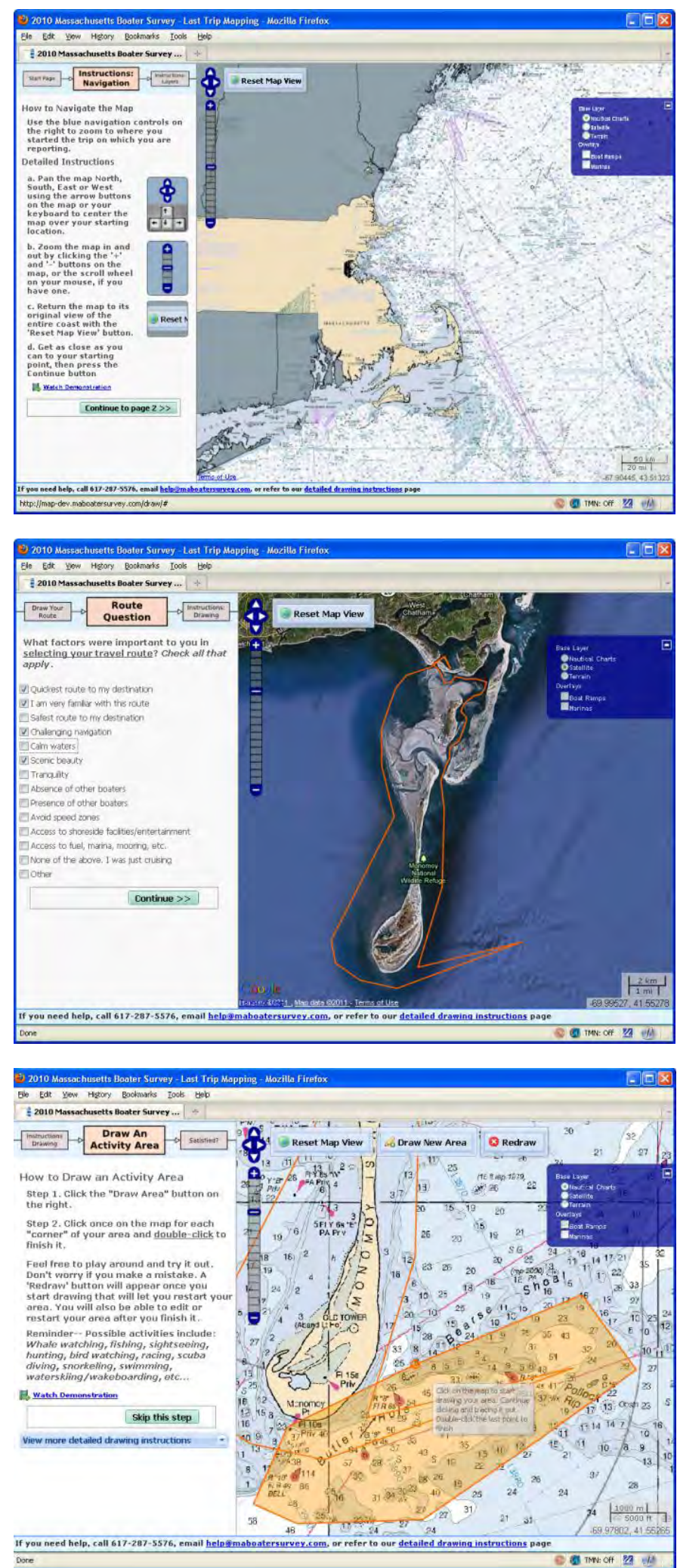

Figure 5: $\quad$ Snapshots of the final recreational boater survey web-mapping application user interface: initial instruction screen (top), route questions (middle) and activity area mapping (bottom). 


\section{Technical Specifications}

The technology stack for the boater survey mapping tool included hardware and software infrastructure, web-service scripting, and spatial database implementation.

Initial development activities occurred on a single, cloud-based server provided by Rackspace. Ubuntu 9.10 (Karmic Koala) Linux was selected as the operating system. Server specifications were initially set to the minimum available; $256 \mathrm{MB}$ memory and $10 \mathrm{~GB}$ storage. As development activities proceeded, the server was scaled up on an as-needed basis. To meet the processing and content-delivery requirements of the final application, server specifications were scaled to 4GB memory and 160GB storage. Upon completion of development activities, the development server was cloned to create an additional 4GB production server. During the survey period, both the development and production server instances were active. After the survey was complete, the development server was scaled back to $256 \mathrm{MB}$, and the production server to $512 \mathrm{MB}$. Both servers remain active for demonstration and testing purposes only.

\section{Technology Stack}

The web-mapping application consisted of a browser client, a server-side survey manager and a mapserver (Figure 6). Each of these integrated one or more free and open-source software components to perform its functions, which will be described in more detail.

- Browser Client

The browser client included the interactive user interface. OpenLayers provides the interactive map capable of displaying custom data layers from the mapserver as well as supporting the drawing and editing of vector features. The larger user interface including the question panels and other interactive elements were developed using the ExtJS and GeoExt software products.

- Survey Manager

The survey manager was developed using the GeoDjango web framework. It managed the state of each ongoing survey, processed and validated all of the input and finally stored the survey information in a geo-database. The PostGIS database management system was used for its close integration with GeoDjango and its robust features for storing and processing spatial data as well as tabular data collected during the survey.

- Mapserver

Custom map tiles including nautical charts and boat ramps were styled and published using the GeoServer software product and then cached using GeoWebCache. These tiles were then transferred to CloudFiles to support efficient content delivery that scales to support a large number of users accessing the tiles at the same time. OpenLayers then is capable of accessing these map tiles and overlaying them on top of the Google and nautical chart base maps. 


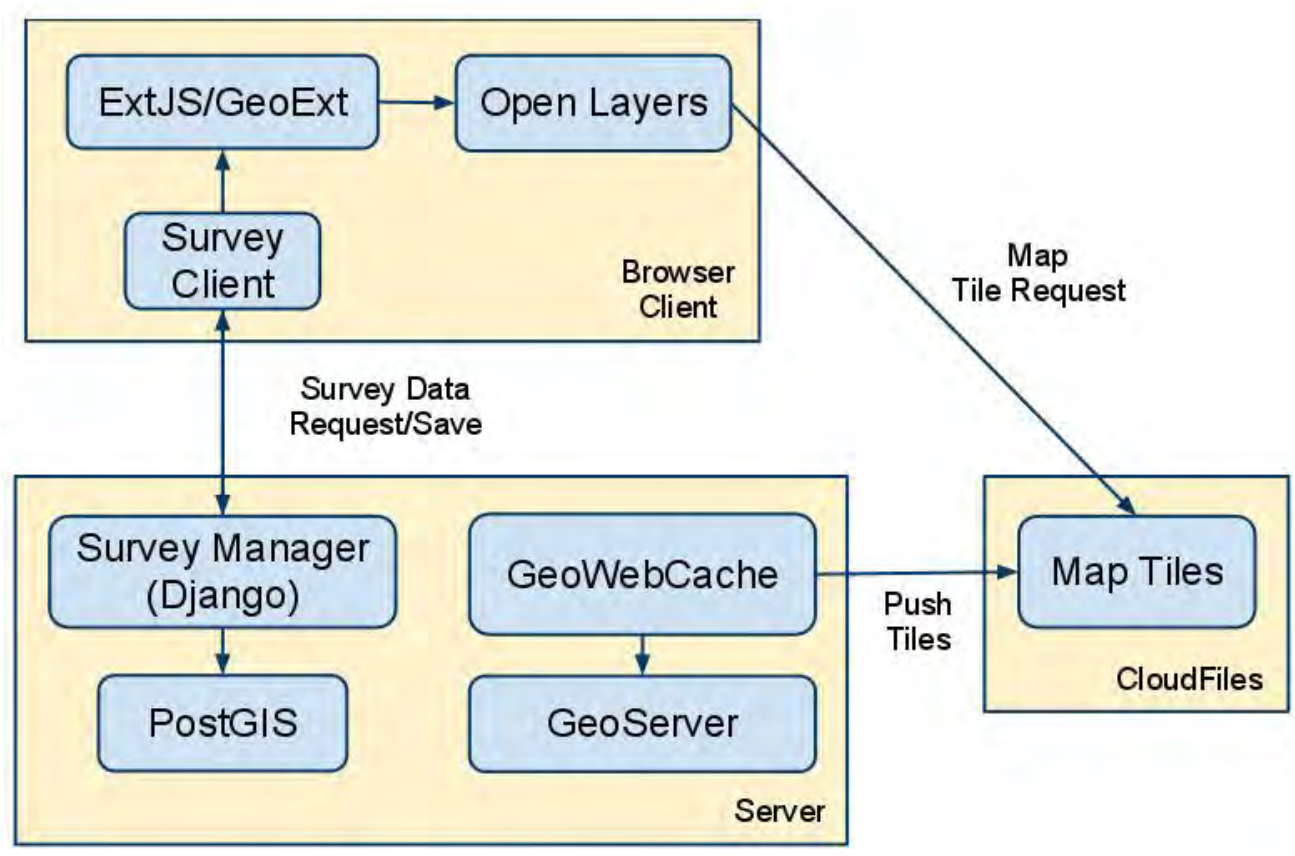

Figure 6: Illustration of the technology stack for the boater survey mapping tool.

$\underline{\text { Issues }}$

Technical assistance was available through a dedicated telephone line and via e-mail. Based on response to the boater survey helpdesk, most user issues were resolved by additional instructions related to using the tools provided. Only one participant had difficulty accessing the mapping application. However, that user did not respond to offers of assistance, which suggests that either the user stopped responding to the survey, or that the problems were solved by the user.

The handoff from the Snap survey component was not entirely seamless. More rigorous interoperability standards would likely have resolved this issue, but the rapid development timeframe did not allow development of these protocols. These issues were resolved during post-processing of the spatial datasets.

During the initial two months of survey, cursory data review suggested that users were "getting lost" during the transfer between the two components. The boater survey mapping application was initially designed to initiate a database record for the user only after the user progressed beyond the "welcome" page. To resolve this issue, the application was re-programmed to initiate the database record upon the user accessing the welcome page. Based on these new data, it was discovered that only a small percentage of users were "getting lost," and that the other portion of these "lost" users was instead users who were accessing the welcome page and then (apparently) choosing not to proceed to the mapping application.

Future activities related to development of boater survey application will be needed to package the application as a deployable, open-source application. However, to the extent practicable, the 
application development was performed such that the application is readily portable as a publicallyavailable toolkit when appropriate.

\subsubsection{Testing}

Due to the technology challenges of the study design, and in spite of the compressed timeline, the complete survey was tested as rigorously as possible by team personnel. All test records were prefixed with a " $T$ " to ensure that test data could easily be purged from the database. A number of errors were identified and corrected.

Once these issues had been addressed, further testing was undertaken by members of the advisory group and by a panel of boaters. Team personnel participated in the boater tests but assumed an observational role, as it was felt that it was important to see if boaters were able to understand what was required and to navigate the mapping application based on the guidance provided. Testers were encouraged to offer as many comments as possible. The online Snap survey was generally found to be clear and easy to complete although a few wording changes were suggested to clarify some sections. In general, the mapping application was also found to work correctly and its purpose was understandable. However, some testers did find that it took a while to become familiar with the tools needed to map routes and areas and that some aspects of navigating the maps could be improved.

A number of improvements were made to the mapping application based on feedback from the testers. Additional improvements were identified but these were deemed less of a priority and were therefore not implemented before the initial monthly surveys were sent. Some features, such as a demonstration video, were added as an instructional aid in August, 2010.

Immediately prior to the first batch of monthly survey e-mails being sent, the full system was tested live by team members including the handoff between the online Snap survey and the web-mapping application during which key information needed to be passed from one to the other. This testing was set up so that multiple team members were completing the survey and mapping at the same time in an effort to test the server capabilities. Some problems were encountered and resolved. A final round of testing revealed that the issues had been addressed and the first round of e-mails asking boaters to report on their May boating activity were sent on June 9.

It should be noted that a conscious decision was made to try not to send out notices of monthly surveys immediately prior to weekends so that personnel were available if technical issues arose.

\subsection{Sample Design}

The sample for this study came from two separate databases. The first was a state database of registered boaters and the second was a US Coast Guard database of documented vessels. The statewide registered boat database had 145,105 boats listed. The database included a field for "use type" that allowed for those vessels that were unlikely to be used for recreational purposes to be removed. These consisted of:144 "Commercial Passenger (C/P)" vessels that included Duck Tour boats, water taxis etc.; 378 "Livery (LIV)" vessels, which were predominantly rental boats; and 1,076 "Other 
(OTH)" boats which were a mix of things including sailing and boat club boats, marina operations boats, school boats, research vessels etc. What remained were the "Pleasure (PLS)" boats and those with a "Commercial Fishing (C/F)" use type. The reasoning for not removing the commercial fishing boats was that this use type does not necessarily mean that there is a fishing license or endorsement associated with the vessel. Based on advice from the advisory group and by analyzing the vessel types and sizes, it was concluded that this class of vessel would likely include those boats that may have been used for a combination of tuna fishing, commercial charter fishing and recreation. There were 2,046 vessels classified as being used for commercial fishing in the database. After eliminating the "passenger," "livery" and "other" boats, the database contained 143,507 vessels.

Based on advice from the advisory group and members of the Massachusetts Marine Trades Association, a search was conducted on the US Coast Guard database of documented vessels to identify all vessels with an owner's address or vessel hailing port in Massachusetts and with "Recreational" listed as the Vessel Service Type (i.e. primary use type). The result was a table containing all boats used primarily for recreation, even if they were endorsed (licensed) to engage in other activities. Finally, all vessels with an expired or pending status were removed from the search results, leaving a total of 11,824 documented boats.

Combining the registered boats and documented vessels produced a list of 155,331 recreational boats in Massachusetts. This defined the "population" or universe of all boats under consideration for the study. An examination of the data made it quickly apparent that sampling boats from these combined databases required something more than just a simple random sample of boats. The two primary factors that needed special consideration were the size of the boat and the storage location of the boat. From this preliminary analysis, it was determined that there were many small boats, especially boats less than 10 feet in length. It also was determined that many boats were stored in areas of Massachusetts that were not near any coastal waters and some even kept out of state. A true simple random sample of boats would lead to a sample that was tilted too much toward boats that may be of little interest to the goals of the study (i.e. small boats used as tenders or those used only on freshwater).

Due to this, a stratified sample design was implemented that took account of both size of boat and boat storage location by region (Figure 7). This is summarized in Table 9. No storage location data existed for documented boats so these were kept as a separate "class".

As can be seen, a sample of 10,000 boats was selected for inclusion in this study. This represented approximately $6.4 \%$ of all recreational boats in Massachusetts. The selection of these boats favored larger boats and boats stored nearer to coastal waters. This was due to the specific goal of the study to investigate coastal and ocean water use by recreational boaters. The sampling fractions varied from a low of about $3 \%$ of boats from Western Massachusetts, which is far from any coastal water, to a high of about $38.1 \%$ for US Coast Guard documented boats 40 feet long or longer which were considered highly likely to be used exclusively in coastal waters. The sample was designed to attempt to target the boats 
most likely to be of interest to the goals of the study. However, all recreational boats in Massachusetts had a chance of selection into the study. This design was considered both inclusive and efficient.

Table 9: $\quad$ The population of recreational boats in Massachusetts and the sample drawn.

\begin{tabular}{|c|c|c|c|c|}
\hline Region $^{1}$ & Boat Size & All Boats in MA & Sample Drawn & Sampling Fraction \\
\hline \multirow[t]{3}{*}{ Southeastern } & Less than 10 feet & 4,323 & 223 & 0.05158 \\
\hline & 10 feet -39 feet & 37,595 & 2,749 & 0.07312 \\
\hline & 40 or more feet & 115 & 23 & 0.20000 \\
\hline \multirow[t]{3}{*}{ East Central } & Less than 10 feet & 3,947 & 235 & 0.05954 \\
\hline & 10 feet -39 feet & 27,972 & 2,028 & 0.07250 \\
\hline & 40 or more feet & 99 & 20 & 0.20202 \\
\hline \multirow[t]{3}{*}{ Northeastern } & Less than 10 feet & 3,619 & 206 & 0.05692 \\
\hline & 10 feet -39 feet & 27,480 & 2,000 & 0.07278 \\
\hline & 40 or more feet & 78 & 16 & 0.20513 \\
\hline Central \& Out of State & All boat sizes & 18,648 & 700 & 0.03754 \\
\hline Western & All Boat sizes & 19,631 & 600 & 0.03056 \\
\hline \multirow[t]{2}{*}{ Documented Boats } & 10 feet -39 feet & 9,596 & 350 & 0.03647 \\
\hline & 40 or more feet & 2,228 & 850 & 0.38151 \\
\hline TOTAL & & 155,331 & 10,000 & 0.06438 \\
\hline
\end{tabular}

1 Southeastern MA included Barnstable, Bristol, Dukes and Nantucket counties.

East Central MA included Norfolk, Suffolk and Plymouth counties.

Northeastern MA included Essex and Middlesex counties.

Central MA and Out of State included Worcester County and all out of state addresses.

Western MA included Berkshire, Hampshire, Hampstead and Franklin counties.

Documented Boats included the entire Coast Guard database for which location was not known.

\subsection{Sample Recruitment}

From the databases, only the name and address of the boat owner was available. These databases did not contain information on telephone numbers or e-mail addresses. Therefore, the only viable way to contact the 10,000 sample boat owners was through the mail. One issue that was critical to address was that the surveys needed to be completed on the web, so getting boat owner's e-mail addresses was necessary. Without these e-mail addresses, the survey could not realistically be done. With the number of surveys being asked of each boat owner, the only effective way to conduct the series of surveys was to e-mail each boat owner and include a link to the survey as it became available. Participants simply clicked on the link to go directly to the newest survey. Once they completed it, they were passed to the mapping application where they could draw their route. This could all happen seamlessly with simply a few clicks of a mouse. 


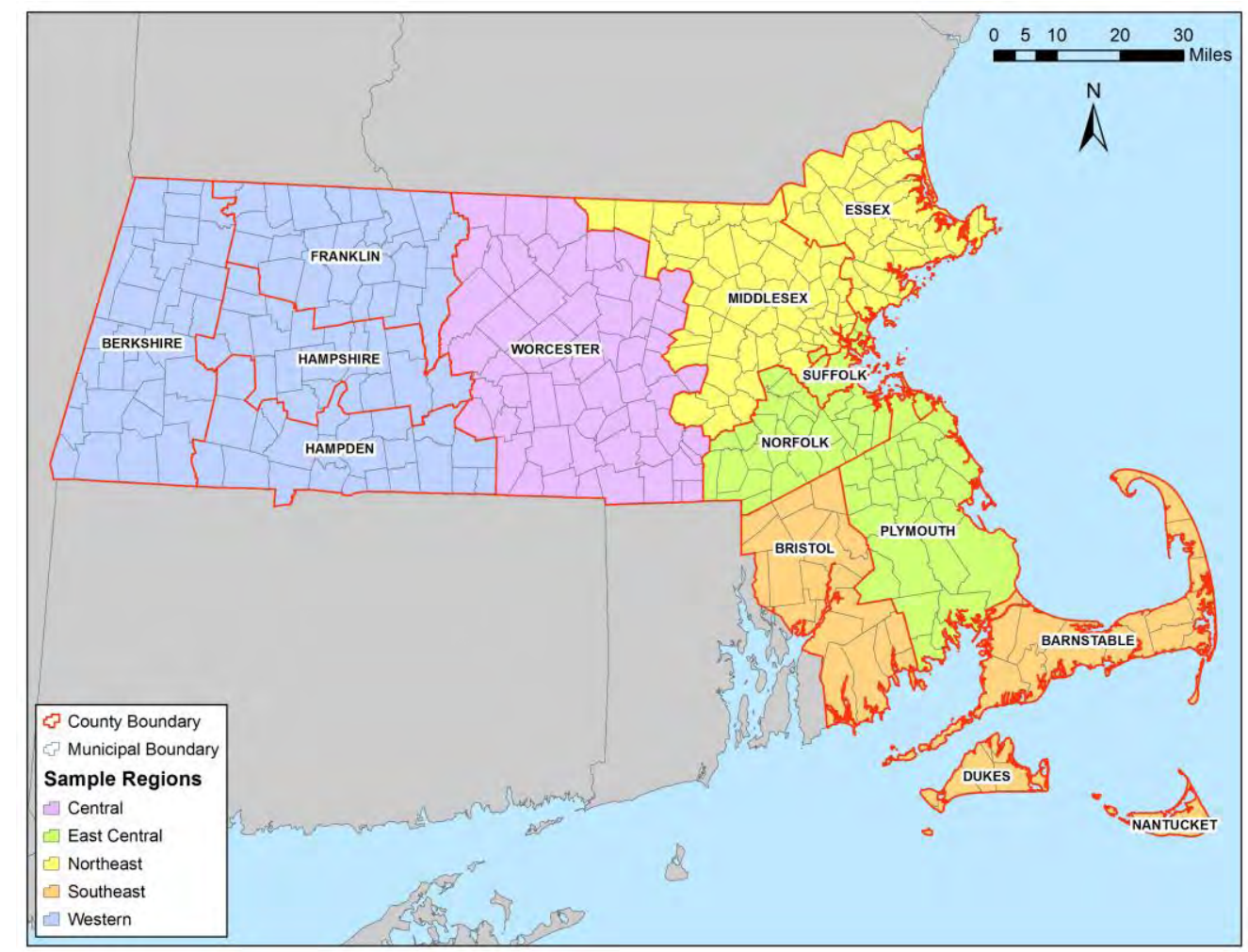

Figure 7: $\quad$ The sample regions were based on county boundaries. Counties are labeled in the figure.

Therefore, in May of 2010, all 10,000 sampled boat owners were mailed a very short recruitment survey and information about the survey. Approximately two weeks later, a postcard reminder was sent to sampled boat owners asking them to respond to the survey. A telephone number and e-mail address was included for anyone who wanted to contact the Urban Harbors Institute about the survey.

The purpose of the recruitment survey was twofold. First, it was to determine survey eligibility by asking three questions. The first question determined that they still owned the boat selected from the recreational boat databases. Clearly, if they no longer owned the boat they were ineligible to participate. The second question determined that they used the boat, at least partially, on coastal or ocean waters. The third question determined if the boat was used exclusively for non-recreational purposes. If the boat was used exclusively on freshwater and/or for non-recreational purposes, the boat owner was not eligible to take part in the survey. The recruitment survey also explained the need for a survey such as this one, why boater participation was so important, and, due to the way in which the survey was to be administered, why a valid e-mail address was essential. Sample boat owners were given a choice of a postage-paid mail-back survey to complete and return, or they could access a webbased version of the survey that they could complete and submit online. After confirming eligibility, boaters were each assigned a unique six-digit identification code, which would be used to track their participation in the surveys and ensure mapped data could be attributed to the use of a specific vessel. 
The assignment of unique identifiers also meant that it was possible to make the boaters' responses to the surveys anonymous. This was achieved simply by not releasing the table that contained both the unique identifiers and information on the vessels and their owners. This information was only available to a small number of key team personnel. Without this table, it is nearly impossible to determine the owner or vessel associated with any one unique identifier.

The unique identifiers also coded the region where each boat was located (apart from documented vessels, where this information was not available) and the size class of their vessel (apart from boaters from the Central and Western regions of Massachusetts). See Table 10. Unique identifiers were also prefixed with a letter to allow for different types of participants to be readily identified. All sampled boaters who agreed to participate were given an " $R$ " prefix. A number of non-existent boater records were created to allow team members to monitor the operations of the online survey and mapping application. These too were given an " $R$ " prefix but the numeric part of their unique identifier started with a " 9 ", which allowed for this information to be readily purged from the database. Initial test records were identified with a " $\mathrm{T}$ " and volunteer boaters were identified with a "V".

\subsection{Outreach and Recruitment Efforts}

While the value of developing a comprehensive outreach plan to encourage boaters to participate in the study was recognized, the tight timeframe limited the amount of effort that could be expended on outreach activities. However, while an extended timeline may have allowed for more comprehensive outreach to have been undertaken, significant efforts were made both prior to the study and while it was underway to encourage both initial and on-going participation.

Table 10: $\quad$ The relationship between the unique identifiers and the sampling strata.

\begin{tabular}{|c|l|c|c|c|c|}
\hline \multicolumn{2}{|c|}{ First Digit } & \multicolumn{2}{c|}{ Second Digit } & \multicolumn{2}{c|}{ Digits 3-6 } \\
\hline \multirow{2}{*}{ Number } & \multicolumn{1}{|c|}{ Region } & Number & Boat Size & Number & Digits3-6 \\
\hline \multirow{2}{*}{1} & \multirow{2}{*}{ Southeast } & 1 & $<10$ & $1-9$ & Random \\
\cline { 3 - 6 } & & 2 & 10 to $<40$ & $1-9$ & Random \\
\cline { 3 - 6 } & & 3 & $40+$ & $1-9$ & Random \\
\hline \multirow{2}{*}{2} & \multirow{2}{*}{ East Central } & 1 & $<10$ & $1-9$ & Random \\
\cline { 3 - 6 } & & 2 & 10 to $<40$ & $1-9$ & Random \\
\cline { 3 - 6 } & & 3 & $40+$ & $1-9$ & Random \\
\hline \multirow{2}{*}{3} & \multirow{2}{*}{ Northeast } & 1 & $<10$ & $1-9$ & Random \\
\cline { 3 - 6 } & & 2 & 10 to $<40$ & $1-9$ & Random \\
\cline { 3 - 6 } & & 3 & $40+$ & $1-9$ & Random \\
\hline \multirow{2}{*}{4} & Central & $1-9$ & Random & $1-9$ & Random \\
\hline \multirow{2}{*}{5} & Western & $1-9$ & Random & $1-9$ & Random \\
\hline 6 & Documented vessel & 2 & $<40$ & $1-9$ & Random \\
\cline { 3 - 6 } & & 3 & $40+$ & $1-9$ & Random \\
\hline
\end{tabular}


The advisory group in particular was extremely helpful in determining the different ways to access boaters and encourage participation. Attempts to contact boaters and encourage participation occurred through a variety of means, including:

- Flyers: Flyers explaining the study and encouraging participation were e-mailed to members of the advisory group as attachments. These flyers could be posted on bulletin boards, displayed on counter tops, etc. Advisory group members were asked to distribute the electronic flyers to any boating-related mailing lists, or other means of contacting marinas, boating goods stores, etc. The flyer can be found in Appendix C.

- Press releases: At the beginning and in the middle of the boating season, press releases were sent to a variety of both local and state newspapers, including the Cape Cod Times, Gloucester Times, the Boston Globe, Patch, the Nantucket Independent. Local newspapers that covered coastal towns and counties were specifically targeted. These press releases described the purpose of the study and encouraged boater participation (see Appendix D).

A number of Massachusetts newspapers ran stories including the Gloucester Times, the Newburyport Daily News, the Lexington Patch, the Swampscott Reporter and the Marblehead Patch. Various online news sites also picked up the story.

- Presentations: Presentations were made at relevant meetings to help spread the word about the survey. These included the Massachusetts Marine Trades Association's Board of Directors Meeting (April 5, 2010) and Annual Meeting (September 9, 2010), the Massachusetts Harbormasters Association Annual Meeting (April 30, 2010), and the Massachusetts Boating and Yacht Clubs Association's Board of Directors Meeting (April 11, 2010) and Membership Meeting (April 23, 2010).

- Website: A dedicated website was created for the survey (www.maboatersurvey.com), which contained information on the study; copies of outreach materials; information on how to participate; and listed the prizes that could be won and the organizations that had provided prizes.

- Monthly electronic mailing lists: A paragraph describing the study and encouraging participation was included in various monthly electronic mailing lists hosted by members of the advisory group (including Massachusetts Coastal Zone Management's CZ-mail, Sailors for the Sea, and the Massachusetts Marine Trades Association). E-mails were distributed to all members of the mailing list, which likely included those interested in coastal and marine-related subjects such as boating.

- Online discussion board: The press releases described above were also added as conversation "threads" to a variety of boating and/or coastal-related online discussion boards, such as "Striper Talk (Striped Bass Fishing, Surfcasting, Boating)", and "Yack on - the Nantucket Online Community". 


\subsection{Recruitment Responses}

Recruitment packages were mailed to 10,000 boat owners on May 6, 2010. Boaters were given the option of completing the recruitment survey online, or completing the paper version and returning it using a pre-paid business reply envelope. Those who wished to access the online form were asked to visit the dedicated Massachusetts Recreational Boater Survey website (www.maboatersurvey.com) and access their customized survey using the unique identifier that was contained in the mailing.

Throughout the whole recruitment process, only 14.8\% (315 boaters) of those who completed the recruitment survey elected to use the online option. However, the online system had a dual purpose in that it provided a simple and accessible way for data entry personnel to enter the data contained in the hard copy survey returns.

Both completed surveys and undeliverable recruitment packages started to arrive within two working days of the mailing going out. One week after the initial mailing, 660 completed surveys had been received and 319 recruitment packages had been returned as undeliverable (Figure 8). A number of the undeliverable packages had been sent to boaters who were no longer at the address in the database but some were returned with a US Postal Service label containing a forwarding address. When this occurred, the recruitment package was relabeled and mailed to the new address. The second week after the initial mailing a further 498 completed surveys had been received, as had 71 more undeliverable packages. The third week saw 211 surveys and 60 undeliverable packages. In total, 533 recruitment packages were returned as undeliverable. Over $90 \%$ of these returns had been received within 4 weeks of the initial mailing. It took 5 weeks for $90 \%$ of the final tally of 1,816 completed recruitment surveys to be received.

Approximately 2 weeks after the initial mailing, a reminder postcard was sent to 8,281 boaters who appeared not to have responded.

As completed recruitment surveys were received, the information they contained was entered into the database being maintained by the Center for Survey Research (CSR). Data entry was done through the same online portal that had been offered to the sampled boaters when they received the recruitment packages. Great care was taken to ensure accurate data entry. After the data had been entered, the completed survey was crosschecked by a second person against a spreadsheet containing the summary information for each boat and boat owner. The spreadsheet was annotated to show which boaters had responded. When data entry errors were identified, the details were noted and passed along to CSR to be corrected. This data entry process required significant personnel time even though the recruitment survey was relatively short.

Probably the most time consuming process during data entry was deciphering sometimes almost ineligible handwriting and trying to ensure that e-mail addresses were entered correctly. If an e-mail address was considered suspect or unclear, the data entry personnel were asked to check the spreadsheet containing the boater and boat information. This was frequently helpful as it provided the boater's name and therefore helped decipher many e-mail addresses. If the e-mail address remained a 
mystery, data entry personnel were asked to use internet searches to try to uncover correct addresses. While this was a somewhat roundabout approach, it was sometimes successful and was deemed necessary as correct e-mail addresses were essential if boaters were to be able to participate in the study. This highly time-consuming detective work was not undertaken if a respondent had been found to be ineligible to participate in the study (i.e. if they no longer owned the specific vessel, if they boated only on freshwater or if their boat was never used for recreational purposes).

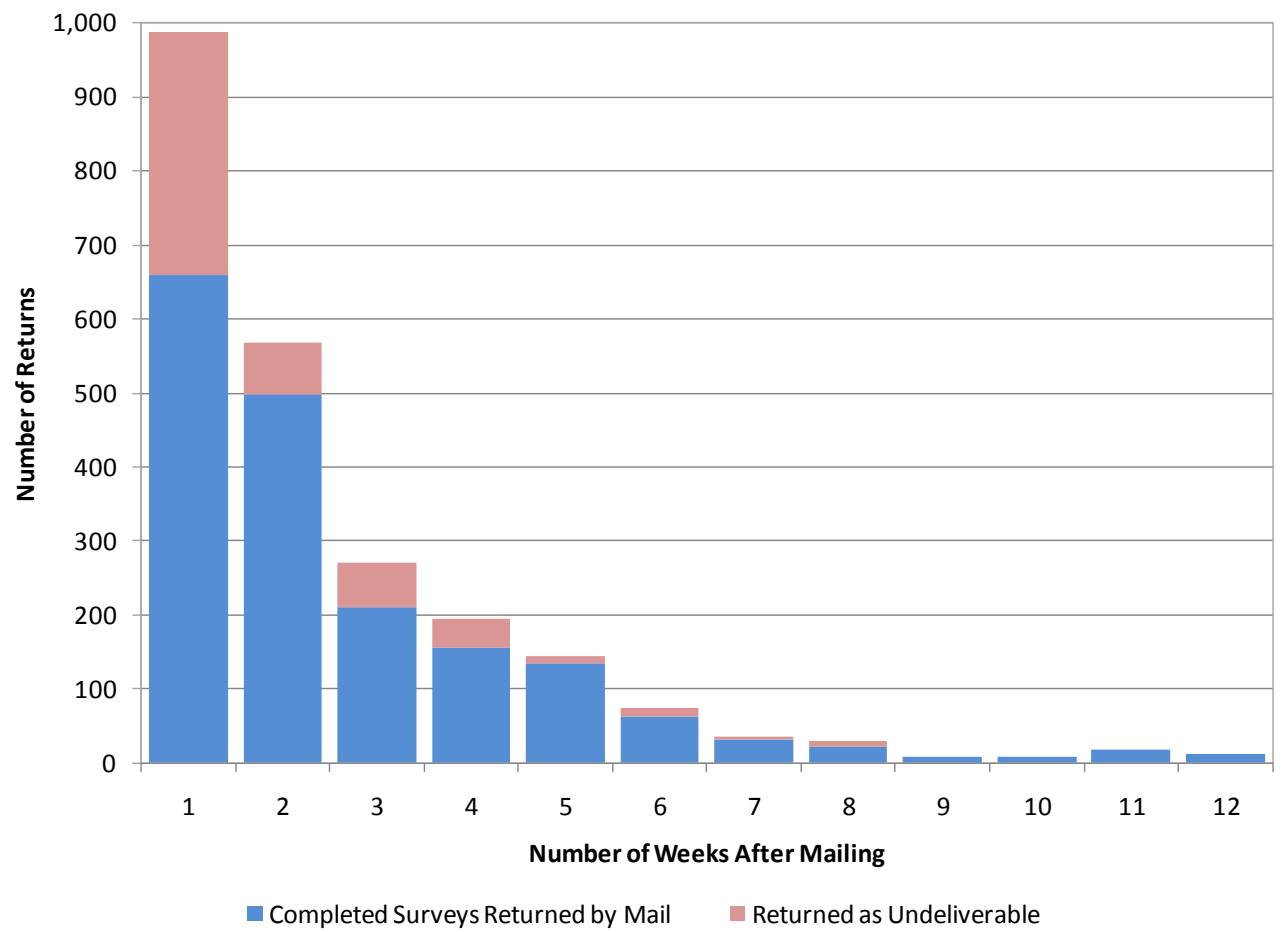

Figure 8: $\quad$ The number of completed recruitment surveys and undeliverable recruitment packages received during the four months following the May 6 mailing.

In future studies, to ensure that e-mail addresses are written in the clearest possible way, a series of boxes could be provided in which respondents could enter their e-mail address rather than simply a line:

\begin{tabular}{|l|l|l|l|l|l|l|l|l|l|l|l|l|l|l|l|l|l|l|l|l|l|}
\hline & $j$ & 0 & $h$ & $n$ & $\cdot$ & $d$ & 0 & $e$ & $@$ & $c$ & 0 & $m$ & $p$ & $a$ & $n$ & $y$ &. & $c$ & 0 & $m$ & \\
\hline
\end{tabular}

Entry of recruitment data ceased on July 26. This allowed for late responders to be included in the survey of July boating activity that was sent out to participants on August 2. While no more boaters were accepted into the study from late July, completed recruitment surveys continued to be received. In total 44 additional completed surveys were received after recruitment closed. Of these, 24 would have been eligible to participate. Interestingly, and somewhat surprisingly, a completed recruitment survey was received in late March, 2011 - almost ten months after the initial recruitment packages were mailed to boaters. 
Table 11 shows that of the 10,000 mailed recruitment surveys, 533 were returned with undeliverable addresses. Since this was the only contact information available for these boat owners, they were declared ineligible for the survey. Of the remaining 9,467 recruitment surveys that were assumed to be delivered to boat owners, a total of 2,131 were completed and returned either through the mail or via the web. This meant an effective return rate of $22.5 \%$ for the surveys. Although a higher rate would have been desirable, this was the approximate rate anticipated from such a mailing without more rigorous efforts to track and contact people that would have significantly increased the cost of this study. Return rates can be seen as being quite consistent across regions and boat sizes varying from about $18 \%$ to about $27 \%$.

A second important result of the recruitment displayed in Table 11 concerns the eligibility rates. These rates relate to the number of completed recruitment surveys that indicate the boat owner was eligible for the series of surveys (i.e. they still owned the boat, used the boat on saltwater and used the boat for recreational purposes). The overall eligibility rate for the returned surveys was $57.9 \%$. This was somewhat lower than what was anticipated. The reason becomes quickly apparent. The eligibility rates were quite diverse ranging from a low of $8.9 \%$ for boat owners in Western Massachusetts and a high of about $84 \%$ for large documented boats (Table 11; Figure 9). Indeed, these results confirmed the initial sample design for lower sample rates in Central and Western regions and higher sample rates for documented boats. In fact, it could be argued that for future surveys of this type, even lower sample rates for Central and Western regions should be used, as the eligibility rates for those regions were significantly lower than any other rates. Overall, the sample design could be made even more efficient by making use of this vital information.

\subsection{Implementation}

As previously discussed, due to the requirement for the online mapping part of this study, it was necessary that this study be conducted using e-mail and the internet. This was also helpful in reducing costs associated with contacting the participants. In total, 24 waves of communications were sent to boaters during the study, comprising of perhaps 25,000 individual messages or letters. As it happened, only three mailings occurred as part of this study:

1. A sample of 10,000 boat owners were initially mailed a recruitment package in May 2010.

2. A postcard reminder asking those who had not replied to fill in the recruitment survey.

3. A letter sent in August thanking boaters for their participation to date and encouraging them to continue to participate.

Details of the implementation timeline for this study are shown in Table 12.

A limitation of using e-mail and the internet to conduct such a study is that those without e-mail access become ineligible to participate. It is not possible to determine how many boaters simply decided not to fill in the recruitment survey as it stated that an e-mail address was necessary to participate. 
However, less than $6 \%$ of eligible returns had to be rejected as they stated that they did not have e-mail or they did not provide an e-mail address.

Table 11: $\quad$ Results of the recruitment survey.

\begin{tabular}{|c|c|c|c|c|c|c|c|}
\hline Region $^{1}$ & Boat Size & $\begin{array}{r}\text { Sample } \\
\text { Drawn }\end{array}$ & $\begin{array}{r}\text { Bad } \\
\text { Address }^{2}\end{array}$ & $\begin{array}{r}\text { Returned } \\
\text { Surveys }\end{array}$ & $\begin{array}{l}\text { Eligible } \\
\text { Sample }\end{array}$ & $\begin{array}{l}\text { Return } \\
\text { Rate }^{3} \%\end{array}$ & $\begin{array}{r}\text { Eligibility } \\
\text { Rate }^{4} \%\end{array}$ \\
\hline \multirow[t]{3}{*}{ Southeastern } & Less than 10 feet & 223 & 17 & 38 & 29 & 18.4 & 76.3 \\
\hline & 10 feet -39 feet & 2,749 & 272 & 640 & 424 & 25.8 & 66.3 \\
\hline & 40 or more feet & 23 & 5 & 4 & 2 & 22.2 & 50.0 \\
\hline \multirow[t]{3}{*}{ East Central } & Less than 10 feet & 235 & 2 & 41 & 30 & 17.6 & 73.2 \\
\hline & 10 feet -39 feet & 2,028 & 87 & 412 & 250 & 21.2 & 60.7 \\
\hline & 40 or more feet & 20 & 0 & 0 & 0 & 0.0 & 0.0 \\
\hline \multirow[t]{3}{*}{ Northeastern } & Less than 10 feet & 206 & 0 & 38 & 29 & 18.5 & 76.3 \\
\hline & 10 feet -39 feet & 2,000 & 65 & 414 & 236 & 21.4 & 57.0 \\
\hline & 40 or more feet & 16 & 0 & 3 & 3 & 18.8 & 100.0 \\
\hline Central \& Out of State & All boat sizes & 700 & 19 & 141 & 22 & 20.7 & 15.6 \\
\hline Western & All Boat sizes & 600 & 21 & 157 & 14 & 27.1 & 8.9 \\
\hline \multirow[t]{2}{*}{ Documented Boats } & 10 feet -39 feet & 350 & 15 & 78 & 56 & 23.3 & 71.8 \\
\hline & 40 or more feet & 850 & 30 & 165 & 139 & 20.1 & 84.2 \\
\hline TOTAL & & 10,000 & 533 & 2,131 & 1,234 & 22.5 & 57.9 \\
\hline
\end{tabular}

1 Southeastern MA included Barnstable, Bristol, Dukes and Nantucket counties.

East Central MA included Norfolk, Suffolk and Plymouth counties.

Northeastern MA included Essex and Middlesex counties.

Central MA and Out of State included Worcester County and all out of state addresses.

Western MA included Berkshire, Hampshire, Hampstead and Franklin counties.

Documented Boats included the entire Coast Guard database for which location was not known.

2 Sample addresses which were returned through the mail as not deliverable.

3 Rate at which mailed recruitment surveys were completed and returned.

4 Rate at which completed recruitment surveys were eligible to continue in the study. 


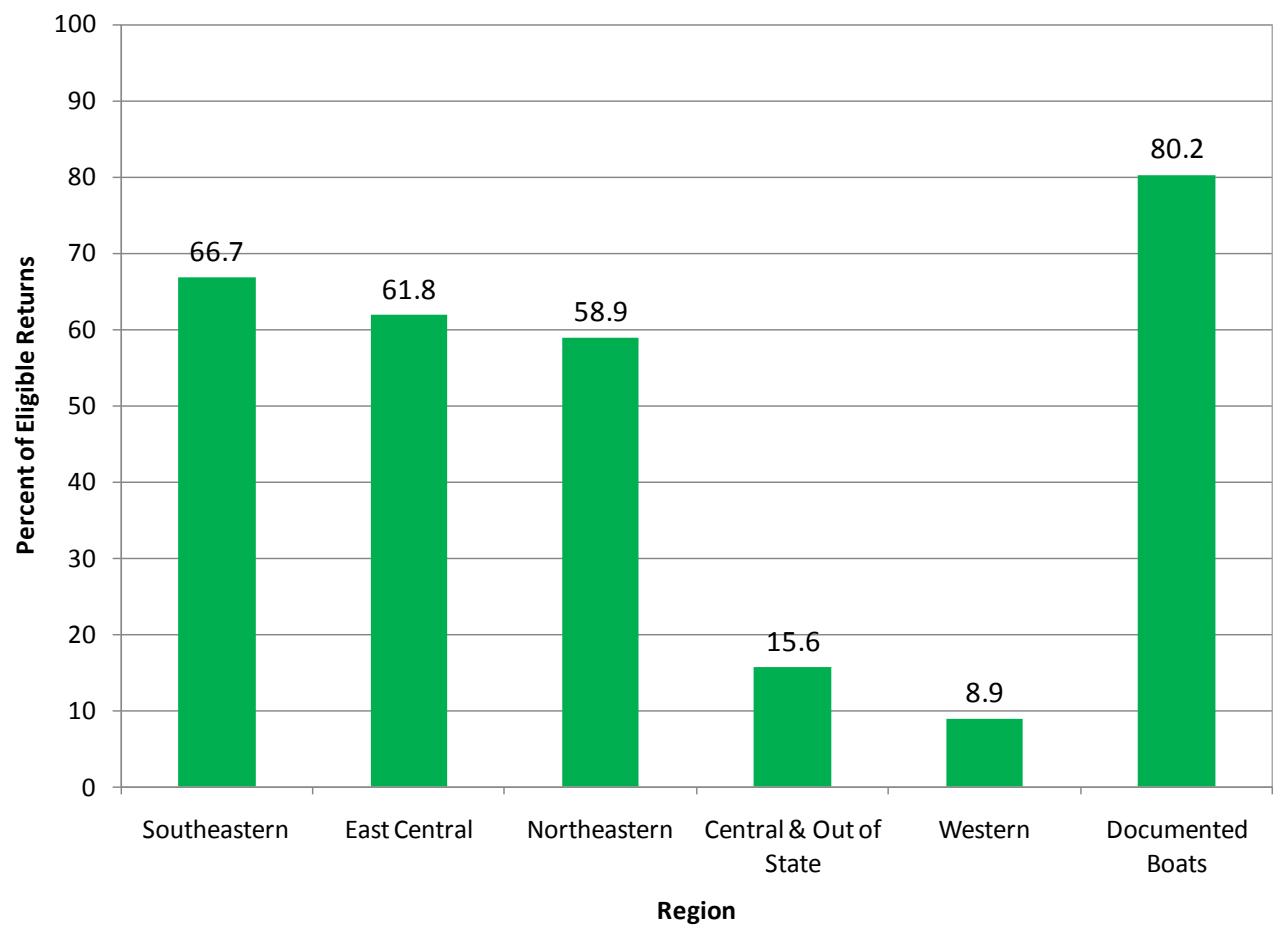

Figure 9: $\quad$ Percent of returns that were found to be eligible by region.

Even when seemingly valid e-mail addresses were provided, some bounced back when they were used. While efforts were made to verify these e-mail addresses through alternate sources (including internet searches using names, addresses etc.) between 5.6\% and $9 \%$ of e-mails sent each month were bounced back. It is possible that some of these returns were due to spam filters on the recipients' computers.

Despite some e-mails not being successfully received by participants, electronic communication appears to have been successful. As Table 12 shows, participants received a monthly e-mail informing them that a survey was available. An example of the generalized text for the monthly e-mails can be found in Appendix E.

When the participating boaters received such an e-mail, they need only click the link to start the survey. Their unique identifier was coded into the embedded link so that the survey was customized with the length and make of their specific boat and the reporting month (e.g. "During this survey you will be asked about your use of your \{VESSEL\} during \{MONTH\}, 2010"). In case the boater had any issues or needed more information, the e-mail also contained a "mailto" link to the study's dedicated e-mail address and a reminder of the study's website.

Approximately a week after the first monthly e-mail, those boaters who had not responded received a reminder e-mail. Those that still did not respond received a second reminder approximately a week after they would have received the first. The general text of the second reminder can be found in Appendix F. 
Table 12: $\quad$ Timeline of mailings and other communications with boaters during the 2010 boating season.

\begin{tabular}{|c|c|}
\hline $5 / 6 / 2010$ & 10,000 Recruitment Packages mailed to sample of boaters \\
\hline $5 / 21 / 2010$ & 8,281 Postcard Reminders sent to non-respondents \\
\hline $5 / 25 / 2010$ & 777 Boat Detail and Demographic Surveys sent \\
\hline $5 / 26 / 2010$ & 77 e-mails returned due to bad addresses \\
\hline $6 / 9 / 2010$ & 777 May Monthly Surveys sent \\
\hline $6 / 13 / 2010$ & May reminder \#1 \\
\hline $6 / 16 / 2010$ & 308 Boat Detail and Demographic Surveys successfully sent to new recruits \\
\hline $6 / 18 / 2010$ & 33 Boat Detail and Demographic Surveys successfully sent to corrected e-mail addresses \\
\hline $6 / 21 / 2010$ & Ineligble boaters e-mailed and thanked \\
\hline $6 / 22 / 2010$ & May reminder \#2 \\
\hline $6 / 29 / 2010$ & DAY-TO-DAY RECRUITMENT DATA ENTRY STOPPED \\
\hline $7 / 1 / 2010$ & 1,200 June Monthly Surveys sent \\
\hline $7 / 8 / 2010$ & June reminder \#1 \\
\hline $7 / 16 / 2010$ & June reminder \#2 \\
\hline $7 / 26 / 2010$ & RECRUITMENT CLOSED - Final late eligible participants entered $(n=46)$ \\
\hline $8 / 2 / 2010$ & 1,222 July Monthly Surveys sent \\
\hline $8 / 10 / 2010$ & July reminder \#1 \\
\hline $8 / 11 / 2010$ & 1,207 Encouragement Letters mailed \\
\hline $8 / 18 / 2010$ & July reminder \#2 \\
\hline $8 / 31 / 2010$ & 1,208 August Monthly Surveys sent \\
\hline $9 / 8 / 2010$ & August reminder \#1 \\
\hline $9 / 16 / 2010$ & August reminder \#2 \\
\hline $9 / 30 / 2010$ & 1,201 September Monthly Surveys sent \\
\hline $10 / 7 / 2010$ & September reminder \#1 \\
\hline $10 / 25 / 2010$ & 1,195 End-of-season, Feedback, and October Monthly Surveys sent \\
\hline $11 / 1 / 2010$ & End-of-season, Feedback, October reminder \#1 \\
\hline $11 / 12 / 2010$ & End-of-season, Feedback, October reminder \#2 \\
\hline $12 / 3 / 2010$ & SURVEYS CLOSED \\
\hline
\end{tabular}

During the study, activity on the boater survey website was monitored and is presented in Figure 10. The red line represents the number of "hits" on the website each day. The blue lines represent the dates that e-mails were sent notifying participating boaters that each monthly survey was available, with the initial survey on May 25, 2010. The green lines indicate the dates on which reminder e-mails were sent to those boaters who had not filled in the current survey. 


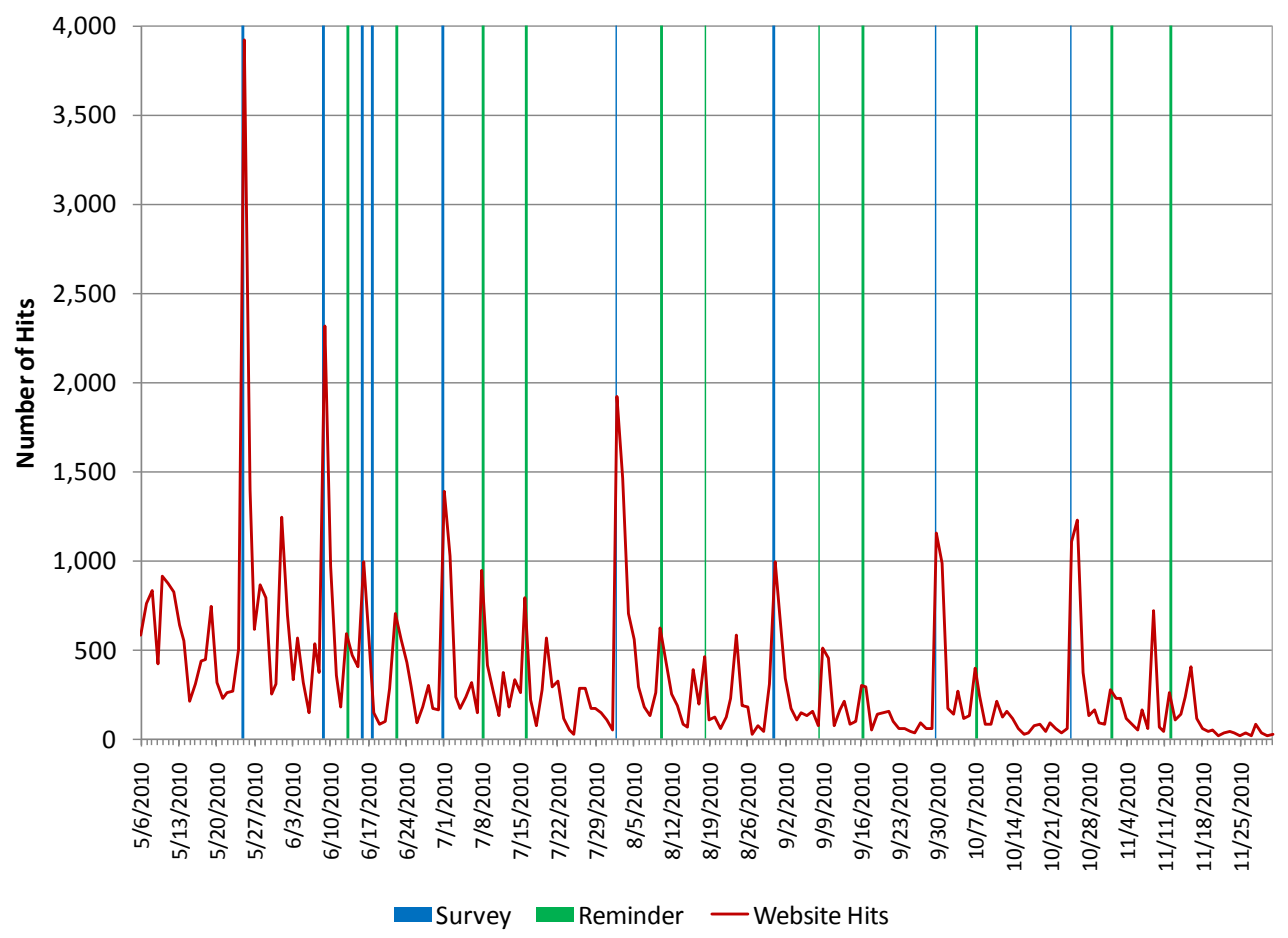

Figure 10: $\quad$ Daily website activity and dates of e-mailings.

Upon survey completion, boaters were automatically transferred to the "thank you" page of the website. This page provided them with a table showing when to expect future surveys, information about what prizes had been won and those yet to be given away, links to those companies that donated prizes and a draft map of boating activity around Boston Harbor based on the information gathered through this study during for May 2010. Only those who completed the survey were redirected to the "thank you" page and there was no link to it from other pages. By monitoring the hits on that specific page, it was possible to see how effective the reminder e-mails were. This is shown in Figure 11. Clearly many boaters filled in the monthly surveys in response to the first e-mail informing them it was available. However, a number of boaters did not do so until they received one or more reminders. This suggests that while such reminders may have been somewhat annoying to participants, they did result in a significant number of additional completed surveys.

While some aspects of this study were technologically challenging and the design, development, testing and launch of the survey had to be achieved in a highly compressed timeline, there were few technical hitches during seven months that the survey was running. To test the system regularly, the technical team created a number of unique identifiers for non-existent boats that were linked to the e-mail addresses of two team members. By monitoring inboxes for survey alerts and reminders, the team was able to ensure that broadcast e-mails were being generated and received by participants. This monitoring effort occurred frequently during the initial phases of the survey but was scaled back in later months when no issues had been identified and the system appeared to be running smoothly. 


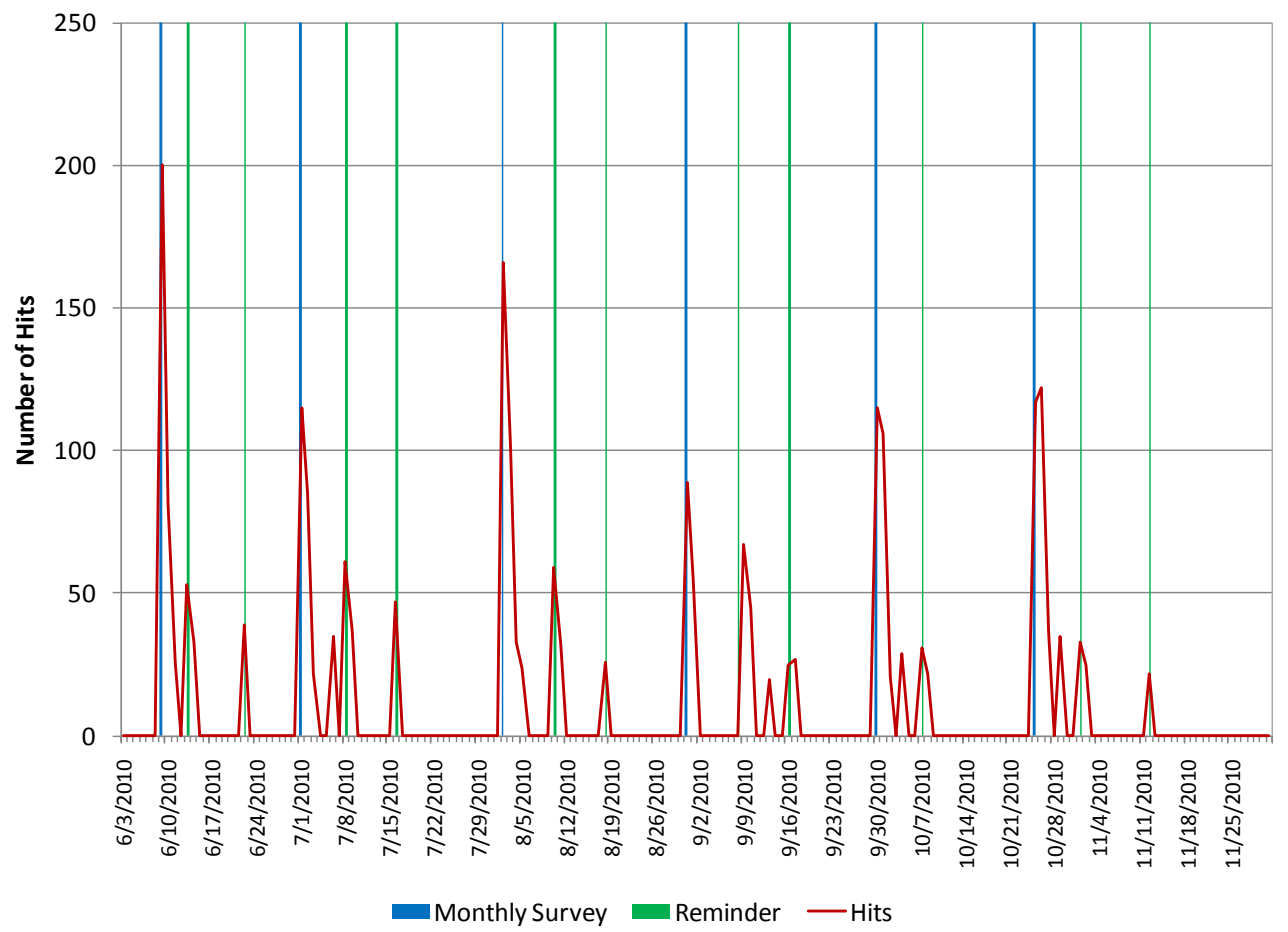

Figure 11: Daily hits on the "thank you" webpage to which boaters were directed automatically when they completed a monthly survey and dates of e-mailings.

\subsection{Participation during the Season}

The recruitment results displayed in Table 11 represent a summary of results from across all months of the study. No particular survey actually had a sample size indicated by the 1,234 returned recruitment surveys. The reason for this is that recruitment surveys were coming in throughout the summer months and in addition, boat owners were selling their boats or dropping out of the study throughout the summer months. Therefore, each survey had a sample size of boat owners reflective of what was known at that time. The data collection results will be summarized by type of survey in the following sections.

\subsubsection{Initial Survey}

The initial survey was conducted by e-mailing known eligible boat owners in May 2010. The survey asked questions concerning details about their boat. A total of 1,162 e-mail invites were sent of which 98 were bounced back as undeliverable, meaning that only 1,064 were assumed to get through to eligible boat owners. Table 13 displays the number of completed initial surveys, stratified by size class and region.

A total of 649 of the initial surveys were completed on the web. This meant an estimated survey response rate of $61 \%(649 / 1,064)$. Again, it would be hoped that a higher rate would have been obtained, but in comparison to response rates of other web surveys, this is considered a very good result. Nationally, web survey response rates are frequently in the $20 \%$ range, so response rates to this 
survey must be considered relatively successful. Due to time constraints, an initial e-mail invitation was sent to everyone with one reminder e-mail that followed about a week later.

\subsubsection{Monthly Surveys}

The most significant part of this study was the monthly surveys that asked about trips taken during May through October. It is through these surveys that trip routes were mapped and details about recreational boat use across the summer and fall were obtained. These data were at the center of why this study was conducted. Each monthly survey was conducted in the same manner. An initial e-mail invitation was sent to all known eligible boat owners at the beginning of the month asking about the prior month. For example, the first monthly survey was e-mailed on June 9 and asked about boat usage in the month of May. The questions in the survey involved the number of trips taken out on coastal waters in May, money spent in May on their boat and finally for details concerning the cost and purposes of the last trip taken that month.

Table 13: $\quad$ Results of the initial survey.

\begin{tabular}{llr}
\hline Region & Boat Size & Completed Surveys \\
\hline Southeastern & Less than 10 feet & 16 \\
\cline { 2 - 3 } & 10 feet -39 feet & 216 \\
\cline { 2 - 3 } & 40 or more feet & 1 \\
\hline East Central & Less than 10 feet & 13 \\
\cline { 2 - 3 } & 10 feet -39 feet & 127 \\
\cline { 2 - 3 } & 40 or more feet & 0 \\
\hline Northeastern & Less than 10 feet & 20 \\
\cline { 2 - 3 } & 10 feet -39 feet & 123 \\
\cline { 2 - 3 } & 40 or more feet & 15 \\
\hline Central \& Out of State & All boat sizes & 6 \\
\hline Western & All Boat sizes & 35 \\
\hline Documented Boats & 10 feet -39 feet & 75 \\
\cline { 2 - 3 } & 40 or more feet & 649 \\
\hline TOtAL & & \\
\hline
\end{tabular}

1 Southeastern MA included Barnstable, Bristol, Dukes and Nantucket counties. East Central MA included Norfolk, Suffolk and Plymouth counties. Northeastern MA included Essex and Middlesex counties. Central MA and Out of State included Worcester County and all out of state addresses. Western MA included Berkshire, Hampshire, Hampstead and Franklin counties. Documented Boats included the entire Coast Guard database for which location was not known. 
It was not feasible to ask about each trip taken during the month, as that would have burdened survey respondents far too much. Asking about a randomly chosen trip during the month was considered, but that was felt to be far too confusing to survey respondents. Asking about the last trip taken was easy for respondents to understand and was probably the easiest for them to remember since it was the most recent trip taken. During months in which there was a major holiday (Memorial Day, Fourth of July and Labor Day), a question was asked if the reported trip was taken as part of that holiday weekend.

After the initial monthly e-mail invite, two reminder e-mails were sent at approximate week intervals to anyone who had not yet responded. Therefore, a sample boat owner received up to three e-mails a month attempting to get them to reply. It was felt that any additional efforts would be considered close to harassment and probably would have angered a number of boat owners. Therefore, three notification e-mails were sent at the intervals specified. Table 14 displays the overall results of the monthly surveys.

Table 14: $\quad$ Overall results of the monthly surveys.

\begin{tabular}{lrrrrrrr}
\hline & May & June & July & August & September & October & Total \\
\hline Emails Sent & 854 & 1,200 & 1,222 & 1,208 & 1,201 & 1,195 & 6,880 \\
\hline Bad Emails & 77 & 90 & 69 & 100 & 106 & 108 & 550 \\
\hline Surveys Complete & 536 & 556 & 629 & 499 & 406 & 363 & 2,989 \\
\hline Percent Complete & $\mathbf{6 9 . 0}$ & $\mathbf{5 0 . 1}$ & $\mathbf{5 4 . 6}$ & $\mathbf{4 5 . 0}$ & $\mathbf{3 7 . 1}$ & $\mathbf{3 3 . 4}$ & $\mathbf{4 7 . 2}$ \\
\hline Eligible for Map & 279 & 381 & 509 & 399 & 247 & 155 & 1,970 \\
\hline Percent Eligible & $\mathbf{5 2 . 1}$ & $\mathbf{6 8 . 5}$ & $\mathbf{8 0 . 9}$ & $\mathbf{8 0 . 0}$ & $\mathbf{6 0 . 8}$ & $\mathbf{4 2 . 7}$ & $\mathbf{6 5 . 9}$ \\
\hline
\end{tabular}

As seen in Table 14, a total of 6,880 e-mails were sent over the six months of the boating season, with 550 being bounced back. This led to 2,989 completed surveys for an estimated response rate of $47.2 \%$. This implies that approximately $47.2 \%$ of all boat owners sent e-mails did complete the survey. It is only possible to suggest an approximate response rate, as there is no true way to determine exactly how many e-mails did arrive in a way that a boat owner saw it and had the opportunity to respond. It is simply assumed that if the e-mail did not bounce back, then it did get through any firewalls, spam filters, etc. and did get to the desired boat owner. As expected, the response rate by month declined over time (Figure 11) from a high of $69 \%$ in the May survey to a low of $33.4 \%$ in the October survey. This decline in response rate was not unexpected as keeping people interested and engaged over six months of surveys is a difficult task. 


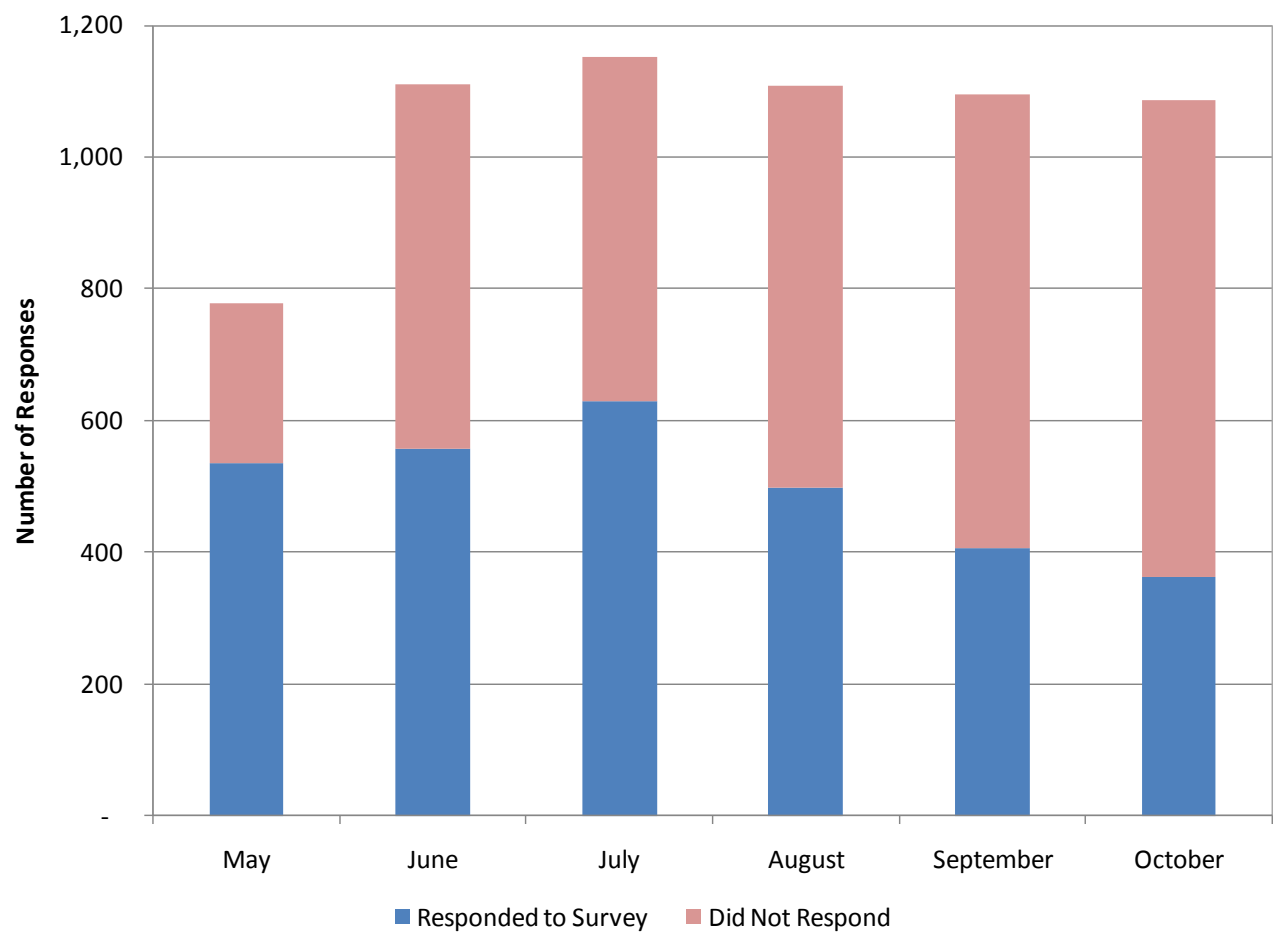

Figure 12: $\quad$ Results of the monthly surveys.

Another interesting result displayed in Table 15 is the rate at which people who responded to the survey actually took their boat out onto the water and were therefore eligible to map a trip. As expected, this peaked in July and August with over $80 \%$ of all survey responders eligible to draw a map. The bordering months of June and September had lower eligibility rates ( $68.5 \%$ and $60.8 \%$ respectively). Finally, the beginning and end months of May and October were lower still with rates around or below $50 \%$. None of this is surprising, but it is interesting to quantify these results to such an exact degree.

Tables 15 and 16 display further breakdowns of the monthly survey results by region and size of boat. 
Table 15: $\quad$ Monthly survey results by region.

\begin{tabular}{|c|c|c|c|c|c|c|}
\hline \multirow[b]{2}{*}{ Region } & \multicolumn{2}{|c|}{ May } & \multicolumn{2}{|c|}{ June } & \multicolumn{2}{|c|}{ July } \\
\hline & $\begin{array}{r}\text { Responded to } \\
\text { Survey }\end{array}$ & $\begin{array}{r}\text { Eligible to } \\
\text { Map }\end{array}$ & $\begin{array}{r}\text { Responded to } \\
\text { Survey }\end{array}$ & $\begin{array}{r}\text { Eligible to } \\
\text { Map }\end{array}$ & $\begin{array}{r}\text { Responded to } \\
\text { Survey }\end{array}$ & $\begin{array}{r}\text { Eligible to } \\
\text { Map }\end{array}$ \\
\hline Southeast & 195 & 91 & 209 & 134 & 228 & 179 \\
\hline East Central & 119 & 63 & 117 & 81 & 142 & 120 \\
\hline Northeast & 110 & 55 & 113 & 77 & 132 & 105 \\
\hline Central & 12 & 7 & 13 & 7 & 14 & 9 \\
\hline West & 5 & 1 & 7 & 5 & 7 & 6 \\
\hline Documented & 95 & 62 & 97 & 77 & 106 & 90 \\
\hline TOTAL & 536 & 279 & 556 & 381 & 629 & 509 \\
\hline
\end{tabular}

\begin{tabular}{|c|c|c|c|c|c|c|}
\hline \multirow[b]{2}{*}{ Region } & \multicolumn{2}{|c|}{ August } & \multicolumn{2}{|c|}{ September } & \multicolumn{2}{|c|}{ October } \\
\hline & $\begin{array}{r}\text { Responded to } \\
\text { Survey }\end{array}$ & $\begin{array}{r}\text { Eligible to } \\
\text { Map }\end{array}$ & $\begin{array}{r}\text { Responded to } \\
\text { Survey }\end{array}$ & $\begin{array}{r}\text { Eligible to } \\
\text { Map }\end{array}$ & $\begin{array}{r}\text { Responded to } \\
\text { Survey }\end{array}$ & $\begin{array}{r}\text { Eligible to } \\
\text { Map }\end{array}$ \\
\hline Southeast & 186 & 143 & 137 & 84 & 137 & 52 \\
\hline East Central & 109 & 88 & 98 & 52 & 75 & 29 \\
\hline Northeast & 103 & 83 & 83 & 56 & 75 & 32 \\
\hline Central & 9 & 4 & 10 & 6 & 9 & 3 \\
\hline West & 6 & 6 & 7 & 3 & 3 & 0 \\
\hline Documented & 86 & 75 & 71 & 46 & 64 & 39 \\
\hline TOTAL & 499 & 399 & 406 & 247 & 363 & 155 \\
\hline
\end{tabular}

\begin{tabular}{|c|c|c|}
\hline \multirow[b]{2}{*}{ Region } & \multicolumn{2}{|c|}{ TOTAL } \\
\hline & $\begin{array}{r}\text { Responded to } \\
\text { Survey }\end{array}$ & $\begin{array}{r}\text { Eligible to } \\
\text { Map }\end{array}$ \\
\hline Southeast & 1,092 & 683 \\
\hline East Central & 660 & 433 \\
\hline Northeast & 616 & 408 \\
\hline Central & 67 & 36 \\
\hline West & 35 & 21 \\
\hline Documented & 519 & 389 \\
\hline TOTAL & 2,989 & 1,970 \\
\hline
\end{tabular}


Table 16: $\quad$ Monthly survey results by boat size.

\begin{tabular}{|c|c|c|c|c|c|c|}
\hline \multirow[b]{2}{*}{ Size } & \multicolumn{2}{|c|}{ May } & \multicolumn{2}{|c|}{ June } & \multicolumn{2}{|c|}{ July } \\
\hline & $\begin{array}{r}\text { Responded to } \\
\text { Survey }\end{array}$ & $\begin{array}{r}\text { Eligible to } \\
\text { Map }\end{array}$ & $\begin{array}{r}\text { Responded to } \\
\text { Survey }\end{array}$ & $\begin{array}{r}\text { Eligible to } \\
\text { Map }\end{array}$ & $\begin{array}{r}\text { Responded to } \\
\text { Survey }\end{array}$ & $\begin{array}{r}\text { Eligible to } \\
\text { Map }\end{array}$ \\
\hline$<10$ feet & 47 & 23 & 39 & 19 & 43 & 33 \\
\hline 10-39 feet & 400 & 197 & 430 & 297 & 483 & 391 \\
\hline $40+$ feet & 72 & 51 & 67 & 53 & 82 & 70 \\
\hline Central \& Western ${ }^{1}$ & 17 & 8 & 20 & 12 & 21 & 15 \\
\hline TOTAL & 536 & 279 & 556 & 381 & 629 & 509 \\
\hline
\end{tabular}

\begin{tabular}{|c|c|c|c|c|c|c|}
\hline \multirow[b]{2}{*}{ Size } & \multicolumn{2}{|c|}{ August } & \multicolumn{2}{|c|}{ September } & \multicolumn{2}{|c|}{ October } \\
\hline & $\begin{array}{r}\text { Responded to } \\
\text { Survey }\end{array}$ & $\begin{array}{r}\text { Eligible to } \\
\text { Map }\end{array}$ & $\begin{array}{r}\text { Responded to } \\
\text { Survey }\end{array}$ & $\begin{array}{r}\text { Eligible to } \\
\text { Map }\end{array}$ & $\begin{array}{r}\text { Responded to } \\
\text { Survey }\end{array}$ & $\begin{array}{r}\text { Eligible to } \\
\text { Map }\end{array}$ \\
\hline$<10$ feet & 30 & 21 & 30 & 15 & 26 & 9 \\
\hline $10-39$ feet & 385 & 307 & 308 & 191 & 277 & 110 \\
\hline $40+$ feet & 69 & 61 & 51 & 32 & 48 & 33 \\
\hline Central \& Western ${ }^{1}$ & 15 & 10 & 17 & 9 & 12 & 3 \\
\hline TOTAL & 499 & 399 & 406 & 247 & 363 & 155 \\
\hline
\end{tabular}

\begin{tabular}{|c|c|c|}
\hline \multirow[b]{2}{*}{ Size } & \multicolumn{2}{|c|}{ TOTAL } \\
\hline & $\begin{array}{r}\text { Responded to } \\
\text { Survey }\end{array}$ & $\begin{array}{r}\text { Eligible to } \\
\text { Map }\end{array}$ \\
\hline$<10$ feet & 215 & 120 \\
\hline 10-39 feet & 2,283 & 1,493 \\
\hline $40+$ feet & 389 & 300 \\
\hline Central \& Western ${ }^{1}$ & 102 & 57 \\
\hline TOTAL & 2,989 & 1,970 \\
\hline
\end{tabular}

${ }^{1}$ This is the Central MA, Western MA and Out of State areas combined and not broken down by size due to the very small number of completed surveys across these areas.

Table 17 breaks down how many boat owners completed multiple surveys across the six months. 
Table 17: $\quad$ Breakdown of how many boaters completed multiple surveys throughout the boating season.

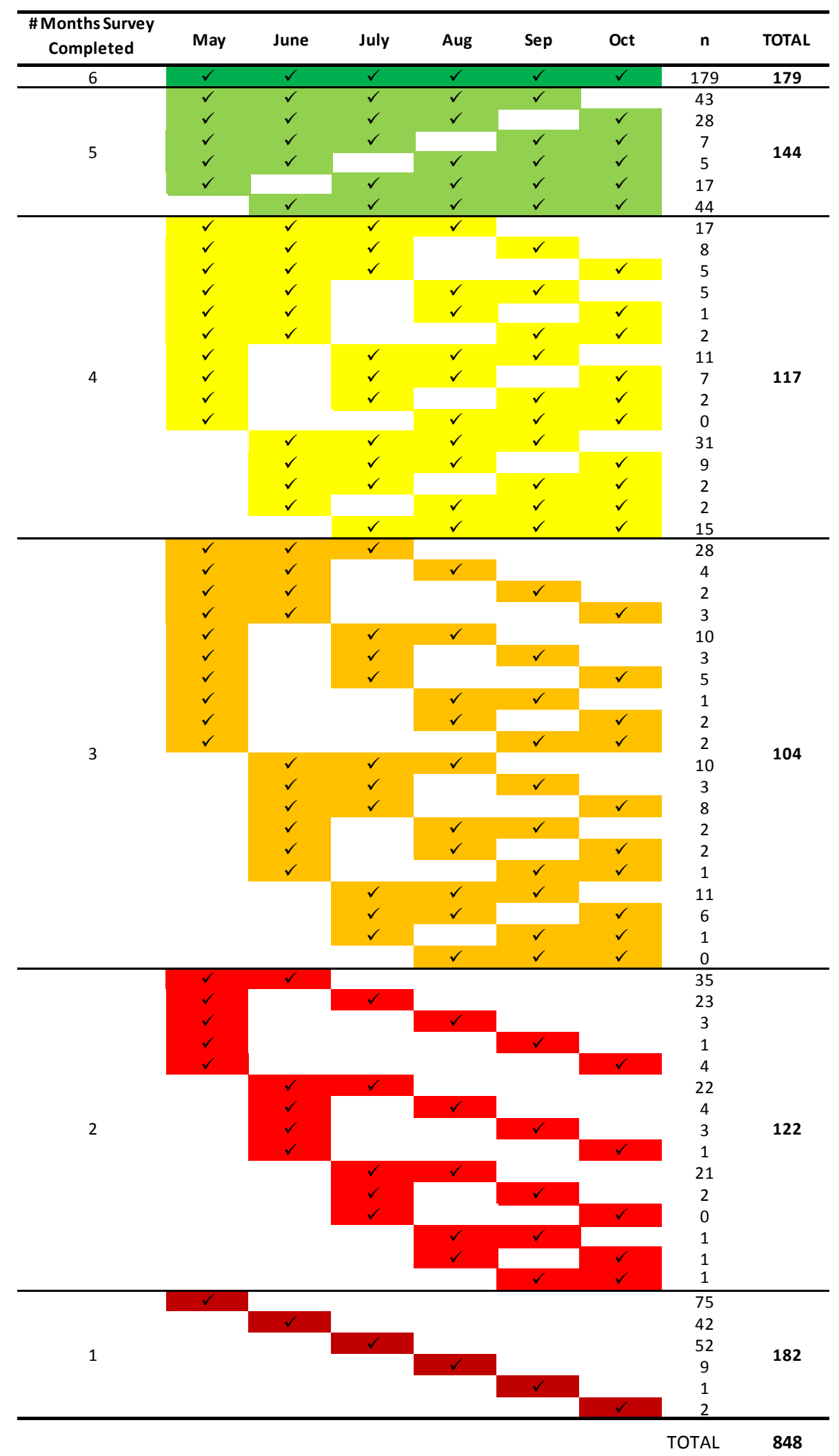


A total of 848 people completed the survey in at least one of the six months. This means that $72.9 \%$ of all those that are believed to have received at least one successful e-mail invitation, responded to at least one survey. This response rate is quite high and considered quite successful for a serial web survey.

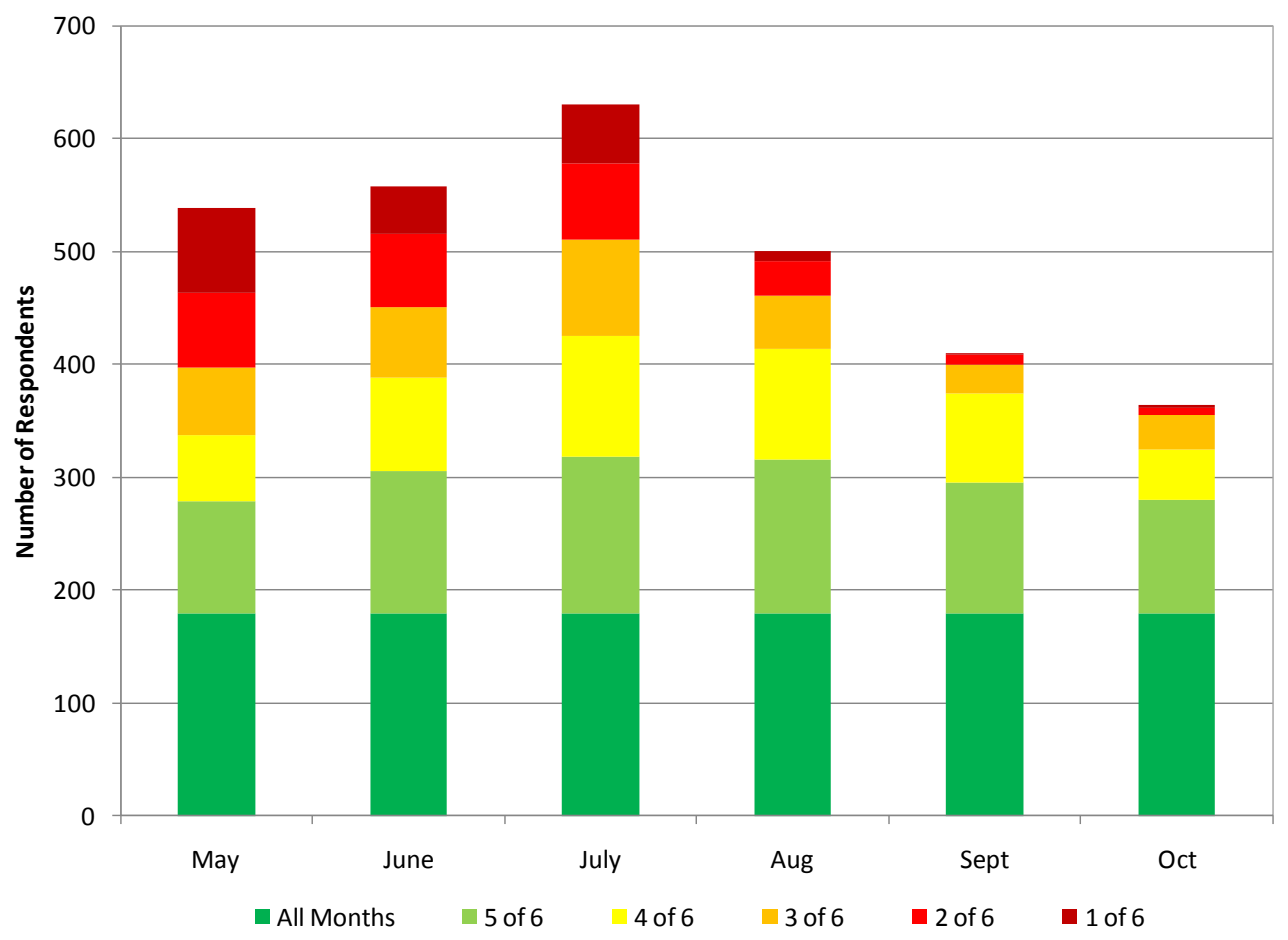

Figure 13: $\quad$ Breakdown of how boaters completed multiple monthly surveys.

\subsubsection{End-of-season Survey}

The end-of-season survey was sent to all eligible boat owners in November 2010. This survey asked boat owners about expenses incurred that did not relate to any specific trip, but were more general expenses associated with boat ownership. Examples of this type of expense were repair costs, storage costs and equipment costs. For people who completed the survey, they were given the option of continuing on to do the normal monthly trip survey about any boat trips in October. A total of 458 people responded to the end-of-season survey and 363 of them agreed to complete the October monthly trip survey. Overall, 1,195 e-mails were sent out, of which 108 bounced back as undeliverable. Of the remaining 1,087 e-mail invites, 458 people completed the end-of-season survey. This implied an approximate response rate of $42.1 \%$. Table 18 displays a breakdown of the end-of-season survey results by region and boat size. 
Table 18: $\quad$ Results of the end-of-season survey.

\begin{tabular}{|c|c|c|}
\hline Region $^{1}$ & Boat Size & Completed Surveys \\
\hline \multirow[t]{3}{*}{ Southeastern } & Less than 10 feet & 16 \\
\hline & 10 feet -39 feet & 154 \\
\hline & 40 or more feet & 0 \\
\hline \multirow[t]{3}{*}{ East Central } & Less than 10 feet & 11 \\
\hline & 10 feet -39 feet & 89 \\
\hline & 40 or more feet & 0 \\
\hline \multirow[t]{3}{*}{ Northeastern } & Less than 10 feet & 10 \\
\hline & 10 feet -39 feet & 79 \\
\hline & 40 or more feet & 0 \\
\hline Central \& Out of State & All boat sizes & 10 \\
\hline Western & All Boat sizes & 4 \\
\hline \multirow[t]{2}{*}{ Documented Boats } & 10 feet -39 feet & 23 \\
\hline & 40 or more feet & 62 \\
\hline TOTAL & & 458 \\
\hline
\end{tabular}

1 Southeastern MA included Barnstable, Bristol, Dukes and Nantucket counties.

East Central MA included Norfolk, Suffolk and Plymouth counties.

Northeastern MA included Essex and Middlesex counties.

Central MA and Out of State included Worcester County and all out of state addresses.

Western MA included Berkshire, Hampshire, Hampstead and Franklin counties.

Documented Boats included the entire Coast Guard database for which location was not known.

\subsubsection{Mapping Application}

Overall statistics related to the boater survey mapping activity are provided in Table 19. In this table, Snap refers to the survey component; Snap was the software used to develop the survey as a web application. Thus, the column titled Snap refers to the number of participating boaters (users) who reported that they undertook a boat trip out on the water during the month listed, and who were therefore handed off to the boater survey web-based mapping application from Snap. The column Snap2Map details the number of boaters who (for May and June, see note 1) continued past the mapping application welcome page or (for the July through October) at least viewed the welcome page.

The column Map Activity describes the number of boaters who continued past the welcome page. Notice that for the months of May and June, Snap2Map and Map Activity are identical values. 
The columns titled Boaters Mapped.... are self-explanatory. The columns under the heading detail the total quantity of Areas or Alternate Areas drawn; in any one month, a boater could only draw one route, but could draw any number of areas (including none).

Table 19: $\quad$ Summary of spatial data provided by participating boaters.

\begin{tabular}{|c|c|c|c|c|c|c|c|c|c|c|c|c|c|}
\hline \multicolumn{12}{|c|}{ Boaters } & \multicolumn{2}{|c|}{$\begin{array}{c}\text { Areas and } \\
\text { Alternate Areas }\end{array}$} \\
\hline \multirow{2}{*}{$\begin{array}{l}\text { Month } \\
\text { May }\end{array}$} & \multirow{2}{*}{$\frac{\text { Snap }}{278}$} & \multicolumn{2}{|c|}{ Snap2Map ${ }^{1}$} & \multicolumn{2}{|c|}{ Map Activity ${ }^{1}$} & \multicolumn{2}{|c|}{$\begin{array}{l}\text { Boaters Mapped } \\
\text { Routes }\end{array}$} & \multicolumn{2}{|c|}{$\begin{array}{c}\text { Boaters Mapped } \\
\text { Areas }^{2}\end{array}$} & \multicolumn{2}{|c|}{$\begin{array}{l}\text { Boaters Mapped } \\
\text { Alternate }^{3}\end{array}$} & \multirow{2}{*}{$\begin{array}{r}\text { Areas }^{4} \\
86\end{array}$} & \multirow{2}{*}{\begin{tabular}{r}
\multicolumn{1}{c}{$\begin{array}{c}\text { Alt } \\
\text { Areas }^{4}\end{array}$} \\
52
\end{tabular}} \\
\hline & & 249 & $89.6 \%$ & 249 & $100.0 \%$ & 178 & $71.5 \%$ & 70 & $28.1 \%$ & 43 & $17.3 \%$ & & \\
\hline June & 380 & 328 & $86.3 \%$ & 328 & $100.0 \%$ & 229 & $69.8 \%$ & 68 & $20.7 \%$ & 44 & $13.4 \%$ & 76 & 45 \\
\hline July & 505 & 496 & $98.2 \%$ & 454 & $91.5 \%$ & 268 & $59.0 \%$ & 87 & $19.2 \%$ & 55 & $12.1 \%$ & 121 & 65 \\
\hline August & 397 & 394 & $99.2 \%$ & 360 & $91.4 \%$ & 226 & $62.8 \%$ & 65 & $18.1 \%$ & 39 & $10.8 \%$ & 86 & 44 \\
\hline September & 246 & 244 & $99.2 \%$ & 222 & $91.0 \%$ & 123 & $55.4 \%$ & 28 & $12.6 \%$ & 19 & $8.6 \%$ & 33 & 20 \\
\hline October & 155 & 152 & $98.1 \%$ & 135 & $88.8 \%$ & 67 & $49.6 \%$ & 20 & $14.8 \%$ & 9 & $6.7 \%$ & 28 & 10 \\
\hline TOTALS & 1,961 & 1,863 & $95.0 \%$ & 1,748 & $93.8 \%$ & 1,091 & $62.4 \%$ & 338 & $19.3 \%$ & 209 & $12.0 \%$ & 430 & 236 \\
\hline
\end{tabular}

1 "No Activity" not tracked in May or June

${ }^{2}$ Individual boaters mapping at least one area

${ }^{3}$ Individual boaters mapping at least one alternate area

${ }^{4}$ Total areas mapped

Throughout the study period, there were a number of boaters who were eligible to map (i.e. had undertaken an on-water trip) but who did not get passed the mapping application welcome page. This page gave boaters the opportunity to skip the mapping if they so wished. In May and June "skipping" was not recorded so it is unclear if boaters simply opted to skip or if there was a problem with the application. From July onwards additional monitoring was implemented, which showed that the "loss" between the Snap survey and the mapping application was small. Initially, over $70 \%$ of those who did not choose to skip the mapping application went on to plot a route. However, this percentage dropped throughout the study so that only $50 \%$ mapped a route in October. This attrition may simply be due to "survey fatigue."

The mapping of activity areas, and alternate areas, was generally not well undertaken by participants (Figure 14 ) with between $28 \%$ and $15 \%$ of boaters mapping activity areas and only $18 \%$ to $7 \%$ mapping alternate areas. 


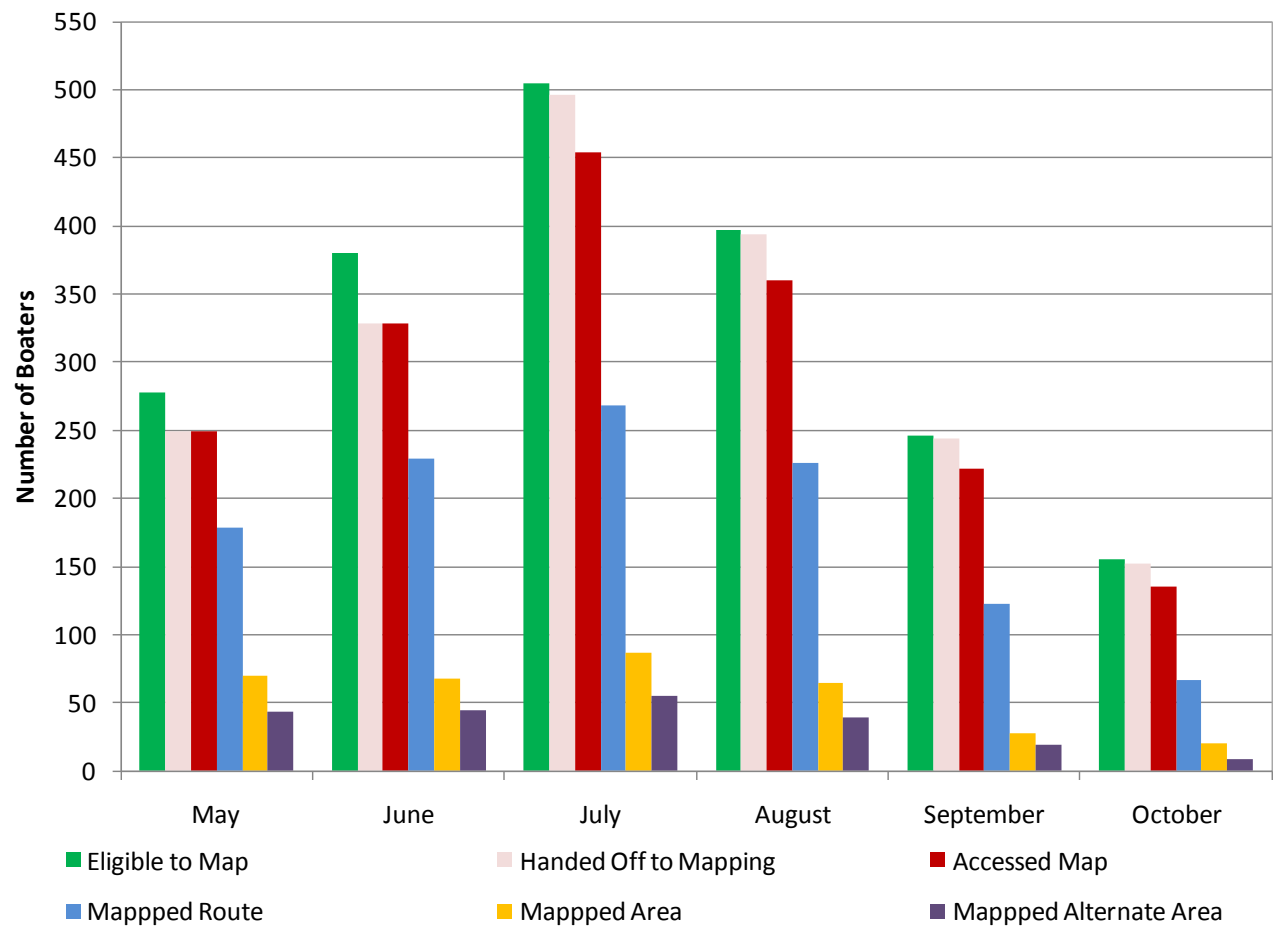

Figure 14: $\quad$ Summary of spatial data provided by participating boaters.

\subsection{Boater Feedback (during the boating season)}

To ensure that boaters were able to communicate with the project team, a telephone line (with voicemail) was dedicated to this study and an e-mail address was created (help@maboatersurvey.com). Voice-mail and e-mail were generally checked every business day. These avenues of communication were included in outreach materials, in the online surveys and on the recreational boater survey website.

During the period that the survey was running, approximately 15 boaters contacted the team either by telephone or by e-mail. Six enquiries centered on technical problems that boaters were experiencing with the online mapping application. These were forwarded to relevant team members and were addressed to the degree possible. Four boaters had misplaced their recruitment packages and needed additional directions on how to participate. Three boaters asked to be removed from the study. The remaining boaters who contacted the project team did so to comment on the survey in general or to clarified or suggest improvements to specific aspects of the survey.

\subsection{Volunteer Survey}

While the clear focus of this survey was on the boating activity of the sampled boaters, it was felt that other boaters (or "volunteers" as they were termed in the study) should be given an opportunity to provide information on their boating activity. Due to the study design, this information could not be included in any of the analysis associated with the sampled boaters. 
Due to time limitations and the need to focus on the primary aim of the study, no significant efforts were made to solicit input from volunteer boaters. However, the ability for any boater to provide input was clearly expressed in all outreach materials, which directed interested boaters to the survey website (www.maboatersurvey.com). From there, volunteer boaters could provide some basic information about their vessel and then could plot their boating routes.

A total of 43 routes were reported by volunteer boaters. This did not provide enough for any detailed analysis and as such, the information provided is not discussed further in this report. However, it is important to note that more comprehensive data could be gathered in this way if a more strategic outreach campaign was implemented.

\subsection{Out-of-state Boater Pilot Survey}

Prior to this survey moving beyond the conceptualization phase, it was acknowledged that the lack of information on out-of-state boater activity represented a significant data gap, but that trying to fill that gap as part of this study was not feasible. The methodology developed for this study required that a stratified, random sample of boats be selected from a known "population." Having a defined population was critical if it were to be possible to scale-up the economic data to a region or to the state as a whole. While it is recognized that out-of-state boater activity may have a significant economic impact within Massachusetts, the inherent mobility of boating and the short distances between New England states allows for frequent visits to Massachusetts by out-of-state boaters. Thus, identifying and locating outof-state boaters is problematic and defining the "population" of such boaters is extremely difficult. The term "out-of-state boater" may bring to mind large vessels or mega yachts visiting Massachusetts en route to other destinations such as Canada or Florida - or perhaps those seen tied-up alongside the dock in Nantucket during the summer. These types of vessels and boaters undoubtedly have the potential to have a significant impact on the local economy. Additionally, it may be possible to estimate the numbers of such vessels visiting or transiting Massachusetts waters because they are conspicuous and require specific shoreside support infrastructure that may limit the number of locations at which they can berth. However, it is likely that most of the out-of-state boating activity consists of smaller boats that either cross into Massachusetts waters for a short visit to a local area or are trailered into Massachusetts and launched at a local boat ramp. While the economic impact associated with any individual small out-of-state boats may be low, the cumulative impact of them all may be considerable.

As smaller out-of-state boats would be expected to be similar to those from Massachusetts, they are likely to be used in similar ways and only be identifiable as being from another state through closer inspection. This makes identifying the population of such vessels highly challenging.

It is also important to note that many out-of-state boaters may enter Massachusetts waters but never come ashore and never spend any money within the state. As such, their economic impact may be extremely low or even non- existent. However, large numbers of out-of-state boaters may have other impacts such as increasing on-water congestion and pollution. 
While attempting to fill the data gaps associated with out-of-state boater activity was beyond the scope of this study, it was decided that a preliminary analysis of some potentially useful existing data sources would be worthwhile. In addition, once the main study was successfully underway, it was decided that a very small pilot study should be implemented to assess one potential means of gathering data on out-ofstate boaters and their activity. The aim of this pilot was to test a data-gathering methodology that, if successful, had the potential to be expanded across the state in a concerted effort to fill some of the data gaps associated with out-of-state boaters. The pilot study was not expected to result in any significant amounts of useful data.

\subsubsection{Cape Cod Canal Data}

The Cape Cod Canal is a 17.4-mile long, 480-foot wide, man-made canal, which bisects the Upper Cape and the "mainland" Town of Bourne. Saving boaters a 135-mile journey circumnavigating the tip of Cape Cod, it is a major transit route for both recreational and commercial vessels traveling between Buzzards Bay and Cape Cod Bay. The canal represents a waterway bottleneck and as such, the movement of vessels through it must be carefully managed. This is especially true for larger, less maneuverable vessels.

The canal falls under the jurisdiction of the US Army Corps of Engineers (USACE). The USACE requires all vessels over 65 feet in length to obtain clearance prior to transiting the canal by contacting the Canal Marine Traffic Controller via VHF radio or by telephone. As the USACE maintains records of such transits, this represents a potentially useful source of information about larger vessel movement between Buzzards Bay and Cape Cod Bay.

Cape Cod Canal Management gathers a number of pieces of information on all vessels of 65 -feet or greater that transit the canal. These include the:

- Date of passage;

- Vessel type;

- Homeport of origin;

- Vessel destination;

- Draft;

- Net tonnage; and

- Vessel flag.

In order to assess the value of the information, the project team requested that Cape Cod Canal field office provide selected data from the permission-to-transit log for vessels exceeding 65 feet in length overall for the period January 1 through November 28, 2010. Consequently, electronic data on vessel net tonnage, port of origin, intended destination, vessel class or type and transit date were provided on February 16, 2011 by the field office. 
Minimal large recreational boat activity was reported in the canal during the first four months of 2010 (two transits in total; one in January and one in April). As would be expected, activity began to pick up in May with 29 transits. Activity continued to increase through June (55 transits) and July (139) before peaking at 215 transits during August. Numbers then fell significantly in September (97), October (50) and November (7). In total there were 594 transits made through the canal by 281 different recreational boats of $65+$ feet. Many of the vessels made round trips through the canal while en route to or from destinations ranging from the Canadian port of Quebec to Key West, Florida.

Vessel traffic through the Cape Cod Canal was highest from May through October peaking in the months of July and August with 139 and 215 transits respectively. The majority of vessels (52\%) were US flagged. A further $30 \%$ were foreign flagged and flag of registry data were incomplete for $17 \%$ of vessels. For those vessels declaring a Port of Origin, the majority hailed from New England and New York. A Massachusetts port was listed as their next Port of Call for 334 transits.

While the data gathered by the USACE on vessels transiting the Cape Cod Canal are of some interest, they are of somewhat limited use for this study in that they provide limited data, on a sub-set of recreational vessels (65-feet or over) that pass through one stretch of water within Massachusetts.

\subsubsection{US Coast Guard Notice of Arrival/Departure Data}

The boater survey focused on evaluating the population, movement and spending of state-registered and USCG documented vessels. However, during the summer months a number of vessels operating in New England waters are foreign flagged (or operate under a "flag of convenience"). As such, they will appear in neither the state nor the USCG databases. These vessels are most frequently larger sailing or powerboats with extended cruising ranges and staffed by professional crew. While the fleet size may be relatively modest, visits by these mega yachts, super yachts and giga yachts may have a significant economic impact both at a local and statewide level.

Currently, the USCG has reporting requirements for foreign-flagged vessels visiting US ports. When a foreign-flagged recreational vessel exceeding 300 gross tons intends to enter or transit through a particular "Captain of the Port (COTP)" zone as demarcated by the USCG, the master of the vessel is required to file a 96-hour advance Notice of Arrival/Departure (NOA/D) with the USCG prior to entering the zone. The USCG requires specific information be submitted as part of each NOA/D including: date of arrival, vessel gross tonnage, last port, destination port, vessel flag, and number of crew and passengers onboard.

The project team identified two COTP zones as being most pertinent to assessing if NOA/D data could be used to study out-of-state boater activity in Massachusetts: Sector Boston and Sector Southeast New England. The team requested (under the Freedom of Information Act of 1974, 5 U.S.C. 552, as amended) that the USCG provide NOA/D data for recreational vessels over 300 gross tons transiting either sector for the period of April 1 through October 1, 2010. 
There were 257 individual NOA/D filed between April 25 and October 2, 2010. These records listed 140 visits to 13 destination "ports" in Massachusetts: Beverly, Boston, Cape Cod Canal, Cuttyhunk, Edgartown, Gloucester, Hyannis, Martha's Vineyard/Vineyard Haven, Nantucket, New Bedford, Newburyport, Plymouth and Provincetown. Nantucket was the most frequented destination (41 visits), followed by Boston (38), Martha's Vineyard (Edgartown, Vineyard Haven and Martha's Vineyard in general [32]). The next most frequented location was Provincetown with nine visits.

Between April 25 and October 2, foreign-flagged vessels spent 695 "vessel-days" in Massachusetts ports (where a "vessel-day" was one vessel spending one day in Massachusetts). These vessels averaged 522 gross tons and had an average of 11 people on board (eight crew and three passengers). Foreignflagged vessels had an average stay of five days in Massachusetts waters.

While the data on foreign-flagged vessels are of interest, they do not identify vessels so it is not possible to determine their overall route within Massachusetts, making the data of limited use for spatial analysis.

\subsubsection{Marina Surveys}

One possible means of gathering data on out-of-state boaters is to carry out intercept surveys at boating facilities. These types of surveys can be both time-consuming and costly, and a full survey was beyond the scope of this study. However, it was decided that it might be possible to solicit the help of those who already interact with out-of-state boaters on a regular basis when they are seeking fuel, moorings, supplies or overnight accommodation - i.e. the staff at marinas and harbormaster's offices. If successful, this could provide a more cost-effective way of conducting an intercept survey compared to deploying dedicated personnel to a number of facilities for extended time periods. To this end, it was decided that a very small pilot study be developed to test the feasibility of having marina staff ask boaters to fill in a short survey.

A brief survey was developed, which asked for details about the trip that an out-of-state boater was undertaking:

- Current facility;

- Type of vessel (power or sail);

- Length of vessel in feet;

- Number of people on board (including children and crew);

- Average number of boating trips into Massachusetts waters per year;

- Hailing / home port:

- Last port of call;

- Estimated duration of current trip in days;

- Estimated number of days in Massachusetts waters during current trip;

- Estimated total amount of trip-related spending in Massachusetts on current trip; 
- Next port of call; and

- Ultimate destination at end of current trip.

Boaters were also asked to plot their approximate route within Massachusetts on a map that was printed on the back of the survey.

Specific destination marinas, or ports, were identified as being best suited for the pilot survey. These facilities included those located near a state border and/or those that were known as popular, high volume boating destinations with facilities that catered to out-of-state boaters. Once the facilities were identified, the management were contacted and asked if they would be willing to participate. Seven facilities accepted the invitation to assist with the pilot. These facilities were located at various locations along the Massachusetts coastline.

On July 1, 2010, survey packages containing detailed instructions, promotional flyers and 100 paper surveys were sent to each of the seven participating facilities for distribution to and collection from boaters whose vessels were registered outside of Massachusetts.

Recognizing the fact that marinas and harbormaster's offices can be extremely busy during the boating season and that conducting surveys is not their primary responsibility, the method of on-site distribution was at the discretion of the participating facility. Some operators distributed the survey at the fuel dock frequented by boaters; some included the survey in a package of dockage registration documents, while others made the survey publicly available in the dock master or harbormaster's office.

From July through the end of September 2010, the facility operators were periodically contacted to determine if more surveys were needed or if they had any questions. During each of these communications, no obstacles were reported. On October 4, 2010, each participating marina was sent instructions and a pre-paid express mail envelope, and was requested to return all completed out-ofstate boater surveys for analysis.

Due to the small number of facilities selected, this pilot study was not expected to result in enough data for detailed analysis of out-of-state boater activity or spending. However, if the methods used to conduct the pilot study proved successful, it might be possible to implement a more comprehensive study at a future time. However, only 10 completed surveys were received and deemed eligible through this pilot study and all of these came from one participating facility, suggesting that the methodology used is not suitable for gathering usable data on out-of-state boaters in Massachusetts.

It appears that there was some confusion about what the facility operators were expected to do, with some not realizing that they needed to collect the completed surveys. In another case, the completed surveys were misplaced before they could be returned for analysis. One operator pointed out that at the height of the season there was simply not enough time to distribute and collect surveys from boaters.

Due to the lack of success of the pilot, it must be concluded that the methodology used should either be considerably refined or an alternative methodology be employed. 


\subsubsection{Recommendations for Future Surveys of Out-of-state Boaters}

Assessing out-of-state boater activity and the economic impact of such activity remains an issue. While some data sources exist, they are of somewhat limited use. Recruiting the help of those who are in regular contact with the out-of-state boaters also appears to be of limited success as marina and harbormaster staff are frequently too busy at the height of the boating season to dedicate the necessary time to informing boaters of a study and encouraging their participation.

An alternative approach could be to have dedicated personnel conduct intercept surveys at marinas, harbormaster's offices and boat ramps. This would be one way to acquire information from these boaters on their activity in Massachusetts and their trip-related spending. However, such surveys can be expensive and time-consuming.

Another alternative approach could be to develop a postcard that could be widely distributed to out-ofstate boaters by simply displaying them prominently at locations commonly visited by out-of-state boaters. The postcard could be a simple survey (which would require a drop-box for responses) or could direct boaters to an out-of-state boater website, which would contain a survey and an adapted version of the online mapping application so that they could report their boating activity and spending. It is likely that participation would be enhanced if incentives were offered, perhaps in the form of monthly prize draws.

While it is likely that with sufficient resources, valuable data could be gathered on out-of-state boater activity and spending, a significant problem remains. Even if analysis of the data allowed for robust estimates of out-of-state boater spending (based on boat size / boat type / duration of trip / number of people on board / a combination of these), this information cannot be scaled up unless the population of out-of-state boaters can be estimated.

One way of estimating the out-of-state boater population could be to look at the records kept by all facilities that provide berthing, dockage or moorings to out-of-state boaters. However, record keeping varies from facility to facility and it would be necessary to standardize the information being gathered. As has already been seen in the pilot study, facility staff are often too busy to dedicate sufficient time to a survey, especially when it is not part of their job.

An alternative might be to ask staff to report on the out-of-state boats located at their facility on a few specific days in a season. This would allow for a snapshot of out-of-state boat types, locations and sizes to be captured throughout the state. This estimated population could be used to scale up the average spending estimated through surveys of boaters. Any efforts to utilize facility staff would require significant outreach to the management of such facilities and follow-up to ensure continued assistance.

Another way to estimate out-of-state boating activity could be to survey a sample of registered boaters from nearby states, assuming that the majority of out-of-state boaters are from within the region. Such a survey would depend upon state registration data being available for neighboring states and would require significant resources. 


\section{ANALYSIS}

A full analysis of all the data was beyond the scope of this study. However, a preliminary analysis of the survey and economic data was undertaken. These analyses are presented in the Results section. The full analytic data files are available to interested parties through the Massachusetts Ocean Partnership.

\subsection{Surveys Analysis}

\subsubsection{Weighting of Data}

The data resulting from these surveys were the direct result of a complex sample involving stratification and over-sampling of particular strata. As demonstrated earlier, this was necessary to attempt to target boat owners who were more likely to be eligible to complete the monthly surveys. Without such a stratified design, far more boat owners would have been ineligible and significantly less data would have been collected. The net result of this stratification was variable probabilities of selection for boat owners depending on region and size of boat. These variable probabilities needed to be taken into account when analyzing survey data. To account for this, weights were placed on each data file. These weights adjusted both for the variable probabilities of selection and for differential survey non-response by stratum. The weights, in other words, adjusted the distribution of boats on the analytic data files to resemble more closely the distribution in the original databases by region and size. Again, it is important to use these weights in analyses of survey data.

A second consideration must be made when considering weighting these data. The weight placed on the monthly data files were boat weights. That implies that when summed, they represented an estimate of the number of recreational boats being used on coastal and ocean waters in Massachusetts. During each monthly survey, boat owners reported on the last trip taken the previous month, if they took the boat out on the water. There was a variable on each monthly data file, which reported the total number of monthly trips reported by each boat owner. For certain analyses, it was better to analyze trips rather than boats. If this was considered important, then the weight on each data file was multiplied by the number of reported trips in the data file. This would then become the appropriate trip weight. These new weights would not sum to the estimated number of recreational boats, but to the estimated number of boat trips.

In doing this, one assumption that was made must be considered. Boaters were reporting on the "last" trip taken during the previous month. If the weight was inflated by the number of trips reported for the previous month, then the assumption was that the last trip was on average similar to the other trips. To the extent that this assumption was incorrect, then analysis results will be flawed. The only way around this problem would have been to have the boat owner report on a randomly selected trip from the previous month. This would have been extremely difficult to do and would have led to reporting errors which would probably have exceeded the problem of assuming the last trip was in some way average. Still, this point must be made and considered. 


\subsubsection{Data Cleaning and Analysis}

One of the primary goals of this study was to fill a number of significant data gaps associated with recreational boating in Massachusetts and to make this information available to both the state and to interested parties such as the boating community and organizations representing recreational boating interests. A vast amount of data was gathered as part of this study with the aim that this information would be used by all interested parties for further analysis. The Urban Harbors Institute and the University of Massachusetts Boston in general, are looking at ways that these data might be used as the basis for graduate research in the near future.

Analytic data files were created separately for the initial survey, each monthly trip survey and for the end-of-season survey. Each of these files contained the appropriate weight as described previously. In addition, each of these files contained the unique identifier, which indicated a particular sampled boat. Therefore, these data files can be considered by themselves or merged for different analyses. For example, the July monthly data file can be analyzed alone to study boater activity in July. The July and August data files can be appended and analyzed together to study boater activity from those two months. If this is done, the weight on each file should be divided by two, as two months are being considered together. Any number of the six monthly can be appended in this manner to look at trips across the entire boating season. The weight should always be divided by the number of months combined for analysis in this way.

In addition, the monthly data files can be matched and merged together by unique identifier. In this way, a longitudinal analysis file can be created to look at what individual boaters did across months. Not every boater completed a survey for each month, so gaps would be frequent. This was best displayed in Table 17. Finally, information from the initial and end-of-season surveys can be merged onto monthly data files, by again using the unique identifier. Once again, gaps would exist as not every boater completed an initial or an end-of-season survey.

The individual data files should be considered building blocks, which can be appended or merged in whatever way suits the analyst as best for studying the specific question they want answered.

All statistics were computed using SAS for Windows version 9.2 (SAS Institute Inc., Cary, NC, USA). Additional analysis was completed using Microsoft Excel.

During the analysis, a number of possible anomalies were identified in the data that boaters had provided. These were addressed using common techniques and the details of this are described below:

- As the sample was based on the boats contained in the two databases, it was important that boaters reported on the spending and activity associated with the selected boat and not on another vessel that they owned. Three records were identified where the boat selected was less than 10 feet in length but the boaters appeared to be reporting on larger vessels. In two of the cases, this was confirmed in the feedback survey when the boaters stated that they had reported on their larger vessel and not the one selected. These vessels were removed from all 
survey analysis (the initial survey, all monthly surveys and the end-of-season survey).

Additionally, these records were stripped from the spatial data.

- One boater listed the number of days that he had visited his boat during July as fifty. This record was removed from the analysis of July data.

- One boater listed the number of days that he had visited his boat during October as forty. This record was removed from the analysis of October data.

- When answering the question about how much boaters had paid in order to launch their trailered boat at a boat ramp, or for parking at the ramp, one boater reported a launch fee of $\$ 1,200$ in October. The next highest launch fee reported at any other point during this study was $\$ 120$. This information was therefore assumed to be an error and this launch fee cost was excluded from any analysis.

- The boaters were asked to estimate the total number of hours they had been under power or sail during the boating season. Four records were identified as being much higher than any others (ranging from 1,500 to 4,000 hours). These were felt to be erroneous and were excluded from the analysis.

- Boaters were asked for the total number of hours spent on the water during the trip that they were reporting on. It quickly became apparent that there was confusion over the question when boaters reported that they spent several days on board a vessel that was less than 10 feet in length. Based on the way the question was worded, this would have been possible if a boater was reporting on his dinghy or tender that he used to access a larger vessel over a multi-day trip. Technically the tender did not return for several days. Due to the confusion, this question was excluded entirely from any analysis.

- In the end-of-season survey, two boaters had reported "other" spending of $\$ 9,999$. These responses were almost $\$ 3,000$ more than the next highest reported expense in this category and were therefore viewed with some suspicion. Additionally, these two outliers significantly increased the total expenditure in this category when scaled up to the population. In order to be somewhat conservative in estimating the economic impact, it was decided that these two records would be re-assigned with a value based on the average of all "other" spending. This gave them a spending in this category of $\$ 1,019$.

- It was noticed that some of the "other" trip-related spending being reported in the monthly surveys would more appropriately be reported as a category of spending in the end-of-season survey (e.g. repairs, maintenance and parts). As there was a strong possibility that this would double count expenditure and overestimate overall spending, the "other" category of triprelated expenditure was not included in the economic analysis. 
- In the end-of-season survey, boaters were asked to check "yes" or "no" to indicate if they had spent money in a specific category. If they answered "yes" then they were asked to enter the amount. However, some boaters checked "yes" and did not enter an amount while others checked "no" but then entered an amount. It was therefore decided that if a dollar amount was provided, it was assumed that the boater had intended to check "yes" even if he had not done so. However, if a boater checked "yes" but left the amount blank, that record was assigned a spending value equivalent to the mean of all the other spending reported in that category.

\subsection{Economic Contribution Analysis and the IMPLAN Model}

\subsubsection{Contributions to the Economy}

Data collected during the survey served as the basis for estimating total expenditures during coastal or ocean recreational boating activity and the impact of these expenditures on both the Massachusetts economy and two different sub-regions.

The basic premise was that an initial investment in one sector of an economy (in this case via recreational boating) spurred additional economic activity in other sectors as the money was re-spent within the state or county. The total economic contribution of the investment was estimated by tracing the flow of money between industries and households until all of the initial investment eventually left the state or county through foreign or domestic trade, or was collected as a tax.

The data collected revealed the dollars spent monthly and seasonally on coastal or ocean recreational boating related activities by county. These expenditures were then inflated from the sample to reflect the likely total expenditures of all recreational boaters.

\subsubsection{The IMPLAN Modeling System}

This analysis used the IMPLAN modeling system to estimate economic contributions generated by the spending of recreational boaters. IMPLAN is a widely used proprietary software, which combines the US Bureau of Economic Analysis' Input-Output Benchmarks data with other federal and regional employment, wage, and industry data to construct quantitative models of the flow of goods and services among businesses that purchase materials and services from one another and from employees who use their increased earnings to purchase additional goods and services from local businesses.

The IMPLAN models for the state and counties reflect the typical expenditure patterns and industry mixes of Massachusetts and its counties, including specific information about when expenditures leave the state or county due to foreign and domestic trade and taxes. The spending patterns and foreign and domestic trade assumptions in the IMPLAN models are based on federal and state government data sources, including the US Census Bureau Economic Census, the US Bureau of Economic Analysis, and the US Bureau of Labor Statistics, among other sources. 


\subsubsection{Data Cleaning and Analysis}

For the purposes of the statewide and regional IMPLAN analyses, all monthly expenditures (mostly vessel operating expenditures) were totaled along with the end of season expenditures (mostly capital expenditures). As with any survey, some assumptions had to be made about the data in order to complete the analysis. In the case of the monthly expenditure surveys, it was noted that expenditures that were classified as "other" were often associated with maintenance or repair of the vessel. Therefore, these expenditures were not included when conducting the IMPLAN analysis because of the risk of double-counting the repair and maintenance expenditures reported in the end of the season survey. The other major decision involved deciding how to treat expenditures in the "other" category from the end of season survey. Most of these expenditures when examined more closely fell into standard IMPLAN expenditure categories and so they were allocated to the relevant area for purposes of the analysis. Expenditures (only $\$ 724,000$ ) that could not be classified or that were clearly not related to recreational boating were not included in the IMPLAN analysis. Finally, as is the case for all expenditures (monthly and seasonal), spending on government taxes or registration fees was dropped as this is a leakage out of the economy and is treated as such by IMPLAN.

\subsection{Mapping Application Analysis}

\subsubsection{Data Cleaning}

Post-processing activities include conversion of PostGIS datasets into shapefiles or attribute tables for desktop review and analysis.

The final spatial database was provided as an ESRI-format personal geodatabase and includes only data associated with valid survey participants. Additional features and data records associated with testing activities were removed during post-processing.

\subsubsection{Analysis}

Analysis of the spatial features and associated attributes was performed only as part of the postprocessing database normalization and quality control activities. The results of these analyses have not been reviewed and are provided solely for demonstration purposes only. More in-depth analysis will be under taken by the MassGIS. 


\section{RESULTS}

\subsection{Vessel Information}

The following information consists of a simple analysis of the information that survey participants provided about their vessels and where they were kept. This information was then scaled up based on the weighting described previously, so that these numbers represent an estimate for all boats in Massachusetts. It is important to remember that these numbers differ from those reported early in the section discussing the vessels in the registered boat database, as these are based on the responses from both registered and documented boat owners. It is also important to note that the number of responses from boaters in the Central and Western regions was low so results for those regions may not accurately reflect the actual situation.

As has been previously suggested by analysis of the registered boat database, the most common vessel type in Massachusetts was "open vessel". The survey data suggested that $62.6 \%$ of boats were of this type (Table 20). It is interesting to note that these data suggest the distribution of vessel types is somewhat different for documented vessels. Almost $62 \%$ of documented boat owners reported that their vessel was a sailboat, as compared to between $10.8 \%$ and $16.7 \%$ of registered boats owners. However, a rough analysis of the raw documented vessel data suggested that only around $32 \%$ were sailboats. It is possible that more owners of documented sailboats responded to the survey than owners of documented powerboats.

Almost all other documented boats were cabin cruisers and it appears that almost no documented vessels were open boats.

Table 20: $\quad$ Boat type by region based on responses to the initial survey.

\begin{tabular}{lcccccr}
\hline Region & Open & $\begin{array}{r}\text { Cabin } \\
\text { Cruiser }\end{array}$ & Sailboat & PWC & Other & n \\
\hline Southeast & $69.3 \%$ & $13.2 \%$ & $13.8 \%$ & $1.7 \%$ & $2.1 \%$ & 230 \\
\hline East Central & $69.6 \%$ & $13.4 \%$ & $11.4 \%$ & $1.3 \%$ & $4.3 \%$ & 140 \\
\hline Northeast & $73.2 \%$ & $10.4 \%$ & $10.8 \%$ & $1.4 \%$ & $4.3 \%$ & 145 \\
\hline Central & $66.7 \%$ & $13.3 \%$ & $13.3 \%$ & $0.0 \%$ & $6.7 \%$ & 15 \\
\hline Western & $66.7 \%$ & $0.0 \%$ & $16.7 \%$ & $0.0 \%$ & $16.7 \%$ & 6 \\
\hline Documented & $0.0 \%$ & $35.2 \%$ & $61.9 \%$ & $0.0 \%$ & $2.8 \%$ & 110 \\
\hline All Massachusetts & $\mathbf{6 2 . 6 \%}$ & $\mathbf{1 4 . 7 \%}$ & $\mathbf{1 7 . 7 \%}$ & $\mathbf{1 . 2 \%}$ & $\mathbf{3 . 8 \%}$ & $\mathbf{6 4 6}$ \\
\hline
\end{tabular}

The fact that most documented vessels were either sailboats or cabin cruisers may be a reflection of the fact that documented boats are generally larger vessels (almost $98 \%$ of documented boats are over 26 feet in length). There are relatively few Massachusetts registered boats of this size with most of them being between 16 and 26 feet, or less than 16 feet (Table 21). 
Table 21: $\quad$ Boat size class by region based on responses to the initial survey.

\begin{tabular}{lrrrrr}
\hline Region & $<\mathbf{1 6}$ & $\mathbf{1 6 - < 2 6}$ & $\mathbf{2 6 - < 4 0}$ & $\mathbf{4 0 +}$ & $\mathbf{n}$ \\
\hline Southeast & $30.0 \%$ & $58.0 \%$ & $11.7 \%$ & $0.2 \%$ & $\mathbf{2 3 0}$ \\
\hline East Central & $33.0 \%$ & $56.3 \%$ & $10.7 \%$ & $0.0 \%$ & 140 \\
\hline Northeast & $37.4 \%$ & $52.6 \%$ & $9.7 \%$ & $0.4 \%$ & 145 \\
\hline Central & $6.7 \%$ & $86.7 \%$ & $6.7 \%$ & $0.0 \%$ & 15 \\
\hline Western & $33.3 \%$ & $66.7 \%$ & $0.0 \%$ & $0.0 \%$ & 6 \\
\hline Documented & $0.0 \%$ & $2.2 \%$ & $80.7 \%$ & $17.1 \%$ & 110 \\
\hline All Massachusetts & $\mathbf{2 8 . 4 \%}$ & $\mathbf{5 1 . 6 \%}$ & $\mathbf{1 8 . 0 \%}$ & $\mathbf{2 . 0 \%}$ & $\mathbf{6 4 6}$ \\
\hline
\end{tabular}

By far the most common hull material reported was fiberglass (76.1\%). Inflatables accounted for almost $11 \%$ of hull types but appeared to be found only in the coastal regions (Table 22). This may reflect the fact that many of these inflatables were probably used as tenders to access a larger vessel.

Table 22: $\quad$ Boat hull material by region based on responses to the initial survey.

\begin{tabular}{lrrrrrrrrr}
\hline Region & Aluminum & Fiberglass & Inflatable & Plastic & Steel & Wood & Other & NA & n \\
\hline Southeast & $6.3 \%$ & $79.2 \%$ & $9.3 \%$ & $2.3 \%$ & $0.0 \%$ & $2.5 \%$ & $0.4 \%$ & $0.0 \%$ & 230 \\
\hline East Central & $5.4 \%$ & $71.3 \%$ & $17.3 \%$ & $0.7 \%$ & $0.0 \%$ & $5.4 \%$ & $0.0 \%$ & $0.0 \%$ & 140 \\
\hline Northeast & $15.9 \%$ & $66.1 \%$ & $13.7 \%$ & $2.1 \%$ & $0.0 \%$ & $1.4 \%$ & $0.7 \%$ & $0.0 \%$ & 145 \\
\hline Central & $20.0 \%$ & $80.0 \%$ & $0.0 \%$ & $0.0 \%$ & $0.0 \%$ & $0.0 \%$ & $0.0 \%$ & $0.0 \%$ & 15 \\
\hline Western & $16.7 \%$ & $83.3 \%$ & $0.0 \%$ & $0.0 \%$ & $0.0 \%$ & $0.0 \%$ & $0.0 \%$ & $0.0 \%$ & 6 \\
\hline Documented & $0.3 \%$ & $96.3 \%$ & $0.0 \%$ & $0.0 \%$ & $0.3 \%$ & $0.6 \%$ & $0.0 \%$ & $2.5 \%$ & 110 \\
\hline All Massachusetts & $\mathbf{8 . 5 \%}$ & $\mathbf{7 6 . 1 \%}$ & $\mathbf{1 0 . 8 \%}$ & $\mathbf{1 . 4 \%}$ & $\mathbf{0 . 0 \%}$ & $\mathbf{2 . 6 \%}$ & $\mathbf{0 . 3 \%}$ & $\mathbf{0 . 3 \%}$ & $\mathbf{6 4 6}$ \\
\hline
\end{tabular}

Once again, the population of documented vessels in Massachusetts differed significantly compared with registered boats when it comes to the type of engine or method of propulsion. Overall, almost $70 \%$ of vessels were powered by outboard engines (Table 23). However, this did not hold true for only documented vessels, which were almost entirely powered by inboard engines. Inboards were very uncommon on registered boats. Once again, the difference between the propulsion systems for documented vessels versus registered boats may well reflect that documented vessels were generally larger and outboard engines are more commonly found on smaller, open boats. Inboard/outboard units (or sterndrives) were the next most common propulsion system for registered boats. 
Table 23: $\quad$ Boat propulsion type by region based on responses to the initial survey.

\begin{tabular}{lrrrrrrrrr}
\hline Region & Inboard & In/Out & Outboard & Electric & Jet Drive & Other & None & NA & n \\
\hline Southeast & $11.5 \%$ & $11.3 \%$ & $74.3 \%$ & $0.4 \%$ & $1.7 \%$ & $0.0 \%$ & $0.8 \%$ & $0.0 \%$ & 230 \\
\hline East Central & $8.0 \%$ & $17.4 \%$ & $70.5 \%$ & $0.7 \%$ & $1.3 \%$ & $0.0 \%$ & $0.7 \%$ & $1.3 \%$ & 140 \\
\hline Northeast & $8.0 \%$ & $9.0 \%$ & $80.2 \%$ & $0.7 \%$ & $1.4 \%$ & $0.0 \%$ & $0.7 \%$ & $0.0 \%$ & 145 \\
\hline Central & $6.7 \%$ & $26.7 \%$ & $66.7 \%$ & $0.0 \%$ & $0.0 \%$ & $0.0 \%$ & $0.0 \%$ & $0.0 \%$ & 15 \\
\hline Western & $0.0 \%$ & $16.7 \%$ & $83.3 \%$ & $0.0 \%$ & $0.0 \%$ & $0.0 \%$ & $0.0 \%$ & $0.0 \%$ & 6 \\
\hline Documented & $94.9 \%$ & $0.0 \%$ & $2.2 \%$ & $0.0 \%$ & $0.0 \%$ & $0.3 \%$ & $0.0 \%$ & $2.5 \%$ & 110 \\
\hline All Massachusetts & $\mathbf{1 8 . 4 \%}$ & $\mathbf{1 1 . 8 \%}$ & $\mathbf{6 6 . 8 \%}$ & $\mathbf{0 . 5 \%}$ & $\mathbf{1 . 2 \%}$ & $\mathbf{0 . 0 \%}$ & $\mathbf{0 . 6 \%}$ & $\mathbf{0 . 6 \%}$ & $\mathbf{6 4 6}$ \\
\hline
\end{tabular}

The difference between documented and registered boats was also apparent in the fuel that they used (Table 24). Over $90 \%$ of registered boats were gas powered compared to only $20.8 \%$ of documented boats. Again, this may reflect the fact that many documented boats are larger vessels with inboard engines and inboard engines on larger vessels are frequently diesel.

Table 24: $\quad$ Boat fuel type by region based on responses to the initial survey.

\begin{tabular}{lccccr}
\hline Region & Gas & Diesel & Other & NA & n \\
\hline Southeast & $90.6 \%$ & $8.2 \%$ & $1.3 \%$ & $0.0 \%$ & 230 \\
\hline East Central & $95.3 \%$ & $2.0 \%$ & $0.7 \%$ & $2.0 \%$ & 140 \\
\hline Northeast & $91.5 \%$ & $5.7 \%$ & $1.4 \%$ & $1.4 \%$ & 145 \\
\hline Central & $93.3 \%$ & $6.7 \%$ & $0.0 \%$ & $0.0 \%$ & 15 \\
\hline Western & $100.0 \%$ & $0.0 \%$ & $0.0 \%$ & $0.0 \%$ & 6 \\
\hline Documented & $20.8 \%$ & $76.7 \%$ & $0.0 \%$ & $2.5 \%$ & 110 \\
\hline All Massachusetts & $\mathbf{8 4 . 7 \%}$ & $\mathbf{1 3 . 2 \%}$ & $\mathbf{0 . 9 \%}$ & $\mathbf{1 . 1 \%}$ & $\mathbf{6 4 6}$ \\
\hline
\end{tabular}

Both berths and moorings appeared to be common in-season storage types for all but Western Massachusetts. Boaters in this region generally stored their boats on a trailer or otherwise on land. This type of storage was also common in Central Massachusetts. This was to be expected, as the majority of boaters would need to trailer their vessels to reach a coastal launch point. Even in the coastal regions, over a third of boats were stored on trailers or on land. A very small percentage of documented vessels were stored in this way and this again is probably a reflection of the fact that they are generally larger boats (Table 25). 
Table 25: $\quad$ Boat in-season storage type by region based on responses to the initial survey.

\begin{tabular}{lcccccr}
\hline Region & Berth & Mooring & Dry Stack & $\begin{array}{r}\text { Trailer/ } \\
\text { Land }\end{array}$ & Other & n \\
\hline Southeast & $25.1 \%$ & $34.1 \%$ & $3.9 \%$ & $34.0 \%$ & $2.8 \%$ & 230 \\
\hline East Central & $30.0 \%$ & $28.0 \%$ & $2.3 \%$ & $34.9 \%$ & $4.8 \%$ & 140 \\
\hline Northeast & $22.4 \%$ & $27.4 \%$ & $3.6 \%$ & $38.2 \%$ & $8.5 \%$ & 145 \\
\hline Central & $20.0 \%$ & $13.3 \%$ & $0.0 \%$ & $66.7 \%$ & $0.0 \%$ & 15 \\
\hline Western & $0.0 \%$ & $0.0 \%$ & $0.0 \%$ & $83.3 \%$ & $16.7 \%$ & 6 \\
\hline Documented & $33.9 \%$ & $63.9 \%$ & $0.0 \%$ & $2.2 \%$ & $0.0 \%$ & 110 \\
\hline All Massachusetts & $\mathbf{2 5 . 9 \%}$ & $\mathbf{3 2 . 6 \%}$ & $\mathbf{2 . 7 \%}$ & $\mathbf{3 4 . 3 \%}$ & $\mathbf{4 . 5 \%}$ & $\mathbf{6 4 6}$ \\
\hline
\end{tabular}

The most common storage facility type for registered boats was a residence. This could include storage such as private berths, moorings, or on a trailer in a boater's driveway. Central and Western regions were again unique in that over $66 \%$ of boats were stored at residences compared to around $45 \%$ for registered boats in other regions (Table 26). Few documented vessels were kept at residences. These vessels were reasonably evenly split between commercial marinas (31.3\%), clubs (26.5\%) and municipal facilities (30.4\%). These three types of facilities were also commonly used for in-season storage by boaters in the three coastal regions.

Table 26: $\quad$ Boat in-season storage facility type by region based on responses to the initial survey.

\begin{tabular}{lrrrrrrr}
\hline Region & $\begin{array}{r}\text { Commercial } \\
\text { Marina }\end{array}$ & Club & $\begin{array}{r}\text { Municipal } \\
\text { Facility }\end{array}$ & Residence & Other & NA & n \\
\hline Southeast & $10.3 \%$ & $12.2 \%$ & $27.4 \%$ & $46.8 \%$ & $3.3 \%$ & $0.0 \%$ & 230 \\
\hline East Central & $15.2 \%$ & $17.5 \%$ & $19.7 \%$ & $43.7 \%$ & $3.2 \%$ & $0.7 \%$ & 140 \\
\hline Northeast & $13.2 \%$ & $19.1 \%$ & $20.4 \%$ & $43.1 \%$ & $3.6 \%$ & $0.7 \%$ & 145 \\
\hline Central & $13.3 \%$ & $6.7 \%$ & $6.7 \%$ & $66.7 \%$ & $6.7 \%$ & $0.0 \%$ & 15 \\
\hline Western & $0.0 \%$ & $16.7 \%$ & $0.0 \%$ & $83.3 \%$ & $0.0 \%$ & $0.0 \%$ & 6 \\
\hline Documented & $31.3 \%$ & $26.5 \%$ & $30.4 \%$ & $5.6 \%$ & $1.4 \%$ & $4.8 \%$ & 110 \\
\hline All Massachusetts & $\mathbf{1 4 . 4 \%}$ & $\mathbf{1 6 . 6 \%}$ & $\mathbf{2 2 . 6 \%}$ & $\mathbf{4 2 . 3 \%}$ & $\mathbf{3 . 2 \%}$ & $\mathbf{0 . 9 \%}$ & $\mathbf{6 4 6}$ \\
\hline
\end{tabular}

Apart from a few documented vessels and a very few boats in the Southeast region, almost no vessels appeared to be stored at berths or on a mooring out of season. By far the most common storage type was on a trailer or otherwise on land. This is to be expected as one need only pass a marina or boatyard to see numerous, shrink wrapped boats up on blocks for the winter. Between $6.3 \%$ and $13.3 \%$ of documented vessels and those from coastal regions were reportedly stored in dry stack facilities (Table 27) 
Table 27: $\quad$ Boat out-of-season storage type by region based on responses to the initial survey.

\begin{tabular}{lccccccr}
\hline Region & Berth & Mooring & Dry Stack & $\begin{array}{r}\text { Trailer/ } \\
\text { Land }\end{array}$ & Other & NA & n \\
\hline Southeast & $0.4 \%$ & $0.7 \%$ & $9.0 \%$ & $79.5 \%$ & $10.4 \%$ & $0.0 \%$ & 230 \\
\hline East Central & $0.0 \%$ & $0.7 \%$ & $6.3 \%$ & $77.0 \%$ & $14.6 \%$ & $1.3 \%$ & 140 \\
\hline Northeast & $0.0 \%$ & $0.0 \%$ & $7.6 \%$ & $76.7 \%$ & $15.6 \%$ & $0.0 \%$ & 145 \\
\hline Central & $0.0 \%$ & $0.0 \%$ & $0.0 \%$ & $100.0 \%$ & $0.0 \%$ & $0.0 \%$ & 15 \\
\hline Western & $0.0 \%$ & $0.0 \%$ & $0.0 \%$ & $100.0 \%$ & $0.0 \%$ & $0.0 \%$ & 6 \\
\hline Documented & $4.8 \%$ & $0.9 \%$ & $13.3 \%$ & $52.1 \%$ & $29.0 \%$ & $0.0 \%$ & 110 \\
\hline All Massachusetts & $\mathbf{0 . 7 \%}$ & $\mathbf{0 . 5 \%}$ & $\mathbf{7 . 9 \%}$ & $\mathbf{7 6 . 5 \%}$ & $\mathbf{1 4 . 1 \%}$ & $\mathbf{0 . 3 \%}$ & $\mathbf{6 4 6}$ \\
\hline
\end{tabular}

The type of out-of-season storage facility was also different for registered and documented boats. Between $\mathbf{7 3 . 5 \%}$ and $\mathbf{1 0 0 \%}$ of registered boats were stored at residences (Table 28 ) but this only true for $19.4 \%$ of documented vessels. Once again, this is probably because such vessels are generally larger and cannot easily be stored at residences. Almost $60 \%$ of documented boats were stored at commercial marinas during the winter.

Table 28: $\quad$ Boat out-of-season storage facility type by region based on responses to the initial survey.

\begin{tabular}{lccccccr}
\hline Region & $\begin{array}{r}\text { Commercial } \\
\text { Marina }\end{array}$ & Club & $\begin{array}{r}\text { Municipal } \\
\text { Facility }\end{array}$ & Residence & Other & NA & n \\
\hline Southeast & $14.0 \%$ & $4.6 \%$ & $1.6 \%$ & $76.5 \%$ & $2.9 \%$ & $0.4 \%$ & 230 \\
\hline East Central & $11.4 \%$ & $2.0 \%$ & $0.7 \%$ & $80.8 \%$ & $5.2 \%$ & $0.0 \%$ & 140 \\
\hline Northeast & $13.1 \%$ & $4.1 \%$ & $0.9 \%$ & $73.5 \%$ & $8.3 \%$ & $0.0 \%$ & 145 \\
\hline Central & $13.3 \%$ & $0.0 \%$ & $0.0 \%$ & $80.0 \%$ & $6.7 \%$ & $0.0 \%$ & 15 \\
\hline Western & $0.0 \%$ & $0.0 \%$ & $0.0 \%$ & $100.0 \%$ & $0.0 \%$ & $0.0 \%$ & 6 \\
\hline Documented & $58.9 \%$ & $9.3 \%$ & $0.6 \%$ & $19.4 \%$ & $11.8 \%$ & $0.0 \%$ & 110 \\
\hline All Massachusetts & $\mathbf{1 7 . 7 \%}$ & $\mathbf{4 . 0 \%}$ & $\mathbf{1 . 0 \%}$ & $\mathbf{7 1 . 3 \%}$ & $\mathbf{5 . 8 \%}$ & $\mathbf{0 . 1 \%}$ & $\mathbf{6 4 6}$ \\
\hline
\end{tabular}

\subsection{Boater Information}

The following information consists of a simple analysis of the information that respondents provided about themselves. This information was then scaled up based on the weighting described previously, so that these numbers represent an estimate for all boat owners in Massachusetts. Again, it is important to note that the number of responses from boaters in the Central and Western regions was low, so results for those regions may not accurately reflect the actual situation.

As is commonly found in other areas of the US, boat owners were predominantly male (Table 29). The maximum percentage of females was $6.7 \%$ in the Southeast region, followed by $4.2 \%$ in the Northeast. 
Table 29: $\quad$ Boater's sex by region based on responses to the initial survey. NA means "no answer".

\begin{tabular}{lcccr}
\hline Region & Male & Female & NA & $\mathbf{n}$ \\
\hline Southeast & $93.3 \%$ & $6.7 \%$ & $0.0 \%$ & 230 \\
\hline East Central & $96.8 \%$ & $2.5 \%$ & $0.7 \%$ & 140 \\
\hline Northeast & $95.1 \%$ & $4.2 \%$ & $0.7 \%$ & 145 \\
\hline Central & $100.0 \%$ & $0.0 \%$ & $0.0 \%$ & 15 \\
\hline Western & $100.0 \%$ & $0.0 \%$ & $0.0 \%$ & 6 \\
\hline Documented & $96.3 \%$ & $3.7 \%$ & $0.0 \%$ & 110 \\
\hline All Massachusetts & $95.4 \%$ & $\mathbf{4 . 3 \%}$ & $\mathbf{0 . 3 \%}$ & $\mathbf{6 4 6}$ \\
\hline
\end{tabular}

The mean age of boaters was 58 years old across the whole of Massachusetts. The lowest mean was in the Western region ( 50.2 years) and the highest mean was 59.8 years for owners of documented boats (Table 30). This is slightly higher than the mean age for boaters in the Southeast region.

Table 30: $\quad$ Mean age of boaters by region based on responses to the initial survey.

\begin{tabular}{lcc}
\hline Region & $\mathbf{n}$ & Mean \\
\hline Southeast & 224 & 59.7 \\
\hline East Central & 139 & 57.5 \\
\hline Northeast & 139 & 56.2 \\
\hline Central & 15 & 55.1 \\
\hline Western & 5 & 50.2 \\
\hline Documented & 109 & 59.8 \\
\hline All Massachusetts & $\mathbf{6 3 1}$ & $\mathbf{5 8 . 0}$ \\
\hline
\end{tabular}

On average, owners of documented boats had operated boats for longer than registered boat owners ( 36 years for documented boat owners and between 26 and 31 years for others). Boaters from Western Massachusetts seemed to have the shortest history of being boat operators (Table 31) but the average for this region was still over two and a half decades. 
Table 31: $\quad$ Mean number of years respondents had been regular boat operators based on responses to the initial survey.

\begin{tabular}{lcc}
\hline Region & $\mathbf{n}$ & Mean \\
\hline Southeast & 229 & 30.3 \\
\hline East Central & 140 & 30.4 \\
\hline Northeast & 144 & 27.7 \\
\hline Central & 15 & 31.0 \\
\hline Western & 5 & 26.0 \\
\hline Documented & 110 & 36.0 \\
\hline All Massachusetts & $\mathbf{6 4 3}$ & $\mathbf{3 0 . 3}$ \\
\hline
\end{tabular}

As would be expected, the mean number of years that boater's had owned a boat was somewhat less than the length of time they had operated one. Across Massachusetts, the mean duration of boat ownership was 5.8 years less than the average length of time people had operated boats. Documented boaters appeared to have owned boats for slightly longer than registered boat owners from different regions of Massachusetts (Table 32). Again, the Western region had the lowest mean duration of boat ownership, but this still spanned over two decades.

Table 32: $\quad$ Mean number of years respondents had owned a boat based on responses to the initial survey.

\begin{tabular}{lcc}
\hline Region & $\mathbf{n}$ & Mean \\
\hline Southeast & 229 & 24.9 \\
\hline East Central & 140 & 24.9 \\
\hline Northeast & 144 & 22.1 \\
\hline Central & 15 & 23.3 \\
\hline Western & 5 & 21.6 \\
\hline Documented & 110 & 28.0 \\
\hline All Massachusetts & $\mathbf{6 4 3}$ & $\mathbf{2 4 . 5}$ \\
\hline
\end{tabular}

Boaters were also asked if they had ever taken a boating safety course (e.g. Boat-Ed through the Massachusetts Environmental Police). Across the state, approximately $53 \%$ of boaters reported that they had taken such a course (Table 33). Owners of documented boats were most likely to have taken such courses (63.4\%). Again, this may reflect the fact that documented vessels are generally larger boats. Well over half of boaters in the East Central and Northeast regions had taken such courses. In the Southeastern region, this number fell to $46.5 \%$ of boaters and fell further to $33.3 \%$ to $40 \%$ in the Western and Central regions. 
Table 33: $\quad$ Percent of boaters who had taken a boating safety course based on responses to the initial survey.

\begin{tabular}{lcccr}
\hline Region & Yes & No & NA & n \\
\hline Southeast & $46.5 \%$ & $49.3 \%$ & $4.2 \%$ & 230 \\
\hline East Central & $57.2 \%$ & $35.8 \%$ & $7.0 \%$ & 140 \\
\hline Northeast & $56.1 \%$ & $37.0 \%$ & $7.0 \%$ & 145 \\
\hline Central & $40.0 \%$ & $60.0 \%$ & $0.0 \%$ & 15 \\
\hline Western & $33.3 \%$ & $50.0 \%$ & $16.7 \%$ & 6 \\
\hline Documented & $63.4 \%$ & $29.0 \%$ & $7.6 \%$ & 110 \\
\hline All Massachusetts & $\mathbf{5 2 . 8 \%}$ & $\mathbf{4 1 . 2 \%}$ & $\mathbf{6 . 0 \%}$ & $\mathbf{6 4 6}$ \\
\hline
\end{tabular}

Similarly, boaters were asked if they had ever taken a navigation course such as those offered by the US Coast Guard Auxiliary, US Power Squadrons or American Sailing Association. While the percentage of all boaters who had taken a navigation course was similar to the percentage who had taken a safety course (53.9\% versus $52.8 \%$ ), significantly more owners of documented vessels had taken navigation courses as opposed to other regions. Almost $81 \%$ of documented boat owners had taken a navigation course (Table 34). The three coastal regions appeared to be similar with $50.3 \%$ to $55.5 \%$ having taken such courses. In Western and Central regions, only a third of boaters reported that they had taken a navigation course. This pattern may be a reflection of the general boat sizes within regions.

Documented vessels are generally larger and may be used for longer journeys that require better navigation skills. Boats that are trailered from Central and Western regions will generally be smaller and possibly only used for shorter, nearshore excursions that may not require advanced navigation skills.

Table 34: $\quad$ Percent of boaters who had taken a navigation course based on responses to the initial survey.

\begin{tabular}{lcccr}
\hline Region & Yes & No & NA & n \\
\hline Southeast & $50.3 \%$ & $48.4 \%$ & $1.3 \%$ & 230 \\
\hline East Central & $55.5 \%$ & $41.8 \%$ & $2.7 \%$ & 140 \\
\hline Northeast & $50.5 \%$ & $47.4 \%$ & $2.1 \%$ & 145 \\
\hline Central & $33.3 \%$ & $66.7 \%$ & $0.0 \%$ & 15 \\
\hline Western & $33.3 \%$ & $50.0 \%$ & $16.7 \%$ & 6 \\
\hline Documented & $80.9 \%$ & $19.1 \%$ & $0.0 \%$ & 110 \\
\hline All Massachusetts & $\mathbf{5 3 . 9 \%}$ & $\mathbf{4 4 . 1 \%}$ & $\mathbf{2 . 0 \%}$ & $\mathbf{6 4 6}$ \\
\hline
\end{tabular}

The survey also asked boaters about their employment status. Almost $59 \%$ of respondents were employed full-time. Western Massachusetts had the lowest percentage in full-time employment but this may be a reflection of the fact that so few boaters from this region responded (Table 35). Overall, 
the percentages ranged from $50 \%$ to a high of $66.7 \%$ for full-time employment. Relatively few boaters reported that they were in part-time employment or were unemployed - $6 \%$ and $4.4 \%$ respectively across the whole state. Just over $30 \%$ of boaters were retired. Again, data from Western Massachusetts may be inaccurate due to low number of responses. In other regions, the percentage of retired boaters ranged from a low of $26.7 \%$ in the Central region, to a high of $34.1 \%$ for the Southeast.

Table 35: $\quad$ Percent of boaters with different employment statuses based on responses to the initial survey.

\begin{tabular}{lrrrrrr}
\hline Region & Full-time & Part-time & Unemployed & Retired & NA & n \\
\hline Southeast & $53.4 \%$ & $9.2 \%$ & $2.9 \%$ & $34.1 \%$ & $0.4 \%$ & 230 \\
\hline East Central & $60.6 \%$ & $4.7 \%$ & $4.0 \%$ & $30.7 \%$ & $0.0 \%$ & 140 \\
\hline Northeast & $62.8 \%$ & $3.5 \%$ & $5.0 \%$ & $27.3 \%$ & $1.4 \%$ & 145 \\
\hline Central & $66.7 \%$ & $0.0 \%$ & $6.7 \%$ & $26.7 \%$ & $0.0 \%$ & 15 \\
\hline Western & $50.0 \%$ & $16.7 \%$ & $16.7 \%$ & $0.0 \%$ & $16.7 \%$ & 6 \\
\hline Documented & $60.0 \%$ & $5.1 \%$ & $4.8 \%$ & $30.2 \%$ & $0.0 \%$ & 110 \\
\hline All Massachusetts & $\mathbf{5 8 . 7 \%}$ & $\mathbf{6 . 0 \%}$ & $\mathbf{4 . 4 \%}$ & $\mathbf{3 0 . 1 \%}$ & $\mathbf{0 . 8 \%}$ & $\mathbf{6 4 6}$ \\
\hline
\end{tabular}

Boaters were also asked to report their estimated household income for 2009. As Table 36 shows, $14.4 \%$ of boaters chose not to provide this information. Overall, $34.3 \%$ of boat owners had a household income of less than $\$ 100,000$ in $2009,26.6 \%$ earned between $\$ 100,000$ and $\$ 150,000,11 \%$ earned between $\$ 150,000$ and $\$ 200,000$, and $13.6 \%$ earned over $\$ 200,000$. This is illustrated in Figure 15. Data for Western and Central Massachusetts are questionable due to low response rates. For the three coastal regions, approximately $33 \%$ to $43 \%$ of boaters earned less than $\$ 100,000$ in 2009 and around $58 \%$ to $66 \%$ earned less than $\$ 150,000$. Information from documented vessel owners suggests that less than $40 \%$ earned less than $\$ 150,000$ in 2009 and only $15 \%$ earned less than $\$ 100,000$. Therefore, the majority of documented vessel owners had an estimated household income of greater than $\$ 150,000$ in 2009. The fact that documented vessel owners seem to have higher incomes is not surprising as many of these vessels are larger than average and likely more costly to buy and maintain. 
Table 36: $\quad$ Percent of boaters with annual household incomes based on responses to the initial survey.

\begin{tabular}{|c|c|c|c|c|c|c|c|c|c|c|c|}
\hline Region & $<25 K$ & $\begin{array}{r}25- \\
49.9 \mathrm{~K} \\
\end{array}$ & $\begin{array}{r}50- \\
74.9 \mathrm{~K} \\
\end{array}$ & $\begin{array}{r}75- \\
99.9 \mathrm{~K} \\
\end{array}$ & $\begin{array}{r}100- \\
124.9 \mathrm{~K} \\
\end{array}$ & $\begin{array}{r}125- \\
149.9 \mathrm{~K} \\
\end{array}$ & $\begin{array}{r}150- \\
174.9 \mathrm{~K}\end{array}$ & $\begin{array}{r}175- \\
199.9 \mathrm{~K}\end{array}$ & $>200 K$ & NA & $\mathbf{n}$ \\
\hline Southeast & $2.4 \%$ & $6.8 \%$ & $11.3 \%$ & $12.1 \%$ & $16.1 \%$ & $9.5 \%$ & $6.6 \%$ & $3.8 \%$ & $14.4 \%$ & $17.1 \%$ & 230 \\
\hline East Central & $0.7 \%$ & $9.0 \%$ & $18.2 \%$ & $16.1 \%$ & $14.2 \%$ & $9.0 \%$ & $4.0 \%$ & $4.0 \%$ & $13.0 \%$ & $11.9 \%$ & 140 \\
\hline Northeast & $1.4 \%$ & $7.0 \%$ & $16.0 \%$ & $9.0 \%$ & $20.9 \%$ & $11.2 \%$ & $6.5 \%$ & $3.5 \%$ & $15.5 \%$ & $9.1 \%$ & 145 \\
\hline Central & $6.7 \%$ & $13.3 \%$ & $6.7 \%$ & $26.7 \%$ & $20.0 \%$ & $0.0 \%$ & $6.7 \%$ & $0.0 \%$ & $6.7 \%$ & $13.3 \%$ & 15 \\
\hline Western & $0.0 \%$ & $0.0 \%$ & $0.0 \%$ & $16.7 \%$ & $50.0 \%$ & $0.0 \%$ & $0.0 \%$ & $16.7 \%$ & $0.0 \%$ & $16.7 \%$ & 6 \\
\hline Documented & $0.0 \%$ & $2.8 \%$ & $10.1 \%$ & $1.7 \%$ & $18.3 \%$ & $5.9 \%$ & $17.2 \%$ & $6.2 \%$ & $14.1 \%$ & $23.6 \%$ & 110 \\
\hline All Massachusetts & $1.6 \%$ & $7.1 \%$ & $13.6 \%$ & $12.0 \%$ & $17.9 \%$ & $8.8 \%$ & $6.9 \%$ & $4.1 \%$ & $13.6 \%$ & $14.4 \%$ & 646 \\
\hline
\end{tabular}

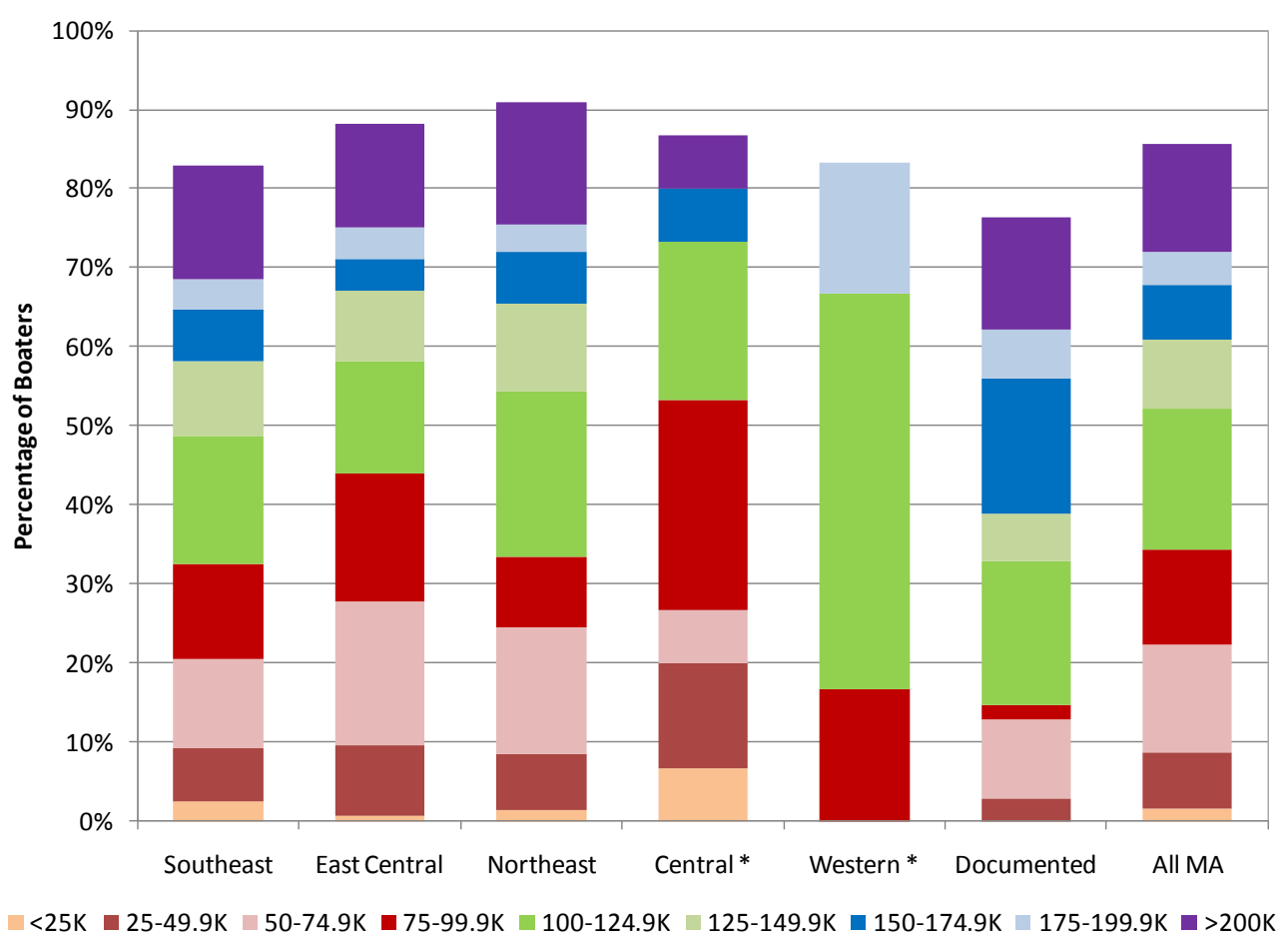

Figure 15: $\quad$ Percent of boaters with specified annual household incomes based on responses to the initial survey. ${ }^{*}=$ low response numbers.

\subsection{Boating-related Activity}

The following section contains some initial analysis of the boat-related activity on which participants were asked to report each month. The economic analysis related to this information can be found later in the document.

As previously stated, this study was interested in both visits to the boat (without an on-water trip), and visits to the boat that include an on-water trip. This section differentiates between boat owners just 
visiting their vessels versus visits that include a trip out onto the water. The monthly surveys asked boaters on how many different days they had visited their boat, if they had taken the boat out on the water at all and, if so, on how many different days that had been out on the water.

During the boating season, a number of owners did not visit their boat at all in some months. In May and October over $30 \%$ of boaters reported that they had not visited their boat (Table 37). In June and September between $23.2 \%$ and $29.3 \%$ of boaters reported that this was the case. The lowest visitation rate was in October (37\%). However, it is important to remember that they were reporting on visits to a specific boat that was selected during the sampling. This may not have been their primary boat, so while they may not have visited that specific vessel, they may have visited and used another vessel that they owned.

Table 37: Percentage of boaters who did or did not visit their boat based on responses to the monthly surveys.

\begin{tabular}{lrr}
\hline By Month & No Visit & Visit \\
\hline May & $32.1 \%$ & $67.9 \%$ \\
\hline June & $23.2 \%$ & $76.8 \%$ \\
\hline July & $14.2 \%$ & $85.8 \%$ \\
\hline August & $15.2 \%$ & $84.8 \%$ \\
\hline September & $29.3 \%$ & $70.7 \%$ \\
\hline October & $37.0 \%$ & $63.0 \%$ \\
\hline
\end{tabular}

Table 38 shows during July and August on over $90 \%$ of the days when owners visited their boats, they also took some sort of on-water trip. In May, boaters reported that on over a quarter of the days that they visited their boat; they did not go out on the water. Furthermore, it appears that around $15 \%$ of boaters in the three coastal regions visited their boats but did not take them out on the water at all during the 2010 boating season. As discussed later, 2010 use patterns may have been affected by the state of the economy.

It is also important to note that during the end of August 2010 and into early September, Massachusetts was preparing for the potential impact of Hurricane Earl, which was moving up the eastern seaboard. Due to this threat, many boats were pulled from the water just prior to the Labor Day weekend, which often represents the end of the boating season in Massachusetts for many boaters. It is unclear whether the threat of Hurricane Earl prematurely ended the boating season for those boaters who had had their vessels pulled and who did not want to pay for them to be refloated so late in the season.

On average, boaters who took their boat on the water did so on 7.5 and 7.8 days respectively in July and August (Table 39). As expected, this number was lowest at the beginning and end of the season. The average number of days per month that boaters went out on the water was 6.0. Documented boat owners appeared to go out on the water more often than other boaters. 
Table 38: $\quad$ Percentage of boaters who did or did not take a trip out on the water based on responses to the monthly surveys.

\begin{tabular}{lcrr}
\hline By Month & Visit & On -water trip & n \\
\hline May & $26.3 \%$ & $73.7 \%$ & 374 \\
\hline June & $12.6 \%$ & $87.4 \%$ & 438 \\
\hline July & $5.3 \%$ & $94.7 \%$ & 536 \\
\hline August & $7.0 \%$ & $93.0 \%$ & 427 \\
\hline September & $14.1 \%$ & $85.9 \%$ & 290 \\
\hline October & $38.0 \%$ & $62.0 \%$ & 233 \\
\hline All & $\mathbf{1 6 . 0 \%}$ & $\mathbf{8 3 . 9 \%}$ & $\mathbf{2 , 2 9 8}$ \\
\hline
\end{tabular}

\begin{tabular}{lrrr}
\hline By Region & Visit & On -water trip & $\mathbf{n}$ \\
\hline Southeast & $15.7 \%$ & $84.3 \%$ & 803 \\
\hline East Central & $14.7 \%$ & $85.3 \%$ & 497 \\
\hline Northeast & $14.4 \%$ & $85.6 \%$ & 469 \\
\hline Central & $22.0 \%$ & $78.0 \%$ & 45 \\
\hline Western & $33.9 \%$ & $66.1 \%$ & 29 \\
\hline Documented & $17.3 \%$ & $82.7 \%$ & 455 \\
\hline
\end{tabular}

Table 39: $\quad$ Mean number of days that boaters took their vessel out on the water based on responses to the monthly surveys.

\begin{tabular}{lcr}
\hline By Month & $\mathbf{n}$ & Mean \\
\hline May & 276 & 4.2 \\
\hline June & 376 & 5.6 \\
\hline July & 505 & 7.5 \\
\hline August & 397 & 7.8 \\
\hline September & 245 & 5.0 \\
\hline October & 154 & 3.9 \\
\hline All & 1,953 & 6.0 \\
\hline
\end{tabular}

\begin{tabular}{lcc}
\hline By Region & $\mathbf{n}$ & Mean \\
\hline Southeast & 676 & 5.5 \\
\hline East Central & 430 & 6.2 \\
\hline Northeast & 402 & 5.9 \\
\hline Central & 36 & 4.6 \\
\hline Western & 21 & 5.3 \\
\hline Documented & 388 & 7.6 \\
\hline
\end{tabular}

Participants were then asked a series of questions based on activities associated with when they last went out on the water on their boat during the previous month. Boaters were asked how many people were on board (including themselves) on that specific trip on the water. Boats of 40 or more feet in length averaged between 3.2 and 3.6 people (Table 40). All documented vessels averaged over three people on boat for the reported trips, with one boater reporting 55 people on board. This was thought to be an erroneous figure but further research revealed that the vessel in question was substantial in size and the number was deemed to be possible.

Vessels between 10 and 40 feet in length averaged 2.6 to 2.8 people on board with a maximum number of 12. The smallest size class (less than $10 \mathrm{feet}$ ) averaged 1.7 to 2.0 people on the reported trip. The maximum number of people on board was four. While this may seem somewhat high for a small boat, many boats this size are used as tenders or dinghies to access large boats and are therefore used in sheltered areas for very short trips to and from a larger boat.

One factor of interest in this study was how many boats were trailered to a launch site rather than being kept at or on the water. Part of the reason why this is of interest is that boaters who trailer their boats 
differ significantly from those who keep theirs at a mooring or slip. Those who trailer their boats have greater flexibility as to what body of water they want to visit as they are able to use boat ramps in numerous locations. However, they are also dependent on there being a suitable boat ramp in the area and sufficient support infrastructure to facilitate their trip (e.g. sufficient vehicle and trailer parking).

Table 40: $\quad$ Mean and maximum number of people on board during the reported trip based on responses to the monthly surveys.

\begin{tabular}{|c|c|c|c|c|}
\hline Region & Size Class & $\mathbf{n}$ & Mean & Max \\
\hline \multirow[t]{3}{*}{ Southeast } & $<10$ & 43 & 1.7 & 4 \\
\hline & 10 to $<40$ & 618 & 2.6 & 8 \\
\hline & $40+$ & 5 & 3.2 & 6 \\
\hline \multirow[t]{3}{*}{ East Central } & $<10$ & 33 & 2.0 & 4 \\
\hline & 10 to $<40$ & 387 & 2.8 & 10 \\
\hline & $40+$ & NO DATA & & \\
\hline \multirow[t]{3}{*}{ Northeast } & $<10$ & 39 & 1.7 & 4 \\
\hline & 10 to $<40$ & 350 & 2.6 & 12 \\
\hline & $40+$ & 5 & 3.5 & 4 \\
\hline Central & All & 36 & 3.1 & 7 \\
\hline Western & All & 21 & 2.9 & 6 \\
\hline \multirow[t]{2}{*}{ Documented } & $<40$ & 98 & 3.2 & 8 \\
\hline & $40+$ & 288 & 3.6 & 55 \\
\hline All Massachusetts & & 1,923 & 2.7 & \\
\hline
\end{tabular}

Additionally, there are vessel size limitations associated with trailering. In general, it is not practical or cost effective to trailer large boats to and from launch sites on a regular basis. Large vessels are often pulled at the end of the boating season to be stored at sites away from the water during the winter. However, this often requires the use of hydraulic trailers that are generally too expensive to be individually owned. Also, many boat ramps are not designed to handle boats over a certain size. There are also significant expenses involved with trailering a boat both in terms of fuel costs associated with towing a vessel, and the launch fees and trailer parking fees. Because of this, trailering is generally associated with smaller vessels and a potentially more mobile type of boater.

Table 41 summarizes the information about boaters who trailered their vessel by month and by region. Across Massachusetts, $28.3 \%$ of reported trips involved trailering a boat. There was little variation by month with September being the lowest at $25.3 \%$, and June being the highest at $30.4 \%$.

There appear to be differences in boat trailering between regions in Massachusetts and documented boats. Documented vessels are generally large and are clearly not trailered for boat trips. As the 
Central and Western regions are further from coastal waters, it would be expected that more vessels would be trailered from these areas as compared to coastal regions. This was supported by the results: $59.6 \%$ of trips by Central region boaters and $71.7 \%$ of trips by Western region boaters involved trailering, compared to between $28 \%$ and $31.9 \%$ of boaters from the three coastal regions.

Table 41: $\quad$ Percentage of boaters who trailered their boat to a launch location during the reported trip based on responses to the monthly surveys.

\begin{tabular}{lrrr}
\hline By Month & No Trailer & Trailer & n \\
\hline May & $70.2 \%$ & $29.8 \%$ & 279 \\
\hline June & $69.6 \%$ & $30.4 \%$ & 380 \\
\hline July & $72.8 \%$ & $27.2 \%$ & 507 \\
\hline August & $71.5 \%$ & $28.5 \%$ & 399 \\
\hline September & $74.7 \%$ & $25.3 \%$ & 247 \\
\hline October & $71.1 \%$ & $28.9 \%$ & 155 \\
\hline All & $\mathbf{7 1 . 7 \%}$ & $\mathbf{2 8 . 3 \%}$ & $\mathbf{1 , 9 6 7}$ \\
\hline
\end{tabular}

\begin{tabular}{lrrr}
\hline By Region & No Trailer & Trailer & $\mathbf{n}$ \\
\hline Southeast & $72.0 \%$ & $28.0 \%$ & 683 \\
\hline East Central & $69.0 \%$ & $31.0 \%$ & 433 \\
\hline Northeast & $68.1 \%$ & $31.9 \%$ & 406 \\
\hline Central & $40.4 \%$ & $59.6 \%$ & 36 \\
\hline Western & $28.3 \%$ & $71.7 \%$ & 21 \\
\hline Documented & $100.0 \%$ & $0.0 \%$ & 388 \\
\hline
\end{tabular}

The boaters were then asked the type of location from which the boat was trailered. The vast majority of trailered trips originated at the boater's permanent home (79.9\%) with a further $10.8 \%$ starting at a second home (Table 42). Trailering from marinas or dry stack facilities, friends' or relatives' houses or other types of facilities each accounted for a small percentage of departure locations.

Table 42: $\quad$ Percentage of boaters who trailered their boats from different location types during the reported trip based on responses to the monthly surveys.

\begin{tabular}{lrrrrrrrr}
\hline By Region & $\begin{array}{r}\text { Premanent } \\
\text { home }\end{array}$ & $\begin{array}{r}\text { Second } \\
\text { home }\end{array}$ & $\begin{array}{r}\text { Marina / } \\
\text { Dry Stack }\end{array}$ & $\begin{array}{r}\text { General } \\
\text { commercial } \\
\text { storage }\end{array}$ & $\begin{array}{r}\text { Friend's / } \\
\text { relative's } \\
\text { house }\end{array}$ & Other & NA & n \\
\hline Southeast & $73.6 \%$ & $17.2 \%$ & $3.4 \%$ & $0.0 \%$ & $2.3 \%$ & $3.4 \%$ & $0.0 \%$ & 195 \\
\hline East Central & $82.1 \%$ & $11.4 \%$ & $2.5 \%$ & $0.6 \%$ & $2.2 \%$ & $1.1 \%$ & $0.0 \%$ & 141 \\
\hline Northeast & $79.0 \%$ & $7.4 \%$ & $4.5 \%$ & $0.7 \%$ & $4.3 \%$ & $2.7 \%$ & $1.4 \%$ & 131 \\
\hline Central & $90.2 \%$ & $0.0 \%$ & $0.0 \%$ & $0.0 \%$ & $0.0 \%$ & $9.8 \%$ & $0.0 \%$ & 22 \\
\hline Western & $100.0 \%$ & $0.0 \%$ & $0.0 \%$ & $0.0 \%$ & $0.0 \%$ & $0.0 \%$ & $0.0 \%$ & 15 \\
\hline Documented & $0.0 \%$ & $0.0 \%$ & $0.0 \%$ & $0.0 \%$ & $0.0 \%$ & $0.0 \%$ & $0.0 \%$ & 0 \\
\hline All Massachusetts & $79.9 \%$ & $10.8 \%$ & $3.1 \%$ & $0.4 \%$ & $2.6 \%$ & $2.9 \%$ & $0.4 \%$ & 504 \\
\hline
\end{tabular}

An important factor associated with trailering a boat is the fees associated with launching. These may be in the form of launch fees or fees associated with parking a vehicle and trailer at a launch facility. Across the state, $37.5 \%$ of boaters reported that there were such fees associated with trailering and 
launching their boat (Table 43). Not surprisingly, there was little variation throughout the season. However, only between $30.5 \%$ and $38.8 \%$ of boaters from coastal regions reported paying fees as compared with $46.7 \%$ to $64.7 \%$ of boaters from Western and Central regions respectively.

Table 43: $\quad$ Percentage of boaters who paid a launch fee or a parking fee at a launch site during the reported trip based on responses to the monthly surveys.

\begin{tabular}{lrrr}
\hline By Month & Fee No & Fee Yes & n \\
\hline May & $68.0 \%$ & $32.0 \%$ & 73 \\
\hline June & $65.0 \%$ & $35.0 \%$ & 105 \\
\hline July & $60.6 \%$ & $39.4 \%$ & 126 \\
\hline August & $60.1 \%$ & $39.9 \%$ & 104 \\
\hline September & $54.8 \%$ & $45.2 \%$ & 57 \\
\hline October & $70.0 \%$ & $30.0 \%$ & 38 \\
\hline All & $\mathbf{6 2 . 5 \%}$ & $\mathbf{3 7 . 5 \%}$ & $\mathbf{5 0 3}$ \\
\hline
\end{tabular}

\begin{tabular}{lrrr}
\hline By Region & Fee No & Fee Yes & $\mathbf{n}$ \\
\hline Southeast & $69.5 \%$ & $30.5 \%$ & 195 \\
\hline East Central & $61.2 \%$ & $38.8 \%$ & 141 \\
\hline Northeast & $64.6 \%$ & $35.4 \%$ & 130 \\
\hline Central & $35.3 \%$ & $64.7 \%$ & 22 \\
\hline Western & $53.3 \%$ & $46.7 \%$ & 15 \\
\hline Documented & $0.0 \%$ & $0.0 \%$ & 0 \\
\hline
\end{tabular}

Those boaters who had paid fees associated with launching a trailered boat were asked to specify the amounts paid. The mean cost was $\$ 13.94$ per trip, with coastal regions ranging between $\$ 13.24$ and $\$ 17.27$ (Table 44). The average amount paid by boaters from Western Massachusetts was $\$ 11.87$, and boaters from Central Massachusetts averaged $\$ 8.55$. The maximum of $\$ 120$ in the East Central region was initially flagged as suspect but several other boaters from that region reported fees associated with launching a trailered boat of $\$ 85$. It was therefore retained for the analysis.

An important factor associated with boating activity is the distance traveled to the water, as there are real costs associated with this. Participants were asked to report the number of miles that they drove or otherwise travelled to reach the place where they launched or boarded their vessel. Not surprisingly, the coastal regions reported the lowest numbers, with a mean of 14.9 miles for the East Central region, 14.2 miles for the Northeast region and only 9.1 miles for the Southeast region (Table 45). The lower number for the Southeastern region may reflect the fact that much of this region consists of Cape Cod and the Island and therefore physical proximity to the water is reduced. Boaters from Central and Western regions reported an average of 31.2 and 54.5 miles respectively, and documented boaters averaged 37.4 miles. While the maximum numbers of miles traveled may seem high, it is important to remember that the maximum represents an extreme and the documented vessel owner who reported a 900-mile trip may have been going to down south to pick up his vessel and bring it back to New England for the summer. 
Table 44: $\quad$ Mean amount that boats paid as a launch fee or a parking fee at a launch site during the reported trip based on responses to the monthly surveys.

\begin{tabular}{|c|c|c|c|c|}
\hline Region & Size Class & $\mathbf{n}$ & Mean & Max \\
\hline \multirow[t]{3}{*}{ Southeast } & $<10$ & NO DATA & & \\
\hline & 10 to $<40$ & 61 & $\$ 13.24$ & $\$ 60.00$ \\
\hline & $40+$ & NO DATA & & \\
\hline \multirow[t]{3}{*}{ East Central } & $<10$ & NO DATA & & \\
\hline & 10 to $<40$ & 52 & $\$ 17.27$ & $\$ 120.00$ \\
\hline & $40+$ & NO DATA & & \\
\hline \multirow[t]{3}{*}{ Northeast } & $<10$ & NO DATA & & \\
\hline & 10 to $<40$ & 41 & $\$ 14.32$ & $\$ 75.00$ \\
\hline & $40+$ & NO DATA & & \\
\hline Central & All & 14 & $\$ 8.55$ & $\$ 20.00$ \\
\hline Western & All & 7 & $\$ 11.87$ & $\$ 20.00$ \\
\hline \multirow[t]{2}{*}{ Documented } & $<40$ & NO DATA & & \\
\hline & $40+$ & NO DATA & & \\
\hline All Massachusetts & & 175 & $\$ 13.94$ & \\
\hline
\end{tabular}

Table 45: $\quad$ Mean number of miles traveled to reach the site where boaters launched or boarded their vessel during the reported trip based on responses to the monthly surveys.

\begin{tabular}{lccc}
\hline By Region & $\mathbf{n}$ & Mean & Max \\
\hline Southeast & 673 & 9.1 & 163 \\
\hline East Central & 424 & 14.9 & 380 \\
\hline Northeast & 398 & 14.2 & 400 \\
\hline Central & 36 & 31.2 & 250 \\
\hline Western & 21 & 54.5 & 300 \\
\hline Documented & 378 & 37.4 & 900 \\
\hline All & 1,930 & 16.8 & \\
\hline
\end{tabular}

Boaters were asked to identify what activities they were engaged in during their last boating trip. It is important to note that they were asked to check "all that apply" rather than being limited to a primary activity and that the percentages are based on those who said "yes", "no" or "no answer" (i.e. "no answer" was not assumed to be "no").

Table 46 is conditionally-shaded (red to green = high to low) to compare the relative percentages of "yes" answers to all others. Overall activity engagement is ranked from general cruising (67.4\%), 
entertaining friends and family (47.6\%), fishing (38.1\%), sightseeing (36\%), swimming $(25.2 \%)$, and sailing (19.3\%).

Table 47 illustrates the same information but conditionally-shaded to highlight seasonal variations within each activity type (red to green = high to low). General water-based activities such as cruising, general on-board entertaining, and sightseeing appeared to be most popular during the peak season months of July and August. Those activities that involved direct contact with the water (i.e. scuba diving, snorkeling, swimming, waterskiing and wakeboarding) were clearly seasonal and were most popular during the warmest months of July and August. Fishing, one of the more popular activities, varied little over the season (answer of "yes" by boaters ranged from $37.2 \%$ to $40.1 \%$ ) but appeared to be slightly more popular earlier in the season. Hunting, while clearly not a common activity, seemed to be much more common at the end of the season (jumping to $2.5 \%$ of activity from $0.7 \%$ or less in other months) which probably reflects the fact that the hunting season for ducks starts in early October. Whale watching seemed to be popular in May (3.4\%) and peaks in July and August at 3.7\% and 5.5\% respectively. Bird watching did not vary much over the season but seemed to gradually increase from $10.1 \%$ in May to $13.2 \%$ in September and October. This late season interest may be tied to fall migrations.

The survey also asked boaters to estimate how much of their spending had occurred "near" to the site that they launched or boarded their boat. As discussed earlier, there are many ways in which this question could have been asked and all have pros and cons. However, what was clear was that most spending occurred local to where boaters launched or boarded their vessels (Figure 16). This is important economically as it could represent a significant boost to the local economy if boaters are travelling to an area to launch or board their vessel and most of their expenditure occurs near to that location. 
Table 46: $\quad$ Percentage of boaters who engaged in specific activities during their monthly reported trip. Shading is based on overall relative responses (high percentage $=$ red, low percentage $=$ green).

\begin{tabular}{|c|c|c|c|c|c|c|c|c|c|c|c|c|}
\hline \multirow{2}{*}{ Month } & \multicolumn{3}{|c|}{ CRUISING } & \multicolumn{3}{|c|}{ ENTERTAINING } & \multicolumn{3}{|c|}{ FISHING/SHELLFISHING } & \multicolumn{3}{|c|}{ HUNTING } \\
\hline & Yes & No & NA & Yes & No & NA & Yes & No & NA & Yes & No & NA \\
\hline May & $65.1 \%$ & $19.4 \%$ & $15.6 \%$ & $40.0 \%$ & $32.7 \%$ & $27.3 \%$ & $40.1 \%$ & $38.6 \%$ & $21.3 \%$ & $0.0 \%$ & $57.7 \%$ & $42.3 \%$ \\
\hline June & $67.8 \%$ & $16.0 \%$ & $16.2 \%$ & $52.2 \%$ & $20.0 \%$ & $27.8 \%$ & $39.9 \%$ & $32.5 \%$ & $27.6 \%$ & $0.0 \%$ & $49.9 \%$ & $50.1 \%$ \\
\hline July & $71.6 \%$ & $13.7 \%$ & $14.7 \%$ & $57.0 \%$ & $20.1 \%$ & $22.9 \%$ & $37.2 \%$ & $32.7 \%$ & $30.1 \%$ & $0.2 \%$ & $49.8 \%$ & $50.0 \%$ \\
\hline August & $75.2 \%$ & $10.6 \%$ & $14.2 \%$ & $54.3 \%$ & $17.4 \%$ & $28.3 \%$ & $39.0 \%$ & $31.5 \%$ & $29.5 \%$ & $0.7 \%$ & $47.2 \%$ & $52.1 \%$ \\
\hline September & $60.3 \%$ & $18.8 \%$ & $20.9 \%$ & $37.4 \%$ & $27.7 \%$ & $34.9 \%$ & $34.0 \%$ & $37.2 \%$ & $28.8 \%$ & $0.4 \%$ & $48.0 \%$ & $51.7 \%$ \\
\hline October & $55.0 \%$ & $22.8 \%$ & $22.2 \%$ & $32.7 \%$ & $36.8 \%$ & $30.5 \%$ & $38.9 \%$ & $36.7 \%$ & $24.4 \%$ & $2.5 \%$ & $50.7 \%$ & $46.9 \%$ \\
\hline All & $67.4 \%$ & $15.9 \%$ & $16.7 \%$ & $47.6 \%$ & $24.1 \%$ & $28.2 \%$ & $38.1 \%$ & $34.3 \%$ & $27.5 \%$ & $0.5 \%$ & $50.1 \%$ & $49.4 \%$ \\
\hline \multirow{2}{*}{ Month } & \multicolumn{3}{|c|}{ WHALE WATCHING } & \multicolumn{3}{|c|}{ BIRD WATCHING } & \multicolumn{3}{|c|}{ RACING } & \multicolumn{3}{|c|}{ SAILING } \\
\hline & Yes & No & NA & Yes & No & NA & Yes & No & NA & Yes & No & NA \\
\hline May & $3.4 \%$ & $55.6 \%$ & $41.0 \%$ & $10.1 \%$ & $52.0 \%$ & $37.9 \%$ & $0.2 \%$ & $57.5 \%$ & $42.3 \%$ & $14.6 \%$ & $48.7 \%$ & $36.8 \%$ \\
\hline June & $1.8 \%$ & $48.9 \%$ & $49.3 \%$ & $11.5 \%$ & $40.9 \%$ & $47.7 \%$ & $1.7 \%$ & $49.0 \%$ & $49.3 \%$ & $21.0 \%$ & $36.7 \%$ & $42.3 \%$ \\
\hline July & $3.7 \%$ & $48.8 \%$ & $47.6 \%$ & $12.8 \%$ & $40.4 \%$ & $46.8 \%$ & $1.6 \%$ & $49.0 \%$ & $49.4 \%$ & $20.2 \%$ & $38.1 \%$ & $41.7 \%$ \\
\hline August & $5.5 \%$ & $43.9 \%$ & $50.6 \%$ & $12.0 \%$ & $38.0 \%$ & $50.0 \%$ & $1.2 \%$ & $47.1 \%$ & $51.6 \%$ & $18.4 \%$ & $36.8 \%$ & $44.8 \%$ \\
\hline September & $2.2 \%$ & $46.4 \%$ & $51.4 \%$ & $13.2 \%$ & $40.6 \%$ & $46.1 \%$ & $1.9 \%$ & $46.2 \%$ & $51.9 \%$ & $21.7 \%$ & $35.3 \%$ & $43.0 \%$ \\
\hline October & $0.9 \%$ & $50.7 \%$ & $48.4 \%$ & $13.2 \%$ & $43.2 \%$ & $43.6 \%$ & $0.0 \%$ & $50.9 \%$ & $49.1 \%$ & $19.3 \%$ & $37.6 \%$ & $43.1 \%$ \\
\hline All & $3.2 \%$ & $48.5 \%$ & $48.3 \%$ & $12.1 \%$ & $41.9 \%$ & $46.0 \%$ & $1.2 \%$ & $49.5 \%$ & $49.3 \%$ & $19.4 \%$ & $38.5 \%$ & $42.2 \%$ \\
\hline \multirow{2}{*}{ Month } & \multicolumn{3}{|c|}{ SCUBA / SNORKELLING } & \multicolumn{3}{|c|}{ SIGHTSEEING } & \multicolumn{3}{|c|}{ SWIMMING } & \multicolumn{3}{|c|}{ WATERSKIING } \\
\hline & Yes & No & NA & Yes & No & NA & Yes & No & NA & Yes & No & NA \\
\hline May & $2.4 \%$ & $56.0 \%$ & $41.5 \%$ & $29.6 \%$ & $39.3 \%$ & $31.1 \%$ & $8.1 \%$ & $52.5 \%$ & $39.4 \%$ & $1.9 \%$ & $56.2 \%$ & $41.9 \%$ \\
\hline June & $2.9 \%$ & $47.0 \%$ & $50.1 \%$ & $33.5 \%$ & $29.0 \%$ & $37.5 \%$ & $28.7 \%$ & $34.0 \%$ & $37.3 \%$ & $2.9 \%$ & $48.2 \%$ & $49.0 \%$ \\
\hline July & $5.3 \%$ & $47.0 \%$ & $47.7 \%$ & $39.4 \%$ & $26.0 \%$ & $34.6 \%$ & $39.3 \%$ & $29.9 \%$ & $30.8 \%$ & $4.8 \%$ & $48.1 \%$ & $47.1 \%$ \\
\hline August & $4.8 \%$ & $43.9 \%$ & $51.3 \%$ & $45.8 \%$ & $20.7 \%$ & $33.6 \%$ & $37.7 \%$ & $27.9 \%$ & $34.5 \%$ & $5.2 \%$ & $44.6 \%$ & $50.2 \%$ \\
\hline September & $1.1 \%$ & $47.4 \%$ & $51.5 \%$ & $30.1 \%$ & $32.0 \%$ & $37.9 \%$ & $13.3 \%$ & $40.1 \%$ & $46.6 \%$ & $0.7 \%$ & $48.0 \%$ & $51.4 \%$ \\
\hline October & $1.5 \%$ & $51.4 \%$ & $47.1 \%$ & $31.1 \%$ & $35.8 \%$ & $33.1 \%$ & $4.9 \%$ & $48.7 \%$ & $46.4 \%$ & $1.2 \%$ & $51.5 \%$ & $47.3 \%$ \\
\hline All & $3.3 \%$ & $48.1 \%$ & $48.6 \%$ & $36.0 \%$ & $29.2 \%$ & $34.8 \%$ & $25.2 \%$ & $36.8 \%$ & $38.0 \%$ & $3.1 \%$ & $48.8 \%$ & $48.1 \%$ \\
\hline
\end{tabular}

\begin{tabular}{|c|c|c|c|c|}
\hline \multirow{2}{*}{ Month } & \multicolumn{3}{|c|}{ OTHER } & \multirow{2}{*}{$n$} \\
\hline & Yes & No & NA & \\
\hline May & $94.6 \%$ & $5.4 \%$ & $0.0 \%$ & 279 \\
\hline June & $94.6 \%$ & $4.7 \%$ & $0.8 \%$ & 381 \\
\hline July & $95.6 \%$ & $4.2 \%$ & $0.2 \%$ & 507 \\
\hline August & $95.1 \%$ & $4.9 \%$ & $0.0 \%$ & 399 \\
\hline September & $91.9 \%$ & $8.1 \%$ & $0.0 \%$ & 247 \\
\hline October & $81.4 \%$ & $18.6 \%$ & $0.0 \%$ & 155 \\
\hline All & $93.1 \%$ & $6.7 \%$ & $0.2 \%$ & 1,968 \\
\hline
\end{tabular}


Table 47: $\quad$ Percentage of boaters who engaged in specific activities during the monthly reported trip. The percentages are conditionally-shaded to highlight seasonal variations within each activity type (high percentage $=$ red, low percentage $=$ green $)$.

\begin{tabular}{|c|c|c|c|c|c|c|c|c|c|c|c|c|}
\hline \multirow{2}{*}{ Month } & \multicolumn{3}{|c|}{ CRUISING } & \multicolumn{3}{|c|}{ ENTERTAINING } & \multicolumn{3}{|c|}{ FISHING/SHELLFISHING } & \multicolumn{3}{|c|}{ HUNTING } \\
\hline & Yes & No & NA & Yes & No & NA & Yes & No & NA & Yes & No & NA \\
\hline May & $65.1 \%$ & $19.4 \%$ & $15.6 \%$ & $40.0 \%$ & $32.7 \%$ & $27.3 \%$ & $40.1 \%$ & $38.6 \%$ & $21.3 \%$ & $0.0 \%$ & $57.7 \%$ & $42.3 \%$ \\
\hline June & $67.8 \%$ & $16.0 \%$ & $16.2 \%$ & $52.2 \%$ & $20.0 \%$ & $27.8 \%$ & $39.9 \%$ & $32.5 \%$ & $27.6 \%$ & $0.0 \%$ & $49.9 \%$ & $50.1 \%$ \\
\hline July & $71.6 \%$ & $13.7 \%$ & $14.7 \%$ & $57.0 \%$ & $20.1 \%$ & $22.9 \%$ & $37.2 \%$ & $32.7 \%$ & $30.1 \%$ & $0.2 \%$ & $49.8 \%$ & $50.0 \%$ \\
\hline August & $75.2 \%$ & $10.6 \%$ & $14.2 \%$ & $54.3 \%$ & $17.4 \%$ & $28.3 \%$ & $39.0 \%$ & $31.5 \%$ & $29.5 \%$ & $0.7 \%$ & $47.2 \%$ & $52.1 \%$ \\
\hline September & $60.3 \%$ & $18.8 \%$ & $20.9 \%$ & $37.4 \%$ & $27.7 \%$ & $34.9 \%$ & $34.0 \%$ & $37.2 \%$ & $28.8 \%$ & $0.4 \%$ & $48.0 \%$ & $51.7 \%$ \\
\hline October & $55.0 \%$ & $22.8 \%$ & $22.2 \%$ & $32.7 \%$ & $36.8 \%$ & $30.5 \%$ & $38.9 \%$ & $36.7 \%$ & $24.4 \%$ & $2.5 \%$ & $50.7 \%$ & $46.9 \%$ \\
\hline All & $67.4 \%$ & $15.9 \%$ & $16.7 \%$ & $47.6 \%$ & $24.1 \%$ & $28.2 \%$ & $38.1 \%$ & $34.3 \%$ & $27.5 \%$ & $0.5 \%$ & $50.1 \%$ & $49.4 \%$ \\
\hline \multirow{2}{*}{ Month } & \multicolumn{3}{|c|}{ WHALE WATCHING } & \multicolumn{3}{|c|}{ BIRD WATCHING } & \multicolumn{3}{|c|}{ RACING } & \multicolumn{3}{|c|}{ SAILING } \\
\hline & Yes & No & NA & Yes & No & NA & Yes & No & NA & Yes & No & NA \\
\hline May & $3.4 \%$ & $55.6 \%$ & $41.0 \%$ & $10.1 \%$ & $52.0 \%$ & $37.9 \%$ & $0.2 \%$ & $57.5 \%$ & $42.3 \%$ & $14.6 \%$ & $48.7 \%$ & $36.8 \%$ \\
\hline June & $1.8 \%$ & $48.9 \%$ & $49.3 \%$ & $11.5 \%$ & $40.9 \%$ & $47.7 \%$ & $1.7 \%$ & $49.0 \%$ & $49.3 \%$ & $21.0 \%$ & $36.7 \%$ & $42.3 \%$ \\
\hline July & $3.7 \%$ & $48.8 \%$ & $47.6 \%$ & $12.8 \%$ & $40.4 \%$ & $46.8 \%$ & $1.6 \%$ & $49.0 \%$ & $49.4 \%$ & $20.2 \%$ & $38.1 \%$ & $41.7 \%$ \\
\hline August & $5.5 \%$ & $43.9 \%$ & $50.6 \%$ & $12.0 \%$ & $38.0 \%$ & $50.0 \%$ & $1.2 \%$ & $47.1 \%$ & $51.6 \%$ & $18.4 \%$ & $36.8 \%$ & $44.8 \%$ \\
\hline September & $2.2 \%$ & $46.4 \%$ & $51.4 \%$ & $13.2 \%$ & $40.6 \%$ & $46.1 \%$ & $1.9 \%$ & $46.2 \%$ & $51.9 \%$ & $21.7 \%$ & $35.3 \%$ & $43.0 \%$ \\
\hline October & $0.9 \%$ & $50.7 \%$ & $48.4 \%$ & $13.2 \%$ & $43.2 \%$ & $43.6 \%$ & $0.0 \%$ & $50.9 \%$ & $49.1 \%$ & $19.3 \%$ & $37.6 \%$ & $43.1 \%$ \\
\hline All & $3.2 \%$ & $48.5 \%$ & $48.3 \%$ & $12.1 \%$ & $41.9 \%$ & $46.0 \%$ & $1.2 \%$ & $49.5 \%$ & $49.3 \%$ & $19.4 \%$ & $38.5 \%$ & $42.2 \%$ \\
\hline \multirow{2}{*}{ Month } & \multicolumn{3}{|c|}{ SCUBA / SNORKELLING } & \multicolumn{3}{|c|}{ SIGHTSEEING } & \multicolumn{3}{|c|}{ SWIMMING } & \multicolumn{3}{|c|}{ WATERSKIING } \\
\hline & Yes & No & NA & Yes & No & NA & Yes & No & NA & Yes & No & NA \\
\hline May & $2.4 \%$ & $56.0 \%$ & $41.5 \%$ & $29.6 \%$ & $39.3 \%$ & $31.1 \%$ & $8.1 \%$ & $52.5 \%$ & $39.4 \%$ & $1.9 \%$ & $56.2 \%$ & $41.9 \%$ \\
\hline June & $2.9 \%$ & $47.0 \%$ & $50.1 \%$ & $33.5 \%$ & $29.0 \%$ & $37.5 \%$ & $28.7 \%$ & $34.0 \%$ & $37.3 \%$ & $2.9 \%$ & $48.2 \%$ & $49.0 \%$ \\
\hline July & $5.3 \%$ & $47.0 \%$ & $47.7 \%$ & $39.4 \%$ & $26.0 \%$ & $34.6 \%$ & $39.3 \%$ & $29.9 \%$ & $30.8 \%$ & $4.8 \%$ & $48.1 \%$ & $47.1 \%$ \\
\hline August & $4.8 \%$ & $43.9 \%$ & $51.3 \%$ & $45.8 \%$ & $20.7 \%$ & $33.6 \%$ & $37.7 \%$ & $27.9 \%$ & $34.5 \%$ & $5.2 \%$ & $44.6 \%$ & $50.2 \%$ \\
\hline September & $1.1 \%$ & $47.4 \%$ & $51.5 \%$ & $30.1 \%$ & $32.0 \%$ & $37.9 \%$ & $13.3 \%$ & $40.1 \%$ & $46.6 \%$ & $0.7 \%$ & $48.0 \%$ & $51.4 \%$ \\
\hline October & $1.5 \%$ & $51.4 \%$ & $47.1 \%$ & $31.1 \%$ & $35.8 \%$ & $33.1 \%$ & $4.9 \%$ & $48.7 \%$ & $46.4 \%$ & $1.2 \%$ & $51.5 \%$ & $47.3 \%$ \\
\hline All & $3.3 \%$ & $48.1 \%$ & $48.6 \%$ & $36.0 \%$ & $29.2 \%$ & $34.8 \%$ & $25.2 \%$ & $36.8 \%$ & $38.0 \%$ & $3.1 \%$ & $48.8 \%$ & $48.1 \%$ \\
\hline
\end{tabular}

\begin{tabular}{|c|c|c|c|c|}
\hline \multirow{2}{*}{ Month } & \multicolumn{3}{|c|}{ OTHER } & \multirow{2}{*}{$n$} \\
\hline & Yes & No & NA & \\
\hline May & $94.6 \%$ & $5.4 \%$ & $0.0 \%$ & 279 \\
\hline June & $94.6 \%$ & $4.7 \%$ & $0.8 \%$ & 381 \\
\hline July & $95.6 \%$ & $4.2 \%$ & $0.2 \%$ & 507 \\
\hline August & $95.1 \%$ & $4.9 \%$ & $0.0 \%$ & 399 \\
\hline September & $91.9 \%$ & $8.1 \%$ & $0.0 \%$ & 247 \\
\hline October & $81.4 \%$ & $18.6 \%$ & $0.0 \%$ & 155 \\
\hline All & $93.1 \%$ & $6.7 \%$ & $0.2 \%$ & 1,968 \\
\hline
\end{tabular}




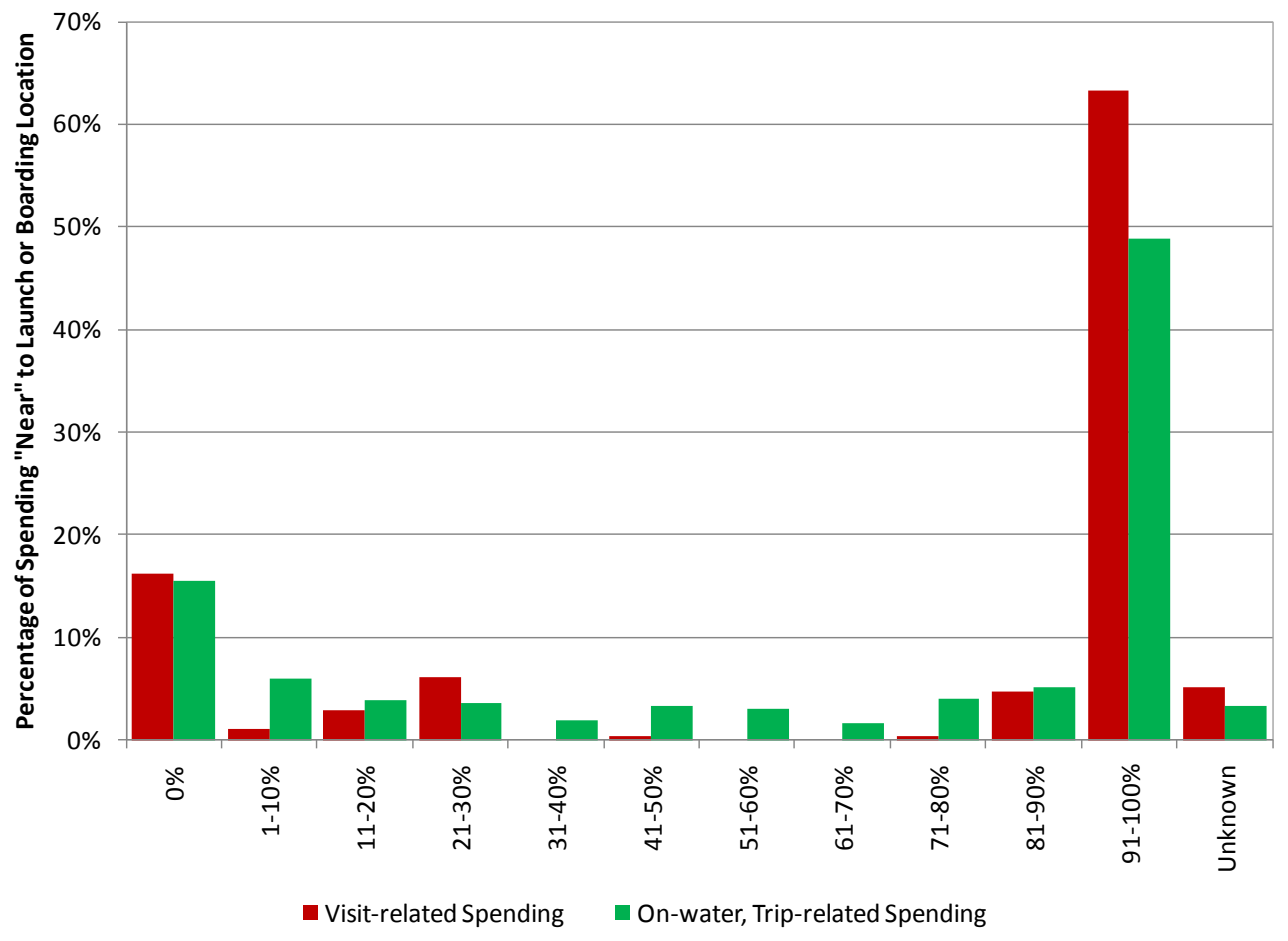

Figure 16: The percentage of visit-related or trip-related spending that occurred "near to" the launch or boarding location based on responses to the monthly surveys. 


\subsection{Economic Contribution}

It is important to note that by several measures the Massachusetts economy was just starting to recover from the severe 2008-2009 recession at the time of this survey and thus the estimates of recreational spending are likely to be below what they would normally be for a more robust period. Recreational spending is highly discretionary and likely to be one of the first areas to feel recessionary pressures and one of the last areas to recover. Massachusetts personal income (the total amount of wages, salaries, and benefits earned in the state in a given year) was stagnant in real terms (inflation adjusted) between 2007 and 2008 and fell by $2.15 \%$ in 2009 to below $\$ 300$ million (inflation adjusted - measured in 2005 dollars). It began to recover in 2010 , but was still down $0.4 \%$ in real terms from its 2007 level. This decline was also reflected in overall employment in the Commonwealth, which was down $3.3 \%$ in 2010 from its 2007 level and the unemployment rate, which had climbed from $4.4 \%$ in 2007 to $8.9 \%$ in 2010.

Based on the data gathered during this study, coastal and ocean recreational boaters in Massachusetts spent, on average, $\$ 529$ million on products and/or services of Massachusetts businesses. Table 48 shows the breakdown of expenditures by major category from the monthly trip and seasonal surveys. In-state spending by these boat owners took place in a variety of sectors. The highest trip-related levels of spending were on boat fuel and transient/guest dockage. The highest levels of non-trip-related spending (i.e., yearly capital and maintenance expenditures) were on seasonal dockage, mooring and storage; and routine maintenance.

This initial spending by boaters continued to generate economic effects in the state. The IMPLAN software and data packages for Massachusetts were used to model the later rounds of local spending that followed the initial expenditures by recreational boaters. Each dollar of direct spending leads to additional inter-industry purchases by businesses affected by this spending. This is known as the indirect effect. This direct and indirect spending results in an increase in income for households providing labor to these industries, which causes them to increase their spending. This is known as the induced effect. The summation of the indirect and induced effects reveals the additional economic impact of an increase in direct spending in the economy. In this case (see Table 49), the model showed that a variety of sectors benefited from these successive rounds of spending, including trade, transportation and utilities; professional business services; and financial activities.

Thus, the total economic contribution of coastal and ocean recreational boating expenditures to Massachusetts in 2010 was at least almost $\mathbf{\$ 8 0 6}$ million. This is a conservative estimate because it did not include any expenditure by out-of-state boaters since they were not included in the main study. It also only reflected monthly coastal and ocean boating activity from May through October in addition to yearly capital and maintenance expenditures. In addition, as noted earlier, this survey was conducted just as Massachusetts was coming out of a severe recession and thus overall expenditures were likely to be considerably lower than during a more prosperous economic period. 
Table 48: $\quad$ Spending by coastal and ocean recreational boaters in Massachusetts, 2010.

\begin{tabular}{|c|c|c|}
\hline \multirow{2}{*}{$\begin{array}{l}\text { Total Trip and Visit Spending (May - October 2010) } \\
\text { Auto gas and oil }\end{array}$} & \multicolumn{2}{|r|}{ Amount } \\
\hline & $\$$ & $12,924,954$ \\
\hline Boat fuel and oil & $\$$ & $84,197,955$ \\
\hline Fishing gear, bait, ice etc. & $\$$ & $13,386,277$ \\
\hline Groceries & $\$$ & $24,924,326$ \\
\hline Launch fees & $\$$ & $5,166,429$ \\
\hline Lodging (camping or $B \& B$ ) & $\$$ & $2,638,773$ \\
\hline Lodging (hotel or motel) & $\$$ & $6,362,194$ \\
\hline Pumpout fees & $\$$ & 264,420 \\
\hline Recreation and entertainment & $\$$ & $4,054,272$ \\
\hline Restaurant meals and drink (inc. take-out) & $\$$ & $31,842,663$ \\
\hline Shopping and souvenirs & $\$$ & $4,350,731$ \\
\hline Transient / guest dockage (marina fees) & $\$$ & $33,307,190$ \\
\hline TOTAL & $\$$ & $223,420,184$ \\
\hline \multicolumn{3}{|l|}{ Season Maintenance } \\
\hline Installation of new engine & $\$$ & $18,888,545$ \\
\hline Installation of new products & $\$$ & $15,191,344$ \\
\hline Routine maintenance & $\$$ & $63,051,859$ \\
\hline Vessel repair & $\$$ & $33,957,951$ \\
\hline TOTAL & $\$$ & $131,089,699$ \\
\hline \multicolumn{3}{|l|}{ Seasonal Other } \\
\hline Boat insurance & $\$$ & $34,220,645$ \\
\hline Boat loan payment & $\$$ & $44,535,093$ \\
\hline Dockage, mooring, seasonal storage & $\$$ & $66,008,923$ \\
\hline New or replacement products (i.e. maintenance/repair) & $\$$ & $5,005,599$ \\
\hline New trailers & $\$$ & $19,567,206$ \\
\hline Other & $\$$ & $5,246,477$ \\
\hline TOTAL & $\$$ & $174,583,943$ \\
\hline $\begin{array}{l}\text { GRAND TOTAL SPENDING FOR ECONOMIC CONTRIBUTION ANALYSIS } \\
\text { MA MODEL }\end{array}$ & $\$$ & $529,093,826$ \\
\hline
\end{tabular}


Table 49: $\quad$ Summary of indirect and induced effects (by category) of coastal and ocean recreational boating spending in Massachusetts, 2010.

\begin{tabular}{lcr}
\hline NAICS Super Sectors & \multicolumn{1}{c}{ Amount } \\
\hline Construction & $\$$ & $2,943,411$ \\
\hline Education and health services & $\$$ & $26,027,221$ \\
\hline Financial Activities & $\$$ & $32,600,370$ \\
\hline Government & $\$$ & $23,955,635$ \\
\hline Information & $\$$ & $16,216,932$ \\
\hline Leisure and hospitality & $\$$ & $15,118,346$ \\
\hline Manufacturing & $\$$ & $24,223,487$ \\
\hline Natural resources and mining & $\$$ & 493,828 \\
\hline Other services & $\$$ & $9,777,484$ \\
\hline Professional and business services & $\$$ & $48,427,778$ \\
\hline Real estate and rental and leasing & $\$$ & $24,744,756$ \\
\hline Trade, transportation and utilities & $\$$ & $52,196,909$ \\
\hline TOTAL & $\$ 276,726,157$ \\
\hline
\end{tabular}

Another important contribution related to the spending of recreational boaters is the employment supported by that spending within the state. The $\$ 529$ million of spending by coastal and ocean recreational boaters supported over 4,730 fulltime-equivalent jobs within the state. This total reflects both the jobs directly supported by the spending as well as the jobs created in supplier businesses (by the indirect and induced expenditures). In terms of sheer numbers of jobs directly supported by coastal and ocean recreational boating expenditures, the sectors most impacted included: leisure and hospitality; other services; and trade, transportation and utilities as shown in Table 50. Once again, it is important to note that this study did not include out-of-state boaters and as such may under estimate both spending and the number of jobs supported. 
Table 50: $\quad$ Total jobs supported by coastal and ocean recreational boating spending in Massachusetts, 2010.

\begin{tabular}{lr}
\hline NAICS Super Sectors & Number \\
\hline Construction & 24 \\
\hline Education and health services & 262 \\
\hline Financial Activities & 424 \\
\hline Government & 23 \\
\hline Information & 43 \\
\hline Leisure and hospitality & 1,720 \\
\hline Manufacturing & 59 \\
\hline Natural resources and mining & 7 \\
\hline Other services & 869 \\
\hline Professional and business services & 387 \\
\hline Real estate and rental and leasing & 100 \\
\hline Trade, transportation and utilities & 821 \\
\hline TOTAL & 4,739 \\
\hline
\end{tabular}

There was a sufficient sample of boaters in an agglomeration of some of the coastal counties for a regional IMPLAN analysis of two key coastal areas to be performed - the Southeast region, consisting of Barnstable, Bristol, Nantucket, and Dukes counties, and the East Central region, consisting of Norfolk, Suffolk, and Plymouth counties.

In the Southeast region of the state, recreational boaters spent over \$121 million in 2010 on recreational boating related activities and products (see Table 51). 
Table 51: $\quad$ Spending by coastal and ocean recreational boaters in the Southeast Region, 2010.

\begin{tabular}{|c|c|c|}
\hline Total Trip and Visit Spending (May - October 2010) & & Amount \\
\hline Auto gas and oil & $\$$ & $1,774,016$ \\
\hline Boat fuel and oil & $\$$ & $25,971,480$ \\
\hline Fishing gear, bait, ice etc. & $\$$ & $3,133,318$ \\
\hline Groceries & $\$$ & $5,081,987$ \\
\hline Launch fees & $\$$ & $1,325,907$ \\
\hline Lodging (camping or B\&B) & $\$$ & 97,740 \\
\hline Lodging (hotel or motel) & $\$$ & 399,293 \\
\hline Pumpout fees & $\$$ & 38,253 \\
\hline Recreation and entertainment & $\$$ & 726,241 \\
\hline Restaurant meals and drink (inc. take-out) & $\$$ & $7,988,910$ \\
\hline Shopping and souvenirs & $\$$ & 855,160 \\
\hline Transient / guest dockage (marina fees) & $\$$ & $3,806,935$ \\
\hline TOTAL & $\$$ & $51,199,240$ \\
\hline \multicolumn{3}{|l|}{ Season Maintenance } \\
\hline Installation of new engine & $\$$ & $7,469,774$ \\
\hline Installation of new products & $\$$ & $3,107,694$ \\
\hline Routine maintenance & $\$$ & $15,408,936$ \\
\hline Vessel repair & $\$$ & $6,091,288$ \\
\hline TOTAL & $\$$ & $32,077,692$ \\
\hline \multicolumn{3}{|l|}{ Seasonal Other } \\
\hline Boat insurance & $\$$ & $6,747,709$ \\
\hline Boat loan payment & $\$$ & $5,675,408$ \\
\hline Dockage, mooring, seasonal storage & $\$$ & $18,360,398$ \\
\hline New or replacement products (i.e. maintenance/repair) & $\$$ & $1,277,125$ \\
\hline New trailers & $\$$ & $4,875,795$ \\
\hline Other & $\$$ & $1,272,353$ \\
\hline TOTAL & $\$$ & $38,208,788$ \\
\hline $\begin{array}{l}\text { GRAND TOTAL SPENDING FOR ECONOMIC CONTRIBUTION ANALYSIS } \\
\text { SOUTHEAST MODEL }\end{array}$ & $\$$ & $121,485,720$ \\
\hline
\end{tabular}

This spending resulted in an additional \$51 million in economic activity in the Southeast region, for a total economic contribution in the region of $\$ 172.6$ million in 2010 . In addition, over 1,000 jobs in the Southeast region were supported by the direct spending of recreational boaters and the indirect and induced economic impact of this spending. 
In the East Central region, coastal and ocean recreational boaters spent almost \$135 million in 2010 on recreational boating related activities and products (see Table 52).

Table 52: $\quad$ Spending by coastal and ocean recreational boaters in the East Central region, 2010.

\begin{tabular}{|c|c|c|}
\hline Total Trip and Visit Spending (May - October 2010) & & Amount \\
\hline Auto gas and oil & $\$$ & $5,390,859$ \\
\hline Boat fuel and oil & $\$$ & $26,490,495$ \\
\hline Fishing gear, bait, ice etc. & $\$$ & $4,757,051$ \\
\hline Groceries & $\$$ & $6,031,451$ \\
\hline Launch fees & $\$$ & $1,304,463$ \\
\hline Lodging (camping or B\&B) & $\$$ & $1,869,694$ \\
\hline Lodging (hotel or motel) & $\$$ & $1,323,850$ \\
\hline Pumpout fees & $\$$ & - \\
\hline Recreation and entertainment & $\$$ & 660,980 \\
\hline Restaurant meals and drink (inc. take-out) & $\$$ & $7,262,474$ \\
\hline Shopping and souvenirs & $\$$ & $1,135,140$ \\
\hline Transient / guest dockage (marina fees) & $\$$ & $17,839,771$ \\
\hline TOTAL & $\$$ & $74,066,228$ \\
\hline \multicolumn{3}{|l|}{ Season Maintenance } \\
\hline Installation of new engine & $\$$ & $2,337,080$ \\
\hline Installation of new products & $\$$ & $1,315,545$ \\
\hline Routine maintenance & $\$$ & $10,863,307$ \\
\hline Vessel repair & $\$$ & $8,568,065$ \\
\hline TOTAL & $\$$ & $23,083,997$ \\
\hline \multicolumn{3}{|l|}{ Seasonal Other } \\
\hline Boat insurance & $\$$ & $7,312,671$ \\
\hline Boat loan payment & $\$$ & $11,116,804$ \\
\hline Dockage, mooring, seasonal storage & $\$$ & $12,887,501$ \\
\hline New or replacement products (i.e. maintenance/repair) & $\$$ & $1,236,673$ \\
\hline New trailers & $\$$ & $3,500,379$ \\
\hline Other & $\$$ & $1,410,596$ \\
\hline TOTAL & $\$$ & $37,464,624$ \\
\hline $\begin{array}{l}\text { GRAND TOTAL SPENDING FOR ECONOMIC CONTRIBUTION ANALYSIS } \\
\text { EAST CENTRAL MODEL }\end{array}$ & $\$$ & $134,614,849$ \\
\hline
\end{tabular}


This spending lead to an additional $\$ 60.2$ million in economic activity in the East Central region, for a total economic contribution in the region of nearly $\$ 195$ million in 2010 . Nearly 1,100 jobs in the East Central region were supported by this spending of coastal and ocean recreational boaters in 2010.

\subsection{Other Boating-related Data}

The end-of-season survey was primarily focused on non-trip-related spending directly associated with owning a boat (discussed above). However, it also asked a few questions about overall activity during the 2010 boating season. The first question asked boaters to estimate the number of hours they spent under power or under sail on the specific vessel on which they were reporting. The average number of hours that a boat was under power or sail during the 2010 boating season was 72.1 hours based on information from 413 boaters. However, as Table 53 shows, there are significant differences between documented boaters and the registered boats in different regions of Massachusetts. Documented boaters averaged 178 hours under power or sail. The Northeast and East Central regions were the next highest, with averages of 64.7 and 62.7 hours respectively. The Southeast had an average of 50.9 hours. Central and Western Massachusetts were the lowest two regions. It is important to note that the numbers of boaters reporting from those regions was very low and the numbers for these two regions may not be robust.

Table 53: $\quad$ The average number of hours under power or sail by size class within a region, and by region.

\begin{tabular}{|c|c|c|c|c|}
\hline Region & Size Class & $\begin{array}{r}\text { Number of } \\
\text { Respondents }\end{array}$ & Average (hrs) & Average (hrs) \\
\hline \multirow[t]{3}{*}{ Southeast } & $<10$ & 14 & 28.9 & 50.9 \\
\hline & 10 to $<40$ & 139 & 53.7 & \\
\hline & $40+$ & 0 & NODATA & \\
\hline \multirow[t]{3}{*}{ East Central } & $<10$ & 9 & 29.3 & 62.7 \\
\hline & 10 to $<40$ & 84 & 67.8 & \\
\hline & $40+$ & 0 & NO DATA & \\
\hline \multirow[t]{3}{*}{ Northeast } & $<10$ & 7 & 47.7 & 64.7 \\
\hline & 10 to $<40$ & 71 & 66.9 & \\
\hline & $40+$ & 0 & NO DATA & \\
\hline Central & All & 6 & 45.8 & 45.8 \\
\hline Western & All & 4 & 36.8 & 36.8 \\
\hline \multirow[t]{2}{*}{ Documented } & $<40$ & 21 & 184.2 & 178.0 \\
\hline & $40+$ & 56 & 155.2 & \\
\hline \multicolumn{2}{|c|}{ All Massachusetts } & 412 & 72.1 & \\
\hline
\end{tabular}

As noted in the previous section, the Massachusetts economy was still recovering from the 2008-2009 recession at the time of this study and it would not be surprising if recreational boating activity was 
reduced as a result of this. The end-of-season survey therefore asked boaters to report how they rated their boating activity during the 2010 season as compared to other years. Across the whole of Massachusetts, just over $17 \%$ of the 455 boaters who responded said that their season had been slightly to much more active compared with over $53 \%$ who said that it had been somewhat to much less active (Table 54). A little over half of documented boaters reported that their boating activity was the same or more than normal.

Table 54: $\quad$ How boaters rated their 2010 boating activity compared to other years.

\begin{tabular}{lrrrrrr}
\hline & $\begin{array}{r}\text { Much More } \\
\text { Active }\end{array}$ & $\begin{array}{r}\text { Slightly More } \\
\text { Active }\end{array}$ & Similar & $\begin{array}{r}\text { Slightly Less } \\
\text { Active }\end{array}$ & $\begin{array}{r}\text { Much Less } \\
\text { Active }\end{array}$ & $\mathbf{n}$ \\
\hline Southeast & $3.6 \%$ & $8.9 \%$ & $32.7 \%$ & $19.6 \%$ & $35.1 \%$ & 168 \\
\hline East Central & $11.1 \%$ & $7.1 \%$ & $26.3 \%$ & $28.3 \%$ & $27.3 \%$ & 99 \\
\hline Northeast & $7.9 \%$ & $14.6 \%$ & $25.8 \%$ & $20.2 \%$ & $31.5 \%$ & 89 \\
\hline Central & $0.0 \%$ & $10.0 \%$ & $20.0 \%$ & $10.0 \%$ & $60.0 \%$ & 10 \\
\hline Western & $0.0 \%$ & $0.0 \%$ & $50.0 \%$ & $0.0 \%$ & $50.0 \%$ & 4 \\
\hline Documented & $9.4 \%$ & $11.8 \%$ & $31.8 \%$ & $22.4 \%$ & $24.7 \%$ & 85 \\
\hline All Massachusetts & $\mathbf{7 . 0 \%}$ & $\mathbf{1 0 . 1 \%}$ & $\mathbf{2 9 . 7 \%}$ & $\mathbf{2 1 . 8 \%}$ & $\mathbf{3 1 . 4 \%}$ & $\mathbf{4 5 5}$ \\
\hline
\end{tabular}

\subsection{Spatial Data}

As noted earlier, this study was largely aimed at using a statistically robust sampling method to gather recreational boating data to supplement the information previously collected through expert opinion. An enormous amount of survey and spatial data was collected and a full analysis of this information was beyond the scope of this work. A more in-depth analysis of these data can be undertaken by a number of entities, including the Massachusetts Office of Coastal Zone Management, MassGIS, graduate students etc.

This section presents some of the spatial data that were gathered. The 1,094 routes that boaters reported are shown in Figure 17, with a focus on coastal Massachusetts' waters.

Figure 17 clearly shows that there are areas of high intensity of boat use in Massachusetts waters. In order to better illustrate these areas of more intensive use, the route information was aggregated into $1 \mathrm{~km} \times 1 \mathrm{~km}$ cells (Figure 18). Cells with the highest intensity (i.e. the highest number of routes intersecting the cell) were colored red and less intense use cells were colored blue. White areas had no routes. This clearly shows that the highest intensities occurred around major boating locations and in "bottle neck" areas such as both entrances to the Cape Cod Canal and the area between Falmouth and Martha's Vineyard.

While no analysis has been undertaken, the route data presented here appears to correlate well with the information that was gathered by the Massachusetts Marine Trades Association as part of the Massachusetts ocean planning process (Appendix A). 


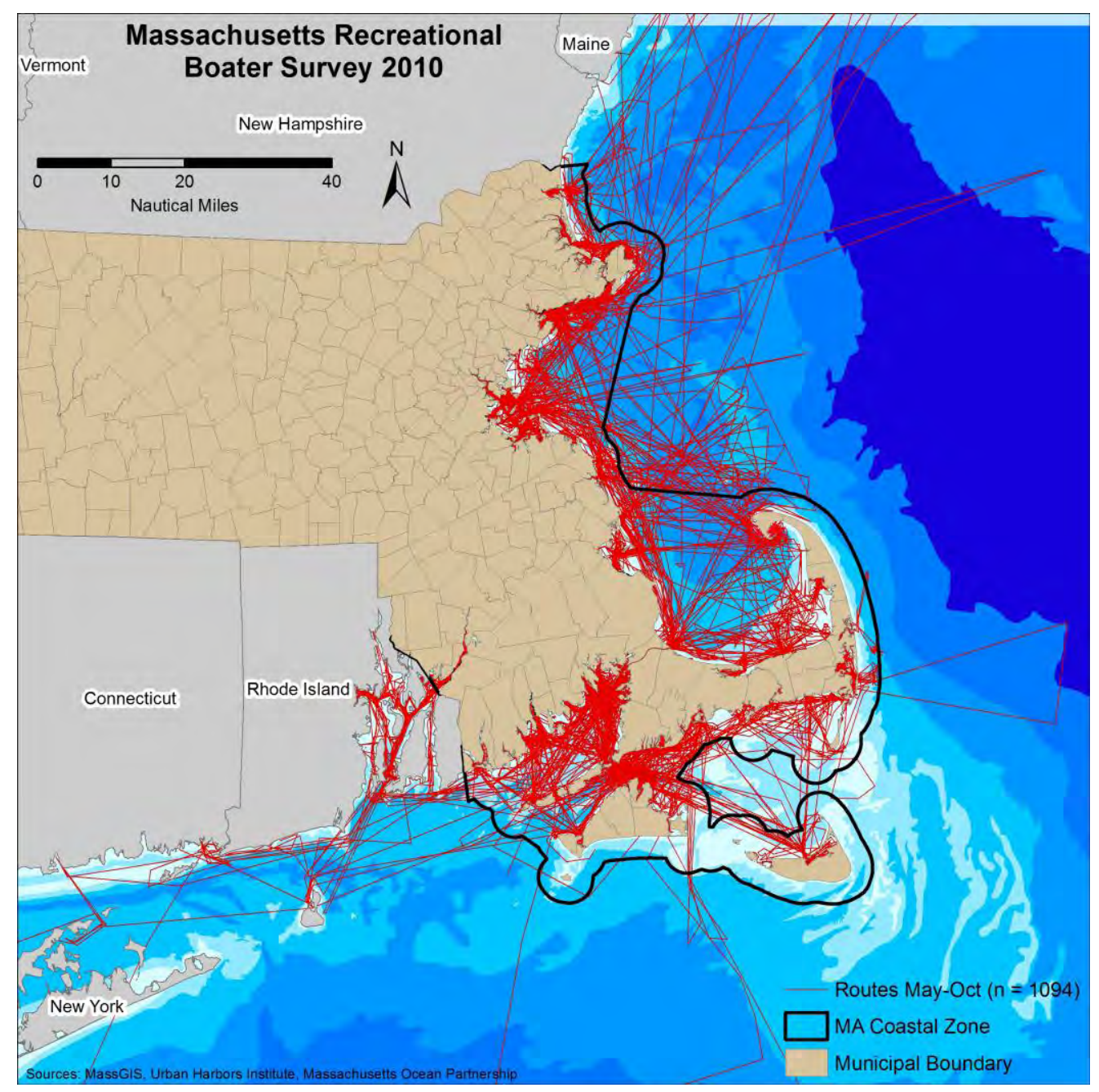

Figure 17: $\quad$ Route data as provided by participants in the boater survey. The lines represent the "last trip of the month" routes plotted by recreational boaters between May and October 2010. 


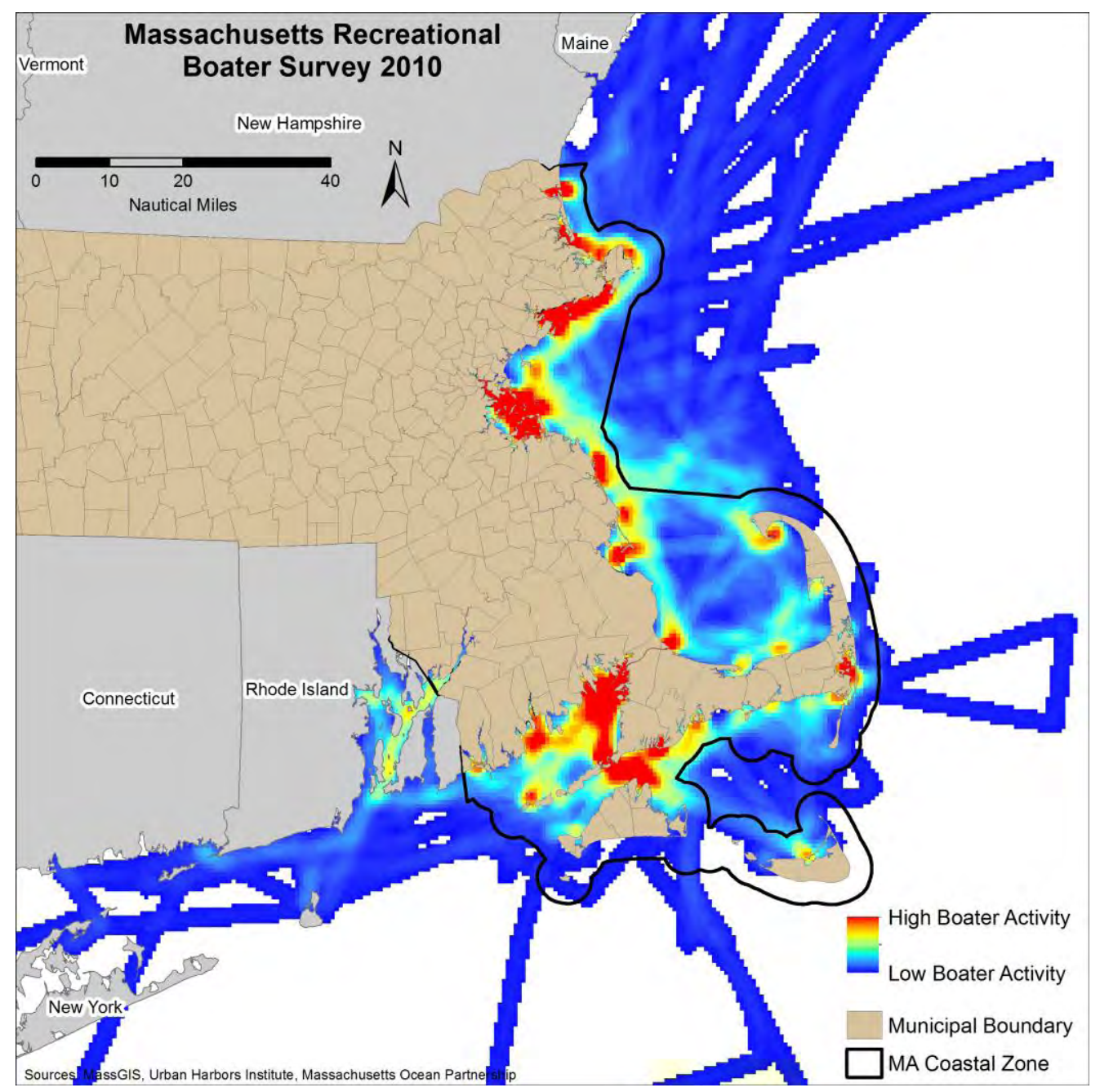

Figure 18: $\quad$ Route data as provided by participants in the boater survey aggregated into $1 \mathrm{~km} \times 1 \mathrm{~km}$ cells. The cells have been shaded to highlight high intensity of boating based on the number of routes that intersect each cell.

Detailed versions of the route and density maps are available in Appendix G.

Figure 19 covers a broader geographic area and shows the same route data but broken down by month. While the number of reported routes varies by month, it appears that the number of long distance trips gradually increases through May, June and July. It appears to peak in August and the start declining towards the end of the season. Figure 20 shows the same data but focused on eastern Massachusetts. Both figures show that the most intense boating activity appears to occur in state waters. 

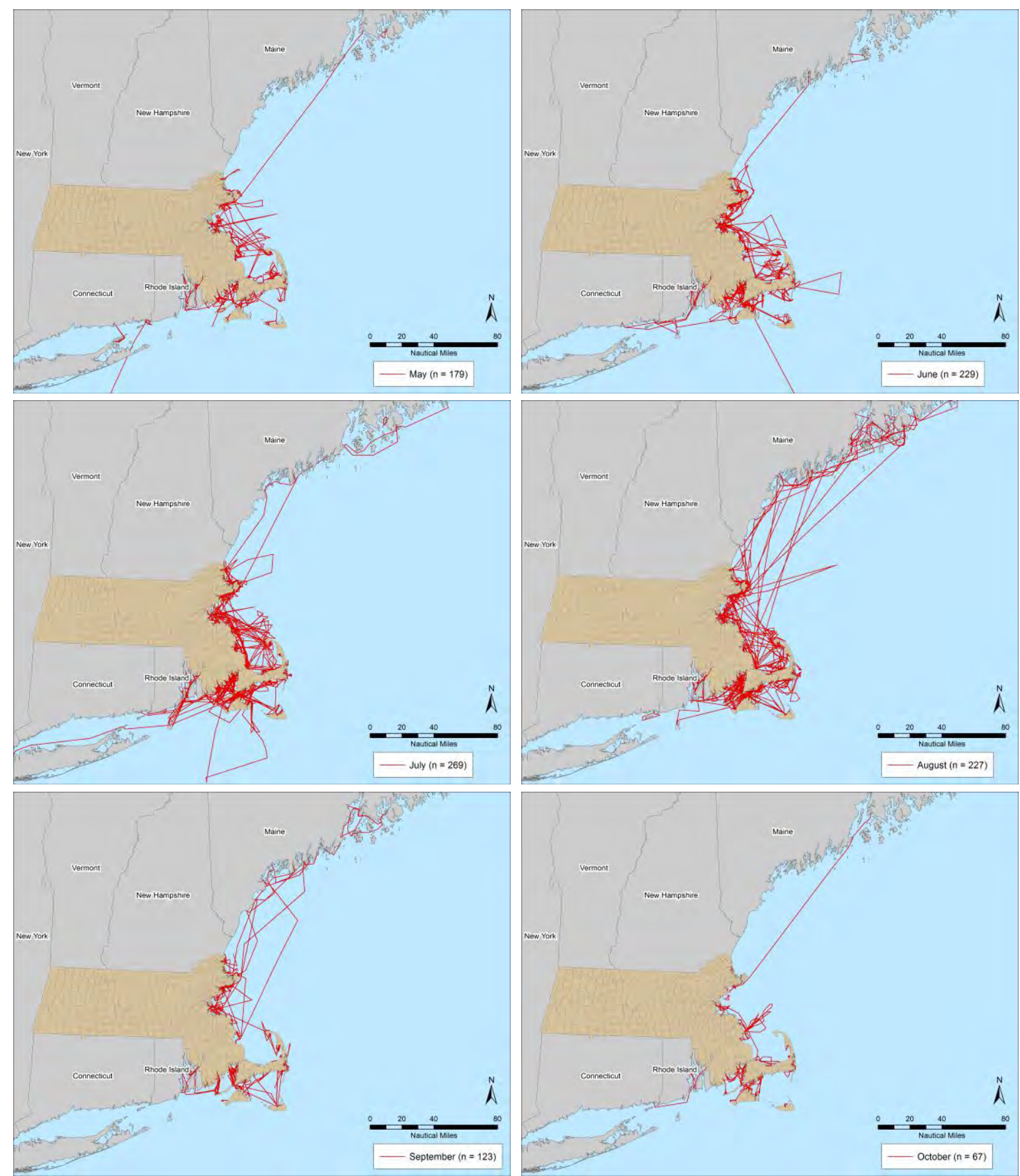

Figure 19: $\quad$ Route data for each month of the boater survey (May - October) as provided by participants. 


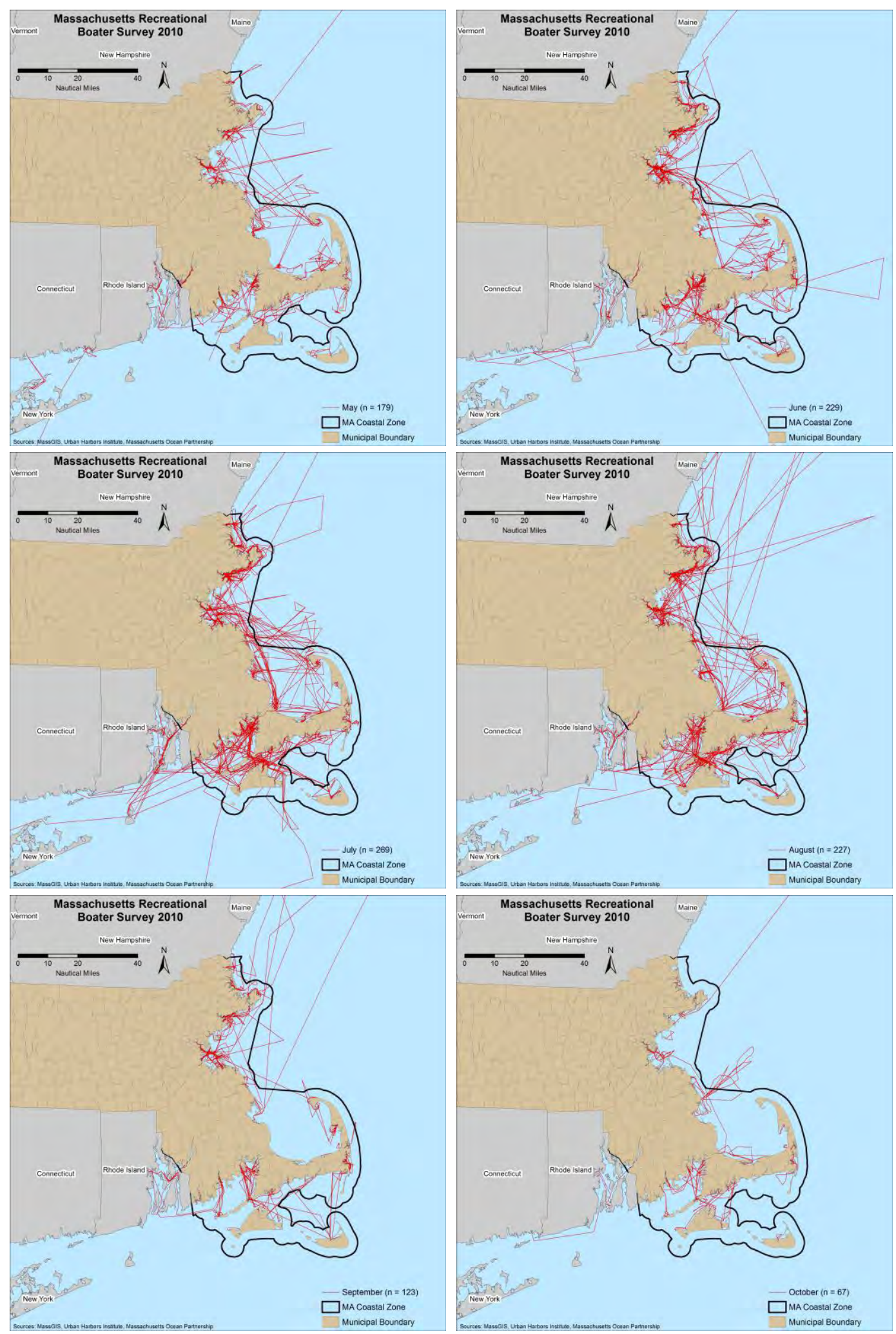

Figure 20: $\quad$ Route data for each month of the boater survey (May - October) as provided by participants. Zoomed-in map containing the same data as the previous figure. 
Figure 21 again shows the routes data gathered during the recreational boater survey but shows the seasonal boating activity around Massachusetts by boats of 10 feet or more in length but less than 40 feet (left) and boats greater than 40 feet in length (right).
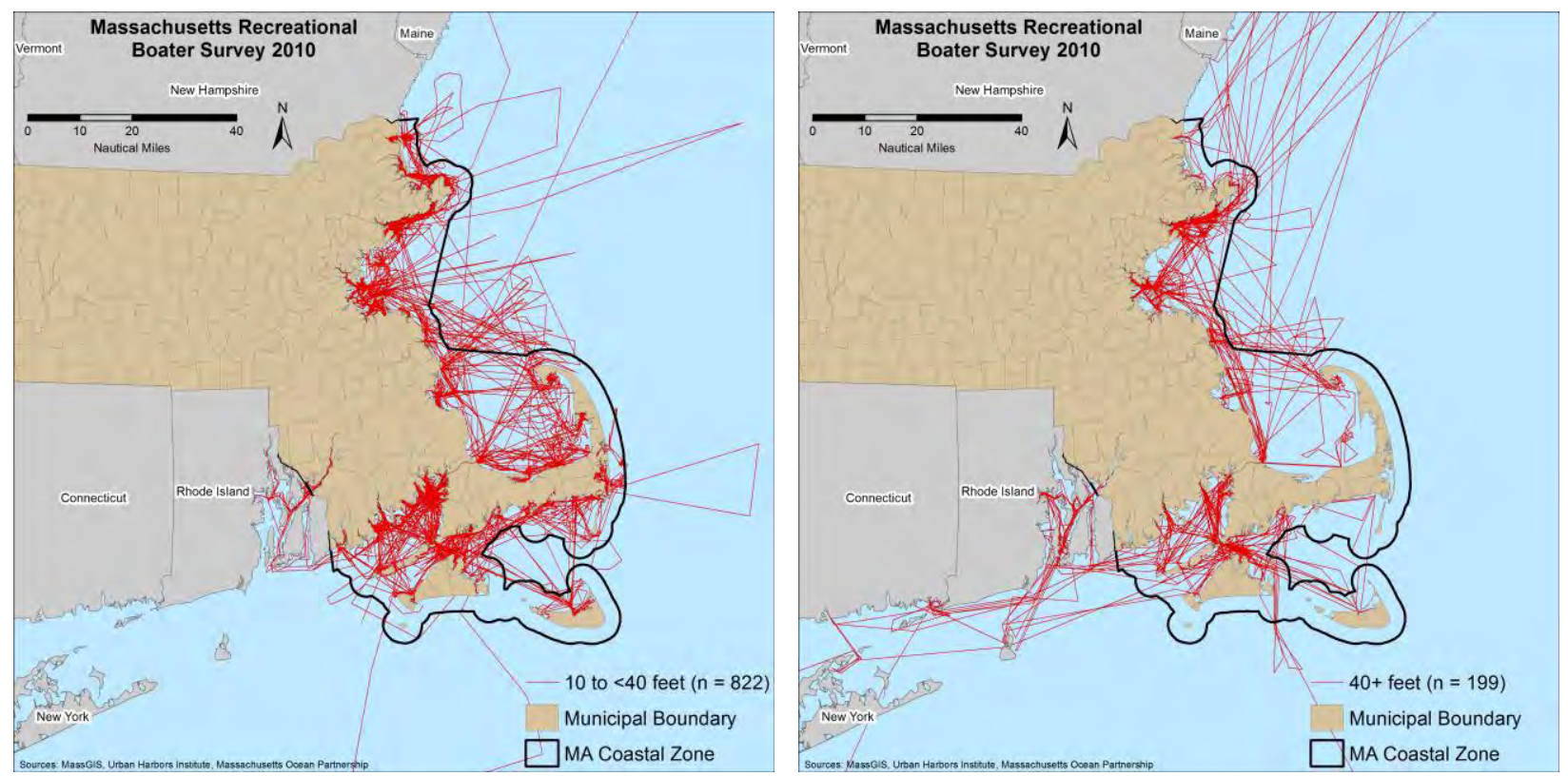

Figure 21:

Route data as provided by participants in the boater survey, broken down by boats of 10 feet or more in length but less than 40 feet (left) and boats greater than 40 feet in length (right).

While there were many routes reported by the smaller of the two size classes, the larger size class seems to show greater offshore activity with more vessels appearing to head up towards Maine and down into Long Island Sound.

During the mapping part of the monthly survey, boaters were asked to identify areas in which they engaged in specific activities. A total of 430 areas were plotted during the boating season (May through October). Many of the areas were small and there were a large number of different activities reported.

Figure 22 shows a simplified map of the activity areas reported. In this map, only three activity types are identified with all others (224 areas) aggregated into an "other" category. The individual areas for the three highlighted activities (sailing, whale watching and fishing) often overlapped so these areas were dissolved so that overlapping areas were combined to form one area. In total 192 fishing areas were identified by boaters along with eight sailing areas and seven whale watching areas.

The largest area identified as one used for whale watching is located in the southern part of the Stellwagen Bank National Marine Sanctuary (shown with a yellow dotted boundary in Figure 22). Figure 23 shows both the sanctuary lines and all the route data for the 2010 boating season. 


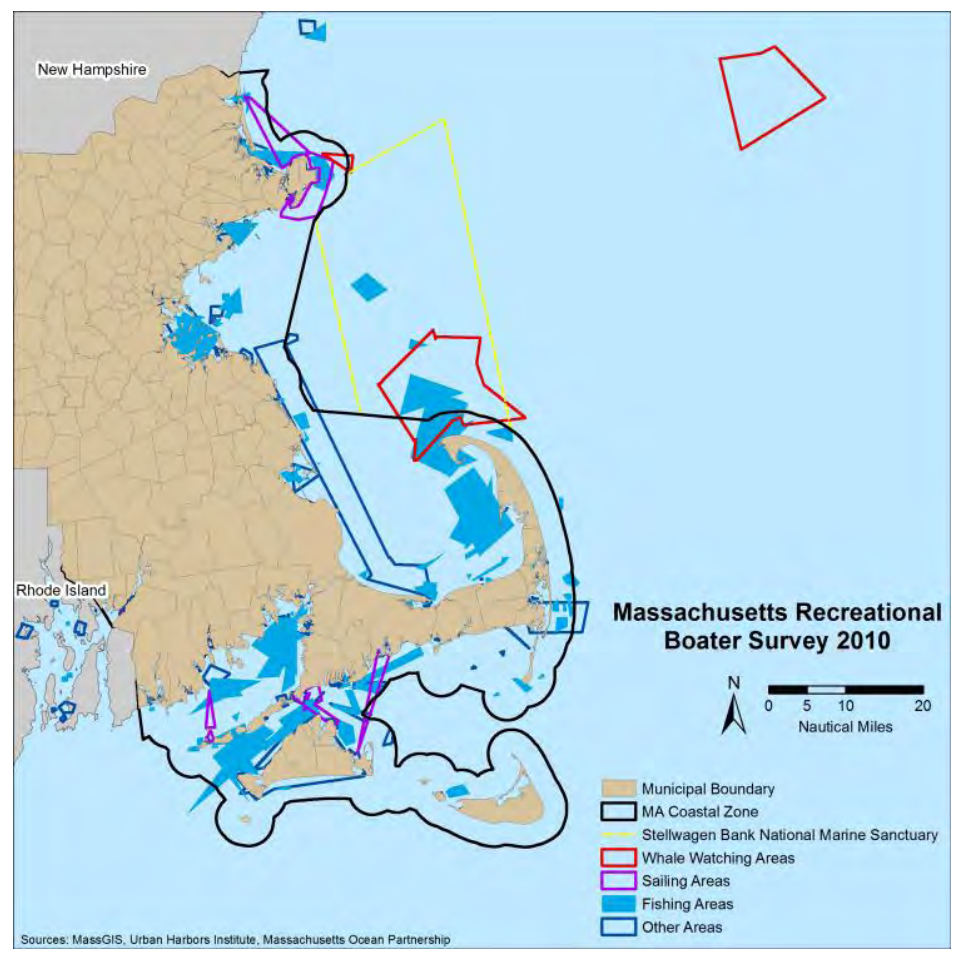

Figure 22: $\quad$ Activity area data as provided by participants in the boater survey.

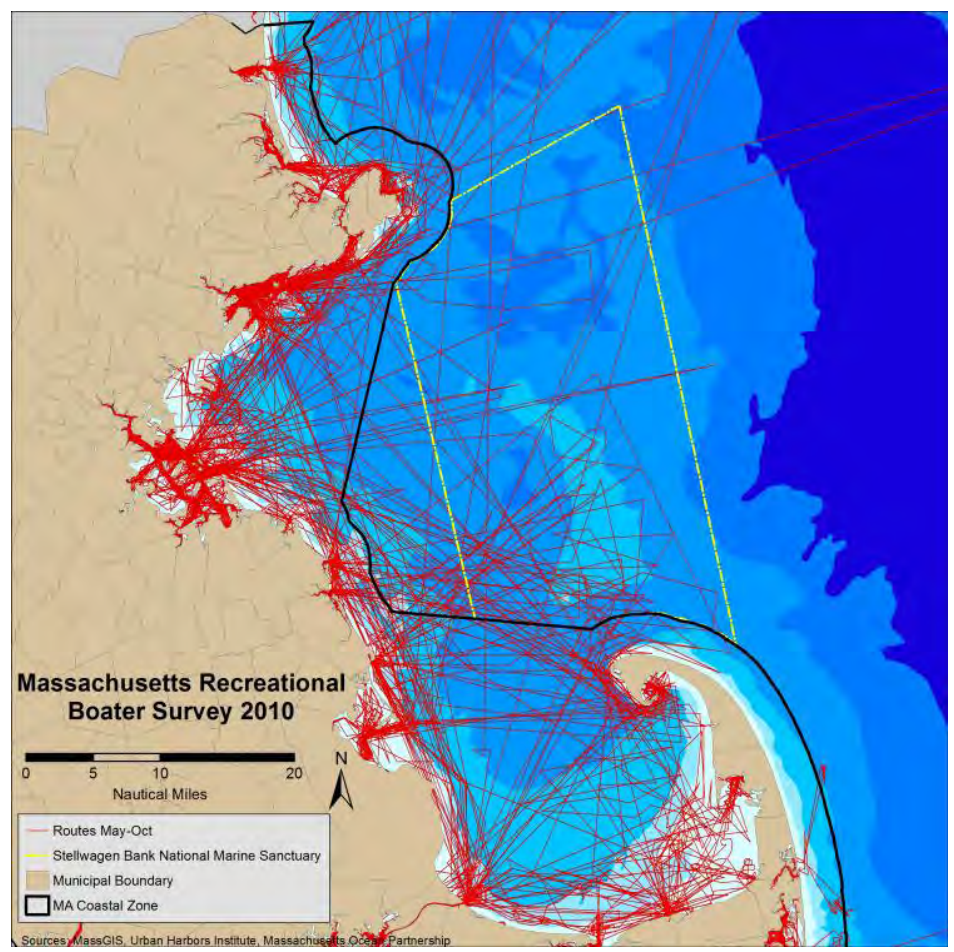

Figure 23: $\quad$ Stellwagen Bank National Marine Sanctuary and the route data gathered during the boater survey. 


\subsection{Boater Feedback}

As part of the end-of-season survey, participating boaters were asked to provide some feedback about the mapping application and the study. It is hoped that this feedback can be used to refine and improve the study design and the mapping application so that studies of this type can continue to be used.

The first question was to determine if the participant had used the online mapping application during any of the months that the study was being conducted. A little over $46 \%$ of the participants that responded to the end of season survey (212 boaters) reported that they had not used the mapping application. Out of those $46 \%$, just over $8 \%$ found that the application did not work on their computers. Almost $17 \%$ reported that they had found the application too complicated or difficult to use, and a further $21 \%$ of respondents did not use their boat during the period over which they were reporting on (Table 55). A small number of boaters had telephoned or e-mailed the boater survey helpline with technical difficulties and team personnel endeavored to solve these issues with limited success.

Table 55: $\quad$ Reasons why boaters did not use the online mapping application by percentage of respondents.

\begin{tabular}{lr}
\hline Response & $\%$ \\
\hline Didn't take boat out & $21.0 \%$ \\
\hline Too complicated / difficult to use & $16.9 \%$ \\
\hline Did not work on my computer & $8.2 \%$ \\
\hline Boating activity was too complicated to map & $9.4 \%$ \\
\hline Other & $43.2 \%$ \\
\hline NA & $1.3 \%$ \\
\hline
\end{tabular}

Greater than $43 \%$ of respondents answered "other". If they answered "other", they were asked to elaborate on their reasoning. The responses suggested that this question had not been clearly understood. Of the 65 boaters who provided a reason in the "other" category, 39 provided responses such as: used onboard GPS; we have adequate navigation material aboard for what we do; and trips did not warrant using it - familiar territory. It is possible that these boaters had never used the mapping application and were unsure as to what the question was referring. Nine boaters said that the maps did not cover the areas where they boated. A further nine either did not know about it or were not interested in using it. Four boaters reported that their trip was short and not worth mapping, and a similar number did not map their route as the vessel in question was their dinghy or tender.

Those participants who had used the mapping application were asked how easy they felt the mapping application had been to use. Of the 258 boaters who responded, $73 \%$ felt that the mapping application had been "somewhat easy" to "very easy" to use (Table 56), and only 4.5\% felt that the application had been "very difficult" to use. 
Table 56: $\quad$ How easy boaters found the online mapping application as a percentage of respondents.

\begin{tabular}{lr}
\hline Response & $\%$ \\
\hline Veryeasy & $30.6 \%$ \\
\hline Somewhat easy & $42.4 \%$ \\
\hline Somewhat difficult & $22.5 \%$ \\
\hline Very difficult & $4.5 \%$ \\
\hline
\end{tabular}

The boaters were also asked if they would be willing to participate in a similar boating survey in the future. Of the 458 boaters who responded, over $88 \%$ reported that they would be "somewhat willing" or "very willing" to do so (Table 57).

Table 57: $\quad$ Boaters' willingness to participate in future similar boating surveys as a percentage of respondents.

\begin{tabular}{lr}
\hline Response & $\%$ \\
\hline Very willing & $41.7 \%$ \\
\hline Somewhat willing & $46.7 \%$ \\
\hline Not very willing & $8.7 \%$ \\
\hline Not at all willing & $2.9 \%$ \\
\hline
\end{tabular}

Finally, boaters were asked if they had any thoughts, comments or suggestion about the online mapping application and the boater survey overall. With regards to the mapping application, a number of people commented on the fact that it was difficult to use, while others found it easy, once they had got the hang of it (Table 58). A number of boaters suggested that it was too slow and/or time consuming and that navigating around the maps and scrolling were not easy. Additional suggestions included: allowing freehand drawing rather than clicking to create each leg of a route; making it possible for the return leg of a journey to be automatically drawn for those trips that went out to a location and returned the same way; and doing away with the route mapping entirely and simply having the names of departure and destination points.

The latter two items were discussed at length during the development of the application. The automated return route was thought to be a good idea but was not implemented due to time constraints. It had been decided that departure and destination points would not accurately capture the spatial use of Massachusetts waters and remove the flexibility that existed for boaters to zoom in and select a specific departure point or destination (even down to an individual slip or mooring). This idea is further complicated by the fact that there are numerous possible departure and destination locations throughout Massachusetts and neighboring states and that people do not always use the same 
name for a particular location. Other suggestions included providing better instructions, to covering greater detail in the charts, and allowing the application developed to run on mobile devices.

Table 58: $\quad$ Summary of thoughts and comments made about the online mapping application.

\begin{tabular}{lr}
\hline Comment & Number \\
\hline Difficult to use & 21 \\
\hline Easy to use & 10 \\
\hline Easy once you got the hang of it & 5 \\
\hline Too slow or time consuming & 4 \\
\hline Allow freehand drawing rather than clicking points & 2 \\
\hline Set it up so return journeys can be atomaticallygenerated & 4 \\
\hline Scrolling / navigation difficult & 13 \\
\hline Have start and end points rather than draw routes & 4 \\
\hline Maps need to cover more area & 4 \\
\hline Cannot handle complicated routes (sailboats) & 3 \\
\hline Better instructions needed & 6 \\
\hline Should be designed for mobile devices & 1 \\
\hline Not applicable to activity & 2 \\
\hline Not used & 3 \\
\hline Did not work & 5 \\
\hline Good job & 3 \\
\hline General comments & 2 \\
\hline
\end{tabular}

Table 59 summarizes the comments and suggestions made by boaters regarding the overall survey. Again, some boaters mentioned the difficulty with using the maps as well as the time that it took to do the mapping. One boater commented that there were simply too many surveys. Seventeen boaters commented on the fact that they were unclear what value this study would have. However, almost the same number hoped that the results would be used to help boaters and boating in Massachusetts and many of these boaters also said that they very much hoped that the results would be made readily available to the public. In fact, one boater commented that he would not participate in the future unless the results were made available to him. A number of boaters commented that they had enjoyed participating in the study and felt that it was important that such work continue. 
Table 59: $\quad$ Summary of thoughts and comments made about the boater survey in general.

\begin{tabular}{lr}
\hline Comment & Number \\
\hline Make mapping easier & 5 \\
\hline Too many surveys & 1 \\
\hline Time consuming & 1 \\
\hline Simplify spending categories & 2 \\
\hline Longer dollarfields & 1 \\
\hline Live-aboard not well covered & 1 \\
\hline Out-of-state activity not well covered & 2 \\
\hline If a boat isn't being used, ask why & 1 \\
\hline Financial questions are not confidential and should not be asked & 1 \\
\hline Didn't understand the overall reason for survey & 17 \\
\hline Boat is a dinghy or tender & 23 \\
\hline Enjoyed participating & 20 \\
\hline Hope results are made available and are used & 16 \\
\hline Good job & 19 \\
\hline General comments
\end{tabular}




\section{LESSONS LEARNED AND RECOMMENDATIONS}

This section contains lessons learned throughout the course of this study and recommendations for similar recreational boating studies that may be undertaken in the future.

\subsection{Timeline}

- This study was developed with a highly compressed timeline. The decision to undertake the 2010 Massachusetts Recreational Boater Survey was made at the very start of January 2010. In order to capture the boating season it was essential that the survey was operational by early June (to capture May's boating activity). Developing such a study involves a large number of inter-related and inter-dependent tasks. Any delay or failure during any one of these tasks could have resulted in a knock-on effect that could have delayed the start of the survey meaning that the whole 2010 boating season could not be captured. While the project was successful, there was an element of luck involved and the study would have benefit from more time being spent on a number of tasks. These included:

- Survey design and testing - a few questions were clearly not universally understood. Additional time may have identified these issues and allowed for them to be rectified.

- Outreach - a more concerted and intensive outreach effort may have increased boater participation.

- Development of mapping application - a number of improvements were identified during the development phase but they could not be implemented due to time constraints. Once the application was up and running, it was decided that making adjustments at that late stage could lead to problems so these improvements were not made. A number of these improvements were identified by boaters in the feedback survey.

To conclude - while the study was a success, it could have been improved upon if more time had been available.

- When developing a realistic timeframe for the study, it should be noted that obtaining the databases of registered and documented vessels may take a considerable amount of time possibly several months.

\subsection{Advisory Group}

- Creating an advisory group with representatives from the various state boating organizations and other stakeholder groups with knowledge of boating and economics associated with recreational boating was extremely valuable. Members of the group provided valuable insight that fed into the study design and process and the development of the surveys. Additionally, the group also facilitated access to data, recruited boaters to be testers during the development phase, encouraged boaters to participate, reviewed results and disseminated the results to the boating community and others. 


\subsection{Determining the Population of Boats Using the Waters of Massachusetts}

- The databases containing boats registered in Massachusetts and those vessels documented with the US Coast Guard provided invaluable information about boats within Massachusetts and it was from a combination of the two that the sample of 10,000 boat owners were drawn.

- The data contained in these data sets allowed for the sample to be stratified by vessel size, and by region for state-registered boats.

- This study could not have been conducted if the database of Massachusetts registered boats had not been available (as may be the case in other states).

- The contact information for boat owners appeared to be good based on the low percentage of letters that were returned as undeliverable. This may be due to the frequency that boat owners are required to verify their information or re-register their boat.

- One limitation of the USCG database of documented vessels was that it was not possible to determine which vessels are actually based/used in Massachusetts.

- A limitation of the database of Massachusetts registered boats was that it did not include nonmotorized vessels, meaning that it may under-represent vessels such as sailboats.

- If additional information were gathered during the Massachusetts boat registration process, the resulting database would be greatly enhanced as a tool to target more accurately a sample for this type of study or other research. Additional information should include:

- A current and valid e-mail address (if available);

- Whether the boat is used only on freshwater versus saltwater;

- Whether the boat is used exclusively for commercial purposes;

- Whether the boat is only used as a tender;

- Greater details on where the boat is stored (i.e. town, type of storage, type of facility for both in and out of season, etc.); and

- If the boat is ever used for recreational fishing.

- Neither data set helps in determining out-of-state boater use of Massachusetts waters. The issue of assessing the impact of out-of-state boaters remains a significant one and requires further research.

\subsection{Sample of Boaters}

- It was assumed that owners of boats stored in Central and Western Massachusetts were more likely to use their boats exclusively on freshwater and would therefore be deemed ineligible for this study as the focus was on coastal and ocean recreational boating. As such, boats in these regions were under sampled (boats from these regions made up $13 \%$ of the sample but represented $25 \%$ of the total population of boats). However, once ineligible boats were 
removed from the responses, eligible boats from these regions only accounted for $3 \%$ of eligible boats. Therefore, those conducting studies focused on coastal and recreational boating in the future should consider under sampling boats stored in Central and Western Massachusetts to an even greater degree unless the sampling could be focused more effectively on eligible boaters.

- While boats 40 feet and over in length were over sampled, the total number of these vessels compared to those in other size classes was very low. Therefore, once ineligible boaters were eliminated, the number of eligible boats of $40+$ feet in length by region was very low. Future studies should consider oversampling the largest size class of boats to an even greater degree.

- Almost $11 \%$ of the 143,507 pleasure and commercial fishing boats registered in Massachusetts were less than 10 feet in length. As these were believed only to be suitable for use very close to shore or as a tender or dinghy associated with a larger vessel, this size class was under sampled. A number of boaters questioned the logic of asking them to report of use of their dinghy when they answered the feedback survey. Therefore, future studies may want to exclude these very small vessels from any sample.

- The characteristics of the population of documented boats appeared to differ significantly from registered boats (e.g. documented vessels generally fell into the larger size classes, many more were sailboats and diesel was the most common type of fuel). These differences suggest that oversampling documented vessels in future studies should be considered.

\subsection{Survey Development}

- Reviewing previous boating studies, such as the Florida Boating Access Facilities Inventory and Economic Study, was useful when developing the design and survey questions for this study.

- Testing the monthly surveys with a few volunteer boaters was very helpful in identifying potential issues and any confusion over questions or the web-mapping application. If time had permitted, additional testing would have been beneficial.

- Boaters were given the option of completing the recruitment survey online, or completing the paper version and returning it using a pre-paid business reply envelope, however only $14.8 \%$ (315 boaters) elected to use the online option. Therefore, it may not have been necessary to develop the online recruitment survey.

- Given that the majority returned their surveys via the mail, the large amount of time and capacity needed to transfer the information from the paper returns to online forms should be noted when considering timeframes.

- It should be noted that a conscious decision was made to avoid sending out notices of monthly surveys immediately prior to weekends so that personnel were available if technical issues arose. 
- One of the most time-consuming tasks associated with entering mailed in recruitment surveys was deciphering sometimes almost ineligible handwriting on the recruitment surveys and trying to ensure that e-mail addresses were entered correctly. In future studies, to ensure that e-mail addresses are written in the clearest possible way, a series of boxes could be provided for respondents to enter their e-mail addresses rather than simply a line:

\begin{tabular}{|l|l|l|l|l|l|l|l|l|l|l|l|l|l|l|l|l|l|l|l|l|l|}
\hline & $j$ & 0 & $h$ & $n$ & $\cdot$ & $d$ & 0 & $e$ & 0 & $c$ & 0 & $m$ & $p$ & $a$ & $n$ & $y$ & $\cdot$ & $c$ & 0 & $m$ \\
\hline
\end{tabular}

- Various sources had suggested that it was common for boaters to spend time on their vessel even if they did not go out on the water. As these dockside visits also have an economic impact, the monthly surveys were developed so that spending information was collected even if no onwater trip was taken.

\subsection{Implementation of the Surveys and Mapping Application}

- Considerable effort was made to keep each survey as short as possible while ensuring that all the necessary information was collected.

- To accelerate the survey process, multiple "skips" were included so that non-applicable questions were not asked. For example, if a boater reported that he had not trailered his boat, all questions associated with trailering were skipped.

- Where possible, yes/no radio buttons or check boxes were used.

- While boaters generally found the questionnaire part of the monthly surveys easy to complete, the success of the mapping application varied considerably. Some boaters found it easy to use. Others found it to be easy to use once they had used it once. Others found it extremely difficult to use and some found that it was impossible for them to use. This may reflect the fact that for accuracy sake, a reasonable degree of complexity was required.

- The mapping of activity areas was relatively unsuccessful. This may be the result of a number of factors: it took boaters too long to reach that section of the survey and so they simply skipped it; the mapping of activity areas was overly complicated; or the idea of activity areas was less clear to the participants than the idea of plotting their approximate route.

- If greater time had been available during the development of the mapping application, a number of improvements that were suggested by the project team could have been implemented and may have increased the user-friendliness of the application. However, such an application requires a degree of complexity that may simply be too much for those less familiar with computers.

\subsection{Incentives to Encourage Participation}

- In order to encourage on-going participation, regular prize drawings were made for cash and marine service-related prizes. Boaters who completed a monthly survey were eligible for that 
month's drawing. In addition, each completed survey represented an additional entry into the end-of-season grand prize drawing for a chance to win $\$ 1,000$.

- Prizes were generously provided by members of the marine industry. The names and logos of those who gave prizes were added to the Massachusetts Recreational Boater Survey website. These sponsors also helped spread the word about the study.

- The prize winners were also posted on the website. However, to preserve anonymity the names of the winners were not posted.

- It is not possible to determine how effective these prize drawings were in encouraging participation, but the use of incentives is common practice during studies such as this one and feedback from some participants suggested that these drawings were appreciated.

- Another incentive that was employed was providing a map of some of the initial spatial data that had been gathered to those who had completed a survey. It was hoped that this would allow boaters to see what the data would look like and therefore encourage further participation.

\subsection{Outreach}

- As it was important to encourage on-going boater participation in the study, information about the study was disseminated through various means (e.g. flyers, a website, presentations to boating groups, notices in monthly e-mail lists). However, due to the tight timeframe for this study, a comprehensive outreach plan was not developed or implemented and some outreach efforts that were undertaken were not followed-up on.

- Any future studies, should develop a more aggressive outreach plan. A comprehensive list of outreach venues (newspapers, relevant radio shows, monthly electronic mailings, boating organizations' member meetings, boat shows, boating magazine etc.) should be developed to ensure that all outreach options are being utilized.

- Depending on the budget and timeframe, flyers describing the study should be distributed to marinas, boat yards, harbormasters offices etc. for posting. For this study, a number of marinas/boat yards received the flyer via e-mail, but it would probably be more effective to send a hard copy.

\subsection{Data Analysis}

- The data in this report represents the initial analysis of only some of the data collected through this study. The complete data collected represent a rich data set that can be mined in various ways to yield important and interesting results and answer a multitude of questions about boats, boat owners, boating activity, spatial use of the waters of Massachusetts and numerous combinations of these. 
- It is important to remember that the accuracy to which boaters plotted their routes will depend on the time that they were willing to spend doing so; the degree to which they zoomed in; and the length/complexity of the route taken. Boaters were often mapping routes covering large areas and so for example, may not have taken the time to plot their exact route accurately through the narrow waters of Cape Cod Canal. As such, when the spatial data are viewed in detail, some routes appear to cross land.

- Similarly, interpretation of the spatial data should consider the scale at which it was collected. This study was conducted statewide and is very useful at showing boating trends and important boating areas in Massachusetts and adjacent federal waters. However, an analysis of boating trends and important boating areas in smaller sub-regions should consider whether the scale and sample size within that sub-region can support conclusions about boating activity. 


\section{Next Steps}

The spatial and economic data collected through this study will be provided to the Massachusetts Office of Coastal Zone Management for inclusion in updating the Massachusetts Ocean Management Plan. The geodatabase will be maintained by the Massachusetts Ocean Partnership, and the spatial data will be made available through the Massachusetts Ocean Resources Information System (MORIS).

One of the main goals of this project was to create a study that:

1. Could be repeated in Massachusetts' coastal and ocean waters;

2. Could be modified to collect information on recreational boating in other locations; and

3. Could be modified to gather other types of spatial information for varying research efforts (either related to the human use of the ocean, or other types of projects).

This study was the first of its kind focused on recreational boating in Massachusetts. As such, it provided an essential baseline data on this activity. If funding were available, it would be of great benefit to repeat this study in the near future, perhaps 2012. Repeating the study will allow for the data to be compared from year to year. To enhance the effectiveness of the study, the methodology and mapping application should be modified slightly based on the lessons learned and recommendations. Considering that approximately $88 \%$ of the survey participants who provided feedback indicated that they would be "somewhat willing" to "very willing" to participate in a similar boating study in the future, it is believed that a future recreational boating study in Massachusetts would be an even greater success.

The "open-source" nature of the mapping application also allows for it to be modified for use in other research efforts, including recreational boating studies in different locations. Considering the current movement towards ocean planning at a regional level, another clear next step would be to expand the Massachusetts recreational boating study to the New England region. This would help enhance our knowledge of regional spatial patterns, the number of boaters visiting Massachusetts (and other New England states) from out of state, and the regional economic impact of recreational boating.

A critical next step is for the data gathered through this study to be more fully analyzed. The analysis contained in this report represents an initial analysis of only some of the data. There are multiple ways in which the boat, boater, economic and spatial data could be cross-referenced and analyzed to provide insight and answers to a multitude of recreational boating related questions. 


\section{APPENDIX A: MAP OF RECREATIONAL BOATING ACTIVITY FROM THE Massachusetts OCEan Management Plan.}

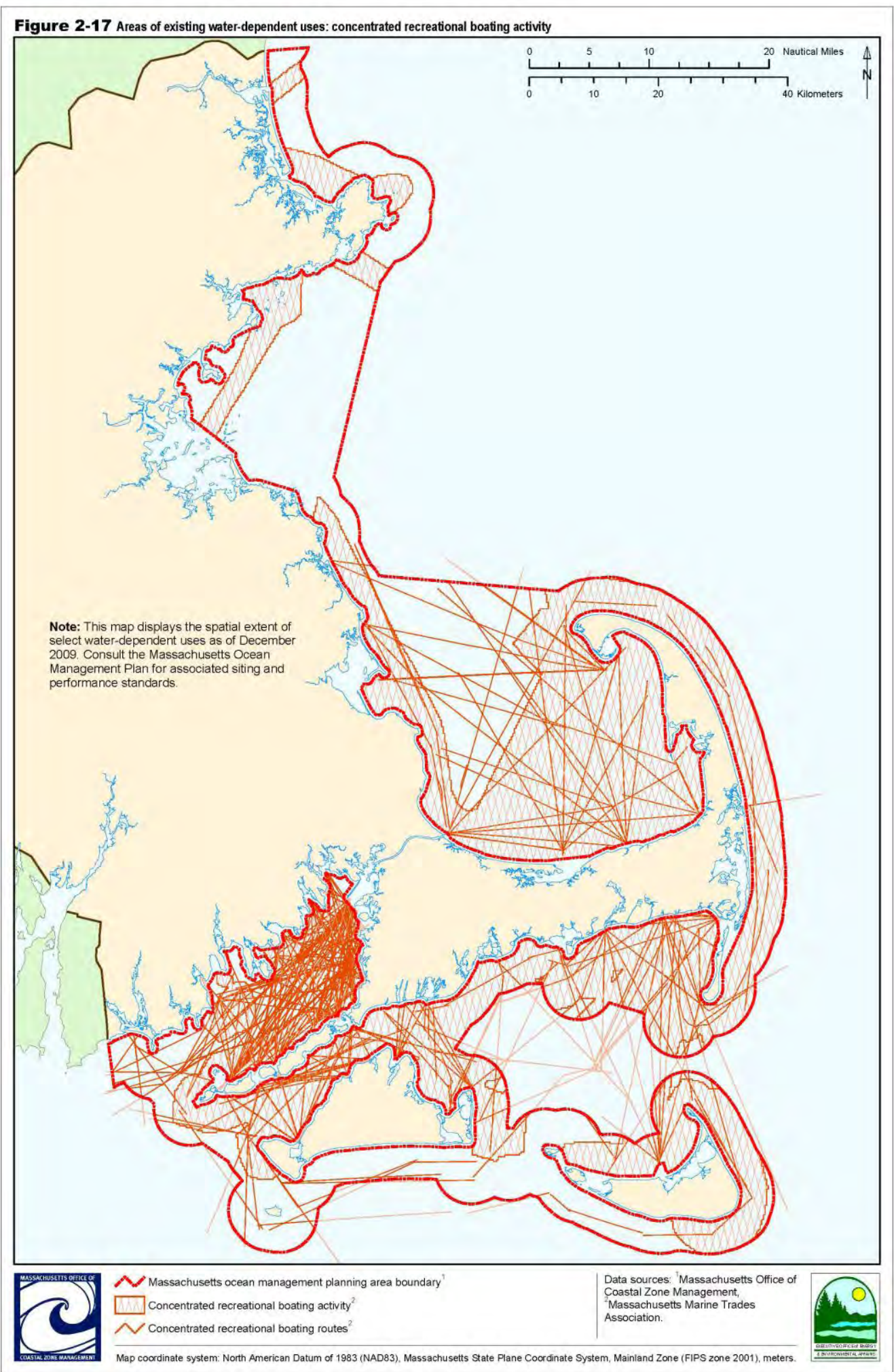




\section{APPENDIX B: SURVEYS}

\section{Introductory or Recruitment Survey}

Mailed out but with the option for responding online.

Unique ID code: \#\#\#\#\#\#

1. Do you currently own a [VESSEL]?

$\begin{array}{ll}\square & \text { No } \\ \square & \text { Yes }\end{array} \quad \begin{aligned} & \text { If we have incorrectly identified you as the registered / documented owner of } \\ & \text { this boat, please simply check this box } \square \text { and return the survey in the } \\ & \text { enclosed envelope. Thank you for your help. }\end{aligned}$

2. Does your [VESSEL] have a name?

Boat Name $\quad \longrightarrow \quad \square \quad$ Boat not named

3. Do you use your [VESSEL]..........?
Yes No
$\square \quad \square \quad$ exclusively on freshwater (rivers or lakes)
$\square \quad \square \quad$ exclusively for non-recreational purposes (e.g. as a charter fishing or commercial fishing vessel)
$\square \quad \square \quad$ exclusively to access another boat (i.e. it is a dinghy or tender)

4. From where do you most frequently launch your boat, or leave the dock or mooring, when taking trips on your [VESSEL]?

Facility / Ramp Name $\quad \overline{\text { Town }} \quad$ State

5. Do you own any other boats?

No

$\square \quad$ Yes

6. Please indicate below $\underline{A L L}$ the different boats / watercraft you own including your [VESSEL].

\begin{tabular}{|c|c|c|c|}
\hline Boat Type & $\begin{array}{l}\text { Number } \\
\text { of this type }\end{array}$ & $\begin{array}{l}\text { Length } \\
\text { (Enter range if you have } \\
\text { more than } 1 \text { boat) }\end{array}$ & $\begin{array}{l}\text { Which boat do you } \\
\text { use most often? } \\
\text { (Please mark only one) }\end{array}$ \\
\hline Open motorboat & 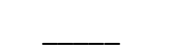 & $\bar{\square}$ & $\square$ \\
\hline Cabin cruiser & & & $\square$ \\
\hline Sailboat & & & $\square$ \\
\hline PWC / jetski & & & $\square$ \\
\hline Canoe / kayak / rowboat & & 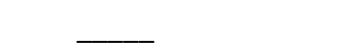 & $\square$ \\
\hline Other Specify: & $\underline{ }$ & 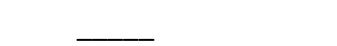 & $\square$ \\
\hline
\end{tabular}

From this point forward, we will be contacting you via e-mail and directing you to a website where you will be able to participate. For the effort to be successful, we need a working e-mail address:

E-mail address

Alternate e-mail address (optional)

YOUR E-MAIL ADDRESS WILL NOT BE USED FOR ANY OTHER PURPOSE AND WILL NOT BE SHARED WITH ANY THIRD PARTY. AT THE END OF THE STUDY, YOUR E-MAIL ADDRESS WILL BE DELETED FROM OUR RECORDS. 


\section{Initial Survey}

Online survey only.

\section{SURVEY INSTRUCTIONS}

Thank you for your participation in the Massachusetts Recreational Boater Survey 2010.

Please read the following instructions before continuing with the survey. There are only a few questions and it should take less than five minutes to answer them all. For more information about the survey, please go to http://www.maboatersurvey.com.

1. Please don't use your browser's 'back' button. If you need to back up, use the button that appears below each question or screen.

2. The question numbers may not be sequential, depending on your responses.

3. After entering each response, click on the 'next' button to continue.

4. When you finish answering all of the questions, click the 'Submit' button to complete the survey and finalize your entries.

\section{BOAT DETAILS}

During this and subsequent surveys, you will be asked about your use of your [VESSEL]. It is critical that your answers are based on your use of this specific vessel, even if it is not the vessel that you use most frequently.

The reason you were asked to participate in this survey is that your [VESSEL] was randomly selected from either the Massachusetts Boat Registration database or the database of U.S. Coast Guard documented vessels.

In the following section, we would like to verify some of the information about your vessel. Please correct any errors using the dropdown menus. If the information is correct, just click on the "Next" button to go on to the next question.

NOTE: The information you provide will ONLY be used to describe the ways people use Massachusetts' waters for boating. Any corrections you make here will not be changed in either the Massachusetts Boat Registration database or the database of U.S. Coast Guard documented vessels.

If the information is correct, just click on the "Next" button to go on to the next question.

If the following information is incorrect or missing, please select the best option from the dropdown menu on the right.

\begin{tabular}{|c|c|c|}
\hline Is your Vessel Type: [VESSEL TYPE]? & If not: & $\begin{array}{l}\text { DROPDOWN } \\
\text { Open motorboat } \\
\text { Cabin cruiser } \\
\text { Sailboat } \\
\text { PWC / jetski } \\
\text { Other }\end{array}$ \\
\hline
\end{tabular}

1b. Is your Size class: [SIZECLASS]?

If not:
DROPDOWN
Less than 16 feet
16 to 26 feet
26 to 40 feet
Over 40 feet

1c. Is your Hull type: [HULL TYPE]? If not: DROPDOWN

Aluminum

Fiberglass

Inflatable

Plastic

Steel

Wood

Other 
1d. Is your Engine type: [ENGINETYPE]?

If not:
DROPDOWN
Inboard
Inboard/Outboard (I/O or stern drive)
Outboard
Electric
Jet Drive
Other
None

1e. Is your Fuel type: [FUELTYPE]?

If not: DROPDOWN

Gas

Diesel

Other

1f. Is your Engine size: [ENGINESIZE]?

If not:

Horsepower

2. Where do you normally keep your [VESSEL] DURING the boating season?
At a berth (i.e. wetslip or at a dock)
On a mooring
In a dry stack or dry rack storage
On a trailer or otherwise on land
Other

2a. Specify "other":

3. Is the place where you generally keep your [VESSEL] DURING the boating season part of a...?
$\square \quad$ Commercial marina / boatyard
Private boat or yacht club
Municipal facility or mooring field
$\square \quad$ A private residence (e.g. your home)
Other

3a. Specify "other":

4. Where do you normally keep your [VESSEL] OUT OF SEASON?

$\begin{array}{ll}\square & \text { At a berth (i.e. wetslip or at a dock) } \\ \square & \text { On a mooring } \\ \square & \text { In a dry stack or dry rack storage } \\ \square & \text { On a trailer or otherwise on land } \\ \square & \text { Other }\end{array}$

4a. Specify "other":

5. Is the place where you generally keep your [VESSEL] OUT OF SEASON part of a...?

Commercial marina / boatyard

Private boat or yacht club

Municipal facility or mooring field

A private residence (e.g. your home)

Other

5a.

Specify "other": 
Any information that you are willing to provide for the following optional questions will help in the final analysis for this study. Please note that all data will be aggregated to ensure privacy.

6. Are you.....?

$$
\begin{aligned}
& \text { Male } \\
& \text { Female }
\end{aligned}
$$

7. What is your current age?

Years

8a. For how many years have you regularly operated a boat?

Years operated

8a. For how many of those years have you been the owner of a boat?

Years owned

9. Have you ever taken a......?

Boating safety course (e.g. Boat-Ed through the MA Environmental Police)

Navigation course (e.g. U.S. Coast Guard Auxiliary, U.S. Power Squadrons

or American Sailing Association)

10. Are you currently.....?

$$
\begin{aligned}
& \text { Employed (full time) } \\
& \text { Employed (part time) } \\
& \text { Unemployed } \\
& \text { Retired }
\end{aligned}
$$

11. What is your best guess of your annual household income from 2009?

$$
\begin{array}{ll}
\square & \text { Less than } \$ 25,000 \\
\square & \$ 25,000 \text { to } \$ 49,999 \\
\square & \$ 50,000 \text { to } \$ 74,999 \\
\square & \$ 75,000 \text { to } \$ 99,999 \\
\square & \$ 100,000 \text { to } \$ 124,999 \\
\square & \$ 125,000 \text { to } \$ 149,999 \\
\square & \$ 150,000 \text { to } \$ 174,999 \\
\square & \$ 175,000 \text { to } \$ 199,000 \\
\square & \$ 200,000 \text { or greater }
\end{array}
$$

Thank you for your participation! We greatly appreciate your time.

YOU MUST CLICK the Submit button to complete the survey. After you submit your responses, your browser will be directed to our website, www.maboatersurvey.com. Please feel free to return to this site at any time for information about the survey.

We will be contacting you soon to ask details about your last trip in May 2010.

If you have any questions, please send an e-mail to urban.harbors@umb.edu.

Thank you again for your time and cooperation! 


\section{Monthly Survey}

Online survey only. Customized so that during months with a holiday, boaters were asked if their activity was associated with that holiday.

\section{SURVEY INSTRUCTIONS}

Thank you for your participation in the Massachusetts Recreational Boater Survey 2010. You will be asked a short series of questions and then will be asked to map your last boat trip. It should take approximately 15-20 minutes to complete the survey.

For more information about the survey, please go to http://www.maboatersurvey.com.

1. Please don't use your browser's 'back' button. If you need to back up, use the button that appears below each question or screen.

2. The question numbers may not be sequential, depending on your responses.

3. After entering each response, click on the 'next' button to continue.

4. When you finish the short series of questions, click the 'Submit' button to finalize and save your responses.

\section{MONTHLY BOAT TRIP INFORMATION}

During this survey you will be asked about your use of your [VESSEL] during [MONTH], 2010. It is critical that your answers are based on your use of this specific vessel, even if it is not the boat that you use most frequently.

After the questions about your boating, a map will be displayed and we will ask you to indicate where you went for your last trip of [MONTH].

Please submit your survey even if you did not take your [VESSEL] out on the water this month, as that information is also important.

\section{GENERAL MONTHLY ACTIVITY}

1. Do you still own your [VESSEL]?

$\begin{array}{lll}\square & \text { NO } & \text { IF NO SKIP TO END OF SURVEY } \\ \square & \text { Yes } & \end{array}$

2. On how many different days during [MONTH] did you visit your [VESSEL] for recreational or maintenance? For example, if you spent an hour onboard one day and again the following day, please count this as two days.

$$
\text { Number of days _ I I Z ZERO SKIP TO END OF SURVEY }
$$

3. Did you actually go out on the water on any of these days aboard?

$$
\begin{array}{ll}
\text { No IF NO SKIP TO QUESTION } 22 \\
\text { Yes }
\end{array}
$$

4. On how many of these days onboard did you actually go out on the water? Number of days

5. How many nights in total did you spend on your [VESSEL] during [MONTH]?

Number of overnights onboard IF ZERO SKIP TO QUESTION 7

6. Based on your answers above, how many of these nights were spent away from your normal berth or mooring location?

Number of overnights away from usual mooring 


\section{LAST “ON WATER” BOAT TRIP OF THE MONTH}

The following questions ask specifically about the LAST “ON WATER” BOAT TRIP that you made on your [VESSEL] during [MONTH].

Even if you were only out on the water for a short trip, we would like you to answer the following questions.

7. Was the last "on water" boat trip on your [VESSEL] during [MONTH] a day trip or an overnight trip?

$\square \quad$ Day trip

$\square \quad$ Overnight trip

8. How many nights were you away from your usual residence on this trip?

If you live aboard your boat indicate the number of nights away from your normal berthing location (e.g. slip, mooring etc.).

Number of nights

9. How many people (including yourself) were onboard for this trip?

Number of people

10. Did you trailer your [VESSEL] to a launch site as part of this trip?

$\square \quad$ No IF NO SKIP TO QUESTION 14

Yes

11. On this particular trip, where did you begin trailering your [VESSEL] from?

$\square \quad$ Your permanent home
$\square \quad$ Your second home
$\square \quad$ The marina or drystack where your boat kept
$\square \quad$ A general commercial storage facility
$\square \quad$ A friend's or relative's home
$\square \quad$ Other location

11a. Specify "other":

12. Did you pay a one time launching fee or parking fee while using this launch site?

$\square \quad$ No

$\square \quad$ Yes

13. Approximately how much did you pay to launch your vessel and for parking on your last "on water" boat trip? When entering costs in dollars, you do NOT need to enter a dollar sign (\$).

Cost in dollars:

14. Approximately how many miles did you drive (or otherwise travel) to reach the place where you launched or boarded your [VESSEL]?

Number of Miles:

15. Please provide information about the site from which you launched or boarded your [VESSEL]:

Name of site

Address of site

Town or city

State 
16. How many hours did you spend on this trip? DO NOT INCLUDE time driving to or from where you launched or boarded your boat.

PLEASE INCLUDE all time between when you headed out on the water to when you finished this trip, even if this included shoreside excursions.

If less than 1 hour please enter 1.

17. Did you participate in any of the recreational activities listed below while on this trip?

$\begin{array}{lcc} & \text { Yes } & \text { No } \\ \text { Cruising } & \square & \square \\ \text { Entertaining family/friends } & \square & \square \\ \text { Fishing or shellfishing } & \square & \square \\ \text { Hunting } & \square & \square \\ \text { Whale watching } & \square & \square \\ \text { Bird watching } & \square & \square \\ \text { Racing } & \square & \square \\ \text { Sailing } & \square & \square \\ \text { Scuba diving/snorkeling } & \square & \square \\ \text { Sightseeing } & \square & \square \\ \text { Swimming } & \square & \square \\ \text { Waterskiing/wakeboarding } & \square & \square\end{array}$

18. Was this last trip of the month undertaken for something other than purely recreational purposes?

For example you were chartered to take customers out fishing or sightseeing or you were fishing commercially?

$\begin{array}{ll}\square & \text { No } \\ \square & \text { Yes }\end{array}$

19. Was this last trip taken as part of the [Memorial Day Weekend] / [4th of July Weekend] / [Labor Day Weekend]?
$\square \quad$ No
$\square \quad$ Yes

\section{LAST “ON WATER” BOAT TRIP OF THE MONTH SPENDING}

20. Approximately how much money did you and your party spend in each category below as part of the last "on water" boat trip on your [VESSEL] in [MONTH]?

Include both spending in preparation for and during this specific trip. If you did not spend money in a category please leave as blank.

When entering costs in dollars, you do NOT need to enter a dollar sign (\$).

$\begin{array}{ll}\text { Boat fuel and oil } & \text { Amount (\$) } \\ \text { Transient/guest dockage (marina fee) } & \\ \text { Launch fees } & \\ \text { Pumpout fees } & \\ \text { Restaurant meals \& drinks (including take-out food \& drinks) } \\ \text { Groceries }\end{array}$


Recreation and entertainment

Lodging (hotel/motel)

Lodging (camping/B\&B)

Fishing gear, bait, ice etc.

Other

21. Approximately what PERCENT of the total spending you have just listed occurred near to where you launched or boarded your boat on this specific trip?

Your best guess will do.
$0 \%$
$1-10 \%$
$11-20 \%$
$21-30 \%$
$31-40 \%$
$41-50 \%$
$51-60 \%$
$61-70 \%$
$71-80 \%$
$81-90 \%$
$91-100 \%$

\section{SKIP TO END OF SURVEY}

\section{LAST VISIT OF THE MONTH SPENDING}

You just indicated you did not take your boat out on the water during [MONTH], but that you did visit your boat during that month. The following questions ask specifically about the LAST TIME you visited your [VESSEL] during [MONTH].

22. Was the last time you visited your [VESSEL] during [MONTH] a day trip or an overnight trip?

$$
\begin{aligned}
& \text { Day trip } \\
& \text { Overnight trip }
\end{aligned}
$$

23. How many nights were you away from your usual residence on this trip?

Number of nights

24. Approximately how much money did you and your party spend in each category below as part of the lat time you visited your [VESSEL] in [MONTH]?

Include both spending in preparation for and during this specific trip. If you did not spend money in a category please leave as blank.

When entering costs in dollars, you do NOT need to enter a dollar sign (\$).

$\begin{array}{ll}\text { Boat fuel and oil } & \text { Amount (\$) } \\ \text { Transient/guest dockage (marina fee) } \\ \text { Launch fees } \\ \text { Pumpout fees } \\ \text { Restaurant meals \& drinks (including take-out food \& drinks) } \\ \text { Groceries } \\ \text { Auto gas and oil } \\ \text { Shopping and souvenirs } \\ \text { Recreation and entertainment } \\ \text { Lodging (hotel/motel) } \\ \text { Lodging (camping/B\&B) }\end{array}$


Fishing gear, bait, ice etc.

Other

25. Approximately what PERCENT of the total spending you have just listed occurred near to where you visited your boat on this specific trip?

Your best guess will do.
$0 \%$
$1-10 \%$
$11-20 \%$
$21-30 \%$
$31-40 \%$
$41-50 \%$
$51-60 \%$
$61-70 \%$
$71-80 \%$
$81-90 \%$
$91-100 \%$

SKIP TO END OF SURVEY

PARTICIPANTS WHO NO LONGER OWNED THEIR BOAT WOULD SEE THE FOLLOWING MESSAGE AT THE END OF THE SURVEY:

Thank you for signing on to the Massachusetts Recreational Boater Survey and providing us with this information.

Because you do not currently own the selected vessel, all you need to do is click on the "Next" button, and then click on

"Submit" on the following page. No further information is needed.

If you do own the selected vessel, please click on the "back" arrow at the bottom of this page, change your answer to

"Yes", and complete the survey.

OTHER PARTICIPANTS WHO VISISTED THEIR BOAT BUT DID NOT TAKE AN ON-WATER TRIP WOULD SEE THE FOLLOWING MESSAGE:

Thank you for signing on to the Massachusetts Recreational Boater Survey and providing us with this information.

Because you did not visit your boat for recreational or maintenance purposes, all you need to do is click on the "Next" button, and then click on "Submit" on the following page. No further information is needed.

If you did visit your boat for recreational or maintenance purposes, please click on the "back" arrow at the bottom of this page, enter the correct answer, and complete the survey.

\section{ALL PARTICIPANTS WOULD SEE THIS FINAL MESSAAGE:}

Thank you for your participation! We greatly appreciate your time.

YOU MUST click the Submit button to finalize and save your responses.

If you took your boat out on the water you will be asked to map this trip.

If you did NOT take your boat out on the water you will be directed to our website, www.maboatersurvey.com.

If you have any questions, please send an e-mail to help@maboatersurvey.com

Thank you again for your time! 


\section{End-of-Season Survey}

Online survey only.

\section{BOAT-RELATED SPENDING IN THE LAST 12 MONTHS}

The questionnaires that you have completed for the 2010 Massachusetts Recreational Boater Survey so far have asked about individual boat trips.

Now we ask you to estimate spending in the last 12 months for your boat that was not trip-specific (for example: boat loans, winter storage, maintenance, repairs etc.)

1. In the LAST 12 MONTHS, approximately how much did you spend on the maintenance and repair of your [VESSEL] in each of the following categories?

Estimated

Amount (to

nearest \$10)

Routine vessel maintenance, including parts and labor:

(e.g., winterize, commission, cleaning, tune ups)

Vessel repairs, including parts and labor:

(e.g., engine, underwater gear, hull, electronics, canvas, sails, upholstery)

Installation of a new engine, including parts and labor:

Installation of new products or upgrades, including parts and labor:

(e.g., electronics, tops, seats)

2. Which of the following non-trip-specific expenditures did you have for your [VESSEL] in the LAST 12 MONTHS?

Yes No Estimated

Amount (to

nearest \$10)

Boat loan payments

Boat insurance (e.g., hull, port risk, liability, theft, fire)

State registration or USCG documentation fees

Taxes (e.g., personal property, excise)

Dockage, mooring, seasonal storage

New trailers

New or replacement products not included in your previous answers: (e.g., parts, sails, supplies, accessories, tender, gear, tackle or safety equipment)

3. In the LAST 12 MONTHS, did you have OTHER expenditures for your [VESSEL] that you did not list in the previous two questions?

$\square$ Yes

$\square$ No IF NO SKIP TO QUESTION 4

3a. What did you spend money on?

3b. What was the total amount you spent?

Please estimate the amount that you spent to the nearest $\$ 10$.

$\$$ 
4. Approximately what PERCENT of the total spending you have just listed in the previous three questions occurred IN THE STATE OF MASSACHUSETTS?

$\begin{array}{ll}0 \% & \square \\ 1-10 \% & \square \\ 11-20 \% & \square \\ 21-30 \% & \square \\ 31-40 \% & \square \\ 41-50 \% & \square \\ 51-60 \% & \square \\ 61-70 \% & \square \\ 71-80 \% & \square \\ 81-90 \% & \square \\ 91-100 \% & \square\end{array}$

5. Approximately how many hours (total) were you under power or under sail on your [VESSEL] during the 2010 boating season?

Hours

6. How would you rate your boating activity on your [VESSEL] in $\mathbf{2 0 1 0}$ compared to other years?

$\begin{array}{llll}\square & \text { Much more active than usual } & \square & \text { Slightly less active than usual } \\ \square & \text { Slightly more active than usual } & \square & \text { Much less active than usual } \\ \square & \text { Similar to other years } & \square & \text { Don't know }\end{array}$




\section{Feedback Survey}

Online survey only. This was included at the end of the End-of-Season survey.

PLEASE HELP US IMPROVE THE BOATER SURVEY

The following few questions ask for your feedback.

1. Did you use the online mapping tool for any month you participated?

$\begin{array}{ll}\square & \text { No } \\ \square & \text { Yes }\end{array}$

2. What prevented you from using the online mapping tool? (Check all that apply)

$\begin{array}{ll}\square & \text { I did not take my boat out on the water } \\ \square & \text { The online mapping tool was too complicated or difficult to use } \\ \square & \text { The online mapping tool did not work on my computer } \\ \square & \text { My boating activity was too complicated to map } \\ \square & \text { Other (Specify in next screen) }\end{array}$

2a Please provide any other thoughts, suggestions or comments you might have on the online mapping application.

3. Was the mapping application ...

$\begin{array}{ll}\square & \text { Very easy } \\ \square & \text { Somewhat easy } \\ \square & \text { Somewhat difficult, or } \\ \square & \text { Very difficult }\end{array}$

3a Please provide any other thoughts, suggestions or comments you might have on the online mapping application?

4. How willing would you be to participate in a similar boating survey in the future?

$\begin{array}{ll}\square & \text { Very willing } \\ \square & \text { Somewhat willing } \\ \square & \text { Not very willing } \\ \square & \text { Not at all willing }\end{array}$

5. Additional comments on the Massachusetts Recreational Boater Survey 2010 are welcome.

We thank you for your participation throughout this boating season. If possible, we would appreciate if you would take time to do one last monthly trip survey to report on any boating activity during the month of October.

We would appreciate a response even if you did not take your boat out on the water during the month of October. 


\section{Appendix C: Project Sheet included in the ReCRUitment Package ANd Used to Publicize the SuRVey}

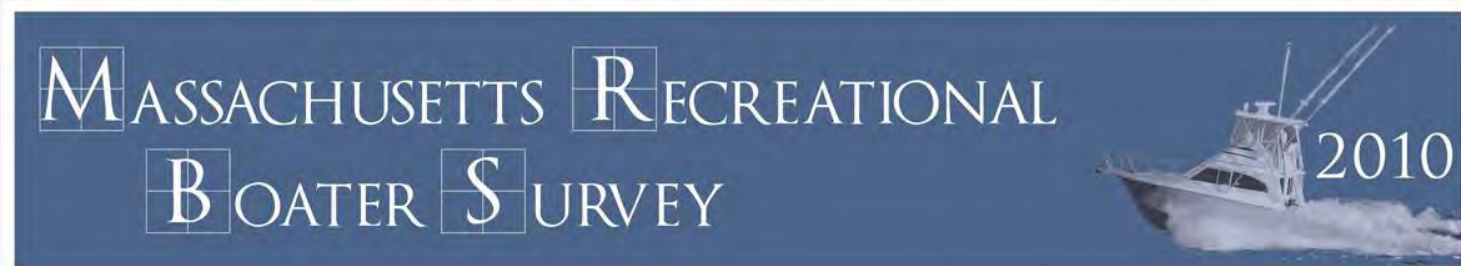

\section{ATTENTION RECREATIONAL BOATERS: WE NEED YOUR HELP!}

This summer, a sample of Massachusetts' recreational boaters is being asked to participate in the Massachusetts Recreational Boater Survey 2010.

Together we will gather information on the recreational uses of coastal waters and boaters' spending in Massachusetts.

Each month between May and October, participants will be asked to fill in a short online questionnaire describing a recent boat trip.

The information gathered will ensure that boaters' favorite routes and destinations receive appropriate attention when management decisions are made about Massachusetts' ocean waters.
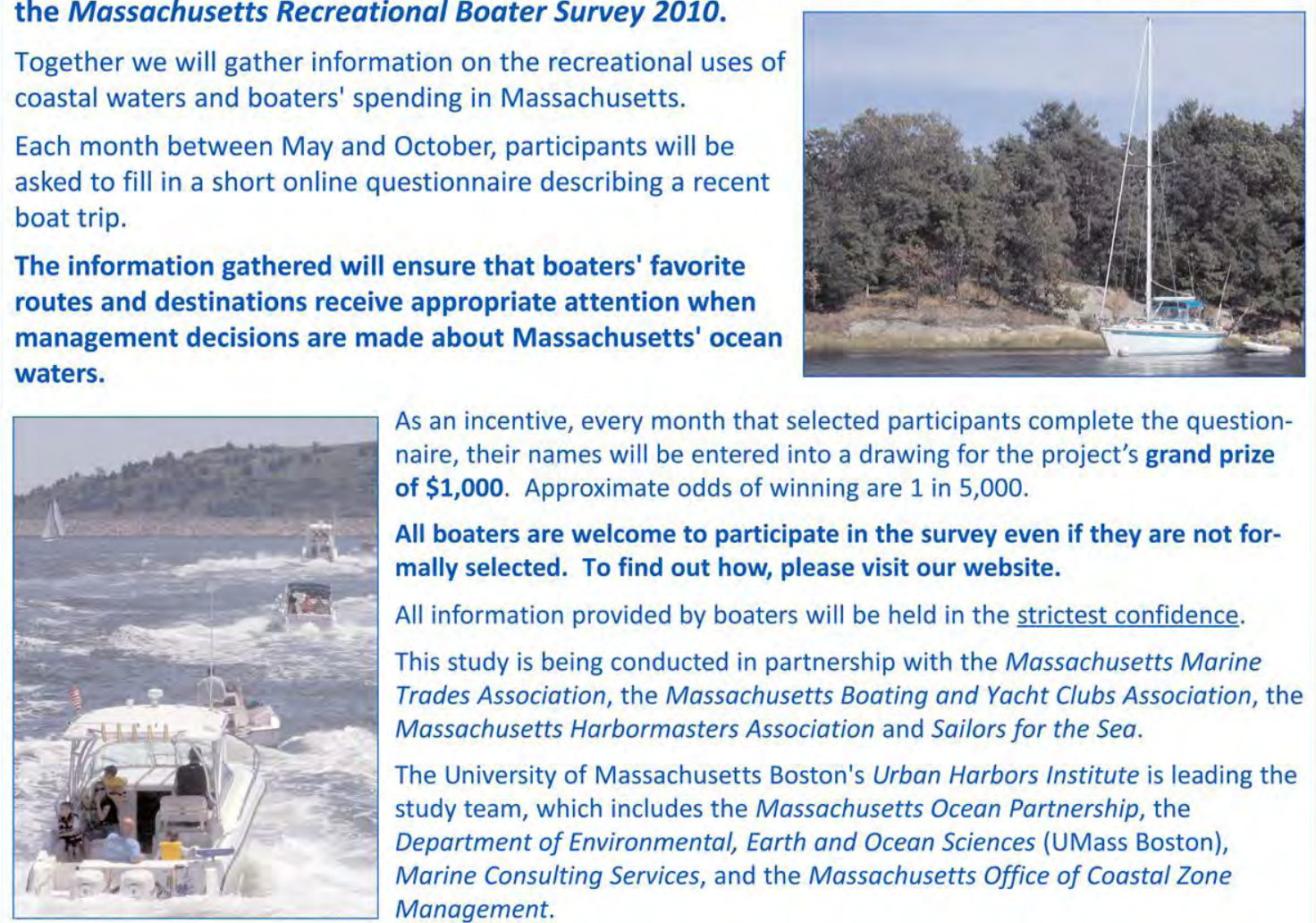

As an incentive, every month that selected participants complete the questionnaire, their names will be entered into a drawing for the project's grand prize of $\$ \mathbf{1 , 0 0 0}$. Approximate odds of winning are 1 in 5,000.

All boaters are welcome to participate in the survey even if they are not formally selected. To find out how, please visit our website.

All information provided by boaters will be held in the strictest confidence.

This study is being conducted in partnership with the Massachusetts Marine Trades Association, the Massachusetts Boating and Yacht Clubs Association, the Massachusetts Harbormasters Association and Sailors for the Sea.

The University of Massachusetts Boston's Urban Harbors Institute is leading the study team, which includes the Massachusetts Ocean Partnership, the Department of Environmental, Earth and Ocean Sciences (UMass Boston), Marine Consulting Services, and the Massachusetts Office of Coastal Zone Management.

Please participate in this survey - your input will benefit current and future recreational boaters in Massachusetts

www.maboatersurvey.com
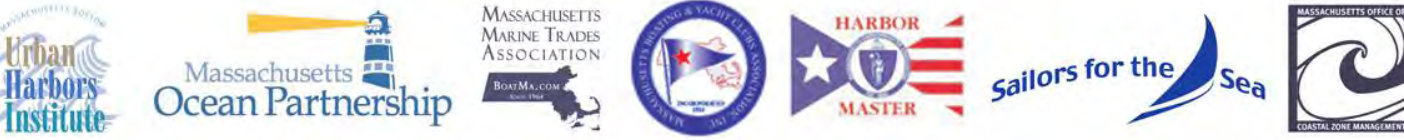

Massachusetts Recreational Boater Survey 2010

Urban Harbors Institute \& the Massachusetts Ocean Partnership | University of Massachusetts Boston 100 Morrissey Boulevard | Boston MA 02125 | (617) 287-5576 


\section{ApPendix D: Generic Press Release TeXt}

Early this summer, letters went out to 10,000 recreational boaters in Massachusetts, inviting them to participate in the Massachusetts Recreational Boater Survey 2010. And now, even those who did not receive a letter about the survey can participate.

The online survey is gathering detailed information on the recreational uses of coastal waters and boaters' spending habits. The information gathered will serve a number of purposes, including ensuring that boaters' favorite routes and destinations receive appropriate attention when management decisions are made about Massachusetts' ocean waters.

The project is being led by the University of Massachusetts Boston's Urban Harbors Institute and the Massachusetts Ocean Partnership, together with Marine Consulting Services and the Massachusetts Office of Coastal Zone Management. The team is working in partnership with the Massachusetts Marine Trades Association, the Massachusetts Boating and Yacht Clubs Association, the Massachusetts Harbormasters Association and Sailors for the Sea.

For more information on the Massachusetts Recreational Boater Survey 2010 and how to participate, visit maboatersurvey.com or call XXX-XXX-XXXX. 


\section{ApPendix E: Generalized TeXt USED fOR THE MONTHLY E-MAILS}

\section{Dear INDIVIDUAL BOATER'S NAME,}

Thank you for agreeing to participate in the MA Recreational Boater Survey. Now that the boating season has started, we would like you to complete a survey about your boating activity during June 2010. The information gathered will ensure that boaters' favorite routes and destinations receive appropriate attention when management decisions are made about Massachusetts' ocean waters.

This survey should only take about 15-20 minutes to complete. We would appreciate a response even if you did not use your boat during June. To start the survey, please click on the link below:

Click here for the survey

The survey should automatically open in your browser. If the link does not work for any reason, please let us know by sending an e-mail to help@maboatersurvey.com.

Don't forget, by completing this survey, you will be entered into the end-of-season drawing for the chance to win the grand prize of $\$ 1,000$. Your name will also be entered into a drawing at the end of the month for a chance to win various prizes, including $\$ 100$.

Congratulations to the two lucky boaters that won either $\$ 100$, or OTHER PRIZE for completing the May boater survey. For details on the drawings and great prizes, please visit www.maboatersurvey.com.

Thank you and best wishes for a safe and enjoyable boating season from the 2010 Massachusetts Recreational Boater Survey Team. 


\section{Appendix F: Generalized TeXt Used fOR the SECONd Reminder E-MAILS}

\section{Dear INDIVIDUAL BOATER'S NAME,}

As you know, the Massachusetts Recreational Boater Survey is underway and you kindly agreed to participate. However, we have not yet received your online completed survey about your boating activity (if any) during June. Please take a few moments to complete this survey as soon as you can by clicking the link below. THIS WILL BE YOUR FINAL E-MAIL REMINDER! Thank you!

Click here for the survey

\section{IMPORTANT REMINDERS:}

- Completed monthly survey will also give you an additional entry into the end-of-season prize drawing with a grand prize of $\$ 1,000$.

- The information that you provide during the 2010 boating season is CRITICAL to ensuring your favorite routes and destinations receive appropriate attention when management decisions are made about the waters of Massachusetts.

After completing the survey, you will redirected to a "thank you" page where you can see a sneak peak of a map that shows some trip routes from data captured by the May monthly survey.

If you are having problems accessing the survey or completing the mapping part of the survey, we would be happy to guide you through it. Please contact us a help@maboatersurvey.com or XXX-XXXXXXX (during business hours).

Thank you again for participating in this survey.

The MA Recreational Boater Survey Team. 


\section{ApPendix G: AdDItIONAL SPATIAL MAPS}

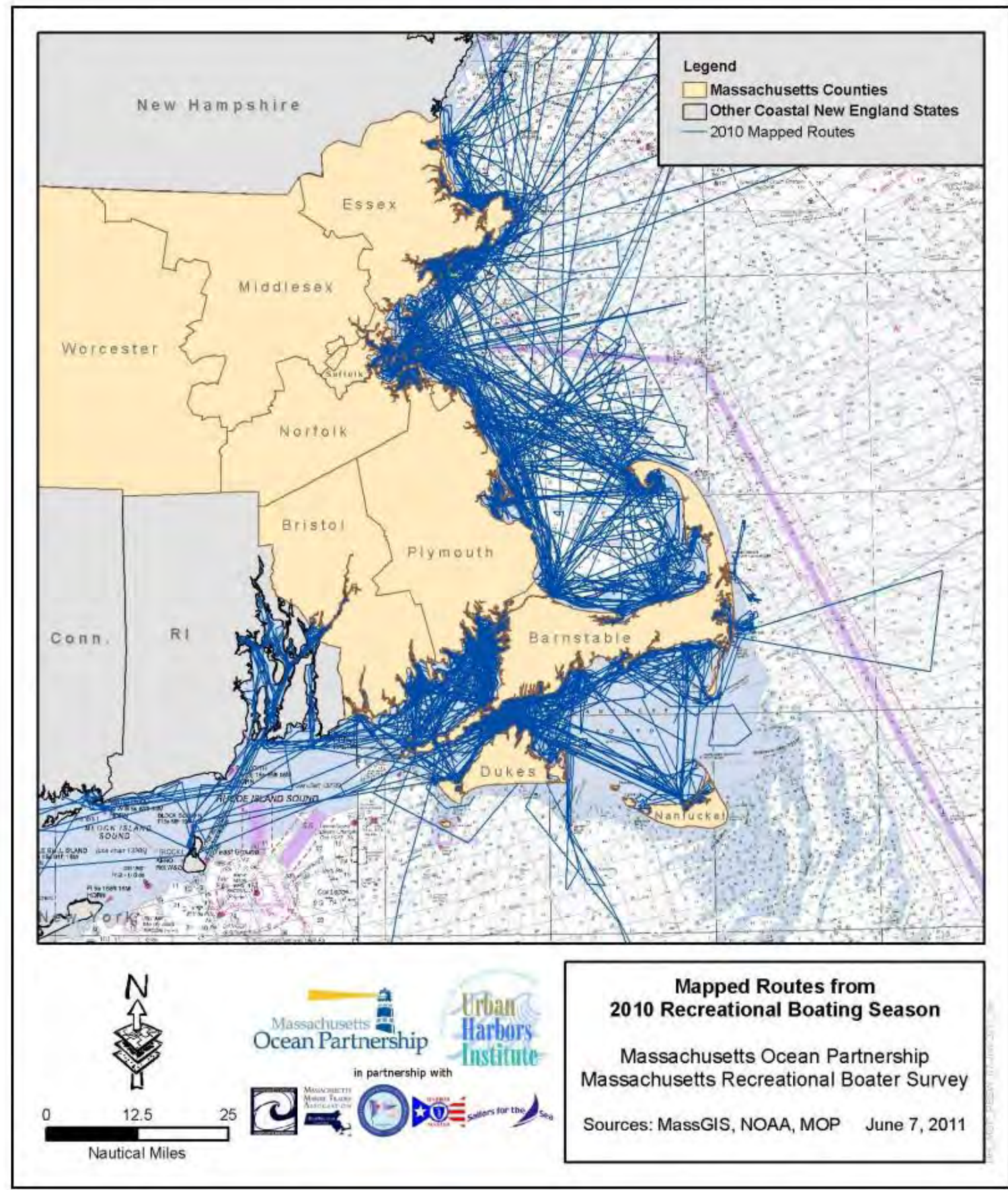




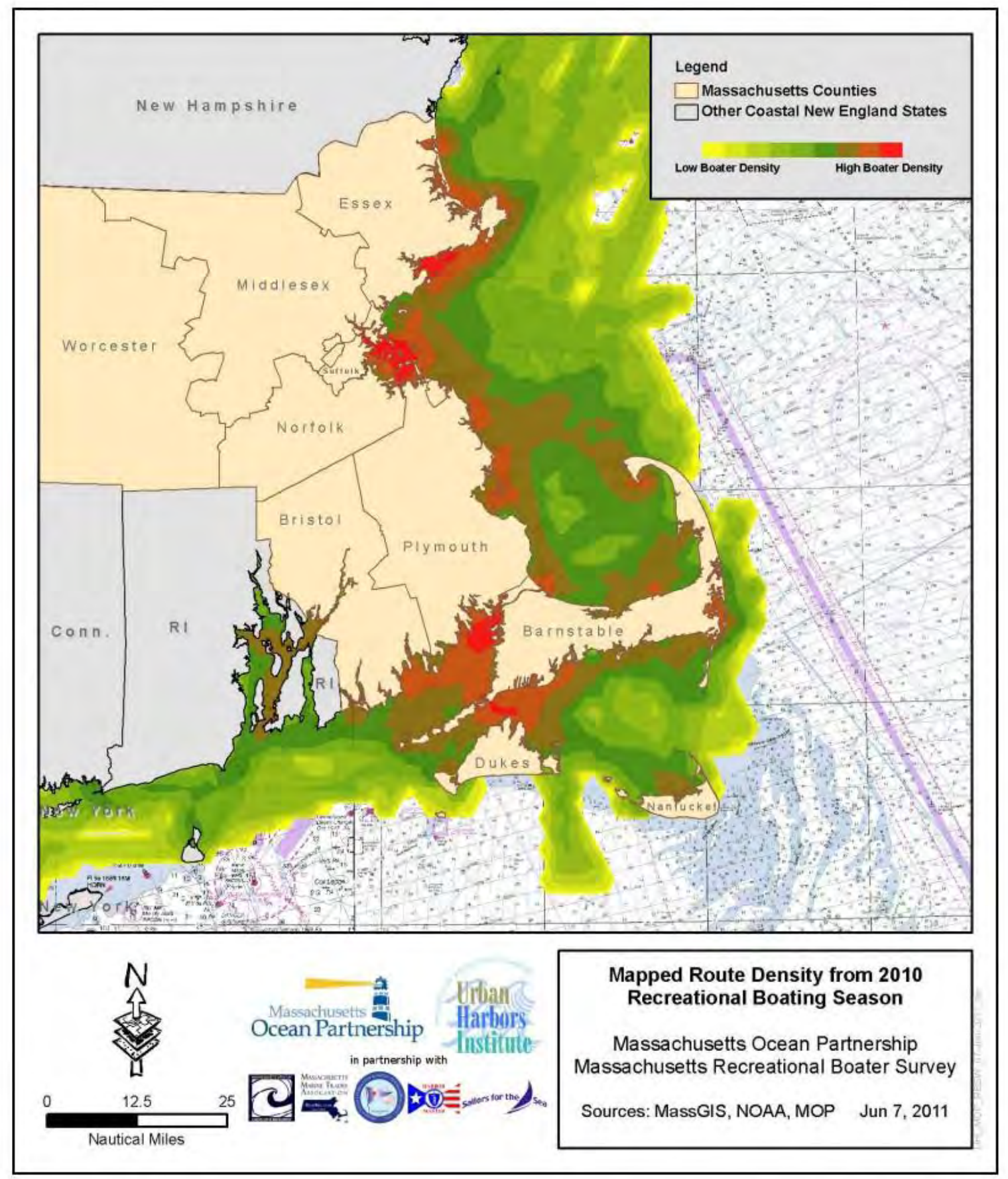

